UNIVERSIDADE DE SÃO PAULO

INSTITUTO DE QUIMICA

\title{
ESTUDO DAS PROPRIEDADES MORFOLÓGICO-ESTRUTURAIS E ELETROQUÍMICAS DE ELETRODOS DE $\mathrm{SnO}_{2}$
}

\section{CLAUDIA LONGO}

Tese de Doutorado

Orientador: Prof. Dr. Paulo Teng An Sumodjo

São Paulo

1998 
Ficha Catalográfica

Elaborada pela Divisão de Biblioteca e

Documentação do Conjunto das Químicas da USP.

\section{Longo, Claudia}

L856e Estudo das propriedades morfológico-estruturais e eletroquímicas de eletrodos de $\mathrm{SnO}_{2} /$ Claudia Longo. -São Paulo, 1998.

$203 p$.

Tese (doutorado) - Instituto de Química da Universidade de São Paulo. Departamento de Quimica Fundamental.

Orientador: Sumodjo, Paulo Teng An

1. Eletroquímica 2. Eletrodo: Físico-química

3. Propriedades microestruturais : Engenharia I. T.

II. Sumodjo, Paulo Teng An, orientador. 


\title{
"Estudo das Propriedades Morfológico- Estruturais e Eletroquímicas de Eletrodos de $\mathrm{SnO}_{2} "$
}

\section{(I.AUDIA LONGO}

Tese de Doutorado submetida ao Instituto de Química da Universidade de São Paulo como parte dos requisitos necessários à obtenção do grau de Doutor em Ciências - Área: Físico-Química

Aprovada por:

\author{
Prof. Dr. PAULO TENG AN SUMODJO \\ IQ - USP \\ (Orientador e Presidente) \\ $\overline{\text { Profa. Dra. SUSANA INÊS CORDOBA DE TORRESI }}$ \\ IQ - USP
}

Prof. Dr. ASSIS VICENTE BENEDETTI

IQ - UNESP - Araraquara
Profa. Dra. MARIA CECÍLIA BARBOSA DA SILVEIRA SALVADORI IF - USP

\author{
Prof. Dr. PAULO OLIVI \\ FFCLRP - USP \\ SÃO PAULO \\ 28 DE OUTUBRO DE 1998
}


Aos meus pais,

Adelaide e Braz,

pelo amor, incentivo e apoio... 


\section{Agradecimentos}

Ao Professor Paulo Sumodjo,

pela amizade e orientação nestes mais de 10 anos (desde a Iniciação Científica!), de inestimável importância para a minha formação.

Ao Professor Fausto Sanz, da Universidade de Barcelona, pela orientação e amizade.

A todos os professores que facilitaram o uso de seus laboratórios, para utilização de equipamentos ou reagentes. Agradeço especialmente aos Professores Assis Benedetti, Henrique Toma, Omar Seoud, Sílvia Serrano, Tíbor Rabockai e a todos os integrantes de seus Laboratórios.

Agradeço também às Dras. Montserrat Baucells e Montserrat Roura, da diretoria dos "Serveis Científico-Tècnics" da Universidade de Barcelona, e ao Prof. Joan Torrent, da Universidade Politécnica da Catalunya.

À Dra. Maria Garcia-Parajó, pela amizade e orientação científica, e ao Dr. Mino Green (Imperial College-Londres), pelas amostras de sílica empregadas como substrato.

Com muito carinho e saudades, agradeço aos queridos companheiros de laboratório da Universidade de Barcelona: Pau, Jordi, Raul, Albert e Gabriel, pela amizade e também pela paciência e solicitude em me ensinar tudo o que aprendi por lá.

A todos dos "Serveis Cietifico-Tècnics" da Universidade de Barcelona, pela atenção e carinhosa acolhida, especialmente às pessoas com as quais trabalhei diretamente:

Dr. Ramon Fontanés, Antonia e Anna (SEM), Xavier e Pepe (XRD), Yves (TEM), Joaquim e todo o pessoal do XPS, Xavier e Javier (Micro-sonda), ao Alex è̀ querida amiga Marisol. Ao pessoal do Departamento de Química-Física, em especial à Lidia e ao Ramon.

Aos integrantes do Grupo: Ana Regina, Fernanda ("virtual") e à Márcia e ao Sadao, do IQ Unesp-Araraquara.

A todo o pessoal do Instituto de Química, professores, técnicos e funcionários, e ao pessoal da Biblioteca, que direta ou indiretamente colaboraram para a realização deste trabalho. Agradeço especialmente ao pessoal da Secretaria de Pós-Graduação, pelas excelentes cópias das figuras desta tese.

Aos queridos amigos que conviveram comigo nestes últimos 5 anos, em especial à Cecília, Efigênia, Anna Regina, Anninha, Cris, Cléria, Rute, Pedro, Wal e Eric; à Márcia e aos amigos do Coral Anima-Ãnima, e ao Fawzi.

Aos amigos de Barcelona: Montse, Ramon, Jordi, Alejandro, Pedro, Paula, Catia, Silvia, Pedro è à pequena Denise, Ionara, Erni, e ao Thomas.

À Cynthia e ao Yuji, pela amizade e a agradóvel companhia nas caronas a caminho do IQ. Ao CNPq, pelas bolsas concedidas de Doutorado e Doutorado Sanduíche no Exterior.

À minha familia: meus pais, Lu, Beto \& Angie, Carol, Ciça \& Wagner, pela imensa compreensão a apoio, imprescindiveis em cada dia de trabalho e em cada linha desta tese. 


\section{ÍNDICE}

Resumo

Abstract

Notação das abreviaturas e símbolos

\section{Introdução}

\section{Revisão Bibliográfica}

2.1 Eletrodos semicondutores: considerações sobre os conceitos fundamentais ....................... 5

2.1.1. A teoria de bandas e o transporte de carga em semicondutores ..................................... 5

2.1.2. A interfase semicondutor|eletrólito e o dobramento das bandas ................................. 8

2.1.3. Os gráficos de Mott-Schottky e a determinação do $E_{F B}$ e $N_{D}$....................................... 11

2.1.4. A não-linearidade dos gráficos de Mott-Schottky e os estados superficiais ................. 13

2.1.5. Reaç̃̃es de transferência de carga em interfases semicondutor|eletrólito ..................... 14

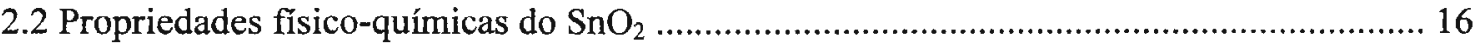

2.2.1. Estrutura cristalina, defeitos estruturais e dopagem ................................................ 16

2.2.2 Propriedades óticas, elétricas, composição e morfologia .............................................. 17

2.2.3 As condições de preparação e as características dos filmes de $\mathrm{SnO}_{2}$......................... 19

2.2.4. Os métodos empregados neste trabalho para a obtenção dos filmes de $\mathrm{SnO}_{2}$............. 21

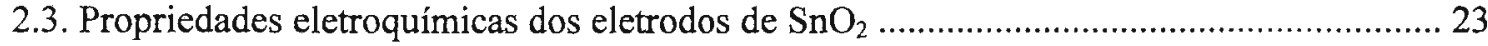

2.3.1. Considerações gerais sobre os estudos realizados para eletrodos de $\mathrm{SnO}_{2}$................ 23

2.3.2. Desenvolvimento dos ânodos à base de filmes de $\mathrm{SnO}_{2}$ depositados sobre titânio ...... 28

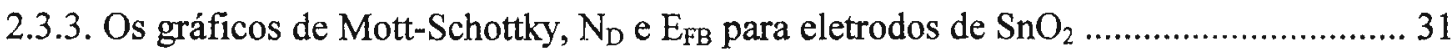

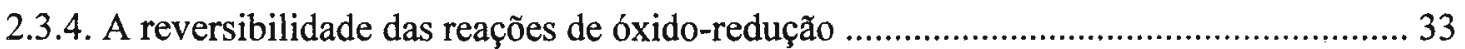

2.3.5. Os processos de hidratação da superfície de eletrodos de $\mathrm{SnO}_{2}$................................ 35

2.3.6. Os perfis $\mathrm{I} / \mathrm{E}$ em solução aquosa de eletrólitos inertes ............................................ 37

2.3.7. Efeitos da polarização catódica: a $\mathrm{RDH}$ e os processos de redução do $\mathrm{SnO}_{2}$.............. 38

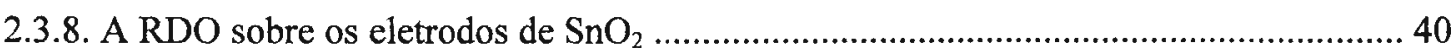

2.4 Considerações gerais sobre eletrodos modificados ................................................................ 42

2.5. Técnicas empregadas para a caracterização dos materiais ...................................................... 44

2.6. Técnicas empregadas para caracterização eletroquímica dos eletrodos ............................. 47

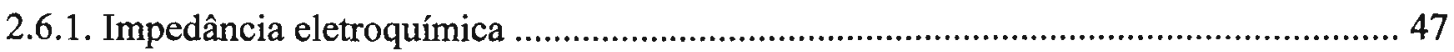

2.6.1.1. Princípios gerais da técnica ............................................................................. 47

2.6.1.2. A atribuição de circuitos equivalentes e a representação gráfica dos espectros de impedância ................................................................................................... 48

2.6.1.3. Circuitos equivalentes propostos para eletrodos semicondutores ......................... 51

2.6.1.4. Circuitos equivalentes propostos para eletrodos de $\mathrm{SnO}_{2}$............................... 54

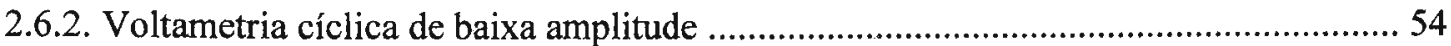

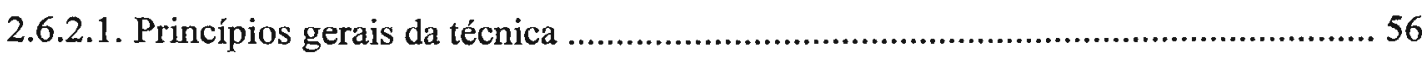

2.6.2.2. Metodologia proposta por D.G. Macdonald ...................................................... 58 


\section{Preparação e caracterização fisica e química dos eletrodos}

3.1. Introdução 61

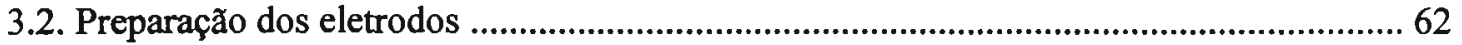

3.2.1.Filmes de $\mathrm{SnO}_{2}$ depositados sobre sílica .............................................................62 62

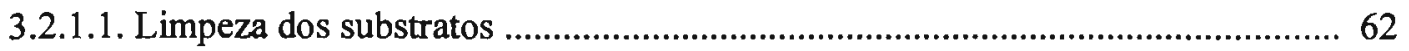

3.2.1.2. Obtenção dos filmes de $\mathrm{SnO}_{2}$ por Spray Pyrolysis .......................................... 63

3.2.2. Eletrodos de filme de $\mathrm{SnO}_{2}(\mathrm{Sb})$ suportado sobre titânio ..........................................6. 64

3.2.3. Preparação dos eletrodos modificados com OTS ........................................................ 64

3.3. Caracterização dos eletrodos depositados sobre sílica ..................................................6 66

3.3.1. Detalhes experimentais referentes às análises realizadas .........................................66 66

3.2.2. Características morfológico-estruturais dos filmes transparentes de $\mathrm{SnO}_{2}$................ 70

3.3.3. Composição química dos filmes transparentes de $\mathrm{SnO}_{2}$.......................................... 89

3.3.4. Espessura, condutividade, e transparência dos filmes depositados sobre sílica .......... 96

3.4. Caracterização dos eletrodos depositados sobre titânio ................................................... 101

3.5. Caracterização dos eletrodos de $\mathrm{SnO}_{2}$ transparentes e de $\mathrm{Ti} / \mathrm{SnO}_{2}$ modificados com OTS 105

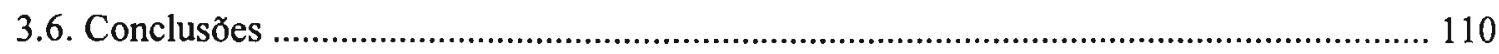

4. Caracterização eletroquímica dos eletrodos de filme de $\mathrm{SnO}_{2}$ suportado sobre sílica ou titânio

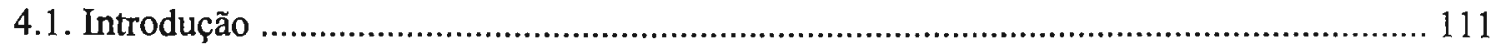

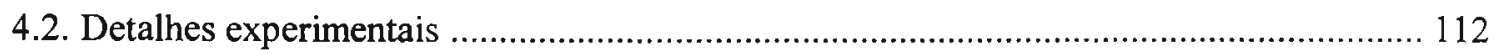

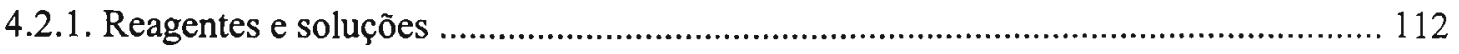

4.2.2. Preparação dos eletrodos para as medidas eletroquímicas ......................................... 113

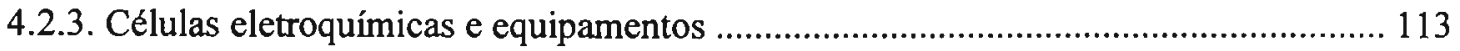

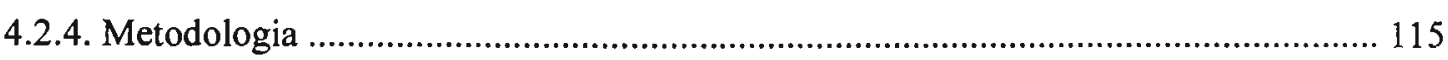

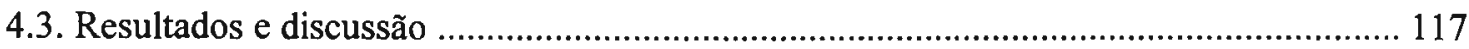

4.3.1. Comportamento eletroquímico dos eletrodos transparentes........................................ 117

4.3.1.1. O potencial de circuito aberto dos eletrodos em solução de $\mathrm{NaClO}_{4}$................... 117

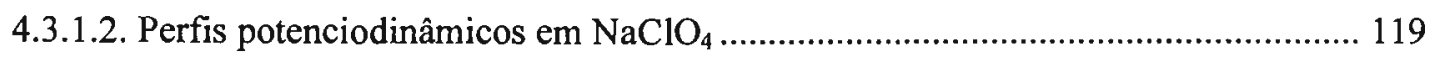

4.3.1.3. A reversibilidade da reação de óxido-redução de $\mathrm{K}_{4} \mathrm{Fe}(\mathrm{CN})_{6}$............................. 124

4.3.2. Comportamento eletroquímico dos eletrodos depositados sobre titânio ..................... 127

4.3.2.1. O potencial de circuito aberto em $\mathrm{NaClO}_{4}$...................................................... 127

4.3.2.2 O comportamento eletroquímico em eletrólito inerte $\left(\mathrm{NaClO}_{4} 0,1 \mathrm{M}, \mathrm{pH} 2,0\right) \ldots . .128$

4.3.2.3. A reversibilidade das reações de óxido-redução do $\mathrm{K}_{4} \mathrm{Fe}(\mathrm{CN})_{6} \ldots \ldots \ldots \ldots \ldots \ldots \ldots \ldots . . . . . . . . . . . .132$

4.3.3. Voltametria Cíclica de Baixa Amplitude .................................................................. 134

4.3.3.1. Aspecto geral dos perfis $\mathrm{I} / \mathrm{E}$ dos eletrodos transparentes e de $\mathrm{Ti} / \mathrm{SnO}_{2}(\mathrm{Sb})$......... 134

4.3.3.2. Determinação da $\mathrm{R}_{S}$ para os eletrodos transparentes e de $\mathrm{Ti} / \mathrm{SnO}_{2}(\mathrm{Sb})$................ 135

4.3.3.3. Determinação de $\mathrm{R}_{\mathrm{P}}$ para os eletrodos transparentes e de $\mathrm{Ti} / \mathrm{SnO}_{2}(\mathrm{Sb})$................ 136

4.3.3.4. Determinação da capacidade interfacial ........................................................... 137

4.3.3.5. Variação da capacidade interfacial com o potencial aplicado ............................... 140 
4.3.4. Espectroscopia de Impedância Eletroquímica .............................................................. 141

4.3.4.1. Espectros de EIS obtidos para os eletrodos transparentes .................................. 141

4.3.4.2. Espectros de EIS obtidos para os eletrodos depositados em titânio .........................144

4.3.4.3. A capacidade interfacial em função do potencial estimada por EIS ..................... 155

4.3.5. Gráficos de Mott-Schotky ........................................................................................ 156

4.3.6. Testes realizados para avaliar possíveis aplicaçóes para os eletrodos de $\mathrm{Ti} / \mathrm{SnO}_{2}(\mathrm{Sb})$ modificados com OTS: oxidação do metanol .............................................................. 162

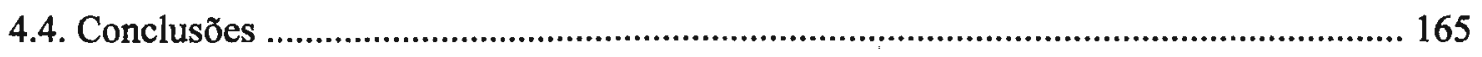

\section{Efeito dos tratamentos eletroquimicos na superficie dos eletrodos}

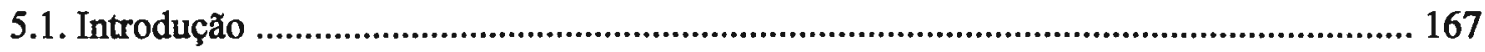

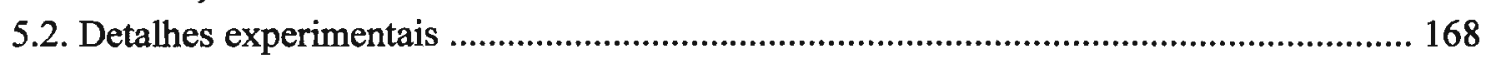

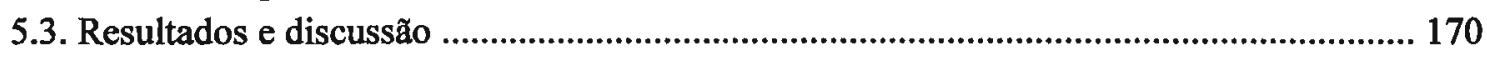

5.3.1. Alteraçðes morfológicas induzidas pela polarização anódica em potenciais da região da RDO ............................................................................................................. 170

5.3.2. Alteraçð̃es morfológicas induzidas pela polarização catódica em potenciais da

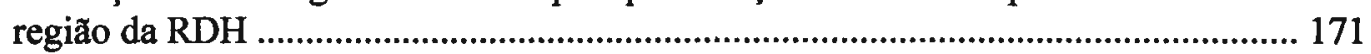

5.3.3. Alterações morfológicas induzidas pela realização de 100 varreduras triangulares entre potenciais da região da RDO e da RDH ........................................................... 175

5.3.4. Alteraç̃̃es morfológico-estruturais induzidas por perturbaçð̃es eletroquímicas na superficie do eletrodo de $\mathrm{SnO}_{2}(\mathrm{Sb})$ investigadas in-situ por STM.............................. 189

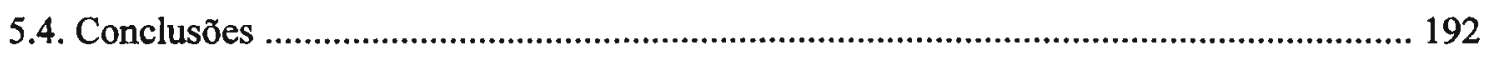

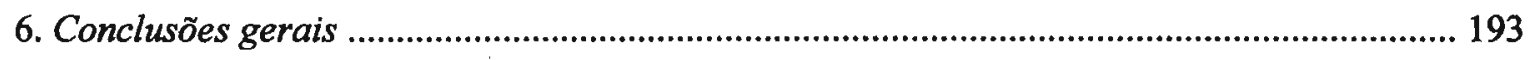

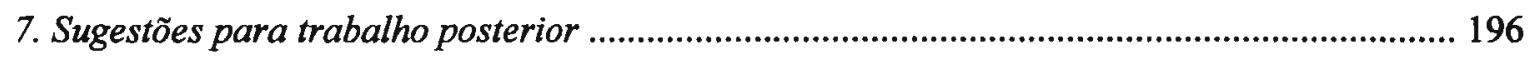

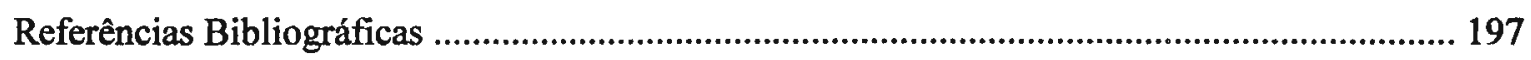

Curriculum Vitae 


\section{RESUMO}

Os eletrodos de filme de $\mathrm{SnO}_{2}$ suportado sobre sílica ou titânio apresentam propriedades eletroquímicas e morfológico-estruturais bastante distintas e são empregados em diferentes aplicações. Estes dois tipos de materiais foram preparados e investigaram-se suas propriedades através de diversas técnicas eletroquímicas e de análise de superfície.

Os eletrodos de $\mathrm{Ti} / \mathrm{SnO}_{2}(\mathrm{Sb})$ apresentaram a superficie porosa e rugosidade de $500 \mathrm{~nm}$. Para os filmes finos $(\sim 40 \mathrm{~nm})$ depositados sobre sílica, porém, observou-se alta transparência, superfície uniforme e rugosidade de $1 \mathrm{~nm}$. Mesmo entre os eletrodos transparentes, dependendo do dopante $(\mathrm{Cl}, \mathrm{F}$ ou $\mathrm{Sb})$, verificaram-se diferenças quanto às orientações cristalográficas predominantes, espessura, resistividade e tamanho das partículas.

As investigações eletroquímicas também revelaram diferenças consideráveis entre ambos os tipos de eletrodos. Para as reações de óxido-redução do $\mathrm{K}_{4} \mathrm{Fe}(\mathrm{CN})_{6}$, p.ex., a transferência de elétrons foi muito mais rápida sobre o eletrodo de $\mathrm{Ti} / \mathrm{SnO}_{2}(\mathrm{Sb})$, possivelmente porque este eletrodo apresentava maior número de portadores de carga e menor resistência ôhmica que os eletrodos transparentes. Investigou-se ainda o comportamento eletroquímico de eletrodos modificados com um filme de octadeciltriclorosilano (OTS). Os estudos revelaram que a presença do OTS não alterou o mecanismo para a reação de geração de oxigênio, porém, alterou significativamente o comportamento do eletrodo de $\mathrm{Ti} / \mathrm{SnO}_{2}(\mathrm{Sb})$ na eletro-oxidação do metanol. Aparentemente, o OTS induziu a formação de espécies poliméricas que bloquearam o eletrodo, indicando, portanto, que estes eletrodos modificados não são indicados para atuar como ânodos na eletro-oxidação de compostos orgânicos.

Os processos de corrosão induzidos por polarização anódica ou catódica foram investigados por microscopia de forças atômicas e de efeito túnel para os eletrodos transparentes modificados ou não com OTS. As análises revelaram que os processos de corrosão iniciaram-se nos contornos dos grãos e atuaram de maneira diferenciada sobre as partículas que constituem o filme. A corrosão foi muito menos pronunciada para os eletrodos modificados com OTS, indicando que este organosilano poderia proteger a superficie do $\mathrm{SnO}_{2}$. Porém, a aplicabilidade do eletrodo $\mathrm{Ti} / \mathrm{SnO}_{2}(\mathrm{Sb})$-OTS seria muito limitada, considerando que o OTS poderia promover a polimerização de espécies orgânicas na superficie do eletrodo. 


\section{ABSTRACT}

The electrochemical and morphological properties of tin oxide electrodes deposited on silica or titanium substrates were investigated by electrochemical and surface analysis techniques. The $\mathrm{Sb}$ doped $\mathrm{SnO}_{2}$ film deposited on $\mathrm{Ti}$ was prepared by thermal decomposition of stannic chloride solution and investigated by SEM and interferometric microscopy. This $\mathrm{Ti} / \mathrm{SnO}_{2}(\mathrm{Sb})$ exhibited a porous surface, with a rms roughness of $500 \mathrm{~nm}$. The transparent film of $\mathrm{SnO}_{2}$ doped with $\mathrm{Cl}, \mathrm{F}$ or $\mathrm{Sb}$, which was deposited on silica by Spray Pyrolysis, were analyzed by XPS, XRD, SEM, AFM and STM techniques. These films were polycrystalline and had an uniform and smooth surface with a rms roughness ranging from 1 to $2 \mathrm{~nm}$. Their microstructure was constituted of coalesced particles with an average diameter and height of $30 \mathrm{~nm}$ and $6 \mathrm{~nm}$, respectively. Thickness, conductivity, grain size, and surface composition of transparent films depended on the dopant.

The electrochemical behavior of both types of $\mathrm{SnO}_{2}$ electrodes were investigated by Cyclic Voltammetry and Electrochemical Impedance Spectroscopy (EIS). For the reversibility of $\mathrm{K}_{4} \mathrm{Fe}(\mathrm{CN})_{6}$ redox reaction, while the $\mathrm{Ti} / \mathrm{SnO}_{2}(\mathrm{Sb})$ electrode supported high rate for electron transfer, the transparent electrodes exhibited a poor electrochemical response, which was attributed to the high ohmic resistance.

The effect of electrochemical perturbation in $0.1 \mathrm{M} \mathrm{NaClO}_{4}, \mathrm{pH} \mathrm{2}$, on the microstructure of transparent electrodes was investigated by $i n$-situ STM and ex-situ AFM, SEM and other techniques. Anodic polarization at potentials near the OER region and potential cycling induces little alterations on the microstructure of the electrode, observable only in sub-micron range by AFM analysis. Cathodic polarization at potentials in the region of the HER, however, strongly damages the film. AFM and STM examination revealed that the grain boundaries are attacked, and both vertical and lateral dimensions of the particles decrease. From the observations, it can be inferred that $\mathrm{SnO}$ is formed during the cathodic polarization and, destruction of the film occurs by dissolution of that more soluble oxide. In-situ STM experiments showed that, at the initial stages, the particles of the damaged film can acquire dimensions even larger than the initial size by anodic polarization. Finally, it can be concluded that a smooth and compact film, with little defects is less susceptible to corrosion. 


\section{Notação: Abreviaturas}

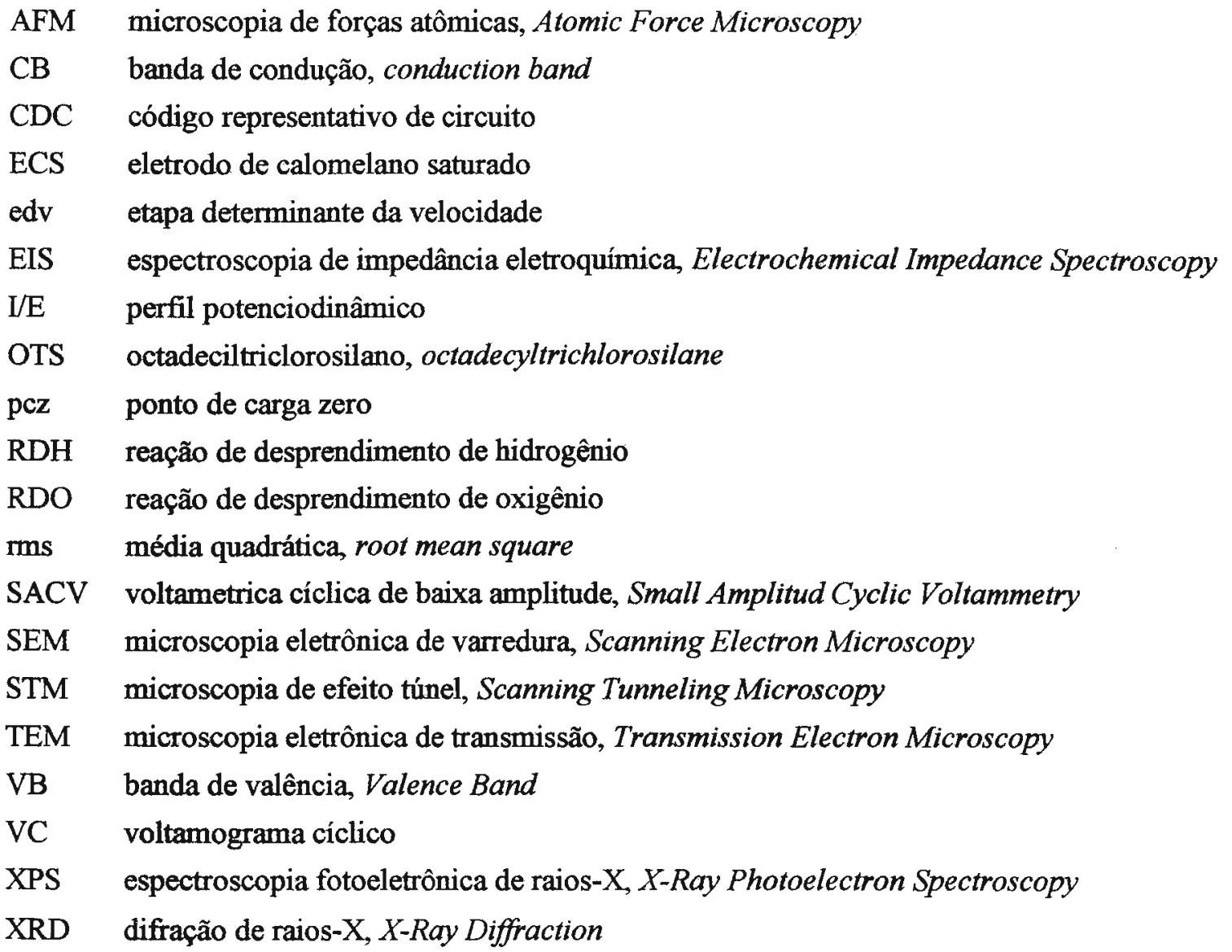

\section{Notação: Símbolos}

C capacidade

$C_{D}$ capacidade da camada difusa, diffuse layer

$\mathrm{C}_{\mathrm{dl}}$ capacidade da dupla camada elétrica, electrical double layer

$\mathrm{C}_{\mathrm{H}}$ capacidade da camada de Helmholtz

$\mathrm{C}_{\mathrm{SC}}$ capacidade da região de carga espacial em um semicondutor, space charge layer

D altura do cristalito

d espessura do filme

e carga do elétron

E potencial

$\mathrm{E}_{\mathrm{CA}}$ potencial de circuito aberto

$E_{\text {corr }}$ potencial de corrosão

$\mathrm{E}_{\mathrm{FB}}$ potencial de bandas planas, Flat Band Potential

$E_{i}$ valor inicial do potencial aplicado na SACV

$\mathrm{E}_{\mathrm{m}} \quad$ valor máximo do potencial aplicado na $\mathrm{SACV}$

$\mathrm{E}_{\mathrm{P}}{ }^{\mathrm{A}}$ potencial de pico anódico

$\mathrm{E}_{\mathrm{P}}{ }^{\mathrm{C}}$ potencial de pico catódico 
$E$ energia

$E_{\mathrm{bg}}$ intervalo de energia correspondente ao "band gap" entre as bandas de condução e valência, ou, espessura da banda proibida

$E_{\mathrm{CB}}, E_{\mathrm{VB}}$ nível de energia correspondente à $\mathrm{CB}$ (ou à $\mathrm{VB}$ ) nos diagramas das bandas de energia

$E_{\mathrm{D}}, E_{\mathrm{R}} \quad$ nível de energia inserido por dopantes doadores (ou aceptores) de elétrons em semicondutores do tipo-n (ou do tipo-p)

$E_{\mathrm{F}} \quad$ energia correspondente ao nível de Fermi

$\boldsymbol{E}_{\text {Lig }}$ energia de ligação (XPS)

I corrente

$\mathrm{I}_{\mathrm{P}}{ }^{\mathrm{A}} \quad$ intensidade da corrente de pico anódica

$\mathrm{I}_{\mathrm{P}}{ }^{\mathrm{C}} \quad$ intensidade da corrente de pico catódica

$\Delta \mathrm{I} \quad\left(\mathrm{I}^{\mathrm{d}}-\mathrm{I}^{\mathrm{i}}\right)$ histerese de corrente entre as varreduras direta e inversa (SACV)

k constante de Boltzmann

$\mathrm{K}$ constante de calibração para estimar o tamanho dos cristalinos (XRD)

$N_{D}$ densidade efetiva dos portadores de carga (doadores em semicondutores do tipo-n)

Q elemento de fase constante (CDC)

$\mathrm{R}$ resistência

$\mathrm{R}_{\mathrm{ap}}$ resistência aparente (SACV)

$R_{D}$ resistência diagonal (SACV)

$R_{C T}$ resistência à transferência de carga

$\mathrm{R}_{\mathrm{P}}$ resistência à polarização

T temperatura absoluta

$\mathrm{Z}$ impedância

$Z^{\prime}\left(Z_{r e}\right)$ componente da impedância em fase

$Z^{\prime \prime}\left(Z_{\text {im }}\right)$ componente da impedância fora de fase

$\beta \quad$ a largura (a meia altura) dos picos de difração (XRD)

$\chi^{2} \quad$ parâmetro de teste de aderência

$\varepsilon \quad$ constante dielétrica do semicondutor

$\varepsilon_{0} \quad$ permissividade no vácuo

$\varphi$ deslocamento no ângulo de fase (EIS)

$\lambda$ comprimento de onda da radiação empregada

$v \quad$ velocidade de varredura

$\theta$ ângulo de difração (XRD)

$\theta$ ângulo total de reflexão, em radianos (reflectometria de XRD)

$\omega \quad$ frequência do sinal aplicado (EIS) 
CAPÍtulo 1

\section{INTRODUÇÃO}


$\mathrm{O} \mathrm{SnO}_{2}$ é um material semicondutor, transparente, de grande estabilidade química e mecânica, que apresenta numerosas e diversificadas aplicações [1]. Na forma de filme depositado sobre vidro ou quartzo, devido à alta transparência e condutividade (aumentada por dopagem), é utilizado como eletrodo transparente em painéis e outros dispositivos eletrocrômicos [2-7], em estudos de Espectroeletroquímica [8-10] e ainda nos estudos de Fotoeletroquímica e no desenvolvimento de células solares [11-16]. Depositado sobre titânio, o $\mathrm{SnO}_{2}$ tem sido empregado no desenvolvimento de ânodos dimensionalmente estáveis para a produção de $\mathrm{Cl}_{2}$ e $\mathrm{O}_{2}$ [17-20] e, por apresentar um elevado sobrepotencial para a reação de geração de $\mathrm{O}_{2}$, tem sido utilizado como ânodo na oxidação eletroquímica de poluentes orgânicos [21-23] e de cianeto [24]. Uma outra aplicação do $\mathrm{SnO}_{2}$ que também merece destaque é a sua utilização em sensores para gases, baseada nas mudanças da condutividade que ocorrem na presença de gases redutores, p.ex. o CO [25-28].

Um dos principais problemas associados à utilização do $\mathrm{SnO}_{2}$ como eletrodo é a degradação do filme causada por processos de corrosão que ocorrem sob polarização catódica ou anódica $[1-3,18,29-34]$. Sob polarização catódica, o filme é destruído porque, quase que simultaneamente à reação de geração de $\mathrm{H}_{2}$, ocorrem diversos processos que reduzem o $\mathrm{SnO}_{2}$ a $\mathrm{Sn}^{\circ}$ ou a $\mathrm{SnO}$, que é um óxido muito mais solúvel [1-3, 11, 29-33]. Por outro lado, sugere-se que a corrosão sob polarização anódica aconteça devido à interação entre a superfície e os radicais que são gerados eletroquimicamente sob altos valores de potencial. Estes radicais $\mathrm{OH}^{\bullet}$ e $\mathrm{Cl}^{\bullet}$ (dependendo do eletrólito) poderiam atacar as ligações Sn-O na superfície, causando o seu enfraquecimento e ruptura [34]. Já foi sugerido também que a polarização anódica alterasse a relação $\mathrm{Sn} / \mathrm{O}$ na superficie, que em geral é deficiente em $\mathrm{O}$. As alterações causadas pela oxidação dos sítios superficiais aumentaria a tensão interna do filme de $\mathrm{SnO}_{2}$, que poderia se desprender do substrato [18].

Apesar da importância do $\mathrm{SnO}_{2}$ nas aplicações citadas, os processos de corrosão que atuam sobre este material foram pouco investigados. Com exceção a um estudo dos efeitos da polarização anódica através de técnicas eletroquímicas aliadas às microscopias eletrônicas de varredura e de transmissão [34], e a uma investigação dos efeitos da polarização catódica que incluiu análises por difração de raios-X [3], os demais relatos apresentados na Literatura se limitaram à caracterização da superfície atacada através de 
microscopia eletrônica de varredura $[2,11,31]$. As técnicas de microscopia por aproximação de sondas, tais como a microscopia de forças atômicas (Atomic Force Microscopy, AFM) ou a de efeito túnel (Scanning Tunneling Microscopy, STM), não têm sido utilizadas nestes trabalhos, exceto para acompanhar variações da rugosidade [3].

A AFM e a STM são técnicas muito importantes em Eletroquímica porque permitem a análise detalhada da superfície e podem ainda operar in-situ, auxiliando na correlação entre a morfologia do eletrodo e as suas propriedades eletroquímicas [35, 36]. Embora tenham sido intensamente empregadas no estudo de eletrodos de Pt, Au ou grafite, sua utilização para eletrodos de óxidos metálicos ainda é bastante restrita [37]. Existem diversos trabalhos referentes ao estudo de filmes de $\mathrm{SnO}_{2}$ ou mesmo de $\mathrm{In}_{2} \mathrm{O}_{3}$ dopado com Sn (ITO) por AFM ou STM [3, 5, 16, 38-48], mas, especificamente para eletrodos à base destes materiais, os relatos são pouco numerosos $[3,5,16,38]$.

Em Eletroquimica, as análises de AFM foram empregadas, p.ex., para estimar as alterações da rugosidade da superficie de eletrodos de $\mathrm{SnO}_{2}(\mathrm{~F})$ submetidos à polarização catódica [3]. Esta técnica revelou ainda que os filmes de $\mathrm{SnO}_{2}$ e $\mathrm{SnO}_{2}(\mathrm{Mo})$ depositados em eletrodos comerciais de $\mathrm{SnO}_{2}(\mathrm{~F})$ através da imersão em sistemas sol-gel apresentavam topografia distinta da observada para o substrato [5]. As análises de AFM e STM também foram úteis ao revelar a presença de grãos e crateras na superficie de eletrodos comerciais de $\mathrm{SnO}_{2}(\mathrm{Sb})$, o que permitiu explicar a má qualidade dos filmes de corantes adsorvidos pelo método de Langmuir-Blodgett $[16,38]$. Neste trabalho, utilizou-se a AFM, associada a outras técnicas de análise de superfície, para caracterizar as propriedades morfológicoestruturais de eletrodos transparentes de filmes finos de $\mathrm{SnO}_{2}$ dopados com $\mathrm{Cl}, \mathrm{F}$ ou Sb, e ainda para investigar as alterações induzidas por perturbações eletroquimicas na morfologia destes eletrodos.

$\mathrm{O} \mathrm{SnO}_{2}$ tem sido investigado pelo Grupo já há algum tempo, como parte de um projeto maior dedicado a investigar propriedades eletroquímicas e interfaciais de óxidos. Os trabalhos realizados incluíram a investigação das propriedades ácido-base e de adsorção do $\mathrm{SnO}_{2}$ na forma de partículas em suspensão $[49,50]$ e o desenvolvimento de ânodos de $\mathrm{SnO}_{2}$ depositado sobre titânio e sua aplicação na eletro-oxidação do cianeto [51, 52]. Dando continuidade ao desenvolvimento deste projeto, no presente trabalho os estudos foram dedicados à obtenção e à investigação de eletrodos depositados em sílica (eletrodos transparentes), e, em alguns aspectos, investigaram-se também eletrodos depositados sobre titânio, para que algumas propriedades pudessem ser comparadas. 
Os eletrodos transparentes foram preparados pelo método conhecido como Spray Pyrolysis: uma solução precursora de cloreto de estanho em metanol foi aplicada através de um atomizador sobre substratos de sílica aquecidos a $600^{\circ} \mathrm{C}$. Prepararam-se eletrodos dopados com $\mathrm{Sb}$ ou $\mathrm{F}$, que foram denominados por $\mathrm{SnO}_{2}(\mathrm{Sb})$ e $\mathrm{SnO}_{2}(\mathrm{~F})$, respectivamente, e ainda eletrodos que apresentaram dopagem não intencional com $\mathrm{Cl}$, referidos como $\mathrm{SnO}_{2}(\mathrm{Cl})$. A deposição do filme de $\mathrm{SnO}_{2}$ em titânio também foi obtida pela hidrólise de uma solução alcóolica de cloreto de estanho, mas, neste caso, a solução precursora foi aplicada ao substrato por pincelamento, e só então a amostra foi submetida ao aquecimento. Estes eletrodos, preparados com um filme de $\mathrm{SnO}_{2}$ dopado com $\mathrm{Sb}$, foram denominados por $\mathrm{Ti} / \mathrm{SnO}_{2}(\mathrm{Sb})$. Prepararam-se ainda eletrodos modificados pela adsorção de um filme hidrofóbico de octadeciltriclorosilano (OTS), referidos como $\mathrm{SnO}_{2}$-OTS.

Os eletrodos transparentes foram investigados por diferentes técnicas de análise de superfície para a caracterização das suas propriedades químicas e morfológico-estruturais. Estas técnicas foram referidas no texto e nas legendas pela abreviatura dos termos em inglês, que são muito mais conhecidos, para que fossem identificadas mais facilmente. As principais técnicas empregadas neste trabalho foram a Espectroscopia Fotoeletrônica de Raios-X (XPS), a Microscopia Eletrônica de Varredura e de Transmissão (SEM e TEM, respectivamente), a Microscopia de Forças Atồmicas e a de Efeito Túnel (AFM e STM), a Microscopia por Interferometria de Luz e a Difração de Raios-X (XRD). Determinaram-se ainda a espessura dos filmes, através de Reflectometria de Raios-X, e a condutividade, pelo método de Van der Pauw. Para os eletrodos depositados em titânio, apenas examinou-se a microestrutura da superfície, considerando que a caracterização destes eletrodos já havia sido realizada em outro trabalho do Grupo [51].

Nos aspectos eletroquímicos, investigou-se para ambos os tipos de eletrodos o comportamento em eletrólito inerte e a reversibilidade das reações de óxido-redução do $\mathrm{K}_{4} \mathrm{Fe}(\mathrm{CN})_{6}$. Como o $\mathrm{SnO}_{2}$ é um material semicondutor do tipo-n, determinaram-se os gráficos de Mott-Schottky para estimar a concentração de portadores de carga $\left(N_{D}\right)$ e o potencial de bandas planas $\left(\mathrm{E}_{\mathrm{FB}}\right)$ para ambos os tipos de eletrodos. Com este objetivo, estimou-se a capacidade interfacial sob a aplicação de diferentes potenciais através de medidas por Espectroscopia de Impedância Eletroquímica (EIS) e por Voltametria Cíclica de Baixa Amplitude (SACV). 
Para finalizar, investigaram-se os efeitos de perturbações eletroquímicas na microestrutura dos eletrodos transparentes, empregando análises ex-situ de AFM e SEM e análises in-situ por STM. Tais estudos também foram realizados para os eletrodos transparentes modificados com OTS, para verificar se estariam menos susceptiveis à corrosão.

A seguir, apresenta-se no Capítulo 2 a revisão bibliográfica considerada necessária para a discussão dos estudos desenvolvidos neste trabalho. Nesta revisão, os conceitos básicos da Eletroquímica de Semicondutores foram brevemente apresentados, já que as propriedades semicondutoras do $\mathrm{SnO}_{2}$ afetam o comportamento eletroquímico deste material. Com maior detalhe, apresentou-se a revisão bibliográfica dos estudos já realizados para eletrodos de $\mathrm{SnO}_{2}$ transparentes e depositados em titânio. Incluiram-se ainda algumas considerações gerais referentes às técnicas eletroquímicas utilizadas neste estudo, e apenas um breve comentário a respeito de algumas técnicas de análise de superficie empregadas neste trabalho.

O trabalho experimental desenvolvido foi apresentado nos capitulos seguintes. No Capítulo 3, descreve-se e discute-se a preparação e a caracterização química e morfológico-estrutural dos materiais investigados neste trabalho. Os estudos eletroquímicos foram descritos e discutidos no Capítulo 4 , e, no $5^{\circ}$ Capítulo, apresentaramse os resultados obtidos no estudo das alterações morfológico-estrutrurais da superfície dos eletrodos induzidas por perturbações eletroquímicas. As conclusões finais sobre este trabalho foram apresentadas no último capítulo. 
CAPITULO 2

REVISÃO BIBLIOGRÁFICA 


\section{1 - ELETRODOS SEMICONDUTORES:}

\section{CONSIDERAÇÕES SOBRE OS CONCEITOS FUNDAMENTAIS}

A interfase entre um semicondutor e um eletrólito está presente em numerosas situações do nosso cotidiano, como, p.ex., na fabricação dos dispositivos empregados em informática, na construção de células fotoeletroquímicas, e ainda em muitos outros sistemas, considerando que os filmes de óxido que se formam sobre alguns metais frequentemente são semicondutores $[53,54]$.

$\mathrm{O}$ estudo destas interfases se intensificou muito nas últimas décadas, motivado principalmente no sentido do desenvolvimento das células solares de junção semicondutorlíquido, e resultou no aparecimento de um ramo especial da Eletroquímica. $\mathrm{Na}$ Eletroquímica de Semicondutores, uma grande parte dos modelos e da terminologia adotados são provenientes da "Física do Estado Sólido", e, por esta razão, apresenta-se a seguir uma breve introdução aos conceitos fundamentais envolvidos [53-55]. Apesar da grande importância dos fenômenos relacionados com a fotossensibilidade dos semicondutores, tais aspectos não serão abordados nesta Revisão Bibliográfica, já que não relacionam-se diretamente com este trabalho.

\subsubsection{A teoria de bandas e o transporte de carga em semicondutores [53-56]}

As propriedades apresentadas pelos semicondutores podem ser descritas através da teoria de bandas. De acordo com a distribuição dos elétrons entre os diversos níveis de energia permitidos, algumas bandas são ocupadas total ou parcialmente, enquanto que outras permanecem vazias. Nos processos de transporte e transferência de cargas, as bandas mais importantes são a banda de maior energia dentre aquelas que estão ocupadas e a de menor energia que está vazia. Na condição do zero absoluto $(\mathrm{T}=0)$, são denominadas respectivamente de banda de valência (valence band, VB) e banda de condução (conduction band, CB ). A Figura 2.1 esquematiza os diagramas de energia previstos pela teoria de bandas para os metais e para os semicondutores ou isolantes.

Nos metais, as bandas estão praticamente sobrepostas e a banda de valência não está completa em $\mathrm{T}=0$ (Fig. 2.1a). O nível de Fermi $\left(\boldsymbol{E}_{\mathrm{F}}\right)$ encontra-se na divisão entre os níveis ocupados e não ocupados. Neste caso, na presença de um campo elétrico, os elétrons podem se movimentar facilmente através dos níveis parcialmente preenchidos, proporcionando assim as altas condutividades térmica e elétrica características dos metais. 
(a)

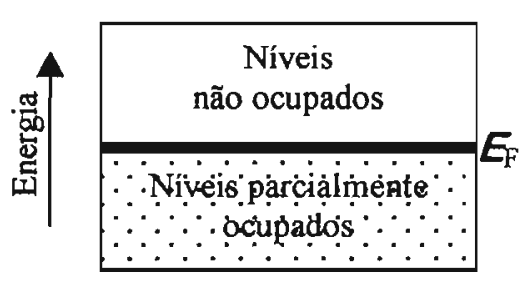

(b)

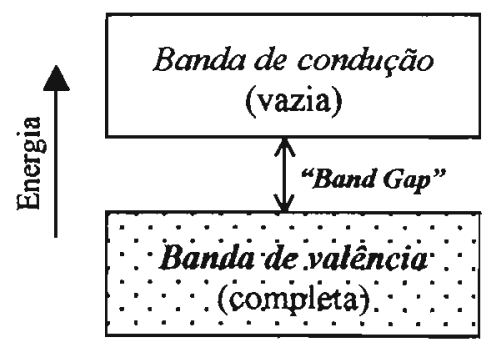

Figura 2.1. Diagrama das bandas de energia: (a) metais; (b) semicondutores e isolantes

Por outro lado, os materiais semicondutores e isolantes são caracterizados por apresentar a banda de valência totalmente preenchida em $\mathrm{T}=0$ e uma zona proibida que a separa da banda de condução. Para que os semicondutores apresentem condutividade necessita-se de portadores de carga, ou seja, é necessário que alguns elétrons sejam promovidos da banda de valência para a de condução, por efeito térmico ou fotoexcitação.

A energia necessária para promover os elétrons de um nivel ao outro depende da espessura da zona proibida, ou seja, do intervalo de energia que separa as bandas de valência e condução, mais conhecido como "band gap" $\left(E_{\mathrm{gg}}\right)$. Portanto, em uma determinada temperatura, é o valor do $E_{\mathrm{og}}$ que distingue um semicondutor de um isolante.

Para cada elétron excitado são gerados dois portadores de carga: o elétron, na banda de condução e uma lacuna, ou seja, uma vacância positiva $\left(h o l e, h^{+}\right)$na banda de valência. Ambos são móveis dentro das suas respectivas bandas de energia e participam no processo de transporte da corrente elétrica.

As concentrações dos elétrons de condução e das lacunas, que são os portadores de carga negativos e positivos, [n] e [p], dependem da temperatura absoluta e da espessura da camada proibida, e estão relacionadas por

$$
[\mathrm{n}][\mathrm{p}]=\mathrm{N}_{\mathrm{C}} \mathrm{N}_{\mathrm{v}} \exp \left(-E_{\mathrm{gg}} / \mathrm{kT}\right)
$$

onde $\mathrm{N}_{\mathrm{C}}$ e $\mathrm{N}_{\mathrm{V}}$ correspondem às densidades dos níveis de energia efetivos nos limites das bandas de condução e valência, respectivamente. À temperatura ambiente, seus valores são da ordem de $10^{19} \mathrm{~cm}^{-3}$.

À temperatura ambiente, os semicondutores intrínsecos (i.e., não dopados) que apresentam $E_{\mathrm{og}}>0,5 \mathrm{eV}$ são essencialmente isolantes. No entanto, a condutividade pode ser aumentada consideravelmente através da dopagem. 
A dopagem consiste em alterar quimicamente o material semicondutor, utilizando como impurezas determinados elementos que tenham valência distinta e que possam ser adequadamente inseridos na estrutura cristalina. $\mathrm{O}$ mesmo efeito também pode ser obtido tornando o material não-estequiométrico, i.e., com um dos elementos em excesso.

O aumento da condutividade resulta da introdução de novos níveis de energia dentro da região da zona proibida, como mostra o esquema representado na Figura 2.2. Estes novos níveis devem estar próximos ao limite de uma das bandas, para que se estabeleça um novo $\boldsymbol{E}_{\mathrm{gg}}$.

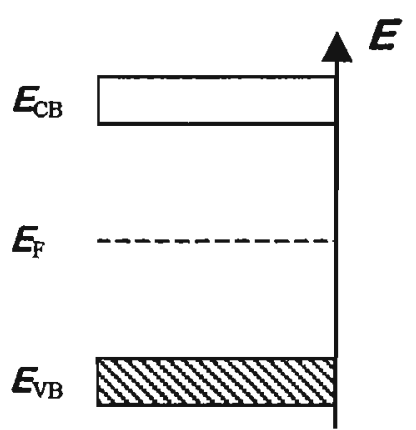

(a)

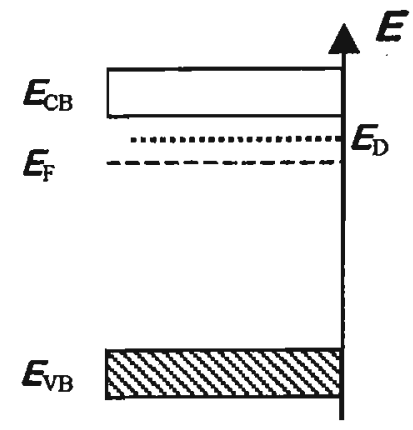

(b)

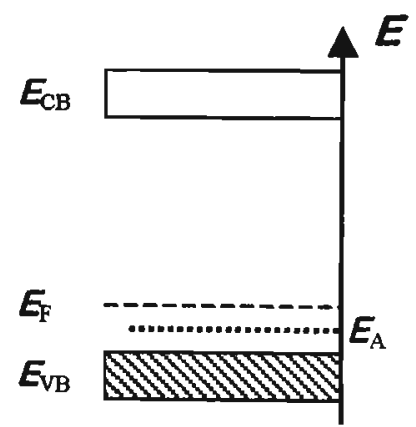

(c)

Figura 2.2. Diagrama ilustrativo das bandas de energia para os semicondutores: intrínsecos (a); extrínsecos do tipo-n (b) e do tipo-p (c).

Quando o dopante é um doador de elétrons, surgirá um novo nível de energia $\left(\boldsymbol{E}_{\mathrm{D}}\right)$ próximo à banda de condução $\left(E_{\mathrm{CB}}\right)$, como ilustrado na Fig. 2.2b. Sob o efeito de excitação térmica, p.ex., uma grande população de elétrons poderá ser doada à banda de condução. De acordo com a equação 2.1, a concentração de lacunas deve diminuir e, portanto, a corrente elétrica será transportada predominantemente por portadores de carga negativos na banda de condução. Por esta razão, o material pode ser classificado como um semicondutor do tipo-n.

Em semicondutores do tipo-p, o dopante é um aceptor de elétrons, e insere um nível de energia logo acima da banda de valência $\left(\boldsymbol{E}_{\mathrm{A}}\right)$. Neste caso, elétrons podem ser capturados da banda de valência, induzindo à formação de lacunas, ou seja, criando um excesso de transportadores de carga positivos. 
A presença de dopantes também altera a posição do nível de Fermi. Nos semicondutores intrínsecos, este nível de energia situa-se aproximadamente no meio da região da zona proibida, entre as bandas de condução e valência (Fig. 2.2a). Nos semicondutores do tipo-n, o nível de Fermi aproxima-se da banda de condução, enquanto que, nos de tipo-p, situa-se mais próximo à banda de valência (Fig. 2.2b e 2.2c, respectivamente).

O efeito dos dopantes pode ser facilmente ilustrado considerando como exemplo o silício, que tem 4 elétrons na camada de valência. Se alguns átomos de fósforo (ou outros elementos do Grupo V) forem introduzidos no Si cristalino, será obtido um semicondutor de tipo-n. Como o P é pentavalente, cada uma das ligações Si-P apresentará um elétron praticamente livre (o P será um doador de elétrons). Estes elétrons ocuparão um nível de energia localizado logo abaixo da banda de condução, para onde poderão ser facilmente transferidos. Por outro lado, se o Si cristalino for dopado com átomos de boro, será obtido um semicondutor de tipo-p. O B é trivalente, e, portanto, em cada uma das ligações Si-B haverá a falta de um elétron. Elétrons de ligações Si-Si vizinhas podem se transferir para as ligações Si-B, causando o aparecimento de lacunas.

\subsubsection{A interfase semicondutor | eletrólito e o dobramento das bandas [53-56]}

Quando o eletrodo semicondutor é colocado em contato com a solução do eletrólito, a diferença de potencial que se estabelece na interface provoca uma variação do potencial em ambas as fases. Existem 3 regiões nas quais o potencial elétrico apresenta variações, como ilustra a Figura 2.3 .

No lado do eletrólito, o potencial varia através das camadas difusa (D) e de Helmholtz $(\mathrm{H})$. No lado do semicondutor, também existe uma camada de carga espacial difusa, na qual o potencial varia lentamente desde o valor que se estabelece na superficie até o valor correspondente ao do interior do sólido.

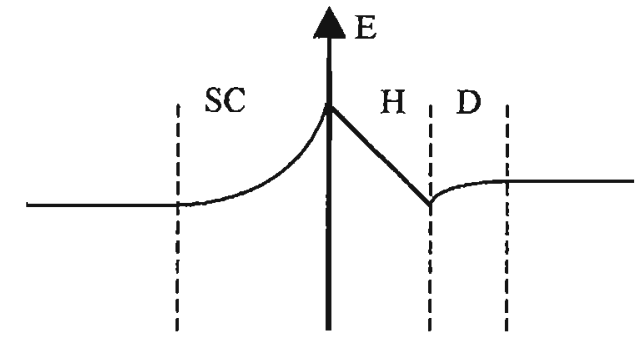

Figura 2.3. Esquema da variação do potencial através da interface semicondutor $\mid$ eletrólito.

A região definida por este gradiente de potencial é denominada região de carga espacial (space charge layer, SC). Esta carga espacial, que ocupa um determinado volume 
próximo à superfície, é resultante dos sítios carregados pela presença dos dopantes e do acúmulo de elétrons ou lacunas. A variação do potencial na região da carga espacial depende do potencial externo que for aplicado ao eletrodo e, similar ao que ocorre na interface semicondutor|metal, promove o dobramento das bandas e a alteração das concentrações relativas dos portadores de carga.

O dobramento nas bandas de energia corresponde à variação que a energia potencial dos elétrons apresenta em função da distância na região da carga espacial. $\mathrm{O}$ dobramento das bandas pode ser positivo ou negativo, dependendo das energias das bandas de condução e valência na superfície e no interior do semicondutor.

Para cada semicondutor em um determinado eletrólito, existe um único valor de potencial no qual não existe qualquer variação entre o potencial da superfície e o do interior do eletrodo, ou seja, não existe a região de carga espacial. Este potencial é denominado potencial de bandas planas, $\mathrm{E}_{\mathrm{FB}}$ (do termo "flat band"), já que não ocorre dobramento das mesmas. Esta condição corresponde ao potencial de carga zero do eletrodo $(\mathrm{pcz})$. $\mathrm{O} \mathrm{E}_{\mathrm{FB}}$ pode ser determinado através técnicas baseadas em medidas de fotocorrente ou através do gráfico de Mott-Sckottky, que consiste em medidas da capacidade da região de carga espacial $\left(\mathrm{C}_{\mathrm{SC}}\right)$ em função do potencial aplicado na interface.

Os efeitos que o potencial aplicado produzem no diagrama de bandas de energia podem ser discutidos considerando especificamente o caso de um semicondutor do tipo-n, como é o caso do eletrodo de $\mathrm{SnO}_{2}$.

Quando o eletrodo é polarizado em potenciais mais positivos que o $E_{\mathrm{FB}}$, uma parte da diferença $\left(E-E_{F B}\right)$ se distribui através da região de carga espacial. Como o potencial elétrico no interior do semicondutor é menor que na superficie, ocorre o dobramento positivo das bandas. Nos diagramas que representam a escala de energia verticalmente, as bandas se dobram "para cima", como mostra a Figura $2.4 \mathrm{~b}$.

Na superfície do eletrodo, a concentração dos elétrons diminui, formando uma camada de exaustão ou depleção, já que estes são os portadores de carga predominantes em um semicondutor de tipo-n. Esta camada de depleção é positivamente carregada, devido à presença das espécies doadoras ionizadas, imobilizadas na estrutura cristalina. No outro lado da interface, o excesso de cargas positivas do semicondutor é compensado pela contra-carga negativa dos íons do eletrólito. 
(a) $\mathbf{E}=\mathbf{E}_{\mathbf{F B}}$

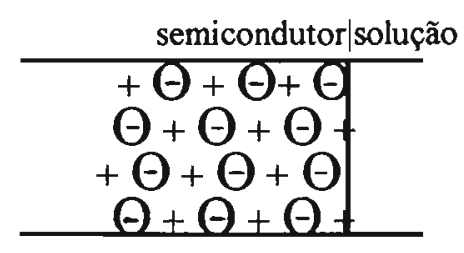

Ausência de carga espacial

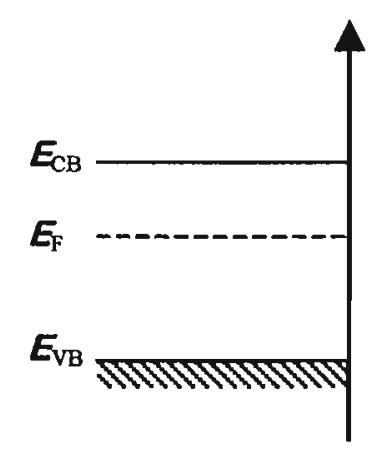

(b) $\mathbf{E}>\mathbf{E}_{\mathrm{FB}}$

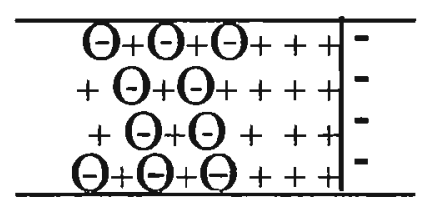

Camada de depleção

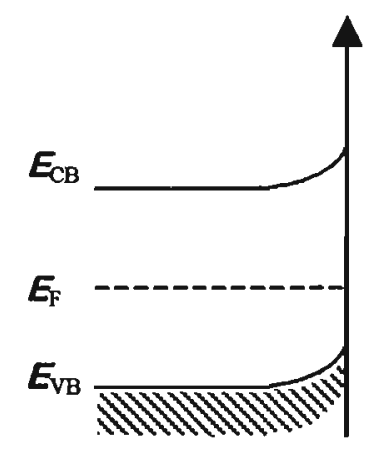

(c) $\mathbf{E}<\mathbf{E}_{\mathrm{FB}}$

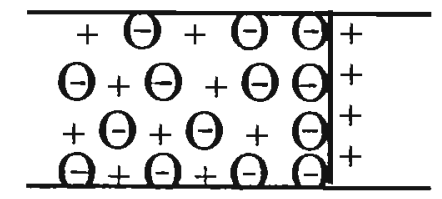

Camada de enriquecimento

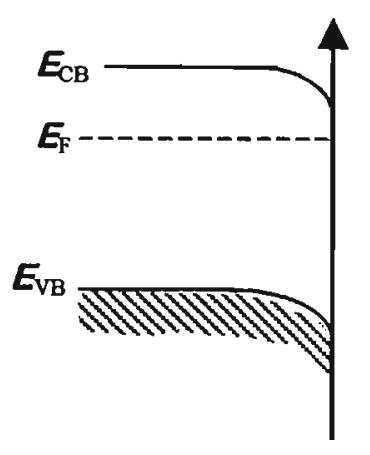

Figura 2.4. Regiões da carga espacial e diagrama de bandas da interfase semicondutor tipo-n|eletrólito em função do potencial aplicado.

A diminuição na concentração de elétrons na superfície provoca o aumento da concentração das lacunas, que são os portadores minoritários. Se a concentração das lacunas superar a de elétrons na superficie, forma-se uma camada de inversão.

Uma situação distinta se verifica quando o eletrodo é polarizado em potenciais mais negativos que o $E_{F B}$. $O$ nível de Fermi se aproxima da banda de condução e, com o acúmulo de elétrons sobre a superfície do eletrodo, forma-se a camada de enriquecimento. A alta concentração de portadores de carga na superficie confere ao eletrodo semicondutor propriedades quase metálicas. No lado do eletrólito, a carga é compensada por cátions da solução.

Por outro lado, para os semicondutores do tipo-p, a polarização do eletrodo em $\mathrm{E}<\mathrm{E}_{\mathrm{FB}}$ resulta na formação da camada de depleção e as bandas se dobram para baixo, enquanto que, sob polarização em $\mathrm{E}>\mathrm{E}_{\mathrm{FB}}$ as bandas se dobram para cima e forma-se na superficie a camada de enriquecimento. 


\subsubsection{Os gráficos de Mott-Schottky e a determinação do $\mathbf{E}_{F B}$ e $\mathbf{N}_{D}$ [53-55]}

A distribuição de carga na interfase não pode ser medida diretamente. No entanto, é possivel obter informações sobre a variação da distribuição da carga através de medidas da capacidade diferencial.

De modo geral, a capacidade da interfase semicondutor|eletrólito pode ser representada como um conjunto de 3 capacitores dispostos em série, que correspondem às capacidades da camada difusa, da camada de Helmholtz e da região da carga espacial, $C_{D}$, $\mathrm{C}_{\mathrm{H}}$ e $\mathrm{C}_{\mathrm{SC}}$, respectivamente. A capacidade total deste conjunto de capacidades em série pode ser estimada por

$$
1 / \mathrm{C}_{\mathrm{T}}=1 / \mathrm{C}_{\mathrm{SC}}+1 / \mathrm{C}_{\mathrm{H}}+1 / \mathrm{C}_{\mathrm{D}}
$$

e, portanto, predominará na capacidade total aquela que apresentar o menor valor, o que é normalmente atribuído ao $\mathrm{C}_{\mathrm{SC}}$.

$\mathrm{Na}$ análise das medidas da capacidade total da interfase, a primeira simplificação que pode ser feita no modelo consiste em desprezar o $C_{D}$. Nas concentrações do eletrólito suporte normalmente empregadas, a variação do potencial nesta camada é extremamente pequena e, portanto, o $C_{D}$ pode ser desprezado.

Na camada de Helmholtz, a variação do potencial é muito sensível à composição do eletrólito em decorrência dos equilíbrios de adsorção na superficie do eletrodo. Em solução aquosa, caso o eletrodo seja um óxido semicondutor ou se um filme de óxido tiver se formado sobre o eletrodo, os equilíbrios mais importantes referem-se à adsorção dos íons $\mathrm{H}^{+}$e $\mathrm{OH}^{-}$na superficie. Os íons $\mathrm{H}^{+}$e $\mathrm{OH}$ são considerados os íons determinantes do potencial da interfase óxido|solução aquosa em função do equilíbrio

$$
\mathrm{M}-\mathrm{OH} \Leftrightarrow \mathrm{M}-\mathrm{O}^{-}+\mathrm{H}^{+}
$$

Portanto, a carga superficial e a variação do potencial na camada de Helmholtz dependem do $\mathrm{pH}$ da solução, assim como o $\mathrm{E}_{\mathrm{FB}}$. Nas medidas da capacidade interfacial realizadas em uma mesma condição de $\mathrm{pH}$, admite-se que o $\mathrm{C}_{\mathrm{H}}$ permanece constante e que a variação do $\mathrm{C}_{\mathrm{T}}$ em função do potencial aplicado na interfase deve-se apenas às variações do $\mathrm{C}_{\mathrm{SC}}$. $\mathrm{Na}$ prática, $\mathrm{C}_{\mathrm{H}}$ ou não é considerado, ou lhe são atribuídos valores que variam de 10 a $100 \mu \mathrm{cm}^{-2}$. 
Para analisar a variação da capacidade da região da carga espacial, no lado do semicondutor, recorre-se às teorias desenvolvidas para a junção semicondutor|metal. É previsto que o $\mathrm{C}_{\mathrm{SC}}$ depende da espessura desta camada e a variação do potencial pode ser calculada a partir das equações de distribuição de Poisson e Boltzmann.

$\mathrm{Na}$ região da carga espacial, a densidade de carga resulta dos portadores móveis (elétrons e lacunas) e dos imobilizados na estrutura cristalina (impurezas do tipo doadoras ou aceptoras de elétrons). P. ex., para um semicondutor do tipo-n sob a aplicação de um potencial $\mathrm{E}>\mathrm{E}_{\mathrm{FB}}$, a densidade de carga resulta da soma das cargas positivas dos centros doadores ionizados com a carga móvel negativa dos elétrons de condução.

No caso limite para a camada de depleção (antes que se forme a camada de inversão), os doadores estão completamente ionizados e a concentração de lacunas é desprezivel. Nesta condição, torna-se válida a equação de Mott-Schottky, que estima a variação do $\mathrm{C}_{\mathrm{SC}}$ com o potencial aplicado ao eletrodo $(\mathrm{E})$, relacionados com outras propriedades do semicondutor através da expressão

$$
\frac{1}{C^{2}}=\left(\frac{2}{\varepsilon \varepsilon_{\infty} e N_{D}}\right) \cdot\left(E-E_{F B}-\frac{k T}{e}\right)
$$

onde $\mathrm{N}_{\mathrm{D}}$ corresponde à densidade efetiva dos portadores de carga, $\varepsilon$ à constante dielétrica para o semicondutor, $\varepsilon_{\mathrm{o}}$ à permissividade no vácuo, $e$ corresponde à carga do elétron $\mathrm{e} \mathrm{k}$ à constante de Boltzman.

De acordo com a equação de Mott-Schottky, $\mathrm{C}_{\mathrm{SC}}{ }^{-2}$ deve variar linearmente com o potencial aplicado na interface. Nesta relação, admite-se que toda a carga presente na camada de depleção é proveniente dos doadores ionizados. Portanto, um gráfico de $\mathrm{C}_{\mathrm{SC}}{ }^{-2}$ em função de $\mathrm{E}$ informa sobre o nível de dopagem no semicondutor, permitindo estimar a densidade efetiva dos portadores de carga e também o potencial de bandas planas.

A equação de Mott-Sckottky é válida somente sob as seguintes condições:

(i) todos os níveis do doador (o dopante) devem estar totalmente ionizados;

(ii) os níveis dos dopantes devem ser imóveis e devem estar distribuídos de maneira uniforme;

(iii) não deve ocorrer inversão de transportadores;

(iv) a capacidade medida deve representar precisamente o $\mathrm{C}_{\mathrm{SC}} \mathrm{e}$ não deve incluir influências de estados superficiais ou adsorção. 
O gráfico de Mott-Sckottky consiste em um método prático para a caracterização de interfaces envolvendo semicondutores porque as medidas do $E_{\mathrm{FB}}$ podem ser realizadas na ausência de luz.

\subsubsection{A não linearidade dos gráficos de Mott-Schottky e os estados superficiais [53]}

Um problema frequentemente encontrado nos gráficos de Mott-Schottky é a ausência de linearidade. Muitas vezes, gráficos não lineares são obtidos quando os valores da capacidade e da resistência medidos são dependentes da frequência do sinal aplicado (p.ex., através de medidas de espectroscopia de impedância eletroquímica). Este fenômeno é designado por "dispersão com a frequência", e acredita-se que é decorrente da presença de estados superficiais.

Os estados superficiais correspondem a níveis de energia que podem estar localizados entre os limites das bandas e assim, podem mediar a transferência dos portadores de carga, controlar a carga superficial, e até mesmo o dobramento das bandas.

Tais estados surgem devido à não uniformidade da superfície, e podem ser intrínsecos ou extrínsecos. As terminações abruptas da estrutura cristalina se constituem em um exemplo de estados intrínsecos. Os estados extrínsecos são criados quando uma nova fase se forma na interfase, durante o crescimento de um filme de óxido ou quando espécies eletroativas se adsorvem na superficie do eletrodo. Nestes casos, a remoção da camada superficial do eletrodo pode removê-los.

Podem ainda existir estados superficiais transientes, criados, p.ex., pela chegada de uma lacuna à superficie. A lacuna pode reagir com uma molécula de água e criar um radical hidróxido adsorvido, que pode atuar como um forte oxidante.

Enfim, além de dificultar a determinação dos principais parâmetros que caracterizam a interfase semicondutor|eletrólito, a presença de estados superficiais proporciona ainda caminhos alternativos para a transferência de elétrons entre o eletrodo semicondutor e espécies em solução, e pode assim alterar o mecanismo de algumas reações. 


\subsubsection{Reações de transferência de cargas em interfases semicondutor|eletrólito $[53,55]$}

As reações de transferência de cargas que ocorrem sobre eletrodos semicondutores diferem em vários aspectos das reações observadas sobre eletrodos metálicos. De modo geral, em ambas as situações, os modelos admitem que, para que ocorra uma reação de redução, p.ex, as moléculas da espécie eletroativa em solução devem apresentar um nível de energia vazio com a mesma energia que um nível ocupado do eletrodo.

Sobre eletrodos metálicos, tal reação poderia ser representada pelo equilíbrio

$$
\mathrm{Ox}+\mathrm{e}^{-}=\mathrm{Red}
$$

onde $O x$ e Red correspondem às formas oxidada e reduzida da espécie eletroativa presente na solução.

Sobre eletrodos semicondutores, porém, deve ainda ser considerado o equilíbrio no qual se forma uma vacância positiva $\left(h^{+}\right)$na banda de valência, ou seja,

$$
\mathrm{Ox}=\operatorname{Red}+h^{+}
$$

Portanto, as reações de transferência constituídas pela remoção de elétrons do semicondutor, assim como pela injeção de lacunas contribuem para a corrente catódica, e aquelas constituídas pela injeção de elétrons e remoção de lacunas contribuem para a corrente anódica.

Identificam-se então as primeiras diferenças entre ambos os tipos de eletrodos. Sobre os eletrodos metálicos, os elétrons são transferidos através de uma única banda de energia e em níveis muito próximos ao nível de Fermi. Por outro lado, nos eletrodos semicondutores, a transferência pode ocorrer através das bandas de condução e valência, e pode exigir altos sobrepotenciais.

No eletrodo semicondutor, a reação de transferência de elétrons dependerá da localização relativa do potencial redox da espécie em solução $\left(E_{\text {redox }}\right)$ e dos limites das bandas de condução e valência do semicondutor no diagrama de energia. Para a comparação destes parâmetros, deve-se correlacionar a escala de energia dos elétrons no sólido com a escala de potenciais redox.

Por exemplo, se o nível de energia do $E_{\text {Tedox }}$ estiver localizado no meio da região da zona proibida do eletrodo semicondutor, a densidade de corrente de troca será muito 
pequena. No entanto, se estiver próximo ao limite de uma das bandas de energia, a transferência de elétrons deverá ser considerável.

Se o nível do $E_{\text {redox }}$ do eletrólito estiver próximo à banda de condução do semicondutor e houver a formação da camada de enriquecimento, espera-se então que a transferência eletrônica seja elevada. Haverá uma alta disponibilidade de elétrons na superfície, e a reação poderá ocorrer através da banda de condução. Se, por outro lado, houver se formado a camada de depleção, a troca de elétrons será impossibilitada. Em tal situação, tanto a superficie não apresentaria elétrons disponíveis para reduzir as espécies oxidadas presentes na solução, como também os elétrons das espécies reduzidas não conseguiriam alcançar o nível de energia da banda de condução por ativação térmica.

Por fim, é possível ainda que a transferência de cargas ocorra através da transferência de lacunas, em situações nas quais o nível de energia das espécies oxidadas estão sobrepostos aos da banda de valência. No entanto, a corrente de troca medida externamente seria muito baixa, devido à alta barreira de energia da camada de inversão.

Para realizar tais análises para um sistema em particular, é necessário estimar o nível de energia dos limites das bandas de valência e condução e relacionar o nível de Fermi do semicondutor com o correspondente potencial redox. Para obter tais informações, deve-se determinar o $\mathrm{E}_{\mathrm{FB}}$ e a densidade de portadores de cargas do semicondutor.

Outras características que diferenciam o comportamento de eletrodos metálicos e semicondutores estão relacionadas com os efeitos provocados pela iluminação. A incidência de um fóton com energia maior que a $E_{b g}$ pode promover um elétron da banda de valência para a de condução, e criar um par elétron-lacuna. Este par pode ser separado na região da carga espacial por um campo elétrico, o que evita a recombinação. Dependendo da direção do campo elétrico, um dos portadores migra em direção ao interior do semicondutor enquanto que o outro migra em direção à superfície, onde pode reagir com alguma espécie eletroativa da solução. Assim, é possível ocorrer uma reação de transferência de cargas foto-induzida. 


\section{2 - PROPRIEDADES FÍSICO QUÍMICAS DO SnO}

As propriedades físico-químicas do $\mathrm{SnO}_{2}$ são muito diversificadas, o que permite que este óxido seja utilizado em numerosas aplicações. Para cada finalidade, é necessário que o material apresente um conjunto específico de características. Para algumas, o $\mathrm{SnO}_{2}$ é depositado sobre quartzo ou vidro para que se apresente como um filme fino, transparente e condutor. Porém, se este mesmo material é depositado como um filme espesso sobre titânio para a fabricação de anodos, adquire a forma de um revestimento escuro, poroso e de alta rugosidade. Entre este dois casos extremos, os filmes de $\mathrm{SnO}_{2}$ podem variar muito em termos de morfologia, condutividade, capacidade de adsorção, etc.

Estas características motivaram a realização de numerosos trabalhos dedicados a investigar as propriedades deste óxido e a desenvolver técnicas para a sua obtenção. $\mathrm{Na}$ Literatura, há um volume imenso de publicações referentes à preparação e à caracterização das propriedades físico-químicas do $\mathrm{SnO}_{2}$. Existem também duas séries de trabalhos de revisão muito detalhados, publicados por Z.M. Jarzebski e J.P. Marton em 1976 [57-59], e por A. Nanthakumar e N.R. Armstrong em 1988 [1]. Nesta Revisão Bibliográfica, serão apresentados e discutidos apenas os aspectos considerados relevantes para a discussão do estudo realizado e dos resultados obtidos.

\subsubsection{Estrutura cristalina, defeitos estruturais e dopagem}

$\mathrm{O} \mathrm{SnO}_{2}$ apresenta estrutura cristalina tetragonal e pertence ao grupo do rutilo. Nesta estrutura, cada átomo de Sn está coordenado a 6 átomos de $\mathrm{O}$, e cada átomo de $\mathrm{O}$ está rodeado por 3 átomos de $\mathrm{Sn}$, resultando na coordenação $6: 3[1,57,60]$.

O esquema da célula unitária pode ser encontrado nos trabalhos de revisão citados $[1,57]$. Diversos livros de mineralogia, como o de C. Klein e C.S. Hurlbut, Jr. [60] p.ex., fornecem descrições detalhadas da estrutura e dos parâmetros da célula unitária, e também das formas mais comuns dos cristais de cassiterita, denominação dada ao mineral de $\mathrm{SnO}_{2}$. Os trabalhos de F.H. Jones [48] e R. Cavichi [61], com seus respectivos colaboradores, trazem também discussð̃es interessantes relacionando a estrutura do $\mathrm{SnO}_{2}$ e os fenômenos de deficiência e adsorção de oxigênio na superficie. Informações importantes podem ainda ser encontradas no trabalho de P. Jones e J.A. Hockey [62], que traz uma discussão 
interessante sobre a estrutura e a hidratação dos planos cristalinos (110), (101) e (100) para o rutilo $\left(\mathrm{TiO}_{2}\right)$, e que são válidas também para o $\mathrm{SnO}_{2}$.

$\mathrm{O} \mathrm{SnO}_{2}$ é classificado como um semicondutor do tipo-n, no qual as bandas de valência e de condução são identificadas com os níveis $2 p$ do $\mathrm{O}$ (parcialmente preenchidos) e com os níveis $5 s$ do $\mathrm{Sn}$, respectivamente. $\mathrm{O}$ intervalo de energia da zona proibida é bem grande: o $E_{\mathrm{bg}} \approx 3,5 \mathrm{eV}$. No entanto, este material apresenta condutividade relativamente alta (especialmente quando está na forma de filme depositado), que se origina dos desvios na estequiometria ou da presença de dopantes $[1,57,58,63]$.

Os desvios na estequiometria aumentam a condutividade porque tanto as vacâncias de $\mathrm{O}$ como a presença de átomos de $\mathrm{Sn}$ intersticiais estão associadas a elétrons que podem se movimentar pela estrutura do cristal [64].

No caso dos dopantes, admitindo que uma fração $\delta$ de sítios $\mathrm{Sn}^{4+}$ seja substituída por $\mathrm{Sb}^{5+}, \delta$ mols de elétrons poderiam ser doados à banda de condução. Para efeito ilustrativo, pode-se considerar que o óxido resultante teria a composição $\operatorname{Sn}_{(1-\delta)} \mathrm{Sb}_{\delta} e_{\delta} \mathrm{O}_{2}$. A substituição de $\mathrm{O}^{2-}$ por $\mathrm{Cl}^{-}$(ou F') em $\delta$ sítios teria o mesmo efeito ( $\mathrm{Sn} e_{\delta} \mathrm{O}_{(2-\delta)} \mathrm{Cl}_{\delta}$ ) [65]. Existe ainda a possibilidade de que os dopantes se incorporem na estrutura do cristal intersticialmente [1].

$\mathrm{O} \mathrm{Sb}$, o $\mathrm{Cl}$ e o $\mathrm{F}$ são os dopantes mais utilizados para aumentar a condutividade do $\mathrm{SnO}_{2}$. O principal motivo é que a introdução destas espécies não altera significativamente a estrutura cristalina do óxido devido à razoável similaridade dos seus raios iônicos: para os cátions $\mathrm{Sb}^{5+} \mathrm{e} \mathrm{Sn}^{4+}$, os raios iônicos correspondem a 0,71 e $0,69 \AA$, e, para os ânions $\mathrm{F}^{-}, \mathrm{Cl}^{-}$ e $\mathrm{O}^{2-}$, correspondem a 1,$33 ; 1,81$ e $1,36 \AA$, respectivamente [66-68]. No caso do $\mathrm{Sb}$, no entanto, podem ocorrer alterações morfológicas significativas para [Sb] $>4 \%$ e que provocam a diminuição da transparência e condutividade $[1,67]$, como será discutido a seguir.

\subsubsection{Propriedades óticas, elétricas, composição e morfologia}

De um modo geral, a morfologia, a transparência, a condutividade e as outras propriedades físico-químicas estão todas relacionadas. Para os filmes de $\mathrm{SnO}_{2}$, a alta condutividade elétrica e a transparência são as principais características responsáveis por muitas das aplicações que lhe são atribuídas. A relação entre estes parâmetros define a chamada "figura de mérito", que avalia a qualidade dos filmes para algumas aplicaçðes [69]. Embora estas propriedades possam variar muito em função do método de preparação, 
há diversos relatos de filmes que apresentam resistividade da ordem de $10^{-4} \Omega \mathrm{cm}$ e transmissão ótica superior a 90\% na região do visível. Na maioria dos estudos, porém, a resistividade relatada é da ordem de $10^{-3} \Omega \mathrm{cm}$ e a transmissão entre 80 e $90 \%$ [1, 70-72].

Em termos gerais, a condutividade em uma dada temperatura depende da concentração de portadores de carga e dos diversos fatores que afetam sua mobilidade, tais como a cristalinidade, o tamanho e o empacotamento dos grãos, etc. Alguns modelos admitem, p. ex. que o transporte da carga seja dificultado nos contornos dos grãos $[66,67$, 73]. Portanto, quanto maiores o tamanho e a proximidade das partículas e a cristalinidade do filme, melhor será a condutividade.

Normalmente, a condutividade aumenta com a concentração de dopante, devido ao aumento do $\mathrm{N}_{\mathrm{D}}$, exceto para a adição de Sb. Neste caso, o aumento da condutividade é verificado apenas até que a [Sb] seja da ordem de 1\% [67]. Nesta faixa de concentração, o $\mathrm{Sb}$ se encontra na forma $\mathrm{Sb}^{5+}$ e pode ocupar os sítios do $\mathrm{Sn}^{4+}$ sem que a estrutura cristalina seja comprometida. Em concentrações mais altas, porém, coexistem as espécies $\mathrm{Sb}^{5+} \mathrm{e} \mathrm{Sb}^{3+}$ e, como esta última não se encaixa na coordenação octaédrica do $\mathrm{Sn}^{4+}$ e do $\mathrm{Sb}^{5+}$, surgem alterações estruturais. $\mathrm{O} \mathrm{Sb}^{3+}$ se encaixa melhor em uma configuração bi-piramidal, que resulta na formação de cristais geminados. Em consequência, o Sb é segregado na forma de $\mathrm{Sb}_{2} \mathrm{O}_{3}$ e gera defeitos, o que provoca a diminuição da condutividade e da transparência $[66,67,74]$.

A presença e a concentração das espécies $\mathrm{Sb}^{3+}$ e $\mathrm{Sb}^{5+}$ nos filmes de $\mathrm{SnO}_{2}$ podem ser determinadas através de análises por espectrometria fotoeletrônica de raios-X, XPS. Como as energias de ligação características para os elétrons de ambas as espécies são distintas, é possível distinguir a contribuição de cada uma nos espectros [21, 75-77].

A técnica de XPS se constitui também na técnica mais usual para a análise da composição química dos filmes de $\mathrm{SnO}_{2}$ depositados em diferentes substratos $[21,47,61$, 75-78]. Existem ainda relatos da utilização de microssonda eletrônica [79] e espectrometria dispersiva de raios-X (EDX) $[21,76]$. Entre os filmes analisados, verificou-se que alguns apresentam deficiência de $O$ na superficie [75], enquanto que outros são estequiométricos em relação às concentrações relativas $[\mathrm{Sn}] /[\mathrm{O}][47,76,79]$.

A morfologia apresentada pelos filmes de $\mathrm{SnO}_{2}$ também é muito diversificada, e tem sido investigada por diferentes técnicas de microscopia, entre as quais SEM, TEM, AFM e STM. Na Literatura, existem desde relatos de filmes com apenas $10 \mathrm{~nm}$ de 
espessura [47, ] a outros com mais de $6 \mu \mathrm{m}$ [76]; o tamanho das partículas que constituem o filme também pode variar desde algumas unidades a centenas de nm [76].

Como já mencionado, a superficie dos materiais desenvolvidos para aplicações que requerem filmes condutores e transparentes é completamente distinta da apresentada pelos materiais depositados sobre titânio, desenvolvidos para serem utilizados como ânodos.

A superfície dos filmes de $\mathrm{SnO}_{2}$ depositados sobre titânio é bastante rugosa e porosa. A comparação das micrografias apresentadas em algumas publicações $[17,51,76]$ revela ainda que a microestrutura destes filmes também varia muito, dependendo do tratamento aplicado ao substrato e da técnica empregada para a deposição do filme.

Por outro lado, os filmes de $\mathrm{SnO}_{2}$ transparentes apresentam a superfície menos rugosa e mais uniforme, embora frequentemente apresentem algumas crateras e falhas na cobertura. Mesmo considerando apenas as micrografias deste tipo de filme apresentadas em alguns trabalhos $[34,66,70,73,81-86]$, identificam-se consideráveis diferenças para o tamanho das partículas que constituem o filme e para o seu aspecto geral.

Em suma, a consulta à Literatura mostrou que as propriedades físico-químicas apresentadas pelos filme de $\mathrm{SnO}_{2}$ são extremamente variadas, e dependem do substrato e do método empregado para a sua obtenção.

\subsubsection{As condições de preparação e as características dos filmes de $\mathrm{SnO}_{2}$}

$\mathrm{O}$ fato do $\mathrm{SnO}_{2}$ apresentar diversas aplicações, onde cada uma requer um material com um conjunto específico de propriedades, motivou numerosos investigadores a estudar e desenvolver técnicas para a obtenção deste óxido.

Os filmes de $\mathrm{SnO}_{2}$ podem ser depositados sobre diversos materiais, tais como vidro, quartzo, sílica, silício, alumina, grafite, titânio e aço. Os métodos empregados baseiam-se na deposição do óxido diretamente sobre o substrato, ou na deposição de Sn ou de uma espécie precursora (p.ex. um filme de um gel organometálico) seguida de uma reação de oxidação ou de decomposição.

As técnicas utilizadas incluem a aplicação de uma fina camada da solução através de um atomizador, mais conhecida pelo termo Spray Pyrolysis [67, 68, 88-96], a deposição química em fase de vapor (CVD, Chemical Vapor Deposition) $[4,70,73$, 97], evaporação do $\mathrm{SnO}_{2}[95,98]$ ou ainda pela imersão do substrato em um gel do óxido ou de precursores 
$[5-7,75,83,99-102]$. Há ainda a técnica de pincelamento do substrato com precursores, que é muito utilizada para preparar os eletrodos depositados em titânio [17, 19,20, 24, 51, 103-110].

As características químicas e morfológicas do substrato afetam os processos iniciais envolvidos no crescimento do filme, ou seja, na nucleação, crescimento e coalescência dos grãos. Suas influências são mais marcantes para filmes mais finos: nas camadas mais próximas ao substrato, haverá predominância de cristalitos com o formato compatível com a energia interfacial mais baixa. Porém, para depósitos mais espessos, podem ocorrer efeitos de reorientação do filme nas camadas mais externas, que podem inclusive causar um menor empacotamento das partículas na superficie. Consequentemente, as características do substrato influem na morfologia final, na resistividade e transparência do filme $[87,92,111]$.

A temperatura também é um parâmetro que afeta a cristalinidade e o tamanho dos cristalitos $[70,88,93,98]$. Em todas as técnicas, deve-se considerar que há uma temperatura mínima para que a reação de formação do $\mathrm{SnO}_{2}$ ocorra e, de modo geral, o aumento da temperatura aumenta a cristalinidade do filme depositado [82]. Para os filmes obtidos pela técnica de Spray Pyrolysis, p.ex., o aumento da temperatura do substrato provoca um aumento no tamanho dos grãos $[68,88]$. Dependendo do substrato, existem ainda outros efeitos a serem considerados. Para filmes depositados sobre Ti, p.ex., o aumento da temperatura pode promover o crescimento de um filme resistivo de $\mathrm{TiO}_{2}[76$, $86,112]$. Para filmes depositados sobre vidro, pode ocorrer também a difusão de $\mathrm{Na}^{+}, \mathrm{K}^{+}$ ou $\mathrm{Ca}^{2+}$ provenientes deste substrato,o que torna o filme opaco $[82,100]$.

As propriedades dos filmes obtidos por técnicas que envolvem a utilização de precursores em solução são ainda fortemente influenciadas pela sua concentração e natureza química e a dos diferentes dopantes adicionados. Para filmes preparados por CVD p.ex., a composição da solução influi na velocidade de crescimento do filme e na densidade de núcleos, que aumenta quanto maior a [Sn] [68]. A solução influi ainda na orientação cristalográfica preferencial, no tamanho dos cristalitos, na resistividade e na transparência dos filmes de $\mathrm{SnO}_{2}[75]$.

Diferentes tipos de dopantes também alteram as características dos filmes. $\mathrm{Na}$ técnica de Spray Pyrolysis, a dopagem com F, comparada com a de $\mathrm{Cl}$, não influencia o tamanho dos grãos mas aumenta a densidade de defeitos estruturais, que são do mesmo 
tipo para ambos os dopantes [67]. O efeito do $\mathrm{Sb}$ já foi discutido anteriormente. A presença de dopantes altera também a direção cristalina preferencial dos grãos. Em geral, os filmes de $\mathrm{SnO}_{2}$ são policristalinos e apresentam como orientação preferencial a (110). Nos filmes dopados com F, porém, quase sempre a orientação preferencial é a $(200)[87,88,92,93]$.

\subsubsection{Os métodos empregados neste trabalho para a obtenção dos filmes de $\mathrm{SnO}_{2}$}

Neste trabalho, empregaram-se as técnicas de Spray Pyrolysis para a obtenção dos eletrodos transparentes e a técnica de pincelamento do substrato com soluções precursoras de $\mathrm{SnCl}_{2}$ para a preparação dos eletrodos depositados sobre titânio.

A técnica de Spray Pyrolysis é amplamente utilizada na preparação de filmes transparentes de $\mathrm{SnO}_{2}$ e de outros óxidos por ser um método simples e de baixo custo, que permite a obtenção de filmes condutores, transparentes, e altamente resistentes à corrosão $[1,34,90,91]$.

O método consiste em aplicar através de um atomizador (spray) uma solução de $\mathrm{SnCl}_{4}$ sobre o substrato aquecido. A formação do óxido ocorre de acordo com a seguinte reação de hidrólise:

$$
\mathrm{SnCl}_{4}+2 \mathrm{H}_{2} \mathrm{O} \rightarrow \mathrm{SnO}_{2}+4 \mathrm{HCl}
$$

A condutividade elétrica dos filmes de $\mathrm{SnO}_{2}$ se deve a lacunas de $\mathrm{O}$ e dopagem. A dopagem pode ser intencional ou não, obtida pela adição de fluoreto ou antimônio na solução precursora ou devido à incorporação de cloreto.

As propriedades físicas dos filmes dependem das condições de preparação, entre as quais a temperatura e as características do substrato, a concentração da solução precursora, a duração e o número de repetições de aplicação do spray, etc. Até mesmo a distância entre o spray e o substrato é um fator crítico, porque, se for muito curta, a reação não terá se completado e as espécies que não reagiram podem se incorporar ao filme; e, se for muito longa, as gotículas podem se vaporizar antes de chegar ao substrato, formando um pó que não adere ou sequer atinge o substrato [92].

A outra técnica utilizada neste trabalho consiste em aplicar a solução precursora sobre o substrato através de pincelamento, seguido por um tratamento térmico. $O$ 
recobrimento total do substrato e a aderência do filme são os fatores mais críticos neste método e, por esta razão, o substrato deve ser submetido a um cuidadoso tratamento antes que o filme seja depositado [17].

Para a preparação de um filme de $\mathrm{SnO}_{2}$, o método consiste em aplicar uma fina camada de uma solução de cloretos de $\mathrm{Sn}$ e $\mathrm{Sb}$ em um solvente volátil (metanol ou propanol) no substrato. A seguir, a amostra é submetida inicialmente a um aquecimento suave $\left(\mathrm{t}<100^{\circ} \mathrm{C}\right)$ apenas para secagem do solvente, e depois a temperaturas mais elevadas $\left(\mathrm{t} \approx 500^{\circ} \mathrm{C}\right)$. Este segundo tratamento térmico proporcionará a decomposição do precursor em $\mathrm{SnO}_{2}$ através de uma reação química similar à que ocorre na técnica de Spray.

O procedimento de pincelamento, secagem e decomposição térmica pode ser repetido diversas vezes, dependendo da espessura desejada para o filme. No Grupo, p.ex., C.S. Fugivara empregou 3 aplicações [51]. L. Lipp e D. Pletcher, no entanto, recomendaram 12 ou 24 aplicações $[17,18]$. O processo deve ser finalizado ainda pelo recozimento da amostra em temperatura elevadas. Esta técnica já foi discutida em detalhes na tese de Fugivara [51].

Este é um dos métodos mais difundidos para a deposição de filmes de $\mathrm{SnO}_{2}$ e muitos outros óxidos sobre titânio, para aplicação como ânodos dimensionalmente estáveis (dimensionally stable anodes, $\mathrm{DSA}^{\circledR}$ ) $[17,19,24,103-106]$.

Estes dois métodos foram utilizados para preparar os eletrodos de filme de $\mathrm{SnO}_{2}$ investigados neste trabalho porque são técnicas muito simples e de baixo custo, além de amplamente conhecidas e recomendadas por diversos investigadores. 


\section{3 - PROPRIEDADES ELETROQUIMICAS DOS ELETRODOS DE $\mathrm{SnO}_{2}$}

As propriedades eletroquímicas do $\mathrm{SnO}_{2}$ começaram a ser investigadas há várias décadas e mesmo atualmente merecem a atenção de diversos grupos de pesquisa. $O$ grande interesse por este material é motivado pela sua ampla aplicabilidade, decorrente das propriedades de condutividade e transparência, aliadas ainda a uma alta estabilidade química e mecânica.

O comportamento eletroquímico destes eletrodos depende das suas propriedades superficiais e das características que apresentam como semicondutores do tipo-n. Por esta razão, a determinação dos gráficos de Mott-Schottky $\left(1 / \mathrm{C}^{2}\right.$ em função de $\left.E\right)$ para estimar a densidade de portadores de carga $\left(\mathrm{N}_{\mathrm{D}}\right)$ e o potencial de bandas planas $\left(\mathrm{E}_{\mathrm{FB}}\right)$ é de grande importância para o entendimento e controle de suas propriedades eletroquímicas.

Os primeiros estudos foram realizados para filmes depositados sobre vidro e quartzo empregados como eletrodos transparentes. Estes eletrodos têm sido utilizados em Espectroeletroquímica, Fotoeletroquímica e no desenvolvimento de células solares. Posteriormente, realizaram-se os estudos para filmes depositados sobre titânio, empregados no desenvolvimento de ânodos dimensionalmente estáveis para a produção de $\mathrm{Cl}_{2}$ e como ânodos para a oxidação eletroquímica de poluentes orgânicos e cianeto.

Estes estudos estão relatados em um grande número de publicações, muitas das quais são brevemente apresentadas a seguir. Discutem-se ainda alguns tópicos investigados para os eletrodos de $\mathrm{SnO}_{2}$ : a determinação dos gráficos de Mott-Schottky, a reversibilidade de algumas reações de óxido-redução, os processos de hidratação da superfície e as reações de desprendimento de hidrogênio e oxigênio, $\mathrm{RDH}$ e $\mathrm{RDO}$, respectivamente, sobre tais eletrodos.

\subsubsection{Considerações gerais sobre os estudos realizados para eletrodos de $\mathrm{SnO}_{2}$}

$\mathrm{O}$ estudo das propriedades eletroquímicas do $\mathrm{SnO}_{2}$ iniciou-se quando os vidros condutores revestidos com $\mathrm{SnO}_{2}$ passaram a ser empregados como eletrodos transparentes. Em 1964, T. Kuwana e col. [113] relataram utilizar amostras comerciais destes materiais para acompanhar espectrofotometricamente a oxidação de o-toluidina. Relatou-se ainda a 
caracterização de tais eletrodos através de Voltametria Cíclica em soluções aquosas de $\mathrm{H}_{2} \mathrm{SO}_{4}, \mathrm{Na}_{2} \mathrm{CO}_{3}$ e $\mathrm{K}_{3} \mathrm{Fe}(\mathrm{CN})_{6}$.

Posteriormente, em 1968, relatou-se que o $\mathrm{pH}$ da solução tinha grande influência nas características dos perfis i-E: dependendo do $\mathrm{pH}$, alteravam-se os potenciais nos quais iniciavam-se a RDH e a RDO em solução aquosa e também a reversibilidade do par redox ferri/ferrocianeto. Através de medidas de capacidade diferencial, mostrou-se ainda que $1 / C^{2}$ em função de E obedecia a uma relação linear, mas não foram apresentadas maiores discussões sobre este tema [114].

Ainda em 1968, publicou-se o estudo realizado por H.A. Laitinen e col. [29], referente ao comportamento eletroquímico de amostras comerciais de $\mathrm{SnO}_{2}$ dopado com $\mathrm{Sb}$ ou $\mathrm{F}$ em meio de $\mathrm{HCl}$ e $\mathrm{HClO}_{4}$. Relatou-se a adsorção específica de cloreto sobre a superficie do eletrodo e o problema de decomposição do filme sob potenciais catódicos, devido à redução do $\mathrm{SnO}_{2}$ a estanho metálico.

Dois anos depois, Laitinen e col. [115] publicaram um estudo mais detalhado, -ealizado para eletrodos transparentes comerciais e amostras preparadas por Spray yrolysis sobre quartzo e $\mathrm{Pt}$, com diferentes teores de $\mathrm{Sb}$. Determinaram-se os gráficos de Mott-Schottky e discutiram-se as propriedades semicondutoras dos eletrodos de $\mathrm{SnO}_{2}$, comparando a reversibilidade de diversas reações de óxido-redução sobre os mesmos e sobre eletrodos de Pt. Para explicar o processo de transferência de cargas através da camada de carga espacial no $\mathrm{SnO}_{2}$, sugeriu-se um processo envolvendo o tunelamento de elétrons. A irreversibilidade verificada para algumas das reações investigadas foi atribuída a interferências causadas pela superfície do óxido.

Estudos similares foram realizados e publicados em 1972 por F. Möllers e R. Memming [30], que desenvolveram também um modelo para as reações de transferência de cargas sobre tais eletrodos [116]. Os autores investigaram ainda a influência do $\mathrm{pH}$ nos gráficos de Mott-Schottky e interpretaram as alterações observadas considerando os equilíbrios de dissociação dos grupos $\mathrm{Sn}-\mathrm{OH}$ presentes na superficie do eletrodo.

No mesmo ano, com a motivação de entender a participação das propriedades superficiais nas reações do eletrodo, P. Kirkov [31, 32] publicou um estudo dos mecanismos do re-estabelecimento do potencial de eletrodos transparentes de $\mathrm{SnO}_{2}$ após terem sido submetidos a polarizações anódicas e catódicas. $O$ autor concluiu que os processos que ocorriam sobre o eletrodo estavam relacionados com a adsorção de íons, e 
que, portanto, dependiam dos equilíbrios que se estabeleciam nos sítios $\mathrm{Sn}-\mathrm{O}-\mathrm{H}$ formados na superfície devido à hidratação do $\mathrm{SnO}_{2}$.

Estes trabalhos foram revelando a importância dos equilíbrios estabelecidos na superfície no comportamento eletroquímico dos eletrodos de $\mathrm{SnO}_{2}$. Concluiu-se então que as propriedades eletroquímicas apresentadas por estes eletrodos eram decorrentes não apenas das características semicondutoras do material $\left(\mathrm{N}_{\mathrm{D}}, \mathrm{E}_{\mathrm{FB}}\right.$, e espessura da camada de carga espacial) como também das características da superfície do óxido.

Prosseguindo em ordem cronológica, em 1974, i.e, 10 anos após os primeiros relatos de estudos eletroquímicos de eletrodos transparentes de $\mathrm{SnO}_{2}$, T. Kuwana e $\mathrm{N}$. Winograd publicaram um artigo de revisão que reuniu e discutiu os avanços obtidos até então [117]. No ano seguinte, H.A. Laitnen e H. Kim relataram o estudo das propriedades fotoeletroquímicas de eletrodos transparentes de $\mathrm{SnO}_{2}$ em eletrólito inerte e na presença de corantes sensibilizadores [118].

Em 1976, destaca-se novamente um trabalho de Kuwana, no qual relatou um detalhado estudo empregando eletrodos comerciais de $\mathrm{SnO}_{2}(\mathrm{Sb})$ e $\operatorname{In}_{2} \mathrm{O}_{3}(\mathrm{Sn})$ [81]. Neste estudo, além das propriedades eletroquímicas, investigaram-se ainda as propriedades superficiais utilizando as técnicas de XPS e espectroscopia Auger. Através de tais análises, identificaram-se mudanças na estequiometria do filme de $\mathrm{SnO}_{2}$ após a realização de eletrólises: a concentração relativa $\mathrm{O} / \mathrm{Sn}$ aumentou após tratamentos de polarização anódica, e diminuiu após polarização catódica. Para o eletrodo submetido à polarização catódica detectou-se também a diminuição no estado de valência do $\mathrm{Sn}$, indicando que este tratamento eletroquímico induzia à redução do $\mathrm{SnO}_{2}$.

Em 1978, surgiram os primeiros relatos sobre a aplicabilidade dos eletrodos de filme de $\mathrm{SnO}_{2}$ depositado sobre titânio como ânodos para as reaçð̃es de desprendimento de $\mathrm{Cl}_{2}$ e $\mathrm{O}_{2}$ [107-109]. Como estes materiais apresentam propriedades distintas das apresentadas pelos eletrodos transparentes, os estudos desenvolvidos para estes materiais serão discutidos no próximo item.

Ainda no final dos anos 70, iniciaram-se também as investigações das propriedades fotoeletroquímicas dos eletrodos transparentes de $\mathrm{SnO}_{2}$ e a possível aplicação destes materiais no desenvolvimento de células solares [118]. Assim como para outros óxidos semicondutores, na maior parte dos trabalhos relatou-se ser necessário modificar a 
superficie do $\mathrm{SnO}_{2}$ com corantes sensibilizadores, que absorvessem fótons e injetassem elétrons na banda de condução do semicondutor.

$\mathrm{Na}$ Literatura dos anos 80 , encontram-se numerosos relatos referentes à preparação e investigação das propriedades fotoeletroquímicas de eletrodos transparentes de $\mathrm{SnO}_{2}$ modificados com diversos corantes sensibilizadores. Alguns destes estudos foram discutidos por N.R. Armstrong e A. Nanthakumar no abrangente trabalho de revisão sobre eletrodos de $\mathrm{SnO}_{2}, \mathrm{In}_{2} \mathrm{O}_{3}$ e $\mathrm{WO}_{3}$ publicado em 1988 [1].

Embora a eficiência de conversão apresentada pelos eletrodos de $\mathrm{SnO}_{2}$ seja bastante baixa, diversos pesquisadores continuaram a investigar este tema nos anos 90 [12, $13,16,119-121]$. Nos trabalhos mais recentes $[12,13,119]$, os eletrodos foram previamente revestidos com um filme de partículas nanométricas antes que fossem modificados pelos corantes. O filme nanoporoso, por apresentar maior área de superficie, adsorve maior quantidade de moléculas do corante e permite que os processos de absorção de luz e de transferência de elétrons entre o corante e o semicondutor sejam mais eficientes. Assim, aumenta-se muito a eficiência destas células solares, que, em geral, é bastante baixa [122]. Esta propriedade, relatada no início dos anos 90 por M. Grätzel para $\mathrm{TiO}_{2}$ [123], tem sido investigada também para $\mathrm{SnO}_{2}$, principalmente por P.V. Kamat $[12,119]$.

Considerando ainda esta última década, destacam-se também os estudos relacionados ao desenvolvimento de sensores para gases e de dispositivos eletrocrômicos empregando eletrodos de $\mathrm{SnO}_{2}$.

Os filmes de $\mathrm{SnO}_{2}$ podem funcionar como sensores devido à variação de condutividade que ocorre quando gases como CO ou metano são adsorvidos na superfície e sofrem oxidação [27]. Como este assunto não está diretamente relacionado aos estudos desenvolvidos neste trabalho, não será discutido nesta Revisão Bibliográfica.

A aplicação em dispositivos eletrocrômicos passou a ser investigada quando verificou-se a propriedade de inserção de íons $\mathrm{Li}^{+}$nos filmes de $\mathrm{SnO}_{2}[5-7,32]$. Como os filmes mais adequados para esta finalidade precisam ser mais porosos, em geral são preparados através de técnicas de dip-coating, ou seja, pela imersão do substrato em sistemas precursores do tipo sol-gel $[5,7,100,101]$.

Esta técnica foi utilizada, p.ex., no trabalho relatado em 1997 por U. Opara Krasovec, B. Orel e col. [5]. Neste estudo, depositaram-se filmes de $\mathrm{SnO}_{2}(\mathrm{Mo})$ sobre 
eletrodos de $\mathrm{SnO}_{2}(\mathrm{~F})$ e caracterizaram-se as propriedades morfológico-estruturais, eletroquímicas e espectroeletroquímicas destes eletrodos. Os autores observaram que as variações de coloração/descoloração do filme acompanhavam os processos de inserção/extração de $\mathrm{Li}^{+}$, e concluiram que os materiais investigados seriam promissores para a utilização como contraeletrodos em dispositivos eletrocrômicos.

Outros estudos interessantes foram desenvolvidos com o objetivo de melhorar a adesão entre metais e filmes transparentes de $\mathrm{SnO}_{2}$ ou ITO usados nos painéis de dispositivos eletroluminescentes ou de cristais líquidos. Verificou-se p.ex., que a adesão de filmes eletrodepositados de cobre, empregados para estabelecer contatos elétricos, poderia ser melhorada significativamente se o eletrodo transparente de $\mathrm{SnO}_{2}$ fosse previamente submetido a um tratamento de polarização catódica $[2,3]$.

Este efeito foi investigado através da caracterização detalhada da superfície de um eletrodo transparente de $\mathrm{SnO}_{2}(\mathrm{~F})$ submetido 'a polarização catódica através de análises por AFM, XRD, XPS e condutividade. A alteração de cor do eletrodo, de transparente para cinza escuro, foi atribuída à presença de $\mathrm{SnO}$ ou $\mathrm{Sn}^{\circ}$. Sugeriu-se que estas espécies seriam formadas na redução do filme de $\mathrm{SnO}_{2}$ pelos átomos ou moléculas de hidrogênio presentes na superfície do eletrodo durante a polarização catódica. As análises por XRD revelaram ainda que a estrutura cristalina dos eletrodos se alterou após a polarização catódica: diminuiu a quantidade relativa dos planos com orientação cristalina (200) e aumentou a dos planos (110). Concluiu-se então que a redução ocorreria preferencialmente nas faces com orientação (200). Este fato já havia sido relatado alguns anos antes, no estudo da redução do $\mathrm{CO}_{2}$ sobre eletrodos de $\mathrm{SnO}_{2}(\mathrm{~F})$ [124]. Os resultados obtidos levaram os autores a concluir que a melhora na adesão do filme de cobre resultaria de uma combinação de fatores que incluiam o aumento na rugosidade da superfície, devido à redução preferencial dos planos (200), e às possíveis ligações químicas envolvendo as espécies reduzidas, já que a presença de Sn metálico possibilitaria, p.ex., a formação de uma liga com o metal eletrodepositado [2].

A redução preferencial dos planos (200) pode ser a razão pela qual os eletrodos de $\mathrm{SnO}_{2}(\mathrm{~F})$ se mostraram mais susceptíveis à corrosão em potenciais anódicos quando comparados aos eletrodos de $\mathrm{SnO}_{2}$ dopados com $\mathrm{Cl}$ ou $\mathrm{Sb}$, no estudo realizado por $\mathrm{H}$. Cachet, M. Froment e col. [34]. Como já foi amplamente relatado, é justamente esta a orientação predominante em filmes de $\mathrm{SnO}_{2}(\mathrm{~F})$, enquanto que, para filmes policristalinos 
de $\mathrm{SnO}_{2}$ não dopados ou dopados com $\mathrm{Cl}$ ou $\mathrm{Sb}$, a orientação predominante dos cristalitos é a (110) [76].

Estes investigadores verificaram também que a morfologia dos eletrodos de $\mathrm{SnO}_{2}(\mathrm{Sb})$ foi a menos afetada pela aplicação da polarização anódica. Considerando os resultados obtidos através de análises em microbalança de quartzo, impedância eletroquímica e microscopia eletrônica de varredura e de transmissão, sugeriu-se que o processo de corrosão observado para ânodos de $\mathrm{SnO}_{2}$ deveria ser causado pelos radicais $\mathrm{OH}^{\bullet}$ e $\mathrm{Cl}^{\bullet}$ formados durante a polarização anódica. Estes radicais poderiam atacar e romper as ligações $\mathrm{Sn}-\mathrm{O}$ da superficie, danificando o filme [34].

Em estudos anteriores, os mesmos autores já haviam investigado a influência do dopante nas propriedades dos eletrodos de $\mathrm{SnO}_{2}$ preparados por Spray Pyrolysis. Foi observado que a presença de $\mathrm{Cl}$ ou $\mathrm{F}$ induzia defeitos estruturais distintos dos observados para filmes dopados com $\mathrm{Sb}$, e que, embora os filmes dopados com $\mathrm{F}$ fossem mais condutores, os filmes dopados com Sb eram mais eficientes para promover as reações de transferência de carga. Concluiu-se então que o Sb seria o melhor dopante para estes eletrodos [67].

Existem ainda diversos outros trabalhos sobre a caracterização das propriedades eletroquímicas de eletrodos transparentes de $\mathrm{SnO}_{2}$, no entanto, não foram incluídos por não haverem acrescentado contribuições significativas às que foram citadas ou por estarem muito pouco relacionados aos estudos desenvolvidos neste trabalho.

\subsubsection{Desenvolvimento dos anodos à base de filmes de $\mathrm{SnO}_{2}$ depositados sobre titânio}

Os estudos dedicados a investigar a aplicabilidade dos eletrodos de filme de $\mathrm{SnO}_{2}$ depositado sobre titânio como ânodos iniciaram-se em torno de 1978. Em um dos primeiros relatos, T.A. Chertykovtseva e col. $[107,108]$ investigaram eletrodos preparados com diferentes dopantes ( $\mathrm{Cl}, \mathrm{F}$ ou $\mathrm{Sb}$ ) e mostraram não haver uma conexão direta entre a condutividade elétrica e a atividade eletroquímica dos eletrodos. Verificou-se ainda que a reação de desprendimento de $\mathrm{Cl}_{2}$ era facilitada para os eletrodos dopados com $\mathrm{Sb}$; sugeriuse que esta característica era decorrente não só do aumento da concentração de portadores de carga como também da presença de sítios de adsorção adicionais sobre a superficie do eletrodo [107]. Os mesmos autores observaram também que a adição de Ru aumenta a atividade catalítica destes ânodos [109]. 


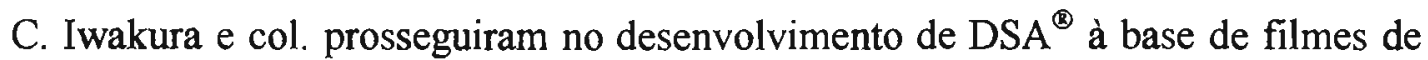
$\mathrm{SnO}_{2}$ [103]. Com este objetivo, prepararam e caracterizaram as propriedades físicas e químicas de filmes de $\mathrm{SnO}_{2}$ dopados com $\mathrm{Sb}$ e diferentes metais nobres $(\mathrm{M}=\mathrm{Ru}, \mathrm{Rh}, \mathrm{Pd}, \mathrm{Ir}$ ou Pt) depositados sobre titânio e Pyrex. Ao investigar as reações de desprendimento de $\mathrm{Cl}_{2}$ e $\mathrm{O}_{2}(\mathrm{RDCl}$ e $\mathrm{RDO})$ sobre estes eletrodos, verificaram que as mesmas ocorriam em potenciais muito mais altos sobre os eletrodos depositados sobre Pyrex. Para os eletrodos depositados sobre $\mathrm{Ti}$, verificaram que o coeficiente de Tafel e a atividade eletrocatalítica para a $\mathrm{RDO}$ dependiam do tipo de metal nobre do filme de $\mathrm{SnO}_{2}-\mathrm{SbO}_{\mathrm{x}}-\mathrm{MO}_{\mathrm{x}}$. No entanto, para a $\mathrm{RDCl}$, estes parâmetros apresentaram valores similares, independente do dopante empregado no eletrodo. Estas evidências levaram os autores a concluir que os centros ativos para a RDO situavam-se nos sítios dos metais nobres, enquanto que, para a $\mathrm{RDCl}$, a etapa determinante da velocidade deveria envolver os sítios de Sn [103].

Posteriormente, já em 1983, outros pesquisadores investigaram eletrodos preparados sobre $\mathrm{Ti}$ como anodos para a $\mathrm{RDCl}$ [110]. Observaram para os eletrodos $\mathrm{Ti} / \mathrm{SnO}_{2}(\mathrm{Sb})$ dopados com $\mathrm{Ru}(5$ a $10 \%$ ) um comportamento similar ao dos eletrodos de $\mathrm{Ti} / \mathrm{RuO}_{2}$, com a vantagem de empregarem muito menor quantidade de rutênio.

Uma outra vantagem observada para os anodos de $\mathrm{SnO}_{2}$ dopados com $\mathrm{Ru}$ foi verificada por Iwakura: empregados para a $\mathrm{RDO}$, a vida útil apresentada por eletrodos $\mathrm{Ti} / \mathrm{SnO}_{2}(70 \%)-\mathrm{RuO}_{2}(30 \%)$ foi em torno de 5 vezes maior que a dos eletrodos $\mathrm{Ti} / \mathrm{RuO}_{2}$ [104]. Este fenômeno foi atribuído às diferenças verificadas na morfologia de ambos os eletrodos. Os eletrodos à base de $\mathrm{SnO}_{2}$ apresentaram a superfície muito mais compacta e lisa, o que deveria diminuir o acesso do eletrólito ao substrato e a consequente formação de um filme resistivo de $\mathrm{TiO}_{2}$. Obtiveram-se ainda evidências de que os centros ativos para a $\mathrm{RDO}$ estariam situados sobre os sítios de Ru.

Considerando os relatos de que a presença do $\mathrm{SnO}_{2}$ melhorava a estabilidade dos $\mathrm{DSA}^{\circledR}$, S. Trasatti e col. $[105,106]$ investigaram a influência da concentração relativa de Sn na $\mathrm{RDO}$ sobre eletrodos de composição $\mathrm{Ru}_{0,3} \mathrm{Ti}_{(0,7-\mathrm{x})} \mathrm{Sn}_{\mathrm{x}} \mathrm{O}_{2}$ depositados sobre titânio. Os autores verificaram que a variação na concentração de $\mathrm{Sn}$ não altera o mecanismo para a RDO, já que não haviam sido verificadas alterações significativas para os coeficientes de Tafel e para a ordem da reação.

Em consideração ao fato de que a RDO ocorria somente em potenciais bastante elevados sobre os eletrodos de $\mathrm{SnO}_{2}, \mathrm{R}$. Kötz e col. [21, 22] sugeriram que os mesmos 
poderiam ser úteis para oxidar eletroquimicamente poluentes orgânicos presentes em águas residuais. Em um trabalho publicado em 1991, discutiu-se a influência do nível de dopagem e dos diferentes dopantes $(\mathrm{Cl}, \mathrm{F}$ e $\mathrm{Sb}$ ) no desempenho destes eletrodos para a $\mathrm{RDO}$ e para a oxidação de fenol. Investigaram-se eletrodos de $\mathrm{Ti} / \mathrm{SnO}_{2}$ preparados por Spray Pyrolysis, e caracterizaram-se suas propriedades físico-químicas através de análises de XPS, da determinação da resistividade, de gráficos de Mott-Schottky e do estudo eletroquímico com o par redox $\mathrm{Ce}^{3+} / \mathrm{Ce}^{4+}$. Para os eletrodos dopados com $\mathrm{Sb}$, as análises mostraram a presença de estados superficiais, o que induziria um aumento na concentração de lacunas na banda de valência. Considerando esta propriedade, os autores sugeriram que a reação de decomposição dos compostos orgânicos poderia ocorrer através de um mecanismo envolvendo lacunas.

Em prosseguimento ao trabalho de Kötz e Stucker, outros Grupos passaram a investigar a aplicação dos eletrodos de $\mathrm{Ti} / \mathrm{SnO}_{2}$ para a oxidação de compostos orgânicos. Merecem destaque, p. ex., os trabalhos publicados em 1993 e 1994 por Ch. Comninellis e col. $[23,125]$, nos quais comparou-se o desempenho destes eletrodos com o de eletrodos de Pt e com métodos de oxidação química. Verificou-se que, sobre os eletrodos de $\mathrm{SnO}_{2}$, obtinha-se a oxidação completa dos compostos orgânicos, com baixa concentração ou mesmo a ausência de produtos intermediários. Sugeriu-se então que o mecanismo de oxidação envolveria radicais ${ }^{\circ} \mathrm{OH}$, produzidos pela oxidação da água.

Assim como havia sido verificado para os eletrodos depositados em vidro, observou-se que as propriedades eletroquímicas dos eletrodos de $\mathrm{SnO}_{2}$ depositados sobre titânio também dependiam muito das condições de preparação. Recentemente, entre $1995 \mathrm{e}$ 97, publicaram-se alguns estudos realizados com o objetivo de desenvolver metodologias apropriadas para a obtenção de eletrodos com características estáveis e reprodutíveis.

B. Correa-Lazano, Ch. Comninellis e A. De Battisti $[76,86,112]$ investigaram os efeitos de alguns parâmetros envolvidos na técnica de Spray Pyrolysis para a deposição de filmes de $\mathrm{SnO}_{2}(\mathrm{Sb})$ sobre Ti. Os autores observaram que a reversibilidade do par redox $\mathrm{Fe}(\mathrm{CN})_{6}^{3-14-}$ sobre estes eletrodos diminuía quanto maiores fossem a temperatura do substrato ou a duração do tratamento térmico durante a preparação do eletrodo. Este efeito foi atribuído à formação e crescimento de um filme de $\mathrm{TiO}_{2}$ na interface.

A influência da temperatura também foi investigada por C.P. De Pauli e $\mathrm{S}$. Trasatti [20], mas para eletrodos de $\mathrm{SnO}_{2}$ e $\mathrm{IrO}_{2}$ depositados sobre Ti por pincelamento. Os 
resultados mostraram que a temperatura ideal encontrava-se entre 350 e $400^{\circ} \mathrm{C}$ e, abaixo desta faixa de temperatura, a decomposição dos precursores estaria comprometida.

$\mathrm{O}$ método de preparação de eletrodos de $\mathrm{SnO}_{2}$ por pincelamento foi empregado ainda por L. Lipp e D.Pletcher [17], que investigaram os efeitos do pré-tratamento do substrato (titânio) nas características morfológico-estruturais e nas propriedades eletroquímicas dos eletrodos. Os autores desenvolveram um método através do qual obtiveram-se reprodutivelmente eletrodos com importantes qualidades, tais como estabilidade, alta condutividade e um comportamento quase metálico, permitindo a transferência de elétrons rápida para as espécies eletroativas investigadas, entre as quais o $\mathrm{K}_{4} \mathrm{Fe}(\mathrm{CN})_{6}$.

No Grupo, os eletrodos de $\mathrm{SnO}_{2}$ estão sendo investigados já há algum tempo. Como tema para sua tese de Doutorado, apresentada em 1997 [51], C.S. Fugivara investigou o desenvolvimento de anodos de $\mathrm{SnO}_{2}$ dopados com $\mathrm{Sb}$ e $\mathrm{Ru}$ e a utilização destes eletrodos para a RDO e para a oxidação de cianetos. Os materiais foram preparados principalmente através do método de pincelamento do substrato (titânio) com as soluções precursoras apropriadas. $\mathrm{Na}$ caracterização dos eletrodos através de análises quantitativas por XRD, identificou-se a formação de um óxido de composição $\mathrm{Sn}_{1-x} \mathrm{Ti}_{\mathrm{x}} \mathrm{O}_{2}$ entre a superficie do substrato e do filme de $\mathrm{SnO}_{2}$. O estudo realizado mostrou ainda que os cianetos podem ser oxidados eletroquimicamente sobre os eletrodos de $\mathrm{SnO}_{2}$, formando produtos com menor toxicidade, como cianatos e carbonatos $[24,51]$

\subsubsection{Os gráficos de Mott-Scottky, $\mathrm{N}_{\mathrm{D}}$ e $\mathrm{E}_{\mathrm{FB}}$ para eletrodos de $\mathrm{SnO}_{2}$}

A determinação do gráfico de Mott-Schottky fornece importantes informações para o entendimento do comportamento dos eletrodos de $\mathrm{SnO}_{2}$, porque suas características como material semicondutor do tipo-n influenciam suas propriedades eletroquímicas.

$\mathrm{Na}$ Literatura, encontram-se numerosos trabalhos que relatam a determinação de $1 / \mathrm{C}^{2}$ em função de $\mathrm{E}$ para eletrodos de $\mathrm{SnO}_{2}$. Em geral, as medidas de capacidade são efetuadas por Espectroscopia de Impedância Eletroquímica [15, 21, 34], embora também existam relatos da utilização de pontes $[31,116,117]$.

Nestes estudos, diversos autores relataram encontrar o problema de dispersão com a frequência, e atribuíram este fenômeno à presença de estados superficiais [30, 115]. G. Biesman [120], p.ex., investigou eletrodos transparentes e citou ter obtido relações lineares 
para o gráfico de Mott-Schottky somente para os valores de C medidos a $100 \mathrm{~Hz}$. Para eletrodos depositados sobre titânio, R. Kötz [21] não discutiu se observou tais problemas, mas relatou que as medidas utilizadas no gráfico foram determinadas a $1000 \mathrm{~Hz}$.

No estudo sobre a corrosão de eletrodos de $\mathrm{SnO}_{2}$ sob polarização anódica, $\mathrm{H}$. Cachet e col. [34] também verificaram que a impedância interfacial dependia da frequência. Porém, considerando um elemento de fase constante $Q$, os autores puderam ajustar um circuito equivalente que representasse o sistema para as medidas efetuadas. Neste estudo, relacionaram-se os efeitos morfológicos da corrosão com o aspecto dos gráficos de Mott-Schottky determinados entre 0,5 e 2,0 V para eletrodos dopados com $\mathrm{F}$ e $\mathrm{Sb}$. A polarização anódica degradou o eletrodo de $\mathrm{SnO}_{2}(\mathrm{~F})$ de forma generalizada, e provavelmente não alterou sua carga superficial durante o processo, já que verificou-se uma excelente linearidade para $1 / \mathrm{C}^{2}$ em função de $\mathrm{E}$ em todo o intervalo de potenciais. Por outro lado, sobre o eletrodo de $\mathrm{SnO}_{2}(\mathrm{Sb})$, a corrosão teve um caráter mais localizado e ocorreu a partir de $1,1 \mathrm{~V}$. Foi justamente a partir deste potencial que detectou-se uma quebra na linearidade do gráfico de Mott-Schottky.

$\mathrm{Na}$ maioria dos trabalhos consultados, observaram-se relações lineares para $1 / \mathrm{C}^{2}$ em função de $E$ e estimaram-se os parâmetros $N_{D}$ e $E_{F B}$ considerando que as variações da capacidade total medida correspondiam às variações da $\mathrm{C}_{\mathrm{SC}}$.

Os valores de $N_{D}$ relatados nestas publicações são muito variados e dependem das condições de preparação dos filmes de $\mathrm{SnO}_{2}$. Para eletrodos transparentes preparados por Spray Pyrolysis, p.ex., as diferenças na concentração dos dopantes na solução precursora resultaram em filmes com $N_{D}$ entre $5 \times 10^{17}$ e $5 \times 10^{19} \mathrm{~cm}^{-3}$ [30]. Em um outro estudo, para [Sb] crescentes entre 0.1 e $8 \%$, os valores de $N_{D}$ variaram entre $2,6 \times 10^{20}$ e $2,9 \times 10^{21} \mathrm{~cm}^{-3}$ [115]. Valores ainda mais altos foram determinados para eletrodos de $\mathrm{SnO}_{2}(\mathrm{Sb})$ depositados sobre titânio pela mesma técnica: $5 \times 10^{21} \mathrm{~cm}^{-3}$, para $7 \%$ de Sb na solução precursora [21].

Para o potencial de bandas planas, os valores relatados também são muito diversificados. $O E_{F B}$ depende das características do eletrodo e também do eletrólito no qual as medidas são efetuadas, principalmente do $\mathrm{pH}$ da solução. Considerando os equilíbrios envolvidos com os grupos $\mathrm{Sn}-\mathrm{OH}$ da superficie, para cada aumento do $\mathrm{pH}$ da solução em uma unidade é previsto que o $E_{\mathrm{FB}}$ se desloque para valores mais negativos aproximadamente $60 \mathrm{mV}$ [1]. No entanto, na prática, verificaram-se deslocamentos 
maiores que o previsto, provavelmente devido a processos de adsorção específica de íons [30]. Comportamentos anômalos também foram verificados para eletrodos semicondutores que apresentavam uma alta densidade de portadores de carga (acima de $10^{20}$ ) [81].

P.ex., os potenciais $\mathrm{E}_{\mathrm{FB}}$ (em relação ao $\mathrm{ECS}$ ) estimados para eletrodos transparentes de $\mathrm{SnO}_{2}(\mathrm{~F})$ com $\mathrm{N}_{\mathrm{D}}$ de $1,5 \times 10^{20} \mathrm{~cm}^{-3}$, em soluções $0,2 \mathrm{M}$ de $\mathrm{NaClO}_{4}$ de pH 3; $5 ; 7$ e 9 , foram respectivamente $-50 ;-350 ;-420$ e $-750 \mathrm{mV}$ [120]. Em um outro estudo, valores distintos de $\mathrm{E}_{\mathrm{FB}}$ foram estimados em $\mathrm{H}_{2} \mathrm{SO}_{4}$ 0,5 $\mathrm{M}$ para eletrodos transparentes de $\mathrm{SnO}_{2}(\mathrm{Sb})$ com $\mathrm{N}_{\mathrm{D}}$ de $5 \times 10^{17}$ e $5 \times 10^{19} \mathrm{~cm}^{-3}:+0,41 \mathrm{e}+0,20 \mathrm{~V}$, respectivamente [30]. Para o $\mathrm{Ti} / \mathrm{SnO}_{2}(\mathrm{Sb})$ preparados a partir de soluções com $[\mathrm{Sb}]$ correspondentes a $0 ; 0,5$ e 4\%, o $\mathrm{E}_{\mathrm{FB}}$ foi determinado em aproximadamente $-150 \mathrm{mV}$, em solução $1 \mathrm{~N}$ de $\mathrm{H}_{2} \mathrm{SO}_{4}$ [21].

Em alguns casos, a análise de Mott-Schottky não pode ser considerada, como, p.ex., quando as concentrações dos portadores de carga são muito altas. Este fenômeno foi discutido por J. Bruneaux e col. [15] para eletrodos transparentes de $\mathrm{SnO}_{2}(\mathrm{~F})$ modificados com nano-agregados de Ir sobre a superfície. Como os valores determinados de $\mathrm{C}$ eram muito elevados para que fossem considerados como $\mathrm{C}_{\mathrm{SC}}$, apresentando a mesma ordem de grandeza esperada para o $\mathrm{C}_{\mathrm{H}}\left(10-30 \mu \mathrm{Fcm}^{-2}\right)$, os autores consideraram que não seria possível determinar $\mathrm{N}_{D}$ por medidas de capacidade em função do potencial aplicado.

\subsubsection{A reversibilidade das reações de óxido-redução}

A investigação das propriedades eletroquímicas dos eletrodos de $\mathrm{SnO}_{2}$ em geral inclui estudos da reversibilidade de algumas reações de óxido-redução, para verificar se os mesmos permitem a transferência de carga rápida com espécies eletroativas em solução. Diversos sistemas redox foram investigados, entre os quais $\mathrm{Ce}^{4+} / \mathrm{Ce}^{3+-}, \mathrm{Cu}^{2+} / \mathrm{Cu}^{+}$, $\mathrm{Fe}^{3+} / \mathrm{Fe}^{2+}, \mathrm{Fe}(\mathrm{CN})_{6}^{4-} / \mathrm{Fe}(\mathrm{CN})_{6}^{3-}$, entre outros.

Como o $\mathrm{SnO}_{2}$ é um semicondutor do tipo-n, seria esperado que as reações de transferência de carga em potenciais nos quais se forma a camada de depleção estivessem bloqueadas. No entanto, desde os primeiros estudos, desenvolvidos para os eletrodos transparentes, verificou-se que a reversibilidade de um determinado sistema redox não dependia necessariamente do seu potencial de óxido-redução [115].

A reação de óxido-redução de $\mathrm{K}_{4} \mathrm{Fe}(\mathrm{CN})_{6}$ foi uma das reações mais utilizadas nestes estudos. Sobre eletrodos metálicos, esta é uma reação reversível, na qual as densidades de corrente nos picos anódico e catódico têm as mesmas intensidades, ou seja, 
$\mathrm{I}_{\mathrm{p}, \mathrm{a}} / \mathrm{I}_{\mathrm{p}, \mathrm{c}}=1$, e a diferença entre os potenciais de oxidação e redução, $\mathrm{E}_{\mathrm{p}, \mathrm{a}}-\mathrm{E}_{\mathrm{p}, \mathrm{c}}=\Delta_{\mathrm{E}}$, corresponde aproximadamente aos $57 \mathrm{mV}$ previstos [126].

Sobre os eletrodos de $\mathrm{SnO}_{2}$, porém, os estudos revelaram que a cinética desta reação depende muito das propriedades do eletrodo, que por sua vez são decorrentes do método e das condições de preparação empregados, do substrato, etc.

Dos trabalhos consultados, o único que relata um comportamento similar ao de eletrodos metálicos é o de Lipp e Pletcher [17], realizado para eletrodos de $\mathrm{SnO}_{2}(\mathrm{Sb})$ depositados sobre titânio por pincelamento. Para os eletrodos de $\mathrm{Ti} / \mathrm{SnO}_{2}(\mathrm{Sb})$ depositados por Spray, Correa-Lazano e col. [112] obtiveram $\Delta_{\mathrm{E}} \cong 110 \mathrm{mV}$ para eletrodos preparados a $400^{\circ} \mathrm{C}$. Os autores verificaram ainda que a separação entre os picos aumentava para eletrodos preparados a temperaturas mais altas, possivelmente devido ao crescimento de um filme resistivo de $\mathrm{TiO}_{2}$.

Para eletrodos transparentes, no entanto, verificou-se que a cinética da reação de óxido-redução do ferrocianeto era muito mais lenta. Os estudos revelaram que a reação de redução do $\mathrm{Fe}(\mathrm{CN})_{6}{ }^{3-}$ ocorria em potenciais similares aos observados sobre Pt: aproximadamente $180 \mathrm{mV}$ (vs. SCE) $[13,29,115]$. No entanto, para o $E_{\mathrm{p}, \mathrm{a}}$, os valores observados eram muito mais anódicos que o potencial previsto e dependiam de $N_{D}$. Este comportamento foi atribuído às propriedades semicondutoras do $\mathrm{SnO}_{2}$.

$\mathrm{O} \mathrm{SnO}_{2}$ é um semicondutor do tipo-n, e, portanto, esperava-se que as reações de transferência de carga com espécies eletroativas em solução ocorressem através dos elétrons da banda de condução [127]. Mas, como os potenciais nos quais ocorrem as reações redox do sistema ferri/ferrocianeto são mais positivos que o $E_{F B}$ deste eletrodo, deveria se formar a camada de depleção na sua superficie. Esta camada se constituiria em uma barreira à transferência de elétrons através da interface.

Para explicar a transferência de carga através da região de carga espacial, sugeriuse um processo envolvendo o tunelamento de elétrons $[29,115]$. No modelo teórico desenvolvido por Memming e Möllers [116], sugeriu-se que a probabilidade do tunelamento dos elétrons dependeria não apenas da espessura da $C_{S C}$ (e portanto, de $N_{D}$ ) como também da distribuição dos níveis de energia no sistema redox [116]. Posteriormente, W. Badawy, H. Gerisher e col. [127] propuseram um modelo no qual os estados eletrônicos agiriam como um degrau intermediário para o processo de tunelamento de elétrons entre o semicondutor e as espécies redox em solução. Devido à estrutura 
policristalina do material, estes estados poderiam estar distribuídos de maneira não uniforme. Surgiriam assim caminhos preferenciais para a tranferência de elétrons, possivelmente localizados nos contornos de grãos.

Este mecanismo que envolve o tunelamento de elétrons também foi adotado por Kötz [21] para discutir a cinética das reações de transferência de carga sobre eletrodos de $\mathrm{SnO}_{2}$ depositados sobre titânio. Os autores verificaram que o nível de dopagem exercia forte influência na cinética da reação de óxido-redução do par redox $\mathrm{Ce}^{4+} / \mathrm{Ce}^{3+}$, e que a corrente de troca aumentava para valores crescentes de $N_{D}$. No entanto, não influia significativamente na $\mathrm{RDO}$, como será discutido no próximo item.

Em geral, as reações de desprendimento de hidrogênio e de oxigênio envolvem etapas de adsorção e dessorção de prótons e hidroxilas na superficie do eletrodo de óxido. Por esta razão, antes de discutir tais reações, convém considerar brevemente os processos de hidratação da superfície dos óxidos.

\subsubsection{Os processos de hidratação da superfície de eletrodos de $\mathrm{SnO}_{2}$}

O processo de hidratação da superfície de óxidos em geral ocorre devido à adição dissociativa das moléculas de água: o próton se adsorve sobre um íon do óxido exposto enquanto que a hidroxila se adsorve sobre o íon metálico adjacente. Como resultado, a superficie do óxido torna-se coberta por uma camada de grupos hidroxila [128].

As propriedades destes grupos hidroxila deve depender da geometria e da coordenação das espécies presentes na superficie do material, bem como da camada que se encontra abaixo. Portanto, estas propriedades variam de acordo com o plano cristalino presente (ou predominante) na superficie do eletrodo [128].

De modo geral, os filmes de $\mathrm{SnO}_{2}$ são policristalinos, e, se a concentração de dopante não for excessiva, há predominância do plano (110) [76]. Esta característica permite fazer uma analogia com a análise feita para a hidratação da superfície da face (110) do rutilo $\left(\mathrm{TiO}_{2}\right)$, que apresenta a mesma estrutura cristalina do $\mathrm{SnO}_{2}[62,128]$.

$\mathrm{Na}$ face (110) do $\mathrm{TiO}_{2}$, os íons podem ser classificados em dois tipos: os íons $\mathrm{Ti}^{4+} \mathrm{e}$ O co-planares (do tipo "A") e os íons dispostos abaixo este plano (tipo "B"). Na hidratação desta superfície, os íons $\mathrm{OH}$ são adsorvidos sobre os íons $\mathrm{Ti}^{4+}$ da linha " $\mathrm{A}$ ", enquanto que os prótons são adsorvidos sobre os íons óxidos da linha " $B$ ", como mostra o esquema 


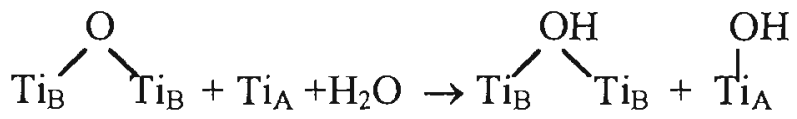

Portanto, a superficie apresenta dois tipos de grupos $\mathrm{OH}$ : os $\mathrm{OH}_{\mathrm{B}}$, ligados a dois ions $\mathrm{Ti}^{4+}$ e os grupos $\mathrm{OH}_{\mathrm{A}}$, ligados a apenas um íon $\mathrm{Ti}^{4+}$.

Como para outros óxidos, os processos de hidratação da superficie do $\mathrm{SnO}_{2}$ também dependem do $\mathrm{pH}$ da solução e resultam na formação de espécies hidroxiladas que podem ser representadas pelos seguintes esquemas [129]

Em soluções aquosas neutras:<smiles>C[SnH](O)O[SnH2]O</smiles>

Em soluções aquosas alcalinas:<smiles>[O-][SnH](O)O[SnH2][SnH2]</smiles>

Em soluções aquosas ácidas:<smiles>O=[SbH][OH+]O[SnH3]</smiles>

Este esquema simples também permite identificar a existência de dois tipos diferentes de oxigênio na superficie: os de tipo "pendente" e os de tipo "ponte" [129].

A distribuição destes diferentes tipos de grupos $\mathrm{OH}$ sobre a superfície do eletrodo afeta a carga superficial, controlada pelos equilíbrios de dissociação destes grupos, e, consequentemente, o pcz e o $\mathrm{E}_{\mathrm{FB}}$ do eletrodo [130].

Os grupos $\mathrm{Sn}-\mathrm{OH}$ da superficie também interagem com as espécies que estiverem

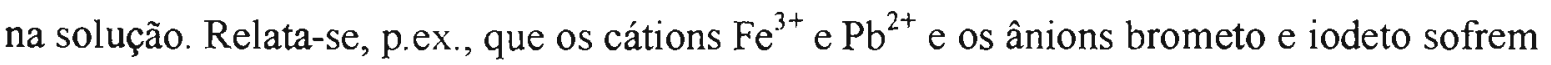
adsorção específica na superficie do $\mathrm{SnO}_{2}$ [131]. Portanto, os equilíbrios que se estabelecem na superfície dos eletrodos de óxidos influenciam também as suas propriedades eletroquímicas, principalmente as reações de desprendimento de hidrogênio e oxigênio. 


\subsubsection{Os perfis I/E em solução aquosa de elétrolitos inertes}

Em geral, os perfis $\mathrm{I} / \mathrm{E}$ determinados para os eletrodos de $\mathrm{SnO}_{2}$ apresentam densidades de corrente muito baixas em um amplo intervalo de potenciais, limitado no lado anódico pela reação de desprendimento de oxigênio e, do lado catódico, pela reação de desprendimento de hidrogênio e de processos relacionados à redução do $\mathrm{SnO}_{2}$. Ambos estes limites dependem tanto da solução (principalmente do $\mathrm{pH}$ ) como das características do eletrodo [1, 114].

A amplitude da corrente capacitiva é proporcional à capacidade de carga espacial, que, em $\mathrm{E}>\mathrm{E}_{\mathrm{FB}}$, consiste em uma camada de depleção. Considerando apenas os aspectos de eletrodo semicondutor, a RDO ocorrerá somente ao se atingir um potencial suficientemente positivo para superar o bloqueio à transferência de carga imposto pela camada de depleção. Portanto, o potencial para a RDO deverá ser mais alto quanto menor $\mathrm{N}_{\mathrm{D}}[130]$.

Em potenciais negativos, os perfis I/E característicos para os eletrodos de $\mathrm{SnO}_{2}$ apresentam um aumento progressivo na carga, que é atribuído a processos de hidratação da superficie do óxido $[1,31]$. Prosseguindo em potenciais mais negativos, a corrente catódica aumenta rapidamente. Este fenômeno se deve à $\mathrm{RDH}$ e à redução do $\mathrm{SnO}_{2}$, já que os potenciais de redução para os sistemas $\mathrm{H}^{+} / \mathrm{H}_{2}, \mathrm{Sn}^{4+} / \mathrm{Sn}^{2+} \mathrm{e} \mathrm{Sn}^{2+} / \mathrm{Sn}^{\circ}$ são muito próximos (de $-0,25$ a $-0,4$ V/ECS) [133].

Para citar alguns exemplos obtidos em diferentes referências para eletrodos transparentes [81, 114], em $\mathrm{KCl} 0,2 \mathrm{M} \mathrm{e} \mathrm{H}_{2} \mathrm{SO}_{4} 1 \mathrm{~N}$, os potenciais observados para a $\mathrm{RDO}$ foram respectivamente 1,6 e $2,0 \mathrm{~V}$ e, e para o limite catódico ( $\mathrm{RDH}$ e outras reações) foram $-1,4$ e $-0,7 \mathrm{~V}$ (vs. ECS).

Para os eletrodos de $\mathrm{Ti} / \mathrm{SnO}_{2}(\mathrm{Sb})$, os potenciais para a $\mathrm{RDO}$ e para a $\mathrm{RDH}$ foram

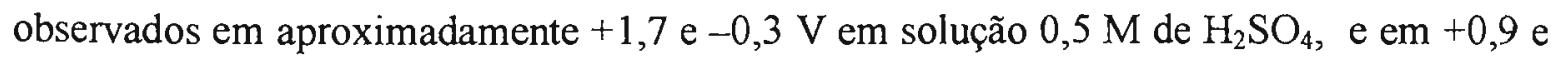
$-0,75 \mathrm{~V}$ em solução $1 \mathrm{M}$ de $\mathrm{NaOH}$ [112]. Em um outro trabalho, realizado em $\mathrm{H}_{2} \mathrm{SO}_{4} 1 \mathrm{M}$, cita-se que a RDO iniciou-se apenas a partir de $+1,8 \mathrm{~V}$ [17].

Embora não seja possível fazer uma comparação direta de todos estes valores, o intervalo entre os limites de potencial anódico e catódico é de aproximadamente $3 \mathrm{~V}$ para os eletrodos transparentes, e $2 \mathrm{~V}$ para os eletrodos depositados sobre titânio. Esta diferença deve estar relacionada principalmente às propriedades superficiais de ambos os tipos de 
materiais. Possivelmente, a superfície dos eletrodos transparentes, por ser pouco porosa, oferece menor número de sítios catalíticos para a $\mathrm{RDO}$ e a $\mathrm{RDH}$ (e os outros processos que ocorrem em potenciais negativos).

\subsubsection{Efeitos da polarização catódica: a $\mathrm{RDH}$ e os processos de redução do $\mathrm{SnO}_{2}$}

Desde os primeiros estudos realizados para eletrodos de $\mathrm{SnO}_{2}$, verificou-se que a polarização catódica na região da $\mathrm{RDH}$ poderia provocar a destruição do eletrodo devido à redução do filme [29, 31]. Laitinen [29], p.ex., relatou ter identificado partículas de Sn metálico que haviam se desprendido do eletrodo. Kirkov [31] observou o escurecimento dos eletrodos transparentes de $\mathrm{SnO}_{2}$ e associou este resultado à formação de $\mathrm{SnO}$. Ambos os produtos da redução do $\mathrm{SnO}_{2}$ podem levar à degradação do filme, já que o $\mathrm{SnO}$ é um óxido muito mais solúvel $[134,135]$.

$\mathrm{Na}$ discussão sobre os efeitos da polarização catódica em eletrodos transparentes de $\mathrm{SnO}_{2}$, Kirkov [31] sugeriu que, em solução aquosa, os sítios superficiais $\mathrm{Sn}-\mathrm{O}$ apresentariam moléculas de água adsorvidas. Sob polarização catódica, o hidrogênio adsorvido se deslocaria, formando ligações $\mathrm{Sn}-\mathrm{OH}$ :

$$
\mathrm{Sn}-\mathrm{O} . . \mathrm{H}-\mathrm{O}-\mathrm{H} \rightarrow \mathrm{Sn}-\mathrm{O}-\mathrm{H}^{+} \ldots \mathrm{OH}^{-}
$$

A formação das ligações $\mathrm{Sn}-\mathrm{OH}$ poderia alterar o potencial da camada superficial e mudar o estado de oxidação do estanho devido à formação de hidróxidos, de acordo com as reações:

$$
\begin{aligned}
& \mathrm{Sn}(\mathrm{IV})-\mathrm{O}+\mathrm{HOH}+2 \mathrm{e} \rightarrow(\mathrm{Sn}(\mathrm{II})-\mathrm{OH})+\mathrm{OH}^{-} \\
& \mathrm{Sn}(\mathrm{IV})-\mathrm{O}+\mathrm{H}^{+}+2 \mathrm{e} \rightarrow(\mathrm{Sn}(\mathrm{II})-\mathrm{OH}) \\
& \mathrm{Sn}(\mathrm{IV})-\mathrm{O}-\mathrm{Sn}(\mathrm{IV})+\mathrm{HOH}+2 \mathrm{e} \rightarrow(\mathrm{Sn}(\mathrm{IV})-\mathrm{OH}+\mathrm{Sn}(\mathrm{II})-\mathrm{OH})
\end{aligned}
$$

Sob potenciais ainda mais negativos, a corrente catódica aumentaria rapidamente devido à $\mathrm{RDH}$ e aos diversos processos relacionados à redução do $\mathrm{SnO}_{2}$ [31, 81, 135]. Yoneyama e Laitnen [135], sugeriram para estes processos as seguintes reações:

$$
\begin{aligned}
\mathrm{SnO}_{2}+4 \mathrm{H}^{+}+4 \mathrm{e} \rightarrow \mathrm{Sn}^{\circ}+2 \mathrm{H}_{2} \mathrm{O} \\
\quad \mathrm{E}=-0,345-0,059 \mathrm{pH}(\mathrm{V} \text { vs ECS })
\end{aligned}
$$




$$
\begin{array}{r}
\mathrm{Sn}(\mathrm{OH})_{4}+2 \mathrm{H}^{+}+2 \mathrm{e} \rightarrow \mathrm{Sn}(\mathrm{OH})_{2}+2 \mathrm{H}_{2} \mathrm{O} \\
\mathrm{E}=-0,166-0,059 \mathrm{pH} \\
\mathrm{Sn}(\mathrm{OH})_{2}+2 \mathrm{H}^{+}+2 \mathrm{e} \rightarrow \mathrm{Sn}^{\circ}+2 \mathrm{H}_{2} \mathrm{O} \\
\mathrm{E}=-0,332-0,059 \mathrm{pH}
\end{array}
$$

Como admitido por H. Feng e col. [33], existe ainda uma outra possibilidade a ser considerada para o processo de redução do $\mathrm{SnO}_{2}$. Sob polarização catódica, a formação de átomos de $\mathrm{H}$ adsorvidos na superfície do eletrodo também poderiam reduzir o óxido da superfície de acordo com as reações:

$$
\begin{aligned}
& \mathrm{SnO}_{2}+2 \mathrm{H}_{\mathrm{ad}} \rightarrow \mathrm{SnO}+2 \mathrm{H}_{2} \mathrm{O} \\
& \mathrm{SnO}+2 \mathrm{H}_{\mathrm{ad}} \rightarrow \mathrm{Sn}^{\circ}+\mathrm{H}_{2} \mathrm{O}
\end{aligned}
$$

A questão da redução preferencial dos planos de orientação cristalina (200) em relação aos planos de orientação (110), investigada pelos mesmos autores, já foi discutida na seção 2.3.1.

De modo geral, os trabalhos que discutiram os efeitos da polarização catódica sobre os eletrodos de $\mathrm{SnO}_{2}$ foram desenvolvidos com eletrodos transparentes. $\mathrm{O}$ estudo de Kirkov [31], p.ex., foi realizado logo que se iniciaram as investigações para os eletrodos de $\mathrm{SnO}_{2}$. Este assunto foi retomado apenas 2 décadas depois, especialmente nas investigações para a eletrodeposição de cobre sobre eletrodos transparentes [3]. Na Literatura consultada, verifica-se que este tema não foi explorado nos estudos realizados para eletrodos depositados sobre titânio. Provavelmente, como tais estudos tinham por objetivo o desenvolvimento de anodos, os investigadores não se preocuparam com os processos que ocorrem sob potenciais negativos.

Em suma, as reações de redução do $\mathrm{SnO}_{2}$ podem, por um lado, impossibilitar seu uso em algumas aplicações. Por outro lado, porém, estas mesmas propriedades podem ser de grande utilidade, como no caso de promover a adesão de metais eletrodepositados para estabelecer contatos elétricos, como citado na seção 2.3.1. 


\subsubsection{A RDO sobre os eletrodos de $\mathrm{SnO}_{2}$}

Os processos relacionados à polarização anódica e à reação de desprendimento de oxigênio sobre os eletrodos de $\mathrm{SnO}_{2}$ têm sido bastante investigados. Neste assunto, porém, existem poucos estudos desenvolvidos para eletrodos transparentes. Como uma das maiores motivações para tais estudos é o desenvolvimento de anodos, a maior parte dos relatos referem-se a eletrodos depositados sobre titânio, muito mais adequados para esta aplicação.

Iwakura e col. [204], p.ex., investigaram eletrodos dopados com Sb e um metal nobre $\left(\mathrm{SnO}_{2}-\mathrm{SbO}_{\mathrm{x}}-\mathrm{MO}_{\mathrm{x}}\right)$ depositados sobre Pyrex e titânio. Comentaram apenas que os potenciais para a $\mathrm{RDO}$ e para a $\mathrm{RDCl}$ eram mais altos sobre os eletrodos depositados sobre Pyrex. As demais discussões referem-se aos eletrodos depositados sobre titânio. Os autores verificaram que o coeficiente de Tafel e a atividade eletrocatalítica para a RDO dependiam do tipo de metal nobre, e concluiram que os metais deveriam atuar como os centros ativos para esta reação.

Possivelmente, os efeitos da adição dos metais nobres na RDO devem ser provenientes principalmente da alteração das propriedades superficiais destes eletrodos. A alteração das propriedades semicondutoras (especialmente $\mathrm{N}_{\mathrm{D}}$ e a espessura da região de carga espacial) não deve ser tão importante neste caso, considerando os resultados obtidos por Kötz e col. [21] para eletrodos dopados apenas com Sb.

Estes autores verificaram que a variação na [Sb] entre 2 e $15 \%$ não provocava alterações significativas no potencial para a RDO e nem no coeficiente de Tafel, determinado em aproximadamente $290 \mathrm{mV} \mathrm{década}^{-1}$. Portanto, a RDO não dependia da espessura da camada de carga espacial nem do número disponivel de estados eletrônicos. Concluiu-se então que o processo de transferência eletrônica de carga não seria a etapa determinante de velocidade para esta reação. Portanto, a RDO deveria estar mais relacionada aos processos de adsorção na superfície, que às propriedades semicondutoras do $\mathrm{SnO}_{2}[21]$.

Correa-Lazano e col. [112] investigaram a $\mathrm{RDO}$ sobre eletrodos de $\mathrm{Ti} / \mathrm{SnO}_{2}(\mathrm{Sb})$ em $\mathrm{H}_{2} \mathrm{SO}_{4} 0,5 \mathrm{M}$ e verificaram que o potencial para esta reação era bastante próximo ao característico para o sistema redox $\mathrm{H}_{2} \mathrm{O}_{2} / \mathrm{H}_{2} \mathrm{O}$. Estes autores propuseram então um mecanismo para esta reação, no qual a primeira etapa consistiria da formação de radicais 
'OH e, na etapa seguinte, estes radicais fracamente adsorvidos seriam oxidados formando $\mathrm{O}_{2}$ através do seguinte mecanismo:

$$
\begin{aligned}
& \mathrm{MO}_{\mathrm{x}}+\mathrm{H}_{2} \mathrm{O} \rightarrow \mathrm{MO}_{\mathrm{x}}\left({ }^{\circ} \mathrm{OH}\right)+\mathrm{H}^{+}+\mathrm{e} \\
& \mathrm{MO}_{\mathrm{x}}\left({ }^{\circ} \mathrm{OH}\right) \rightarrow 1 / 2 \mathrm{O}_{2}+\mathrm{H}^{+}+\mathrm{e}+\mathrm{MO}_{\mathrm{x}}
\end{aligned}
$$

Neste trabalho, os autores verificaram também que, na primeira varredura de potencial realizada para o eletrodo, a RDO ocorria em potenciais muito mais baixos que os obtidos em "condições estáveis". Perfis voltamétricos estáveis eram obtidos apenas depois que o eletrodo fosse submetido à polarização anódica na região da $\mathrm{RDO}$ ou após a realização de diversos ciclos repetitivos de varredura de potencial entre os limites anódico e catódico. Sugeriu-se então que a superficie do eletrodo recém-preparado, por ser nãoestequiométrica, deveria apresentar um maior número de sítios catalíticos sobre os quais os radicais ${ }^{\circ} \mathrm{OH}$ se formariam. Os filmes de $\mathrm{SnO}_{2}$ submetidos a diversas varreduras de potencial ou à polarização anódica poderiam perder aqueles sítios catalíticos, tornando-se estequiométricos.

Este fenômeno de "desativação" do eletrodo para a RDO já havia sido relatado por Ch. Comninellis e col. [23]. Naquele trabalho, sugeriu-se que os primeiros tratamentos eletroquímicos aplicados ao eletrodo poderiam alterar a composição química da superfície devido à hidratação das ligações $\mathrm{Sn}=\mathrm{O}$. Porém, não foram realizadas análises químicas da superficie, que comprovassem alterações na relação $[\mathrm{Sn}] /[\mathrm{O}]$.

Para eletrodos submetidos à polarização anódica, Kuwana [81] detectou um aumento na relação [O]/[Sn] através de análises por XPS. Para os eletrodos submetidos ao mesmo tratamento, Kötz [21] afirmou não haver detectado variações no estado de oxidação do Sn, e nem na relação [Sb]/[Sn]. Também por XPS, identificou-se apenas a presença de grupos $\mathrm{OH}$, comprovando o fenômeno de hidratação da superfície. Porém, ainda não foi comprovado se a hidratação da superfície é responsável pelo deslocamento da RDO para potenciais mais anódicos. 


\section{4- CONSIDERAÇÕES GERAIS SOBRE ELETRODOS MODIFICADOS}

Os eletrodos modificados pela presença de um revestimento na superficie apresentam uma série de aplicações, entre as quais na catálise de reações eletroquímicas, como proteção à corrosão, em sensores eletroanalíticos ou biológicos, em células solares, etc. Nestes sistemas, as reações eletroquímicas das espécies em solução ocorrem através do filme que reveste a superficie do eletrodo. De acordo com a finalidade que the for destinada, o filme não precisa necessariamente ser eletroativo. Para atuar como um meio de pré-concentração na análise de espécies em baixa concentração, p.ex., o filme deve apenas possibilitar a transferência de elétrons entre o eletrodo e o eletrólito [136, 137].

Os eletrodos modificados podem ser obtidos por diversos métodos, entre os quais por adsorção física, química ou eletroquimicamente. Para os revestimentos adsorvidos fisicamente, em geral basta submergir o eletrodo na solução do adsorbạto. No entanto, a facilidade de preparação é acompanhada por desvantagens graves tais como a instabilidade dos filmes e a dificuldade em controlar o número de moléculas no revestimento. Os filmes de moléculas ligadas quimicamente à superfície não apresentam estes problemas, no entanto, exigem um método de preparação muito mais trabalhoso. Os revestimentos que podem ser preparados eletroquimicamente são fáceis de controlar e estáveis, mas, por outro lado, apresentam menor aplicabilidade [136].

Para os revestimentos adsorvidos quimicamente, diversos métodos de obtenção envolvem reações entre os grupos $\mathrm{OH}$ da superfície e grupos ativos do adsorbato. Para modificar a superfície de eletrodos semicondutores com corantes sensibilizadores p.ex., frequentemente utilizam-se compostos que apresentem grupos carboxílicos, como os complexos de rutênio-piridina utilizados como sensibilizadores para o $\mathrm{SnO}_{2}[38,119]$. Também são muito utilizados os compostos que apresentam grupos silanos, que interagem com a superfície através de reações do tipo

$$
\mathrm{M}-\mathrm{OH}+\mathrm{X}-\mathrm{Si}-\mathrm{R} \rightarrow \mathrm{M}-\mathrm{O}-\mathrm{Si}-\mathrm{R}+\mathrm{HX}
$$

Geralmente, utilizam-se compostos do tipo triclorosilanos, R-Si- $(\mathrm{Cl})_{3}$, para possibilitar um maior número de interações com a superficie ou com outras moléculas do próprio adsorbato. A $4^{\mathrm{a}}$ posição, $\mathrm{R}$, constitui-se do próprio grupo que irá modificar o eletrodo ou de um grupo que possibilite a futura síntese do grupo de interesse (neste caso, $\mathrm{R}$ pode conter centros como $\mathrm{NH}_{2}, \mathrm{Cl}$ ou $\mathrm{COOH}$, por ex.) [136]. 
Dentre os compostos que formam revestimentos muito estáveis e ordenados, destaca-se o octadeciltriclorosilano, OTS, empregado como revestimento lubrificante em microeletrônica e ainda em biomateriais, para facilitar a adsorção de proteínas [138]. Os revestimentos com OTS são formados por automontagem (self assembled monolayers), e resultam de interações químicas com a superfície e entre as próprias moléculas de OTS e de interações hidrofóbicas entre as longas cadeias hidrocarbônicas. $\mathrm{O}$ mecanismo sugerido para o processo de adsorção do OTS sobre sílica e vidro está representado na Fig. 2.5 [138, 139]. Este mesmo modelo também foi sugerido para a adsorção de diversos alquilsilanos na superficie de $\mathrm{SnO}_{2}[87]$.

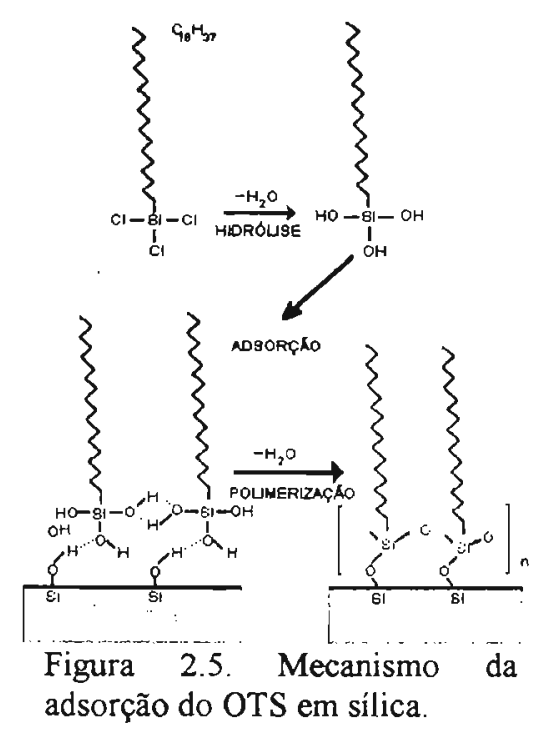

Como o grupo clorosilano é muito reativo, admite-se que a etapa inicial envolva a hidrólise do mesmo, resultando na formação de um composto do tipo $\mathrm{R}-\mathrm{Si}-(\mathrm{OH})_{3}$. As moléculas deste composto adsorvem na superficie do óxido, inicialmente por interações de ponte de hidrogênio. A seguir, as moléculas adsorvidas podem sofrer reações de condensação, formando uma ligação covalente com a superficie e também com outras moléculas que estiverem nas proximidades. Devido às ligações covalentes e de ponte de hidrogênio, a camada formada sobre a superficie é muito estruturada e estável.

No entanto, a obtenção de uma monocamada perfeita é muito dificil. O OTS pode polimerizar facilmente na solução, ou seja, formar oligômeros nos quais cada molécula de OTS está interligada através das três posições Si-O. A formação destes polímeros não só altera o empacotamento da camada, como também impossibilita a formação das ligações covalentes com a superfície. Para evitar este problema, deve-se desenvolver o processo de adsorção em condições anidras, para garantir que a primeira reação de hidrólise das moléculas de OTS ocorra apenas nas proximidades da superficie do óxido, com as moléculas de água da camada de hidratação do material, para que, em seguida, estas moléculas possam reagir com os grupos $\mathrm{M}-\mathrm{OH}$ da superficie.

Na prática, a obtenção de uma monocamada perfeita como idealiza o modelo deve ser muito difícil. Não só pela dificuldade em controlar a camada ideal de hidratação do substrato, mas também porque esta monocamada perfeita requer que os ângulos e as distâncias ideais de todas as ligações Si-O-Si das moléculas do OTS sejam respeitadas. 


\section{5 - TÉCNICAS EMPREGADAS PARA A CARACTERIZAÇÃO DOS MATERIAIS}

As características químicas e morfológico-estruturais de um eletrodo têm grande influência sobre suas propriedades eletroquímicas. Por esta razão, a caracterização detalhada do material é de grande importância para que se obtenha um melhor entendimento e controle do seu desempenho como eletrodo.

Atualmente, existe um número muito grande de técnicas que podem ser empregadas para a caracterização das propriedades químicas, morfológicas e estruturais dos eletrodos e materiais em geral. Muitas destas técnicas são aplicáveis apenas em análises ex-situ, tais como a SEM, a XRD e a XPS. Existem outras, porém, que podem operar in-situ e permitem monitorar as alterações de algumas propriedades do eletrodo durante o experimento eletroquímico, como, p.ex., a STM e a espectroscopia Raman. Para decidir sobre o conjunto de técnicas mais adequado para realizar um estudo, é necessário refletir inicialmente sobre quais as informações se deseja obter do sistema e, a seguir, entre as técnicas indicadas e disponíveis, observar quais as restrições para sua utilização e as limitações inerentes na determinação dos parâmetros analisados.

No estudo desenvolvido neste trabalho, utilizaram-se numerosas técnicas de análise de superfície na etapa inicial de caracterização dos eletrodos. Das diversas técnicas utilizadas, destacam-se a XPS, empregada para determinar a composição química dos eletrodos novos, e a SEM, a AFM e a STM, utilizadas nas análises morfológico-estruturais dos eletrodos novos e dos eletrodos submetidos a perturbações eletroquímicas. Os princípios básicos destas técnicas são brevemente comentados a seguir.

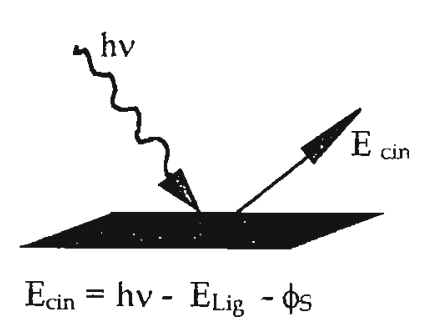

Figura 2.6. Diagrama ilustrativo do efeito fotoelétrico e a XPS.

Espectroscopia Fotoeletrônica de Raios-X [77, 141]. A XPS, também conhecida por ESCA, Espectroscopia Fotoeletrônica para Análise Química, consiste basicamente na irradiação da superficie da amostra com um feixe de Raios-X seguida por detecção e análise da energia dos elétrons emitidos pelo efeito fotoelétrico. Os elétrons emitidos apresentam uma energia cinética $\left(E_{c i n}\right)$ que depende da energia de ligação do orbital atômico que ocupavam $\left(E_{\mathrm{Lig}}\right)$. Cada elemento quimico possui um único conjunto de $\mathrm{E}_{\mathrm{Lig}}$, e, portanto, a XPS pode ser utilizada para identificar os 
elementos presentes na superfície. O espectro resultante de um composto corresponde a aproximadamente a soma dos picos dos elementos constituintes; portanto, a área relativa dos picos informa sobre a concentração relativa dos elementos na amostra analisada. Como a $E_{\text {Lig }}$ apresenta pequenas variações (chemical shift) dependendo da polarizabilidade do composto, é possivel identificar também o estado químico de cada elemento na amostra. Devido à sensibilidade e quantidade de informações que oferece, a XPS é uma das técnicas mais indicadas para a determinação da composição química de materiais em geral, inclusive eletrodos.

Microscopia Eletrônica de Varredura $[141,142]$. A SEM é uma das técnicas mais empregadas para examinar a superfície dos materiais, porque combina uma alta capacidade de aumento e grande resolução com grande facilidade para a observação das amostras. A técnica consiste em incidir sobre a superfície da amostra um feixe de elétrons previamente focalizado e direcionado através de um conjunto de lentes eletromagnéticas e detectar os produtos da interação entre ambos. Os sinais emitidos são coletados e fornecem diversas informações: os elétrons secundários (secondary electrons, SE) fornecem a imagem da superficie analisada; os elétrons retrodifundidos (backscattered elctrons, BSE), revelam áreas onde predominam elementos de diferentes pesos atômicos, fornecendo um mapeamento dos mesmos na superficie da amostra; e ainda, com os Raios-X emitidos, efetua-se a microanálise, identificando os elementos presentes na superficie.

Microscopia de Forças Atômicas e de Efeito Túnel [144]. A AFM e a STM são classificadas como técnicas de microscopia por aproximação de sondas (Scanning Probe Microscopy, SPM). Estas técnicas fornecem informações estruturais de superficies através do monitoramento de interações que dependem da distância entre a sonda e a amostra, e que, portanto, "traduzem" a topografia da superficie. Os métodos de sondagem local utilizam sondas com alto poder de resolução, sensíveis a forças, campos magnéticos, etc. A sonda deve se mover com grande precisão nas três dimensões, controlada por tubos piezoelétricos. Dependendo da propriedade medida e do tamanho da sonda utilizada, é possivel caracterizar a superficie até mesmo com resolução atômica.

STM. A STM foi desenvolvida em 1982 por Binning e Rohrer e, desde então, tem sido amplamente utilizada em diversas áreas. A STM é baseada na corrente de tunelamento que surge pela aplicação de uma tensão entre a amostra e uma sonda condutora e pontiaguda posicionada muito próxima. A corrente de tunelamento depende exponencialmente da distância de separação entre a ponta e a amostra, o que confere a alta 
sensibilidade das medidas. Durante as medidas, a ponta realiza um rastreamento da superficie da amostra em varreduras sucessivas, enquanto a tensão é controlada através de um sistema de retroalimentação, que mede e controla a corrente de tunelamento e o potencial aplicado. As medidas podem ser feitas em modo de "corrente constante" ou de "altura constante", e, posteriormente, o conjunto dos sucessivos perfis determinados é convertido para uma imagem tridimensional. Esta técnica pode fornecer informações estruturais até mesmo em escala atômica, mas é limitada pela exigência de que a amostra e a ponta sejam materiais condutores. A utilização desta técnica também é restrita a amostras com superficie de baixa rugosidade, porque alterações bruscas na topografia em geral provocam a danificação irremediável da ponta.

AFM. Nesta técnica, também desenvolvida por Binning e colaboradores, são medidas as forças interatômicas que surgem da interação entre os átomos da ponta e os da superfície da amostra. Dependendo da distância entre sonda e amostra, estas forças podem ser atrativas ou repulsivas; assim, a AFM apresenta dois modos de operação, o "atrativo" e o "repulsivo". No primeiro, a ponta é mantida a uma pequena distância da

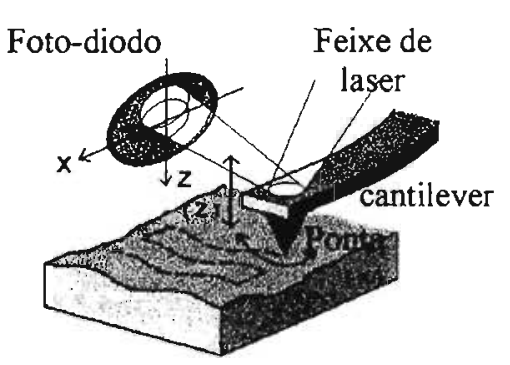

Figura 2.7. Tlustração do sistema de medida da deflexão do cantilever na AFM. amostra, e um sistema de retroalimentação evita que haja o contato. No modo repulsivo, a ponta é colocada em contato direto com a amostra. Em ambos os modos, a ponta é montada em uma pequena alavanca, um cantilever. Ao realizar a varredura da amostra, a ponta provoca deflexões no cantilever, que são detectadas por sistemas óticos (de modo geral). Cada método apresenta um conjunto de vantagens e desvantagens, dependendo das características da amostra. Existe ainda um modo de operação intermediário, o tapping mode, no qual a ponta toca a amostra intermitentemente, com amplitude da ordem de $20 \mathrm{~nm}$ e frequência entre 50 e $500 \mathrm{kHz}$. Este modo de operação apresenta as altas resoluções obtidas no modo de contato, sem as desvantagens de danificar a superficie analisada. A utilização desta técnica também é restrita a amostras que apresentem superficie de baixa rugosidade, embora a exigência seja menor que na STM. De modo geral, a AFM é a técnica mais utilizada na família das SPM. Para empregá-la, não há qualquer exigência quanto à condutividade da amostra. Por esta razão, e por poder operar em líquidos, tem sido utilizada nas mais diversificadas áreas, como p.ex. em Microeletrônica ou com amostras biológicas. 


\section{6 - TÉCNICAS EMPREGADAS PARA A CARACTERIZAÇÄO ELETROQUIMICA DOS ELETRODOS}

\subsubsection{Impedância Eletroquímica}

\subsubsection{Princípios gerais da técnica $[145,146]$}

As medidas de impedância eletroquímica têm sido amplamente empregadas no estudo de sistemas eletroquimicos porque fornecem informações importantes sobre os diversos fatores que contribuem nos processos do eletrodo, tais como a difusão das espécies eletroativas até a interfase, o carregamento da dupla camada elétrica, a transferência de cargas, etc.

Para determinar a impedância de um sistema, aplica-se uma pequena perturbação de potencial $\mathrm{AC}(\mathrm{E})$ e mede-se a corrente (I) que surge como resposta e que, em geral, difere do sinal aplicado tanto na fase como na amplitude. A impedância $(Z)$ é o fator de proporcionalidade entre o potencial e a corrente.

Se o sinal de potencial aplicado ao sistema variar com o tempo segundo a relação:

$$
E(t)=E_{0} \sin \omega t
$$

onde $E_{0}$ é a amplitude máxima e $\omega$ é a frequência de perturbação, a resposta do sistema será uma corrente $\mathrm{I}(\mathrm{t})$ descrita por

$$
\mathrm{I}(\mathrm{t})=\mathrm{E}_{\delta}|\mathbf{z}| \sin (\omega \mathrm{t}+\varphi)
$$

onde $\varphi$ é o deslocamento no ângulo de fase. Se a amplitude $E_{o}$ for suficientemente pequena, a resposta da interfase poderá ser considerada linear, como é admitido para o desenvolvimento dos tratamentos teóricos.

A impedância do sistema pode ser definida como um número complexo, constituída por componentes em fase, $Z^{\prime}$ ( ou $Z_{\mathrm{re}}$ ) e fora de fase, $Z^{\prime \prime}$ ( ou $Z_{\mathrm{im}}$ ), relacionados por

$$
\mathbf{Z}=\mathrm{Z}^{\prime}+\mathrm{i} \mathbf{Z}^{\prime \prime}
$$

A impedância total do sistema resulta das contribuições de diversos processos que dependem da frequência do sinal aplicado. Por esta razão, durante as medidas, varia-se a 
frequência de modulação do sinal aplicado $(\omega)$ sobre um amplo intervalo e registra-se um espectro de impedância $Z(\omega)$.

\subsubsection{A atribuição de circuitos equivalentes e a representação gráfica dos espectros de impedância [145-147]}

$\mathrm{Na}$ caracterização de um sistema eletroquímico através da espectroscopia de impedância eletroquímica costuma-se admitir que a interfase eletrodo| solução pode ser representada por circuitos elétricos equivalentes compostos por elementos simples, tais como resistências e capacitâncias, arranjados em série ou em paralelo.

Considerando o aspecto geral dos espectros de impedância e os prováveis processos que ocorreram na interfase durante as medidas, realiza-se a atribuição de um circuito elétrico equivalente ao sistema investigado. Para verificar se o circuito atribuído caracteriza o sistema satisfatoriamente, realizam-se simulações que são comparadas aos resultados experimentais. Na atribuição dos circuitos, deve-se buscar não apenas a melhor correspondência entre as curvas simuladas e os dados experimentais, mas, principalmente, preocupar-se com a correspondência entre o circuito proposto e os possíveis processos fisicos que ocorrem na interfase.

Um método frequentemente utilizado para realizar estas simulações é o dos Mínimos Quadrados Não Linear, empregado no programa desenvolvido por Boukamp [148]. Na utilização deste programa, sugere-se um circuito no Código Representativo de Circuito, CDC, e o programa realiza as simulações e fornece o melhor ajuste dos parâmetros do circuito e calcula as incertezas da medida [51].

Os espectros de impedância podem ser representados graficamente de diferentes maneiras. Na forma do gráfico de Bode, p.ex, representa-se em escala logarítmica o valor absoluto de $|z|$ e o ângulo de fase $\varphi$ em função da frequência $\omega$. Os resultados também podem ser representados através do diagrama de Nyquist, no qual a parte imaginária da impedância, $-Z_{\text {im }}$ é apresentada em função da parte real, $Z_{\mathrm{re}}$.A análise do aspecto geral dos espectros já fornece algumas informações sobre o sistema. No diagrama de Bode, p.ex., a resposta de uma resistência pura é uma linha horizontal $\operatorname{com} \varphi$ de $0^{\circ}$, enquanto que para um elemento capacitor puro, a resposta é uma linha reta com inclinação de -1 e um ângulo de fase constante de $90^{\circ}$. 
Nos gráficos de Nyquist, os circuitos que incluem um elemento capacitivo (C) e uma resistência $(R)$ dispostos em série apresentam uma linha vertical, onde, na parte real, $Z_{\mathrm{re}}$ é constante e corresponde ao valor da resistência $\left(Z_{\mathrm{re}}=\mathrm{R}\right)$, enquanto que, na parte imaginária, $Z_{\mathrm{im}}=1 / \omega \mathrm{C}$. Este simples circuito $\mathrm{RC}$ pode ser adequado para representar alguns sistemas eletroquímicos, p.ex. eletrodos semicondutores, como será discutido a seguir.

Por outro lado, se o capacitor e a resistência estiverem em paralelo, o gráfico de Nyquist apresentará um semi-círculo de raio $R / 2$ no plano complexo, no qual $Z_{\mathrm{re}}=\mathrm{R}$ em frequências baixas (quando $\omega \rightarrow 0$ ) e o valor máximo de $\left|Z_{\text {im }}\right|$ será obtido em $\omega=1 / R C$. Um circuito ainda muito simples, no qual uma segunda resistência é adicionada em série com a resultante dos elementos $(\mathrm{RC})$ em paralelo, pode ser útil para representar diversos sistemas eletroquímicos, como, p.ex., a interfase na qual ocorre uma reação redox simples, em que uma espécie na forma oxidada $O$ é reduzida para $R$, ou seja, $O+n e \rightarrow R$. A representação genérica do circuito equivalente para esta interfase está ilustrado na Fig. 2.8.

Neste circuito, a dupla camada elétrica e a impedância dos processos faradaicos de transferência de carga foram representados, respectivamente, por um capacitor $\left(C_{\mathrm{dl}}\right)$ disposto em paralelo com um elemento de impedância $Z_{\mathrm{F}}$. $A$ resistência existente entre os eletrodos de trabalho e o de referência, oferecida pela solução, contatos e materiais do eletrodo, está representada pela resistência $\left(R_{S}\right)$, disposta em série com $C_{d l}$ e $Z_{F}$.

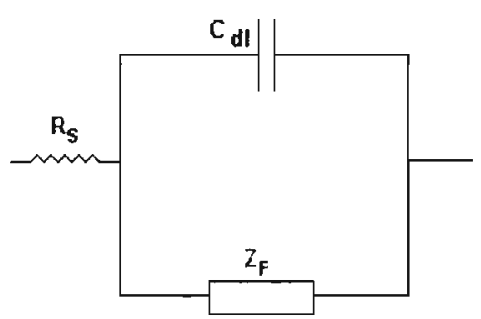

Figura 2.8. Circuito elétrico equivalente da interfase eletrodo|solução para um processo de eletrodo simples.

Em alguns sistemas eletroquímicos, o elemento de impedância dos processos do eletrodo $\left(Z_{F}\right)$ pode ser representado por apenas uma resistência à transferência de carga $\left(R_{C T}\right)$. Na notação do $C D C$, este circuito seria descrito através da expressão $R_{S}\left(R_{C T} C_{d l}\right)$. Dependendo dos valores de cada elemento, o gráfico de Nyquist de um espectro de impedância para este circuito é um semi-círculo, que intercepta o eixo das abcissas em dois pontos: em $Z_{\mathrm{re}}=\mathrm{R}_{\mathrm{S}}$ quando $\omega \rightarrow \infty$ e em $\mathrm{Z}_{\mathrm{re}}=\mathrm{R}_{\mathrm{CT}}+\mathrm{R}_{\mathrm{S}}$ quando $\omega \rightarrow 0$

$\mathrm{Na}$ presença de espécies eletroativas, o circuito deve incluir ainda um elemento que representa a dificuldade de transferência de massa destas espécies, denominado impedância de Warburg $\left(\mathrm{Z}_{\mathrm{W}}\right)$, que é colocado em série com $\mathrm{R}_{\mathrm{TC}}$. $\mathrm{O}$ circuito equivalente que inclui $\mathrm{R}_{\mathrm{S}}, \mathrm{C}_{\mathrm{dl}} \mathrm{R}_{\mathrm{CT}}$ e $\mathrm{Z}_{\mathrm{W}}$ é denominado circuito de Randles. 
Alguns aspectos gerais dos espectros de impedância podem ser discutidos considerando ainda a reação do tipo $O+n e \rightarrow R$. Dependendo dos valores de cada elemento do circuito, podem ser obtidos espectros semelhantes ao ilustrado nos gráficos de Bode e de Nyquist, representados nas Figuras $2.9 \mathrm{a}$ e e $2.9 \mathrm{~b}$, respectivamente.
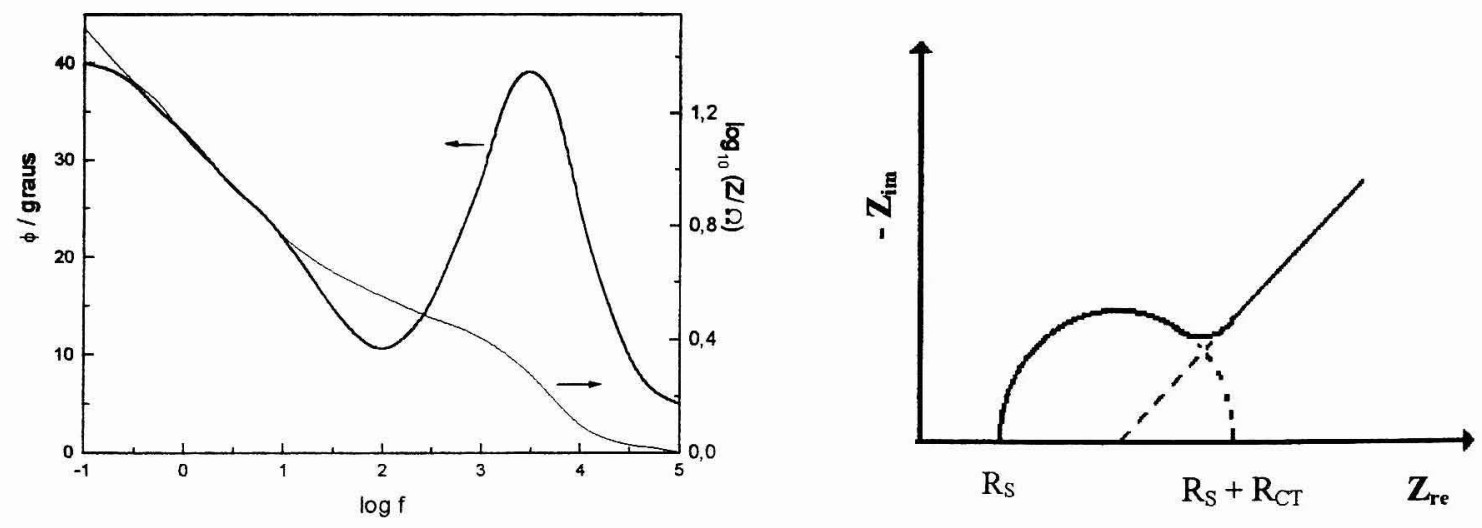

Figura 2.9. Espectro de impedância para o circuito de Randles, representado nos diagramas de Bode (a) e de Nyquist (b).

Em frequências altas, ou seja, quando a escala de tempo é pequena, a corrente muda de sinal continuamente e a difusão dos reagentes contribui pouco na impedância total. Nesta situação, a impedância do sistema é determinada principalmente pela resistência ôhmica de

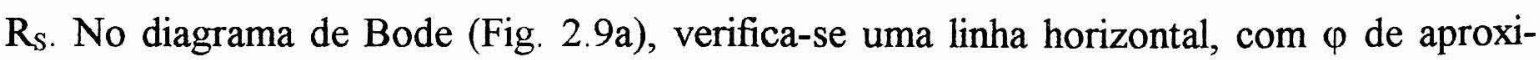
madamente $0^{\circ}$. No gráfico de Nyquist, (Fig. 2.9b), pode ser observado um semi-círculo, que, quando $\omega \rightarrow \infty$, intercepta o eixo das abcissas $\left(Z_{\text {re }}\right)$ no valor correspondente a $R_{S}$.

Por outro lado, em frequências baixas, os processos de transporte das espécies eletroativas contribuem significativamente. Se a reação for controlada apenas por difusão, será observado no gráfico de Nyquist uma linha reta com inclinação de $-1 / 2$ e ângulo de fase de $45^{\circ}$, característico da impedância de Warburg.

Em geral, nestes circuitos, as contribuições da capacidade da dupla camada elétrica predominam entre $10^{3}$ e $10^{4} \mathrm{~Hz}$. O gráfico de Bode pode apresentar ângulos de fase maiores, e um semi-círculo pode ser observado no de Nyquist. No entanto, dependendo do sistema e dos valores relativos dos componentes do circuito, pode ser observado apenas o semi-círculo ou apenas a linha reta. De modo geral, os espectros de impedância obtidos para os sistemas eletroquímicos podem apresentar os mais diversos aspectos, dependendo do eletrodo empregado e das condições em que estiver sendo investigado. 


\subsubsection{Circuitos equivalentes propostos para eletrodos semicondutores}

De modo geral, os eletrodos semicondutores apresentam algumas propriedades distintas das verificadas para os eletrodos metálicos que devem ser consideradas na interpretação dos espectros de impedância eletroquímica e na atribuição dos circuitos equivalentes. Estas propriedades são decorrentes da baixa densidade de portadores de carga na superfície do semicondutor e da presença da região de carga espacial.

$\mathrm{Na}$ Literatura, foram sugeridos numerosos circuitos equivalentes para a interfase eletrodo semicondutor | eletrólito, dependendo do material do eletrodo e das condições nas quais foi investigado. Dos trabalhos consultados, diversos relatam ter efetuado medidas de impedância eletroquimica para a obtenção das curvas de Mott-Sckottky e determinação da densidade de portadores de carga e do potencial de bandas planas do semicondutor [53, 149, 150]. Para atender esta finalidade, estima-se a capacidade da região da carga espacial $\left(\mathrm{C}_{\mathrm{SC}}\right)$ através da determinação de espectros de impedância $Z(\omega)$, ou de medidas de impedância em um único valor de frequência, em diversos valores de potencial.

Muitas vezes, relata-se que a capacidade varia dependendo da frequência do sinal aplicado. Este fenômeno, denominado por dispersão com a frequência, é atribuído à existência de estados superficiais no semicondutor, que poderiam apresentar tempos de relaxação distintos para os processos de carga e descarga. Em frequências mais baixas, por exemplo, a carga poderia ficar "presa" nestes estados, aumentando a contribuição dos mesmos na impedância total do sistema. A presença dos estados superficiais também é considerada como um dos fatores responsáveis pela não linearidade das curvas de MottSckottky, verificadas para alguns sistemas [53, 115].

Em resumo, nos circuitos propostos para os eletrodos semicondutores, além dos elementos normalmente considerados para os eletrodos metálicos em geral, são incluídos elementos adicionais que representem a região da carga espacial e os estados superficiais.

A presença da região da carga espacial nos eletrodos semicondutores inclui mais uma capacitância a ser considerada na capacidade da dupla camada elétrica. Portanto, na ausência de reações faradaicas, soma-se a capacidade da região da carga espacial $\left(\mathrm{C}_{\mathrm{SC}}\right)$ às capacidades da camada de Helmoltz $\left(C_{H}\right)$ e da camada difusa $\left(C_{D}\right)$. Como estas capacitâncias estão dispostas em série, a menor capacidade predominará na capacitância total, de acordo com a expressão 2.2 . 
Em geral, na presença de um eletrólito concentrado, a capacidade da região da carga espacial é muito menor que as demais e domina a capacidade total. Portanto, em uma primeira aproximação, a interfase eletrodo semicondutor/eletrólito poderia ser representada por um circuito RC simples, como o ilustrado na Figura 2.10.

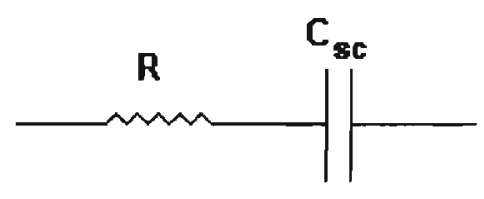

Figura 2.10. O mais simples dos circuitos elétricos sugeridos para representar a interfase eletrodo semicondutor $\mid$ eletrólito
Neste circuito, o elemento resistor representaria a resistência do eletrólito e do próprio semicondutor, enquanto que o elemento capacitor representaria a $\mathrm{C}_{\mathrm{SC}}$. $[53,149-151]$. Este circuito foi empregado, p.ex., para determinar as curvas de Mott-Schottky para eletrodos de $\mathrm{TiO}_{2}$ em solução

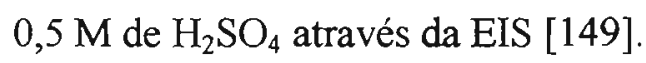

Esta representação costuma ser adequada somente em condições de alta frequência e na ausência de processos faradaicos, ou ainda para semicondutores pouco dopados e que não apresentem estados superficiais (para que a condição $C_{S C}<C_{H}$ e $C_{D}$ seja válida). $A$ existência de estados superficiais pode ainda ser responsável por uma distribuição não homogênea dos portadores de carga na superfície, além de provocar o fenômeno de dispersão em função da frequência $[53,149]$.

Se os estados superficiais forem considerados na atribuição do circuito elétrico equivalente, os elementos que os representam $\left(R_{S S}\right.$ e $\left.C_{S S}\right)$ devem ser incluídos em paralelo à capacidade da região da carga espacial, $\mathrm{C}_{\mathrm{SC}}$, como mostra a Fig. 2.11. O circuito ilustrado considera ainda os elementos que representam a resistência à polarização e a capacidade da camada de Helmholtz, $R_{p}$ e $C_{H}$,

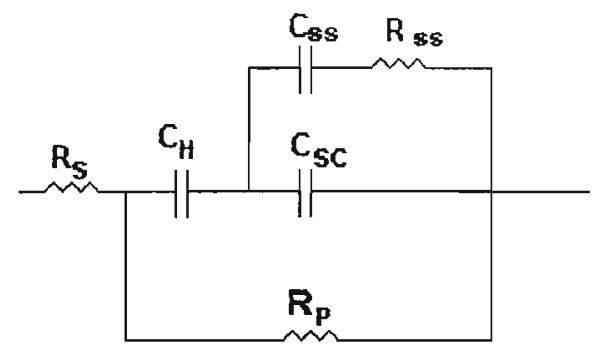

Figura 2.11. Circuito equivalente para eletrodos semicondutores, considerando os estados superficiais. respectivamente.

Para eletrodos semicondutores, a capacidade da camada de Helmholtz pode variar entre 10 e $100 \mu \mathrm{Fcm}^{-2}$, de acordo com o eletrólito e o pH [53]. De modo geral, na interpretação dos resultados de impedância, é atribuído um valor fixo para $\mathrm{C}_{\mathrm{H}}$, admitindose que esta não sofre variações em função do potencial ou da frequência do sinal aplicado ao eletrodo. P.ex., para o $\mathrm{C}_{\mathrm{H}}$ de um eletrodo de n-GaAs em $\mathrm{H}_{2} \mathrm{SO}_{4} 0,5 \mathrm{M}$, admitiu-se um 
valor de $20 \mathrm{Fcm}^{-2}$ [153] e, para uma liga de $\mathrm{Sn}$ e In revestida com uma camada de óxido em meio de $\mathrm{NaOH} 0,2 \mathrm{M}$, o valor atribuído foi $23 \mu \mathrm{Fcm}^{-2}$ [154].

$\mathrm{Na}$ Literatura, verificou-se também que a capacidade da camada de Helmholtz pode estar disposta em diferentes lugares nos circuitos sugeridos. Enquanto que alguns autores a representam em paralelo à resistência à polarização, como ilustrado no circuito da Fig. $2.11[53,150,153]$, outros dispõem a $C_{H}$ em série com a $R_{S}$, como ilustrado na Fig. $2.12[151,152,155]$.

O circuito representado na Fig. 2.12, p.ex., foi proposto para representar a interfase de um eletrodo de n-GaAs em solução $5 \times 10^{-4} \mathrm{M}$ de $\mathrm{Ce}\left(\mathrm{SO}_{4}\right)_{2}$ em $\mathrm{H}_{2} \mathrm{SO}_{4} 1 \mathrm{~N}$ [155]. Inicialmente, os autores discutiram um outro circuito muito mais complexo, composto por 10 elementos, idealizado para representar um eletrodo semicondutor do tipo-n sob condições de depleção, ou seja, polarizado em $E>E_{\mathrm{FB}}$. Embora pudesse representar a maior parte dos possíveis processos que ocorreriam no sistema, a complexidade do circuito dificultaria muito a análise e interpretação dos resultados.

O circuito da Fig. 2.12 foi apresentado como uma simplificação, na qual admitiu-se que apenas uma das capacidades interfaciais, relacionadas às capacidades da camada de inversão ou dos estados superficiais, predominaria. Desprezando a possibi-

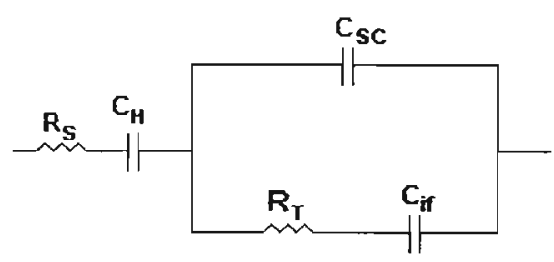
lidade de inversão, admitiram que as resistências da superficie e da região da carga espacial poderiam ser combinadas em uma única resistência total, $\mathrm{R}_{\mathrm{T}}$. Com estas suposições, concluiram que o circuito da Fig. Figura 2.12. Circuito equivalente para um eletrodo semicondutor, onde a contribuição dos estados superficiais foi simplificada ao elemento $\mathrm{C}_{\text {if }}$.

2.12 poderia ser representativo para as condições nas quais o sistema havia sido investigado [155].

Além destes, foram sugeridos ainda muitos outros circuitos equivalentes para representar a interfase eletrodo semicondutor|eletrólito. A validade destes circuitos dependerá das características do sistema investigado. 


\subsubsection{Circuitos equivalentes propostos para eletrodos de $\mathrm{SnO}_{2}$}

Considerando especificamente os eletrodos de $\mathrm{SnO}_{2}$, foram encontrados relativamente poucos relatos que apresentassem e discutissem os resultados de medidas de impedância. De modo geral, as medidas foram realizadas com o objetivo de determinar as curvas de Mott-Schottky. Kötz e col. [21], p.ex., apenas citaram ter realizado medidas a $1000 \mathrm{~Hz}$ para obter as curvas $\mathrm{C}^{-2}$ vs $\mathrm{E}$ para eletrodos de filmes depositados sobre titânio. No trabalho de J. Bruneaux [15], os valores da capacidade interfacial foram determinados a partir de espectros de impedância obtidos entre 1 e $30 \mathrm{kHz}$ (não apresentados no artigo). Discutiu-se que a capacidade interfacial total deveria ser resultante de uma combinação de $\mathrm{C}_{\mathrm{SC}}$ e $\mathrm{C}_{\mathrm{H}}$ em série, e que, como os valores de ambas as capacidades apresentavam a mesma ordem de grandeza (entre 10 e $30 \mu \mathrm{Fcm}^{-2}$ ) a aproximação de Mott-Schottky não era aplicável.

Alguns espectros de impedância representados na forma de diagrama de Bode foram apresentados por G. Biesman e col. [120]. Investigaram-se eletrodos transparentes de $\mathrm{SnO}_{2}$ modificados ou não com corantes sensibilizadores em meio de $\mathrm{NaClO}_{4} \quad 0,01 \mathrm{M}$ e tampão de fosfato. Os autores discutiram apenas que a impedância do sistema era praticamente resistiva a frequências maiores que $100 \mathrm{~Hz}$, e que o comportamento das curvas de Mott-Schottky dependia da frequência na qual determinaram-se os valores de capacidade. Afirmaram que apenas para os valores medidos a $100 \mathrm{~Hz}$ eram obtidas relações lineares para $\mathrm{C}^{-2}$ vs $\mathrm{E}$; para os valores obtidos em frequências maiores, além do desvio da linearidade, determinavam-se inclinações maiores em até duas ordens de grandeza.

Investigando eletrodos de filmes de $\mathrm{SnO}_{2}$ sob polarização anódica em meio de $\mathrm{HCl}$, Cachet e col.[34] determinaram os espectros de impedância em diversos valores de potencial. $\mathrm{O}$ trabalho apresentou um espectro de impedância na representação de Nyquist, no qual se observa um arco capacitivo; os autores mencionaram ter obtido resultados similares em todos os valores de potencial. Para representar este sistema, atribuiu-se um circuito elétrico equivalente do tipo $\mathrm{R}_{\mathrm{S}}\left(\mathrm{R}_{\mathrm{CT}} \mathrm{Q}\right.$ ) (Fig. 2.13), onde $Q$ representava o elemento de fase constante.

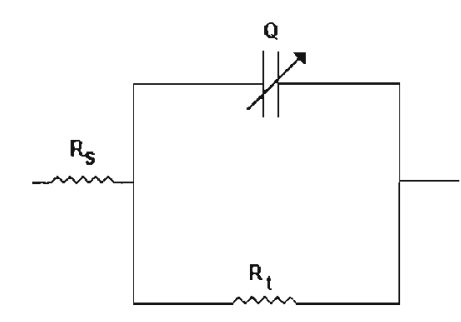

Figura 2.13. Circuito equivalente à interfase $\mathrm{SnO}_{2}(\mathrm{Sb}) \mid \mathrm{LiClO}_{4}$ (aq.) 
$Q$ é um elemento empregado em circuitos equivalentes para representar sistemas nos quais a dupla camada da interfase não se comporta como uma capacitância pura. Este elemento é utilizado para representar sistemas nos quais a distribuição de corrente não é homogênea sobre a superficie do eletrodo, como, p.ex., para eletrodos porosos [156].

Em estudos realizados para sensores cerâmicos de $\mathrm{SnO}_{2}, \mathrm{M}$. Labeau e col. [157] mostraram espectros de impedância representados no gráfico de Nyquist nos quais também se observa um arco capacitivo. Neste caso, o sistema pôde ser representado por um circuito simples $\mathrm{R}(\mathrm{RC})$.

Verificaram-se ainda alguns trabalhos nos quais eletrodos transparentes de $\mathrm{SnO}_{2}$ ou ITO foram empregados como substratos para a deposição de filmes como $\mathrm{WO}_{3}$, Azul da Prússia, e até uma membrana de lipídios, no entanto, o estudo do substrato em si foi pouco enfatizado [158-160]. Para os filmes de $\mathrm{WO}_{3}$ sobre $\mathrm{SnO}_{2}$, p.ex., os espectros de impedância eletroquímica obtidos mostraram que o sistema podia ser representado por circuitos do tipo $\mathrm{R}_{S}\left(\mathrm{R}_{1} \mathrm{C}_{1}\right)\left(\mathrm{R}_{2} \mathrm{C}_{2}\right)$, onde cada conjunto $\mathrm{RC}$ em paralelo estava relacionado com o substrato condutor e com o filme depositado [158].

No Grupo, estudos por impedância eletroquímica foram desenvolvidos para caracterizar eletrodos à base de $\mathrm{SnO}_{2}$ depositados sobre titânio em meio de $\mathrm{H}_{2} \mathrm{SO}_{4} 0,5 \mathrm{M}$ [51]. As medidas foram realizadas apenas em potencial de circuito aberto e no potencial no qual ocorre a reação de desprendimento de oxigênio, a 0,20 e $2,0 \mathrm{~V}$, respectivamente.

Fugivara [51] verificou que o circuito elétrico ilustrado na Fig. 2.14 podia representar adequadamente o sistema investigado. O elemento de fase constante $Q_{1}$ e $\quad$ o $R_{1}$ correspondiam respectivamente, à capacitância da dupla camada elétrica de uma superfície irregular e à resistência à transferência de carga, enquanto que os elementos $Q_{2}$ e $R_{2}$ estavam relacionados à capacidade e à

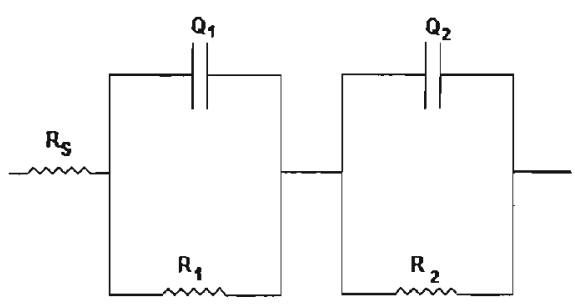

Figura 2.14. Circuito elétrico equivalente para eletrodos de filmes de $\mathrm{SnO}_{2} / \mathrm{Ti}$ em solução aquosa de $\mathrm{H}_{2} \mathrm{SO}_{4}$. resistência da interfase metal/filme. 


\subsubsection{Voltametria Cíclica de Baixa Amplitude}

\subsubsection{Princípios gerais da técnica}

A técnica de Voltametria Cíclica consiste basicamente na medida da corrente que flui em um eletrodo em função de uma perturbação triangular de potencial aplicada ao mesmo. O potencial aplicado ao eletrodo de trabalho é controlado em relação a um eletrodo de referência e varia com o tempo. O potencial aplicado varia a partir de um valor inicial $E_{\mathrm{i}}$ até atingir um valor máximo pré-selecionado $E_{\mathrm{m}}$, e, a seguir, a direção da varredura é invertida e prossegue até alcançar um outro valor de potencial prédeterminado.

$\mathrm{Na}$ voltametria cíclica de baixa amplitude, small amplitud cyclic voltammetry, $\mathrm{SACV}$, a amplitude entre os potenciais aplicados é bastante baixa, em torno de $20 \mathrm{mV}$ de um limite de potencial ao outro. Esta metodologia é empregada em estudos de corrosão para estimar a resistência à polarização ou à transferência de carga $\left(R_{P}\right)$ [161-166].

A técnica é muito simples na prática: consiste em determinar a curva de polarização nas proximidades do potencial de corrosão $\left(E_{c o r}\right)$. $O$ valor de $R_{P}$ é obtido através da tangente da curva corrente-potencial, ou seja,

$$
\mathrm{R}_{\mathrm{P}}=(\mathrm{dE} / \mathrm{dI})_{\text {Ecorr }} \cong(\Delta \mathrm{E} / \Delta \mathrm{I})_{\text {Ecorr }}
$$

No entanto, a análise teórica deste método é bastante complexa e mereceu diferentes interpretações. C. Gabrielli e col. [161], p.ex., verificaram que a deformação das curvas I/E com a velocidade de varredura ( $v$ ) alterava a estimativa de $R_{p}$. Os autores realizaram medidas de SACV e de impedância eletroquímica para eletrodos de uma liga à base de diversos metais (principalmente $\mathrm{Ni}$ e $\mathrm{Cr}$ ) e observaram que, para ambas as técnicas, os valores estimados de $R_{p}$ diminuiam quando se aumentava a frequência do sinal aplicado. Concluiram assim que $R_{p}$ podia ser determinado através da relação (2.27) apenas a $v$ muito baixos [161].

Praticamente ao mesmo tempo, D.D. Macdonald [162-164] empregou uma abordagem matemática distinta para analisar a variação dos perfis potenciodinâmicos com o v. Considerando estudos anteriores desenvolvidos por L.G. Austin e E.G. Gagnon [165168], Macdonald propôs que a SACV fosse empregada para estimar também a resistência da solução $\left(R_{S}\right)$ e a capacidade da dupla camada elétrica $\left(C_{d l}\right)$ do eletrodo na solução. 
A metodologia proposta consiste em obter os perfis potenciodinâmicos $\mathrm{I} / \mathrm{E}$ a diferentes $v$. Das medidas realizadas em $v$ elevadas, estima-se o valor de $R_{S}$, enquanto que a partir das medidas realizadas em $v$ muito baixas estima-se $\mathrm{C}$ e a soma $\left(\mathrm{R}_{\mathrm{S}}+\mathrm{R}_{\mathrm{P}}\right)$. Esta metodologia foi empregada também por H. Shih e H.W. Pickering em estudos publicados posteriormente, nos quais uma outra análise matemática é apresentada para esta mesma técnica $[169,170]$.

De modo geral, os modelos admitem que o sistema eletroquímico possa ser representado por um circuito elétrico equivalente simples, $\mathrm{R}_{\mathrm{S}}\left(\mathrm{R}_{\mathrm{P}} \mathrm{C}_{\mathrm{dl}}\right)$, como ilustrado na Fig. 2.15. A capacidade $C_{d l}$ situa-se em paralelo à $R_{P} e$ ambas estão em série com a resistência $R_{S}$.

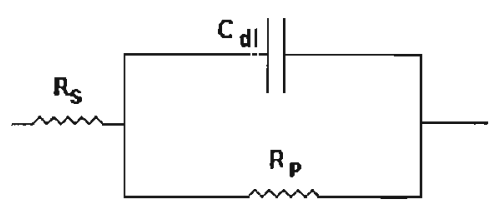

Figura 2.15. Circuito equivalente à interfase eletrodo $/$ solução para a SACV.

Quando se aplica uma excitação triangular de potencial à interfase eletrodo $\mid$ solução, como a função representada na Fig. 2.16a, a resposta do sistema é uma curva que apresenta as características gerais do voltamograma ilustrado na Fig. 2.16b.
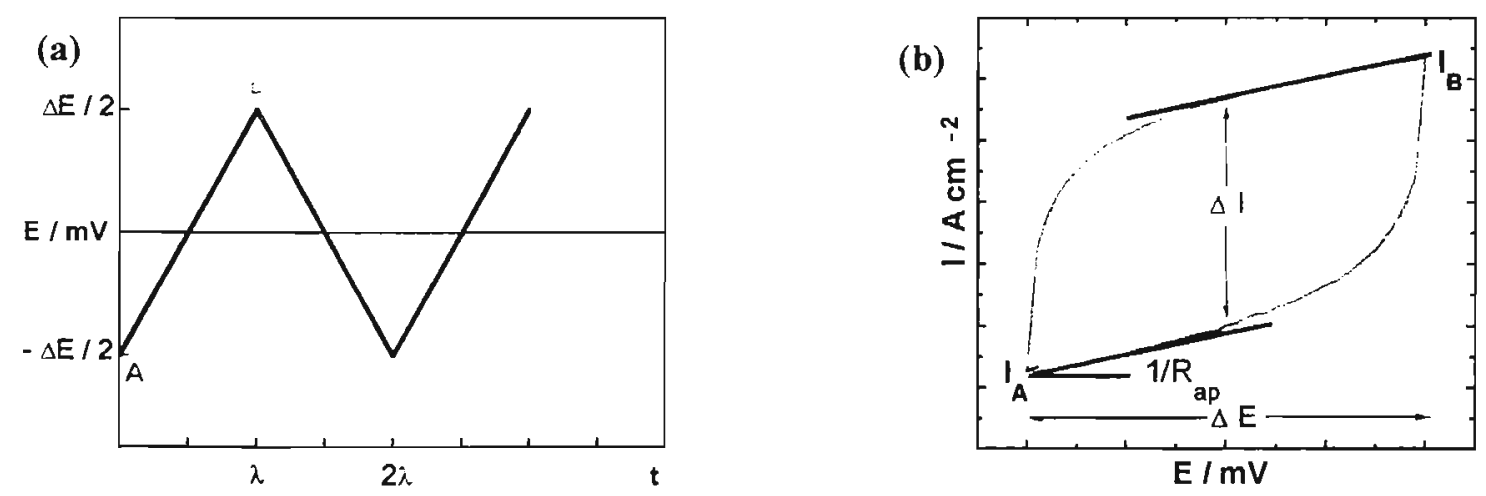

Figura 2.16 (a) Função da excitação de potencial aplicada ao eletrodo no método de SACV; (b) Curva I/E típica obtida para uma varredura triangular de potencial.

De modo geral, verifica-se uma histerese entre as curvas de polarização resultantes das varreduras direta e inversa, e um comportamento do tipo exponencial no início da varredura em cada direção. Tanto a extensão da histerese como a inclinação da curva dependem dos elementos do circuito e do $v$, ou seja, da frequência deste sinal triangular de potencial.

O sinal triangular de potencial aplicado na interfase para as varreduras direta e inversa é representado respectivamente pelas expressões: 


$$
\begin{aligned}
& E=E_{m}[t / \lambda-2 n], \\
& e \\
& E=E_{m}[2(n+1)-t / \lambda]
\end{aligned}
$$

onde $E_{m}$ é o valor máximo do sinal de potencial aplicado, $\lambda$ é o tempo no qual o sentido da varredura é invertido e $n=0,1,2, \ldots$ é o número de ciclos.

Para um sistema como o representado na Fig. 2.15, a equação matemática que descreve a resposta a este sinal no decorrer do tempo é uma função complexa das resistências e da capacitância dos elementos do circuito, do potencial máximo aplicado e da velocidade de varredura. Uma condição para a utilização da SACV é que a amplitude desta função seja baixa, para que a impedância do sistema eletroquímico possa ser linearizada. Em geral, aplica-se de $20 \mathrm{mV}$ de um pico a outro. A resposta do sistema descrita pela lei de Ohmn é:

$$
I(t)=E(t) / Z(p)
$$

onde $I(t)$ e $E(t)$ são, respectivamente, a resposta de corrente para o potencial aplicado em função do tempo, e $Z(p)$ é a impedância do sistema em função de um operador de impedância $p$.

$Z(p)$ é dada por:

$$
Z(p)=R_{S}+R_{P} /\left(1+p R_{P} C_{d l}\right)
$$

\subsubsection{Metodologia proposta por D.G. Macdonald}

Macdonald propôs um conjunto de equações para descrever a evolução dos perfís potenciodinâmicos com o tempo e para analisar a variação dos mesmos em função do $\mathrm{v} . \mathrm{O}$ tratamento matemático, que envolve a utilização de "transformadas de Laplace", foi desenvolvido para a análise de um circuito simples $R_{S}\left(R_{P} C_{d l}\right)$ e ainda para um circuito um pouco mais complicado, que inclui também um elemento indutor [163]. Segue abaixo a metodologia proposta para estimar os valores dos elementos do circuito simples $R_{S}\left(R_{p} C_{d 1}\right)$ [162].

A técnica consiste em obter os perfis potenciodinâmicos $\mathrm{I} / \mathrm{E}$ em diferentes $v$. Para cada voltamograma cíclico, deve-se determinar a histerese de corrente $(\Delta \mathrm{l})$ entre as 
varreduras direta $\left(\mathrm{I}^{\mathrm{d}}\right)$ e inversa $\left(\mathrm{I}^{\mathrm{i}}\right)$, a resistência diagonal $\left(\mathrm{R}_{\mathrm{D}}\right)$ e a resistência aparente $\left(\mathrm{R}_{\mathrm{ap}}\right)$, como ilustrado na Figura $2.16 \mathrm{~b}$.

Nas curvas I/E, estes parâmetros são definidos graficamente por

$$
\begin{aligned}
& \Delta I=I^{d}\left(t^{\prime}=\lambda / 2\right)-I^{i}\left(t^{\prime \prime}=3 \lambda / 2\right) \\
& 1 / R_{D}=\left[I_{B}\left(t^{\prime}=\lambda\right)-I_{A}\left(t^{\prime \prime}=2 \lambda\right)\right] / E_{m} \\
& 1 / R_{a p}=(d I / d E)_{t=\lambda}
\end{aligned}
$$

ou seja, $1 / \mathrm{R}_{\mathrm{ap}}$ equivale à inclinação da curva de polarização em $t=\lambda$ na varredura direta e a $t "=2 \lambda$ na varredura inversa.

$\mathrm{Na}$ análise teórica do método, estes parâmetros estão relacionados através das seguintes equações:

$$
\begin{array}{ll}
\text { Sendo } & a=R_{S}+R_{P} \\
e & b=R_{S} R_{P} C_{d l}
\end{array}
$$

entao:

$$
\begin{aligned}
& 1 / \mathrm{R}_{\mathrm{D}}=1 /\left(\mathrm{R}_{\mathrm{S}}+\mathrm{R}_{\mathrm{P}}\right)+\left\{2 \mathrm{R}_{\mathrm{P}}^{2} \mathrm{C}\left(e^{\mathrm{aEm} / \mathrm{b} v}-1\right) / \mathrm{E}_{\mathrm{m}}\left(\mathrm{R}_{\mathrm{P}}+\mathrm{R}_{\mathrm{S}}\right)^{2}\left(e^{\mathrm{aEm} / \mathrm{b} v}+1\right)\right\} v \\
& 1 / \mathrm{R}_{\mathrm{ap}}=1 /\left(\mathrm{R}_{\mathrm{S}}+\mathrm{R}_{\mathrm{P}}\right)+2 \mathrm{R}_{\mathrm{P}} / \mathrm{R}_{\mathrm{S}}\left(\mathrm{R}_{\mathrm{S}}+\mathrm{R}_{\mathrm{P}}\right)\left(1+e^{\mathrm{aEm} / v \mathrm{~b}}\right) \\
& \Delta \mathrm{I}=2 \mathrm{R}_{\mathrm{P}}^{2} \mathrm{C}_{\mathrm{dl}}\left\{1-2 e^{\mathrm{aEm} / 2 v \mathrm{~b}} /\left(1+e^{\mathrm{aEm} / 2 v \mathrm{v}}\right)\right\} v /\left(\mathrm{R}_{\mathrm{S}}+\mathrm{R}_{\mathrm{P}}\right)^{2}
\end{aligned}
$$

Os parâmetros $1 / R_{D}$ e $1 / R_{a p}$ determinados em diversas $v$ permitem estimar as resistências do circuito.

Como mostra a Figura 2.17, para $v$ altas, ambas as funções aproximam-se do valor correspondente a $1 / R_{S}$. Em $v$ baixas, ambas as resistências $R_{a p}$ e $R_{D}$ se aproximam do valor correspondente à resistência total do circuito, $\left(R_{S}+R_{P}\right)$.

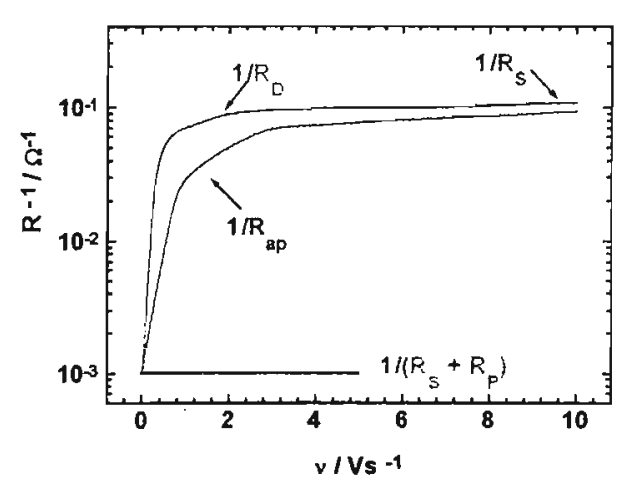

Figura 2.17. Comportamento previsto para as funções que descrevem os parâmetros $1 / R_{D}$ e $1 / R_{a p}$ em função da velocidade de varredura. 
Para medidas de $\Delta I$ em funçăo da velocidade de varredura, verifica-se através da equação (2.37) que, para $v$ muito baixas,

$$
(d \Delta I / d v)_{v \rightarrow 0}=2 R_{P}^{2} C_{d l} /\left(R_{P}+R_{s}\right)^{2}
$$

De modo geral, $R_{P} \gg R_{S}$, então,

$$
C_{d l} \approx 1 / 2(d \Delta I / d v)_{v \rightarrow 0}
$$

Portanto, todos os elementos do circuito, $C_{d l}, R_{P}$ e $R_{S}$, podem ser estimados através da determinação dos parâmetros $\Delta I, 1 / R_{D}$ e $1 / R_{\text {ap }}$ em diferentes velocidades de varredura.

Esta metodologia foi aplicada por Macdonald no estudo da corrosão de uma liga de cobre e níquel em água do mar. Para efeito de comparação, o autor empregou também a técnica de impedância eletroquímica para estimar os elementos do circuito equivalente ao sistema (um circuito $R_{S}\left(R_{P} C_{d l}\right)$ ), e obteve excelente concordância para os valores obtidos for ambas as técnicas $[162,164]$.

As vantagens da SACV para a determinação de $R_{p}$ e dos demais elementos do circuito foram apresentadas com grande entusiasmo tanto nos artigos de Macdonald, em 1978, [162-164] como nos de Shi e Pickering, aproximadamente 10 anos depois [170, 171]. No entanto, foram encontrados poucos relatos sobre a aplicação desta técnica na Literatura. Este fato leva a supor que, ou esta metodologia não despertou o interesse de outros investigadores, ou aqueles que a empregaram não publicaram as investigações realizadas. De fato, esta técnica não parece muito atraente, principalmente porque exige um longo e detalhado trabalho de tratamento dos dados experimentais, como será apresentado no Capítulo 4. 


\section{1 - INTRODUÇÃO}

$\mathrm{O} \mathrm{SnO}_{2}$ tem sido investigado pelo Grupo já há algum tempo, como parte de um projeto mais amplo dedicado a investigar propriedades eletroquímicas e interfaciais de óxidos. No desenvolvimento deste projeto, já se investigou a obtenção e a caracterização de pós de $\mathrm{SnO}_{2}$ em suspensão [49] e o desenvolvimento de ânodos de $\mathrm{SnO}_{2}$ sobre titânio e sua aplicação na eletro-oxidação do cianeto [24, 51, 52]. Neste trabalho, investigaram-se os eletrodos de $\mathrm{SnO}_{2}$ depositados sobre sílica (eletrodos transparentes) e sobre titânio. Porém, nesta parte de preparação e caracterização dos materiais, a maior parte dos estudos foi dedicada aos eletrodos transparentes, em função das técnicas empregadas e também porque o eletrodo de $\mathrm{Ti} / \mathrm{SnO}_{2}$ já havia sido detalhadamente investigado por Fugivara [51].

Os filmes de $\mathrm{SnO}_{2}$ depositados sobre sílica foram preparados com a finalidade de obter eletrodos de superfície uniforme e de baixa rugosidade, que pudessem ser investigados através das técnicas de AFM e STM. Entre as técnicas mais indicadas (e disponiveis), optou-se pelo método de Spray Pyrolysis. Após um considerável trabalho dedicado a ajustar as condições de preparação, realizado em colaboração com E. Videra e o Prof. Dr. J. Torrent $[172,173]$, obtiveram-se os materiais com as características desejadas para dar prosseguimento ao estudo que será apresentado nos próximos capítulos. Estes eletrodos foram detalhadamente caracterizados através das diversas técnicas de análise de superficie disponíveis nos Serveis Cientifico-Tècnics da Universidade de Barcelona.

$\mathrm{Na}$ preparação dos $\mathrm{Ti} / \mathrm{SnO}_{2}(\mathrm{Sb})$, empregou-se o método desenvolvido por Fugivara em seu Doutorado [51]. Estes eletrodos foram caracterizados apenas no aspecto morfológico através de microscopia eletrônica de varredura e por interferometria de luz.

Prepararam-se ainda eletrodos modificados com organosilanos, seguindo o mesmo procedimento adotado pelo Grupo do Laboratório de Técnicas Nanométricas da Universidade de Barcelona para a obtenção de filmes de OTS em silício [140]. Estes eletrodos modificados também foram investigados por AFM e por análises qualitativas em relação à hidrofobicidade e à composição química da superficie. 


\subsection{PREPARAÇÃO DOS ELETRODOS}

\subsubsection{Eletrodos de filmes de $\mathrm{SnO}_{2}$ depositados sobre sílica}

Para a obtenção dos eletrodos com as características desejadas, observaram-se diversos cuidados com o objetivo de favorecer a nucleação e o crescimento uniforme do filme em toda a superfície. Como fator fundamental, os cuidados com a limpeza do substrato e de todo o material utilizado foram observados com o máximo rigor. Embora as publicações mais recentes utilizem soluções precursoras da ordem de 0,5 $\mathrm{M}[67,68]$, preferiu-se utilizar soluções precursoras com [Sn] alta, para favorecer a nucleação [68]. A concentração dos dopantes, especialmente no caso do $\mathrm{Sb}$, também se mostrou um fator crítico para a morfologia do filme. Nas preparações preliminares, a comparação entre a morfologia dos filmes "não dopados" e dopados com Sb mostrou que mesmo para a razão $[\mathrm{Sb}] /[\mathrm{Sn}]=0,4 \%$ o filme de $\mathrm{SnO}_{2}(\mathrm{Sb})$ apresentava-se mais rugoso. Por este motivo, a razão $[\mathrm{Sb}] /[\mathrm{Sn}]$ empregada na preparação da amostra sobre sílica foi de apenas $0,2 \%$. Observouse ainda que a rugosidade do filme aumentava consideravelmente com o aumento da espessura; por esta razão. realizaram-se apenas duas aplicações rápidas do spray, para depositar filmes finos mas uniformes e de baixa rugosidade. As condições experimentais empregadas na preparação das amostras que foram investigadas em todo o trabalho estão descritas a seguir

\subsubsection{Limpeza dos substratos}

Os substratos foram sempre manuseados com extremo cuidado, para evitar qualquer dano à superfície. As peças de sílica, originalmente com dimensão de $7,5 \times 7,5 \times$ $1,5 \mathrm{~mm}^{3}$ foram cuidadosamente marcadas com lápis de diamante, cortadas em retângulos de $7,5 \times 2,5 \mathrm{~mm}^{2}$ e então submetidas ao procedimento de limpeza.

O procedimento de limpeza foi sugerido pela Dra. M. Garcia-Parajo considerando sua experiência na deposição de filmes. Inicialmente, cada peça foi lavada em solução aquosa de detergente "Decon 75 " e enxaguada com água bi-destilada. A seguir, a peça foi mantida em solução aquosa do detergente a $80^{\circ} \mathrm{C}$ (em banho de areia) por 30 minutos, e abundantemente enxaguada. Para finalizar o enxague, cada amostra foi colocada em água purificada por sistema "Mili-Q", e mantida durante 3 minutos em tanque de ultra-som. 
Realizou-se então uma segunda etapa de limpeza com álcool isopropílico: inicialmente um enxague, e, a seguir, a amostra foi submetida a um banho de ultra-som neste solvente durante 3 minutos. Para a finalização do processo de limpeza, cada peça foi imersa em isopropanol a quente (em banho de areia) durante 15 minutos. Com o auxílio de uma pinça, a amostra foi retirada do solvente lentamente, para que este secasse completamente. A seguir, cada amostra foi embalada diretamente em papel de limpeza de lentes, que não risca a superfície nem deixa resíduos.

\subsubsection{Obtenção dos filmes de $\mathrm{SnO}_{2}$ por Spray Pyrolysis}

Os filmes finos de $\mathrm{SnO}_{2}$ foram preparados pela aplicação da solução precursora sobre o substrato quente com o auxílio de um atomizador. As soluções foram preparadas com $25 \mathrm{~g}$ de $\mathrm{SnCl}_{4} .5 \mathrm{H}_{2} \mathrm{O}$ em $6 \mathrm{~mL}$ metanol. Para preparar os filmes dopados, adicionou-se $\mathrm{SbCl}_{3}$ ou $\mathrm{NH}_{4} \mathrm{~F}$ à solução de $\mathrm{SnCl}_{4}$, em concentração correspondente a $0,2 \%$ em relação à concentração de Sn. Empregaram-se reagentes de grau p.a., de procedência "Aldrich" e "Merck".

O procedimento consistiu em inicialmente aquecer os substratos limpos em estufa a $100{ }^{\circ} \mathrm{C} \mathrm{e}$, a seguir, transferi-los para o forno a $600{ }^{\circ} \mathrm{C}$ durante 5 minutos.

Com o auxílio de uma pinça, o substrato foi retirado do forno e colocado em posição vertical em um suporte. Imediatamente a seguir, aplicou-se o spray durante 4 segundos e a amostra foi então rapidamente recolocada no forno, em posição horizontal, por 2 minutos e meio. A aplicação do spray foi então repetida, seguindo o mesmo procedimento. Após a segunda aplicação do spray, a amostra foi mantida no forno durante 5 minutos.

A amostra foi então retirada do forno, colocada por alguns minutos sobre uma placa de Pyrex que estava sobre uma chapa elétrica e então transferida para outra placa à temperatura ambiente. Depois de resfriada, cada amostra foi cuidadosamente embalada em papel especial utilizado em laboratórios de ótica e guardada em caixas fechadas, em um dessecador.

O suporte para apoiar a amostra durante a aplicação do spray foi situado ao lado do forno e dentro de uma capela para exaustão de gases. A distância entre a amostra e o spray foi mantida fixa em 30 centímetros. Para evitar alterações bruscas de temperatura, a pinça e 
o suporte foram previamente aquecidos com a chama de um bico de Bunsen antes de serem colocados em contato com amostra.

\subsubsection{Eletrodos de filme de $\mathrm{SnO}_{2}(\mathrm{Sb})$ suportado sobre titânio}

Os eletrodos de $\mathrm{Ti} / \mathrm{SnO}_{2}$ foram preparados através da aplicação da solução precursora sobre a superfície do substrato por pincelamento, seguido por secagem e calcinação. Utilizou-se o procedimento desenvolvido por Fugivara [51].

Os eletrodos foram depositados sobre placas de titânio de $1 \mathrm{~mm}$ de espessura "Aldrich" novas, cortadas em quadrados com $2 \mathrm{~cm}$ de lado.

Os substratos foram lavados inicialmente com acetona. Após a secagem, foram colocados em solução aquosa de $\mathrm{NaOH} 10 \%$ durante 10 minutos e enxaguados com água destilada. A seguir, foram mantidos durante 5 minutos em solução fervente de $\mathrm{H}_{2} \mathrm{C}_{2} \mathrm{O}_{4} 3 \mathrm{M}$, e novamente enxaguados com água destilada. As amostras foram então imersas em solução aquosa de $\mathrm{HCl} 50 \%$, retiradas e imediatamente colocadas sobre a chapa elétrica para secagem e aplicação da solução precursora.

A solução precursora foi preparada com $\mathrm{SnCl}_{2} \cdot 2 \mathrm{H}_{2} \mathrm{O}$ e $\mathrm{SbCl}_{3}$ em $\mathrm{HCl}$ (conc) e npropanol $(1: 1, \mathbf{v}: \mathbf{v})$, de tal modo que a [Sn] era de aproximadamente $0,336 \mathrm{M}$ e a razão [Sb]/[Sn] de 3\%. Empregaram-se reagentes de procedência "Carlo Erba" e "Merck".

Esta solução foi aplicada com o auxílio de um pincel sobre apenas um dos lados do substrato. A amostra foi então colocada sobre chapa elétrica a aproximadamente $80^{\circ} \mathrm{C}$, para secagem do solvente, e a seguir colocada em um forno a $450{ }^{\circ} \mathrm{C}$ por 5 minutos. Realizaram-se no total 3 aplicações da solução. Após a última aplicação, a amostra foi mantida no forno durante 30 minutos para recozimento.

\subsubsection{Preparação dos eletrodos modificados com OTS}

A preparação dos eletrodos modificados com organosilanos foi realizada seguindo o mesmo procedimento adotado pelo Grupo dos Laboratórios de Técnicas Nanométricas para a obtenção de filmes de OTS em silício [140]. Para evitar a polimerização do OTS, observaram-se diversas precauções para minimizar a umidade e a presença de impurezas polares [138-140]. 
Todo o procedimento de preparação foi efetuado em uma Sala Limpa, em condições rigorosamente controladas de temperatura e umidade. A preparação da solução de OTS e o processo de adsorção foram realizados sob umidade relativa inferior a $8 \%$ (dentro de uma glovebox contendo sílica gel). O material empregado foi previamente submetido a um cuidadoso processo de limpeza. Utilizaram-se soluções $1: 1(\mathrm{v} / \mathrm{v})$ de $\mathrm{H}_{2} \mathrm{SO}_{4}$ (conc.) e $\mathrm{H}_{2} \mathrm{O}_{2}$ a $80^{\circ} \mathrm{C}$ durante 5 minutos, enxaguando-se a seguir com água deionizada (Milli-Q) abundantemente. Após secagem em forno, todo o material foi mantido dentro da caixa à umidade controlada antes e durante o processo de preparação.

Antes de iniciar o processo de adsorção do organosilano, os eletrodos foram submetidos a um processo de limpeza por banho em ultra-som em diversos solventes. Empregaram-se sucessivamente clorofórmio, metanol, etanol e água (Milli-Q), durante 3 minutos, 2 vezes cada solvente e 4 vezes com água.

Preparou-se a solução $5 \times 10^{-4} \mathrm{M}$ de OTS em uma mistura de solventes constituída por $8 \%$ de $\mathrm{CHCl}_{3}, 12 \%$ de $\mathrm{CCl}_{4}$ e $80 \%$ hexadecano. Todos os solventes foram previamente filtrados através de colunas de alumina, para minimizar possível contaminação com impurezas polares [138-140]. A solução de OTS foi mantida sob agitação magnética continuamente. Para o processo de adsorção, os eletrodos foram imersos na solução de OTS durante 5 minutos. Quando retirados da solução de OTS, os eletrodos modificados foram enxaguados abundantemente com $\mathrm{CCl}_{4}$, a seguir mantidos sob banho de ultra-som em $\mathrm{CCl}_{4}$ durante 5 minutos, por duas vezes, para eliminação dos resíduos de OTS que não houvessem aderido à superficie. Efetuou-se a secagem com fluxo de nitrôgenio e armazenaram-se as amostras em caixas, dentro de um dessecador, para submetê-las às análises de caracterização e aos estudos eletroquímicos. 


\section{3 - CARACTERIZAÇÃO DOS ELETRODOS DEPOSITADOS SOBRE SÍLICA}

\subsubsection{Detalhes experimentais referentes às análises realizadas}

Os eletrodos depositados sobre sílica foram inicialmente caracterizados através de microscopia por interferometria de luz, medidas de transmitância da luz e por difração de raios-X, por serem técnicas não destrutivas e não exigirem qualquer tratamento prévio para as análises. A seguir, cortaram-se amostras com as dimensões adequadas para cada análise, empregando-se um lápis de diamante. Durante a preparação e em todas as análises, observaram-se cuidados rigorosos para não danificar a superficie dos eletrodos.

A composição química dos filmes foi analisada através de XPS, empregando o equipamento Perkin-Elmer Physical Electronics PHI 5500 ESCA. As análises foram realizadas para a superficie dos filmes e também em profundidade, após diversos ciclos de bombardeio com $\mathrm{Ar}^{+}$para a remoção gradual do filme. Posteriormente, examinou-se a superficie destas amostras na região onde o filme havia sido removido por interferometria de luz, para obter informações referentes à espessura dos mesmos.

Para determinar a composição química, realizaram-se ainda análises por microsonda eletrônica, utilizando o equipamento CAMECA-Camebax SX-50. Para estimar a composição dos filmes, utilizaram-se como padrão para cada elemento os valores característicos para $\mathrm{SiO}_{2}$ (substrato), $\mathrm{SnO}_{2}, \mathrm{CaF}_{2}$ e $\mathrm{Sb}_{2} \mathrm{O}_{3}$. Como os valores dos padrões referiam-se a amostras recobertas com grafite, as análises foram realizadas nas mesmas condições, i.e., após a aplicação de um recobrimento de grafite. A composição química dos filmes foi determinada através de análises interativas considerando os componentes e a espessura de cada filme.

A transparência das amostras foi verificada através de medidas de transmitância da luz entre 250 e $800 \mathrm{~nm}$, utilizando o espectrofotômetro UV-VIS 2101-Shimadzu e uma amostra do substrato como referência.

As análises por SEM foram realizadas com o equipamento Cambridge Stereoscan360. Por serem suficientemente condutoras, as amostras foram analisadas diretamente, sem que houvesse necessidade de utilizar qualquer recobrimento condutor. Realizaram-se apenas quatro pequenos contatos com prata coloidal entre a superficie da amostra e o suporte. 
As análises de microscopia por interferometria de luz foram realizadas com o equipamento Zygo New View-100, em varreduras de $2 \times 1,5 \mathrm{~mm}^{2}$ e $90 \times 68 \mu^{2}$. O mapeamento da superficie foi realizado com luz branca, de comprimento de onda de $\sim 0,5$ $\mu \mathrm{m}$ (valor que correponde à resolução lateral das medidas). $\mathrm{O}$ deslocamento da amostra foi realizado através de piezoelétricos, que oferecem resolução de $0,4 \mathrm{~nm}$ na direção-z.

$\mathrm{Na}$ investigação da superfície por AFM, utilizou-se o equipamento Nanoscope IIImultimode AFM, em regime de Tapping Mode, empregando cantilevers retangulares de Si. As amostras foram observadas em diversas regiões, em varreduras de $(4 \times 4)$ e $(1 \times 1) \mu \mathrm{m}^{2}$ $\mathrm{e}(500 \times 500) \mathrm{nm}^{2}$.

As análises por TEM foram efetuadas apenas para o eletrodo transparente de $\mathrm{SnO}_{2}(\mathrm{Cl})$, na forma de seções transversais do filme. Na preparação da amostra, cortaram-se lâminas de $700 \mu \mathrm{m}$ de espessura com o auxílio de uma serra micrométrica. A seguir, as lâminas foram polidas com lixas de carbeto de silício até que apresentassem espessura da ordem de 30 a $40 \mu \mathrm{m}$ e foram então afinadas com ions $\mathrm{Ar}^{+}$até que apresentassem espessura inferior a $100 \mathrm{~nm}$. As medidas foram feitas em um microscópio Philips.

As análises por difração de raios-X foram realizadas no equipamento Siemens D-500 com tubo de cobre. As medidas foram efetuadas a baixo ângulo de incidência $\left(0,5^{\circ}\right)$, em varreduras de $2 \theta$ variando entre 10 e $75^{\circ}$, em passos de 0,025 ou $0,05^{\circ}$. Nas medidas de reflectometria de raios-X empregou-se monocromador secundário de grafite. Realizaramse varreduras de $2 \theta / \theta$ no intervalo de 0,3 a $2^{\circ}$, com passos de $0,005^{\circ}$, de 1 segundo. $O$ tamanho dos grãos e a espessura dos filmes foram determinados através dos programas de tratamento de dados do equipamento. Os princípios básicos envolvidos nos cálculos destes parâmetros são brevemente discutidos a seguir.

Difração de Raios-X. Determinação do tamanho dos grãos. O tamanho dos cristalitos (na direção perpendicular, ou seja, a altura dos grãos) foi estimado através da equação de Scherrer [174]. Em termos gerais, considera-se que a largura dos picos de difração ( $\beta$ ) está relacionada com o tamanho dos cristalitos (D) através da expressão

$$
\mathrm{D}=\frac{\mathrm{k} \lambda}{\beta \cos \theta}
$$

onde $\mathrm{D}$ é o tamanho do cristalito, $\mathrm{K}$ é uma constante de calibração, $\lambda$ é o comprimento de onda da radiação empregada (neste caso, para radiação k $\alpha$ do tubo de $\mathrm{Cu}$, $\lambda=1,5418 \AA$ ), $\beta$ é a largura (a meia altura) dos picos de difração e $\theta$ é o ângulo de difração. 
Em alguns casos, o aumento na largura dos picos se deve não só à diminuição no tamanho dos cristalitos como também a fatores de microdeformação. $O$ ajuste dos picos de difração com funções matemáticas permite estimar a contribuição de cada fator. De modo geral, o efeito das microdeformações está associado a funções de tipo Gaussianas, enquanto que efeitos decorrentes da diminuição do tamanho dos cristalitos estão associadas a funções de tipo Lorentzianas [174].

Utilizando-se tais funções, analisaram-se apenas os 3 picos iniciais dos difratogramas obtidos, referentes ao substrato e aos planos (110) e (101) do óxido de estanho. Verificou-se que o pico referente ao substrato era $100 \%$ Gaussiano (tratava-se de silica amorfa), e os picos referentes ao filme de óxido eram 100\% Lorentzianos. Por esta razão, os valores de $\beta$ puderam ser determinados por um programa que empregava uma função do tipo Voigt, e admitiu-se para a constante de calibração o valor $K=0,9$.

Determinação da espessura dos filmes por reflectometria. A determinação da espessura de um filme depositado sobre um substrato através de medidas de reflexão dos raios-X deriva-se do mesmo tratamento dado para a reflexão da luz. A um ângulo de incidência um pouco acima do ângulo crítico para reflexão total, parte da radiação penetra no filme e sofre reflexão na interface entre o filme e o substrato. A radiação refletida da interface interfere com a radiação refletida da superficie. Variando-se o ângulo de incidência, ambas as contribuições originam franjas de interferência, cujo espaçamento está relacionado com a espessura do filme através da expressão [174, 175]

$$
d=\frac{\lambda}{2 \cdot \cos \theta \cdot \delta \theta}
$$

onde $d$ é a espessura do filme e $\theta$ é o ângulo total de reflexão, em radianos.

A condutividade das amostras foi determinada através do método de Van der Pauw. [176]. Para a aplicação do método, quatro pequenos contatos foram realizados na amostra, de acordo com a ilustração apresentada na Figura 3.1a. Durante a realização das medidas, a amostra foi colocada em uma pequena caixa fechada (na ausência de luz) e os contatos foram feitos utilizando pasta de prata coloidal. As medidas foram efetuadas para 3 valores distintos de corrente.

A determinação da condutividade foi realizada a partir de medidas da diferença de potencial resultante entre dois contatos consecutivos $\left(\mathrm{V}_{\mathrm{kl}}\right)$, ao se aplicar uma intensidade de 
corrente conhecida $\left(\mathrm{I}_{\mathrm{ij}}\right)$ entre os outros 2 contatos. Para obter resultados mais confiáveis, realizaram-se também as medidas do potencial resultante ao se inverter o sentido da corrente $\left(\mathrm{I}_{\mathrm{ji}}\right)$.

A condutividade foi calculada através da expressão:

$\frac{1}{\sigma}=\frac{\pi \cdot d}{8 \cdot \ln 2}\left[\frac{\left|V_{34}(+)-V_{34}(-)\right|}{I_{12}}+\frac{\left|V_{41}(+)-V_{41}(-)\right|}{I_{23}}+\frac{\left|V_{12}(+)-V_{12}(-)\right|}{I_{41}}+\frac{\left|V_{22}(+)-V_{23}(-)\right|}{I_{41}}\right] f\left[\frac{R_{2234}}{R_{23,41}}\right]$

onde $\mathrm{I}_{\mathrm{ij}}$ é a intensidade da corrente que circula entre dois contatos sucessivos, $\mathrm{V}_{\mathrm{kl}}$ é a diferença de potencial medida entre os outros 2 contatos $\left(V_{k l}=V_{1}-V_{k}\right), R_{i j, k l}=V_{k l} / I_{i j}$. $f\left[\frac{R_{12,34}}{R_{23,41}}\right]$ é uma função implícita, mas, como uma aproximação, os valores podem ser calculados graficamente a partir da função representada na Figura 3.1b.

Figura 3.1a

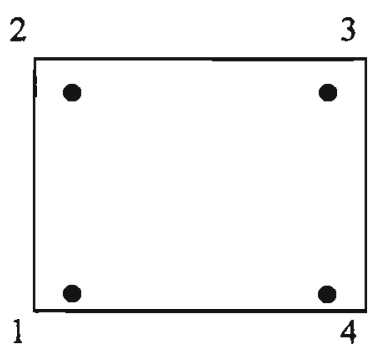

Figura 3.1b

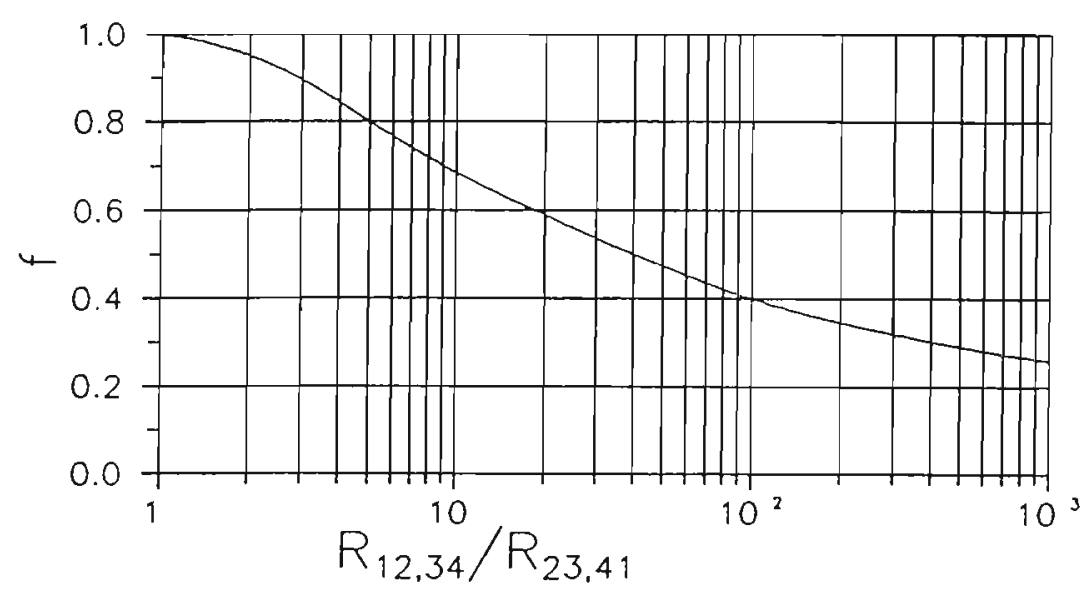

Figura 3.1. (a) Ilustração representativa dos contatos para a determinação da condutividade; (b) Representação gráfica da função $f\left[\frac{R_{12,34}}{R_{23,41}}\right]$ 


\subsubsection{Características morfológico-estruturais dos filmes transparentes de $\mathrm{SnO}_{2}$}

Microscopia eletrônica de varredura. As análises por SEM realizadas em diversas áreas de cada amostra revelaram que os filmes de $\mathrm{SnO}_{2}$ depositados em sílica apresentaram a superfície bastante uniforme. Em aumentos inferiores a 1000 vezes, raramente identificaram-se alguns grãos, com diâmetro máximo de $4 \mu \mathrm{m}$ e algumas áreas mais escuras, muitas vezes nas proximidades destes grãos.

A Figura 3.2 ilustra as imagens obtidas com aumentos de 2000 vezes para os filmes de $\mathrm{SnO}_{2}(\mathrm{Cl}), \mathrm{SnO}_{2}(\mathrm{Sb})$ e $\mathrm{SnO}_{2}(\mathrm{~F})$, representando áreas de aproximadamente $60 \times 40 \mu \mathrm{m}^{2}$. Cada imagem foi registrada em uma área que incluísse pelo menos um grão, para certificar que o foco estivesse adequadamente ajustado. De certo modo, estas figuras são relativamente representativas da morfologia observada em distintas áreas para cada amostra, porque, de modo geral, a presença destes grãos e crateras era muito rara.

As extensas regiões de coloração distinta observadas nas Fig. 3.2a, assim como as áreas que se assemelham a faixas observadas na Fig. 3.2c, foram analisadas sob aumentos maiores e não apresentaram diferenças morfológicas consideráveis quando comparadas às demais áreas da superficie. É possível que a espessura do filme não fosse uniforme para estas amostras, causando diferenças de contraste nas micrografias. As regiões negras observadas nestas imagens, no entanto, constituiam-se de falhas no recobrimento do filme. Estas falhas, que se assemelhavam a crateras, apresentavam profundidades distintas e geralmente apresentavam pequenas partículas em seu interior.

Algumas das irregularidades verificadas na superfície dos filmes estão representadas nas imagens da Figura 3.3. Estas imagens representam áreas de aproximadamente $10 \times 7 \mu \mathrm{m}^{2}$, e foram observadas com aumentos de 10 mil vezes. Na Fig. 3.3a, observa-se uma região que apresentou diversos grãos e aspecto irregular no recobrimento do filme de $\mathrm{SnO}_{2}(\mathrm{Cl})$. É provável que o substrato apresentasse alguma impureza nesta região durante o processo de deposição do filme de $\mathrm{SnO}_{2}$, o que alterou o seu crescimento. A Fig. 3.3b mostra uma das crateras observadas para o filme de $\mathrm{SnO}_{2}(\mathrm{Sb})$, revelando a presença de grãos em seu interior. No filme de $\mathrm{SnO}_{2}(\mathrm{~F})$, as irregularidades da superfície mais frequentes constituíam-se por "faixas" um pouco mais escuras. Embora a imagem não esteja muito bem definida na Fig. 3.3c, verificou-se que estas regiões também se assemelhavam a falhas no recobrimento do filme, e apresentavam diferenças na profundidade. 
A Figura 3.4 revela imagens obtidas com aumentos de 40 mil vezes, de áreas de aproximadamente $3 \times 2 \mu \mathrm{m}^{2}$. Nestas imagens, verifica-se apenas que o filme era constituído por pequenas partículas, não sendo possível identificar a morfologia das mesmas. $\mathrm{Na}$ extremidade superior direita da Fig. 3.4a é possível observar também como a morfologia do filme se apresentava alterada nas proximidades dos grãos que a superfície eventualmente apresentava.

Em termos gerais, entre os três tipos de amostras, o filme de $\mathrm{SnO}_{2}(\mathrm{Cl})$ foi o que apresentou menor número de grãos na superfície; as áreas um pouco mais escuras observadas, p.ex., na Fig. 3.2a, não apresentaram diferenças quando observadas sob aumentos maiores. $\mathrm{O}$ filme de $\mathrm{SnO}_{2}(\mathrm{Sb})$ foi o que apresentou, de modo geral, a superficie mais uniforme, embora a presença de grãos fosse um pouco mais frequente. Comparativamente, o filme que apresentou o maior número de falhas na estrutura foi o de $\mathrm{SnO}_{2}(\mathrm{~F})$.

Microscopia por interferometria de luz. A análises realizadas por interferometria de luz forneceram informações adicionais sobre a microestrutura destes filmes. A Fig. 3.5 representa as imagens da topografia da superfície dos eletrodos obtidas em varreduras de $91 \times 68 \mu \mathrm{m}^{2}$. Para todos os três eletrodos, as imagens e os histogramas correspondentes revelaram que, de um modo geral, a diferença entre pico e vale na superfície é da ordem de $5 \mathrm{~nm}$. Nas regiões analisadas, observaram-se ainda raros grãos com altura máxima de 10 $\mathrm{nm}$, para o eletrodo de $\mathrm{SnO}_{2}(\mathrm{Sb})$, e de $15 \mathrm{~nm}$ para os eletrodos dopados com cloro e com flúor. Para todos os três tipos de amostras, a rugosidade média foi de apenas $1 \mathrm{~nm}$.

Para investigar a microestrutura dos filmes de $\mathrm{SnO}_{2}$ depositados sobre sílica mais detalhadamente, realizaram-se análises por AFM em diversas áreas de cada amostra e do substrato. As análises revelaram que, de maneira geral, as amostras eram muito uniformes também em escala sub-micrométrica. 
SEM - Aspecto geral da morfologia dos filmes de $\mathrm{SnO}_{2}(\mathrm{Sb})$ depositados em sílica

(a) $\mathrm{SnO}_{2}(\mathrm{Cl})$

(b) $\mathrm{SnO}_{2}(\mathrm{Sb})$
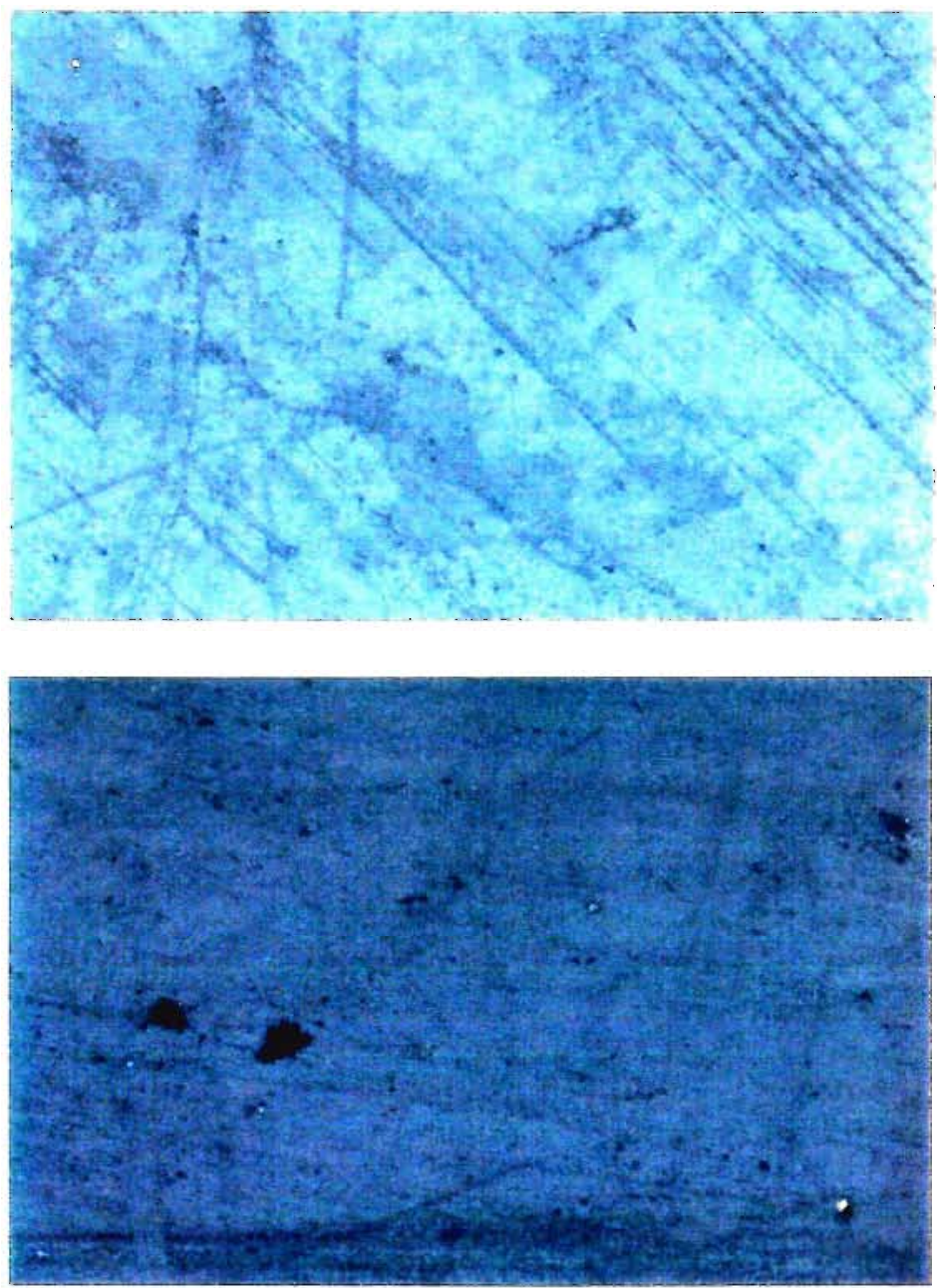

(c) $\mathrm{SnO}_{2}(\mathrm{~F})$

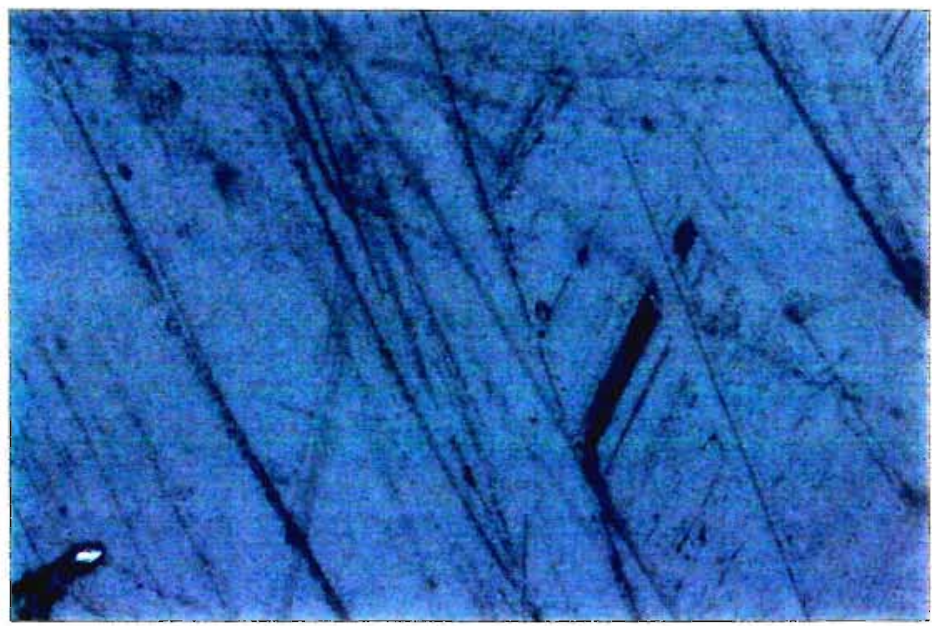

L=SEI $\quad[H \mathrm{HT}=30.0 \mathrm{KV}$ WD=5 mm $\mathrm{VAG}=\mathrm{X} 2.00 \mathrm{~K}$

20.0 $\mu \mathrm{m}$

Figura 3.2. Imagens obtidas por SEM da superfície dos eletrodos transparentes de filme de $\mathrm{SnO}_{2}$ dopados com $\mathrm{Cl}$, $\mathrm{Sb}$ ou $\mathrm{F}$. 
SEM - Detalhes de áreas que apresentaram defeitos na estrutura

(a) $\mathrm{SnO}_{2}(\mathrm{Cl})$

(b) $\mathrm{SnO}_{2}(\mathrm{Sb})$
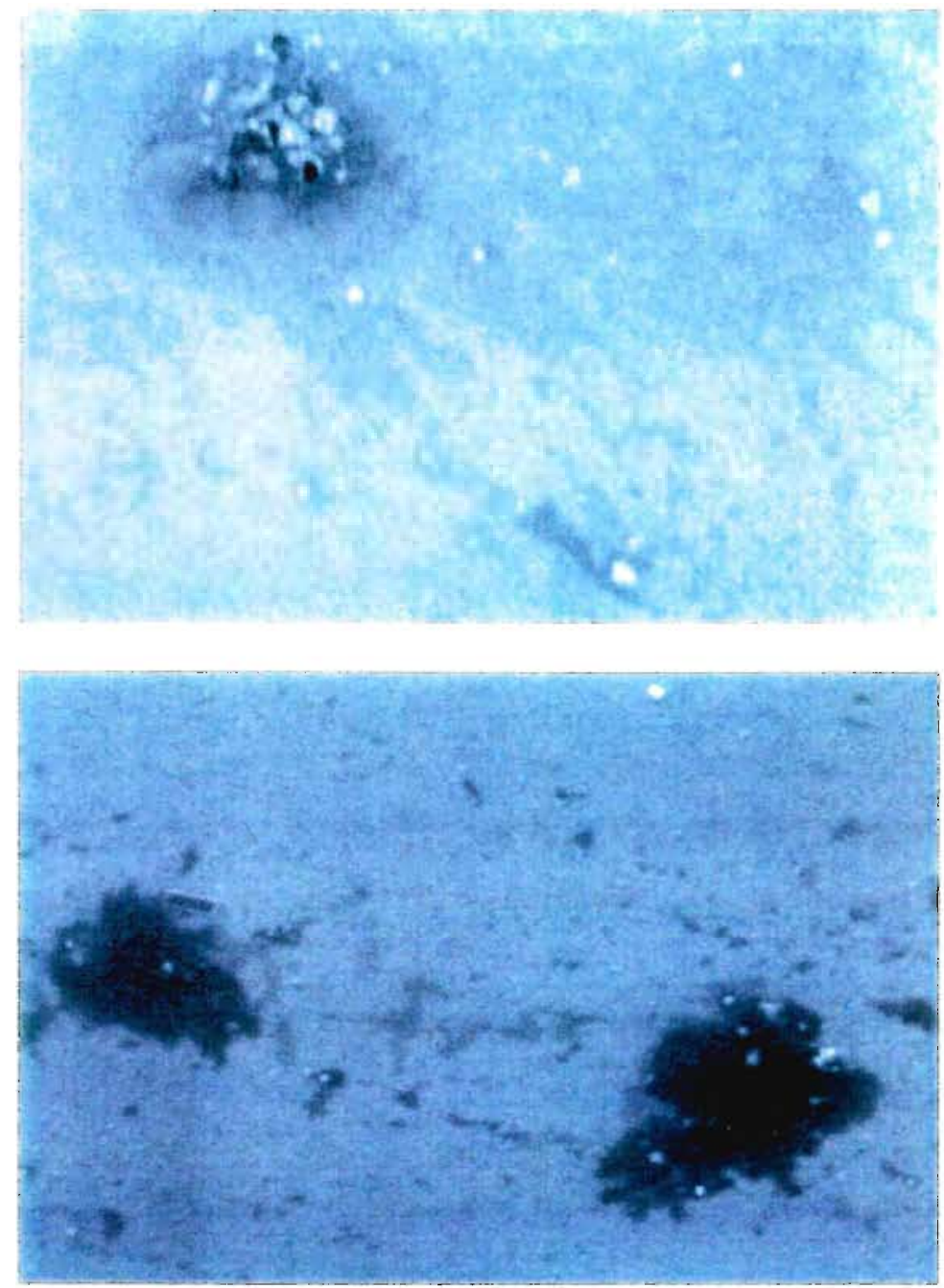

(c) $\mathrm{SnO}_{2}$ (F)

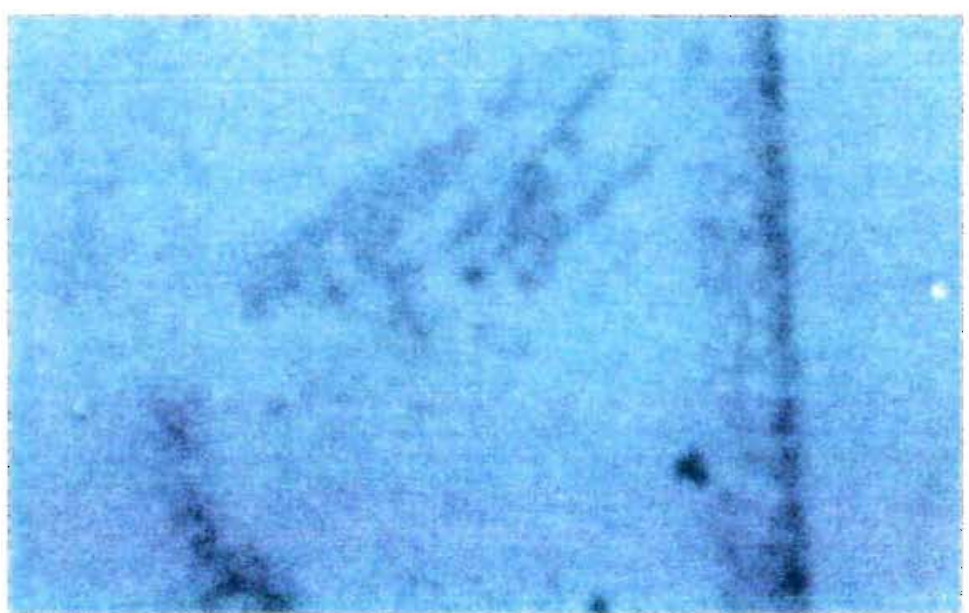

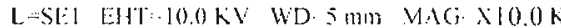

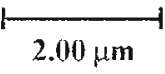

Figura 3.3. Imagens da superfície dos eletrodos transparentes de filme de $\mathrm{SnO}_{2}$, evidenciando algumas áreas que apresentaram defeitos na estrutura. 
SEM - Morfologia dos filmes transparentes de $\mathrm{SnO}_{2}$

(a) $\mathrm{SnO}_{2}(\mathrm{Cl})$

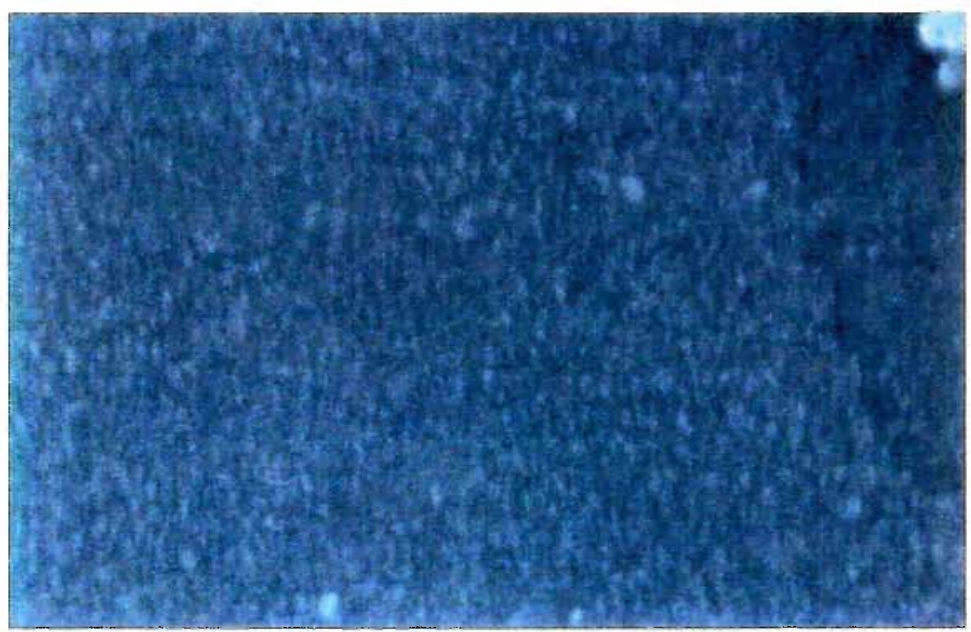

(b) $\mathrm{SnO}_{2}(\mathrm{Sb})$

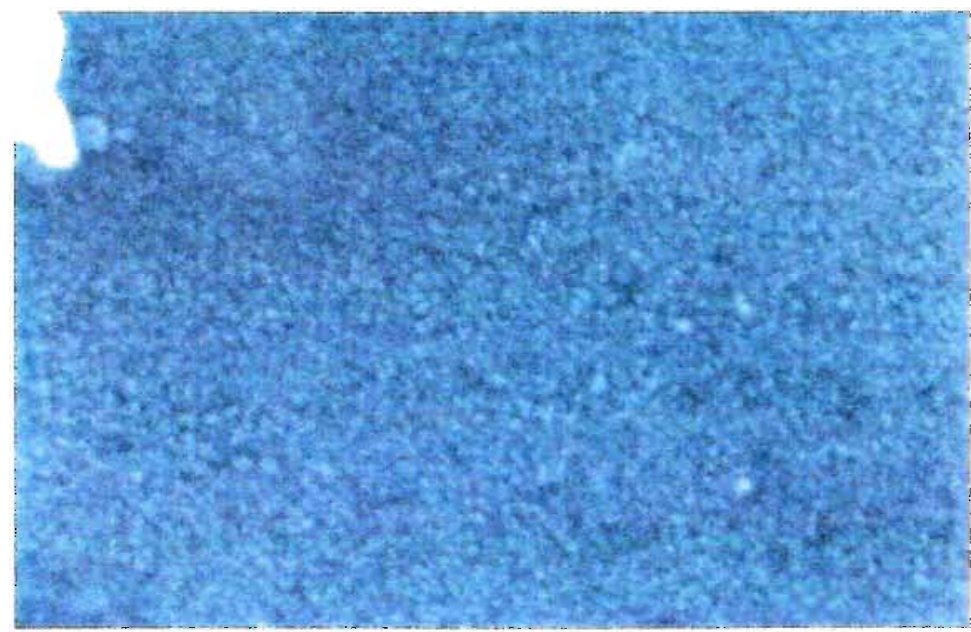

(c) $\mathrm{SnO}_{2}$ (F)

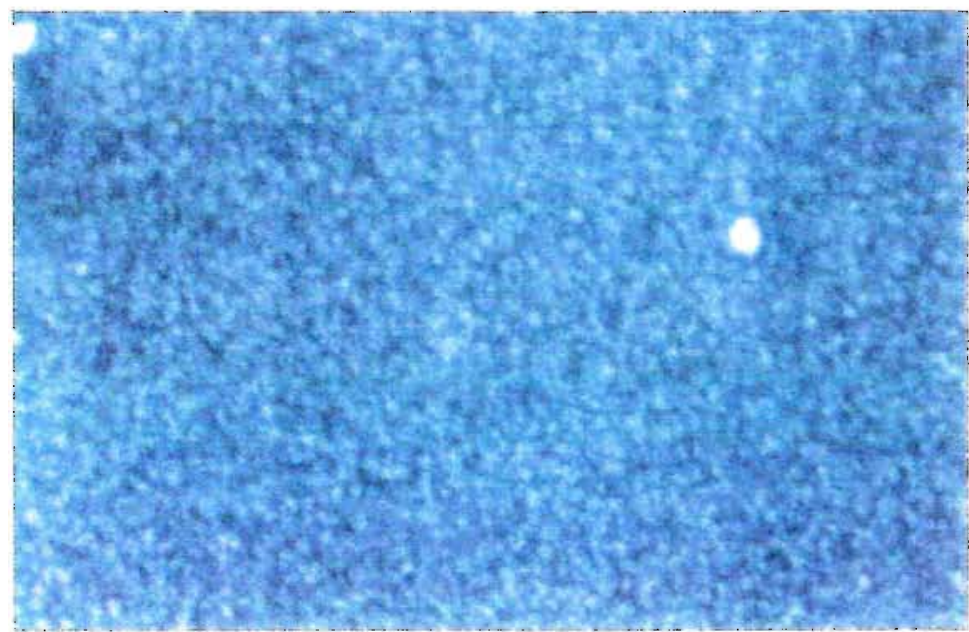

$=\mathrm{SE} 1 \quad \mathrm{EHT}=10.0 \mathrm{KV} \quad \mathrm{WD}=2 \mathrm{~mm} \quad \mathrm{MAG}=\mathrm{X} 40.0 \mathrm{~K}$

$1.00 \mu \mathrm{m}$

Figura 3.4. Superfície dos eletrodos transparentes de filme de $\mathrm{SnO}_{2}$. Imagens obtidas por SEM através de aumentos da ordem de 40000 vezes. 

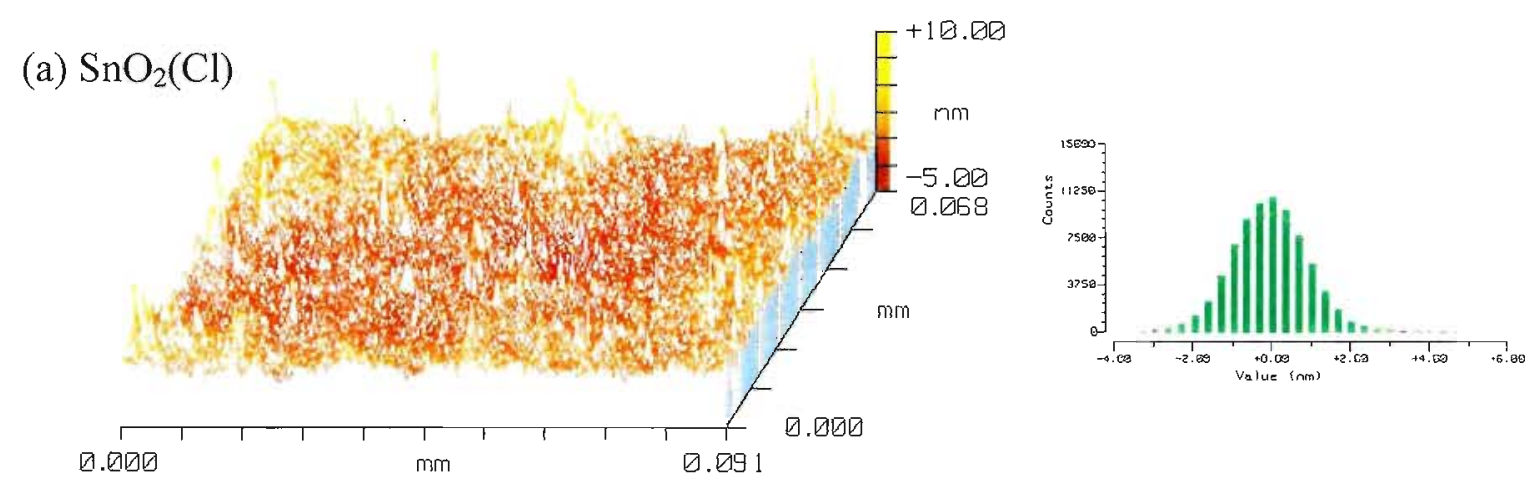

(b) $\mathrm{SnO}_{2}(\mathrm{Sb})$
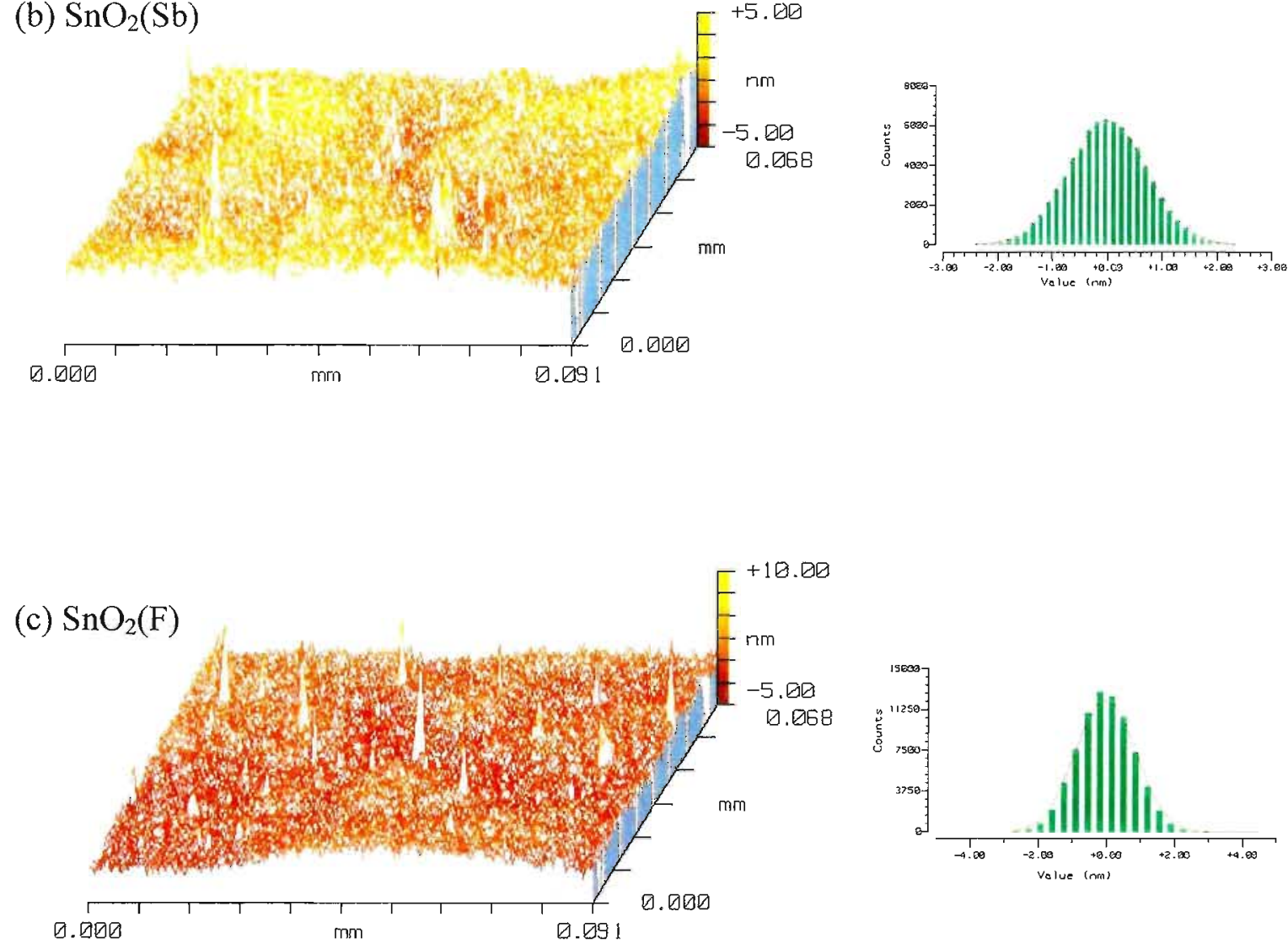

Figura 3.5. Imagens da superfície dos eletrodos transparentes de filme de $\mathrm{SnO}_{2}$ e dos correspondentes histogramas da distribuição de altura das partículas. 
Microscopia de forças atômicas. As análises realizadas para o substrato revelaram que a rugosidade média da superficie variava entre 5 e $7 \AA$. Nestas análises, identificaramse algumas áreas que apresentavam "faixas", como pode ser verificado na imagem de $4 \times 4$ $\mu \mathrm{m}^{2}$ representada na Fig. 3.6. Estas irregularidades na superficie do substrato podem estar relacionadas com as falhas observadas nos filmes através das análises por SEM.

Algumas das imagens de AFM obtidas para os três tipos de eletrodos em varreduras de $4 \times 4 \mu^{2}$ estão representadas nas Figuras 3.7 a 3.9. A comparação destas imagens de AFM com as obtidas por SEM em aumentos de 40000 vezes (ilustradas na Fig. 3.4) revela uma boa correspondência. No entanto, os valores da rugosidade média quadrática estimada através das imagens de AFM ( $\mathrm{rms} \sim 2$ a $3 \mathrm{~nm}$ ) foram superiores aos estimados por interferometria de luz ( $\mathrm{rms} \sim 1 \mathrm{~nm}$ ). Entre os resultados obtidos por ambas as técnicas, os valores estimados nas análises por AFM são mais representativos que os estimados por interferometria, considerando que as análises por AFM oferecem maior resolução vertical e lateral, já que a ponta de AFM é muito mais afilada e a interação entre a amostra e o instrumento de medida é muito maior.

Nas Figuras 3.10 a 3.13, estão representadas as imagens obtidas por AFM em varreduras de $1 \times 1 \mu \mathrm{m}^{2}$, para o substrato e os filmes de $\mathrm{SnO}_{2}$. Ao lado, estão representados os perfis correspondentes às seções transversais indicadas em cada imagem. A comparação entre estas imagens mostra que, de modo geral, os filmes dopados com Sb ou F (Fig. 3.12 e 3.13) apresentaram partículas maiores que o filme de $\mathrm{SnO}_{2}(\mathrm{Cl})$ (Fig. 3.11).

As diferenças para o tamanho das partículas podem ser melhor analisadas considerando as imagens apresentadas nas Figuras 3.14 a 3.17, que representam imagens e seções transversais obtidas em varreduras de $500 \times 500 \mathrm{~nm}^{2}$. Estas figuras incluem também alguns valores para o diâmetro de alguns grãos dos filmes e de irregularidades observadas na superfície do substrato.

De modo geral, a análise da topografia dos filmes de $\mathrm{SnO}_{2}$ depositados sobre sílica por AFM revelou que estes materiais eram constituidos por partículas de dimensões nanométricas. A comparação das imagens obtidas para as três amostras revela que o filme de $\mathrm{SnO}_{2}(\mathrm{Cl})$ era constituído por partículas menores, tanto em termos de altura (entre 3 e 7 $\mathrm{nm}$ ) como de diâmetro dos grãos (de 25 a $35 \mathrm{~nm}$ ). Para o filme de $\mathrm{SnO}_{2}(\mathrm{Sb}$ ), a altura média das partículas foi de $5 \mathrm{~nm}$, e o diâmetro um pouco maior, entre 30 e $60 \mathrm{~nm}$, embora existissem diversas partículas com dimensões maiores. No filme de $\mathrm{SnO}_{2}(\mathrm{~F})$, a maioria das 
partículas apresentou diâmetro entre 30 e $50 \mathrm{~nm}$, e maior variação em termos de altura, que variou entre 3 e $10 \mathrm{~nm}$.

Para o eletrodo de $\mathrm{SnO}_{2}(\mathrm{Sb})$ realizaram-se também algumas análises por STM. Tais análises serão apresentadas em detalhes apenas no Capítulo 5. Para comparação, a Fig. 3.18 apresenta imagens em três dimensões obtidas por AFM e por STM (em ar) em varreduras de $500 \times 500 \mathrm{~nm}^{2}$. Aparentemente, as partículas constituintes do filme apresentaram menor dimensão na imagem obtida por STM. Como a ponta da AFM é muito menos afilada que a de STM, entre ambas as técnicas, a dimensão das partículas em geral parece maior na AFM.

Microscopia eletrônica de transmissão. As análises por TEM foram efetuadas apenas para o eletrodo de filme de $\mathrm{SnO}_{2}(\mathrm{Cl})$. A Figura 3.19 representa imagens de seções transversais do filme, obtidas respectivamente em campos claro (3.19a) e escuro (3.19b). $\mathrm{Na}$ imagem obtida em campo claro, ou seja, a partir dos elétrons transmitidos, o constraste apresentado pode ser devido à difração, ou ainda a diferenças na densidade e na espessura do filme. Na imagem obtida em campo escuro, i.e., a partir dos elétrons espalhados, o contraste resultou de cristais com diferentes orientações cristalográficas, onde as regiões mais claras correspondem aos cristais orientados sob o ângulo de Bragg. As análises revelaram ainda que o filme apresentava estrutura colunar e, na região analisada, a espessura do filme variava de aproximadamente 35 a $45 \mathrm{~nm}$. A Fig. 3.20 ilustra algumas das imagens de alta resolução obtidas (High Resolution TEM, HRTEM), nas quais podem ser identificadas regiões com diferentes orientações e ainda a presença de defeitos cristalográficos.

O padrão de difração obtido através desta análise está representado na Figura 3.21. A partir dos diâmetros dos pontos, identificaram-se as distâncias interplanares 3,38; 2,30; 1,78 e $1,42 \AA$, correspondentes aos planos (110); (111); (211) e (301), respectivamente. 
AFM - Morfologia do substrato e do fillme de $\mathrm{SnO}_{2}(\mathrm{Cl})$

Figura 3.6. Substrato (sílica)

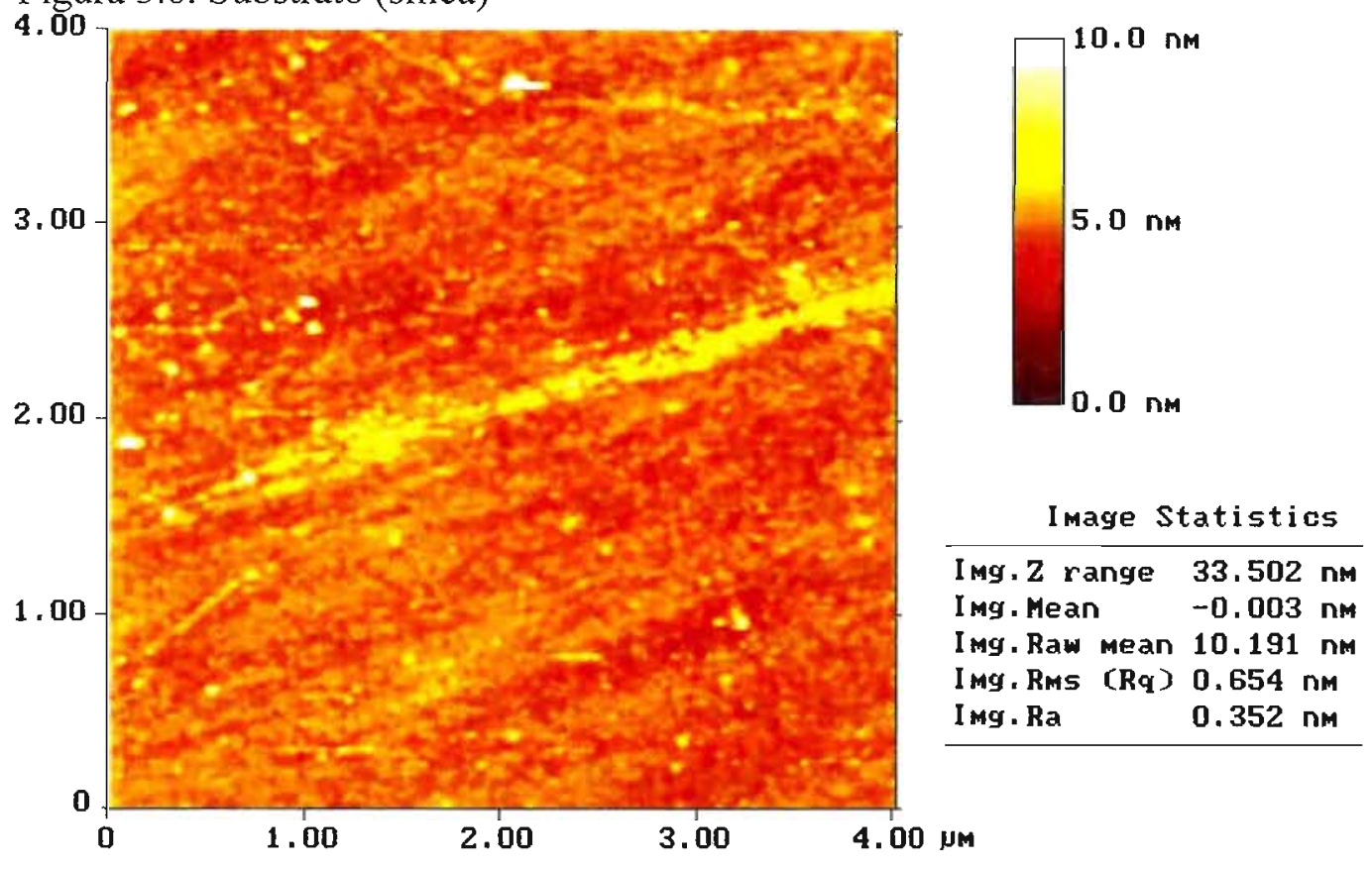

Figura 3.7. $\mathrm{SnO}_{2}(\mathrm{Cl})$

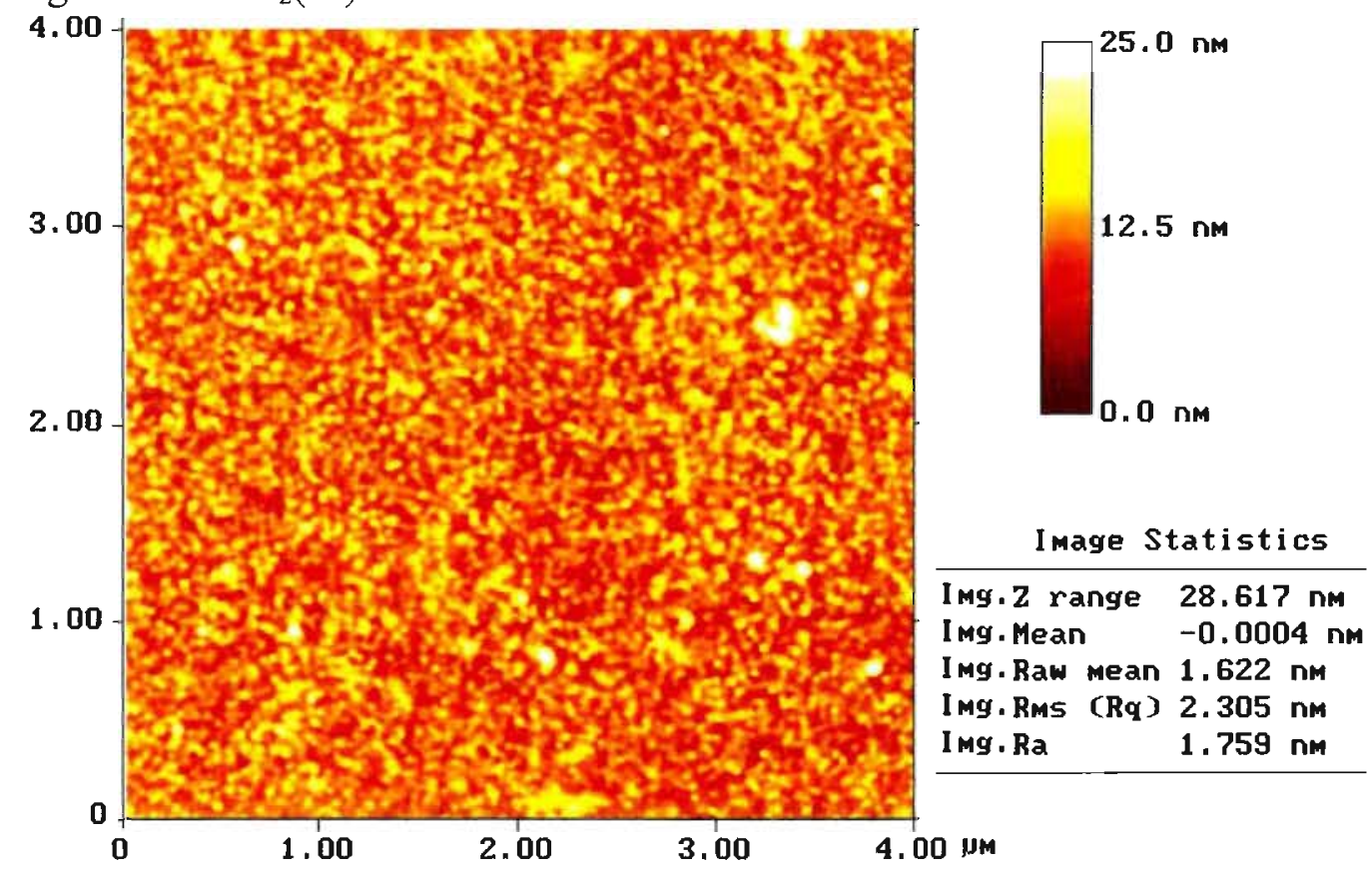

Figuras 3.6 e 3.7. Imagens de AFM e análise da rugosidade da superfície do substrato (sílica) e do filme de $\mathrm{SnO}_{2}(\mathrm{Cl})$, respectivamente. 
AFM - Morfologia do eletrodos transparentes de filme de $\mathrm{SnO}_{2}(\mathrm{Sb})$ e $\mathrm{SnO}_{2}(\mathrm{~F})$

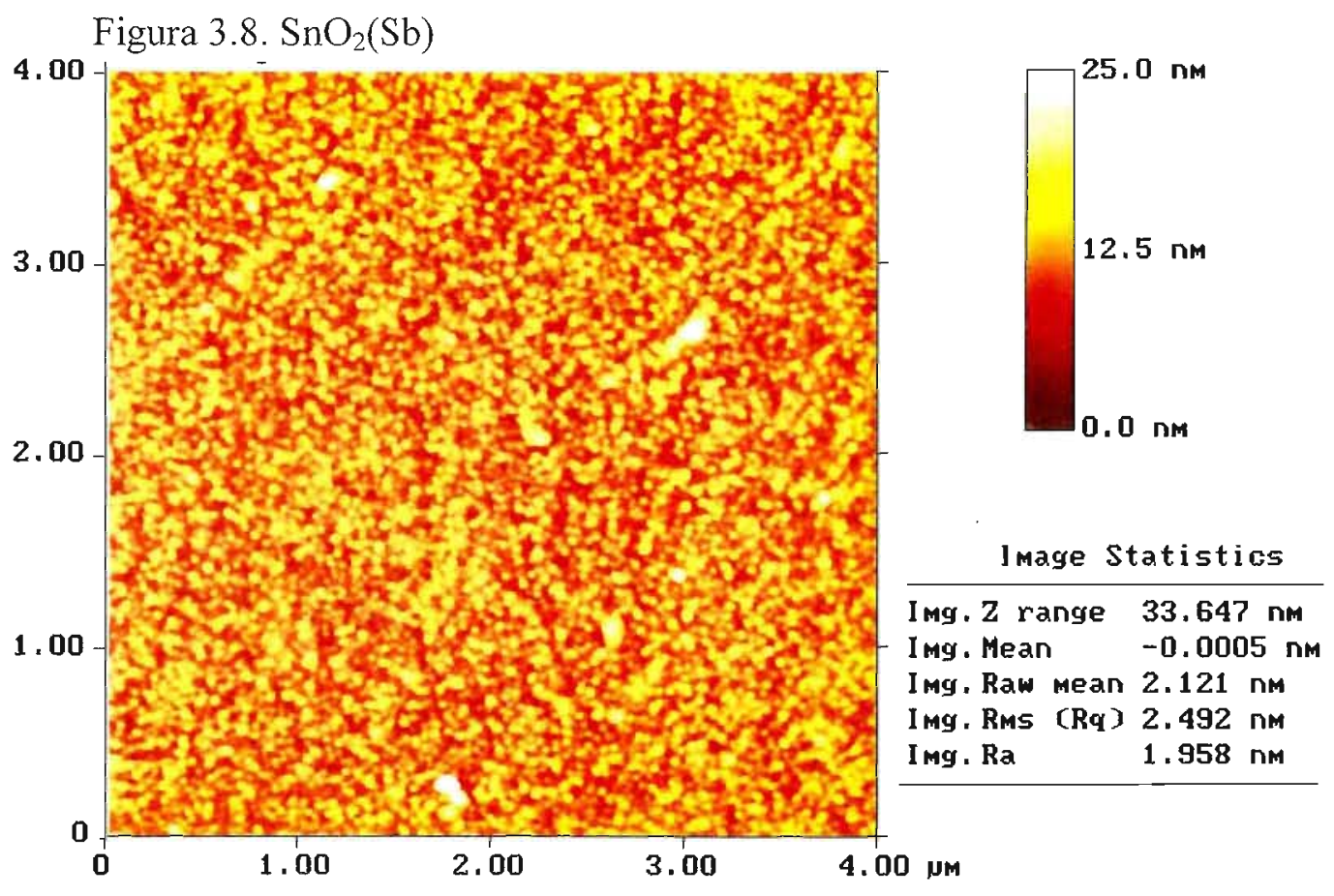

Figura 3.9. $\mathrm{SnO}_{2}(\mathrm{~F})$

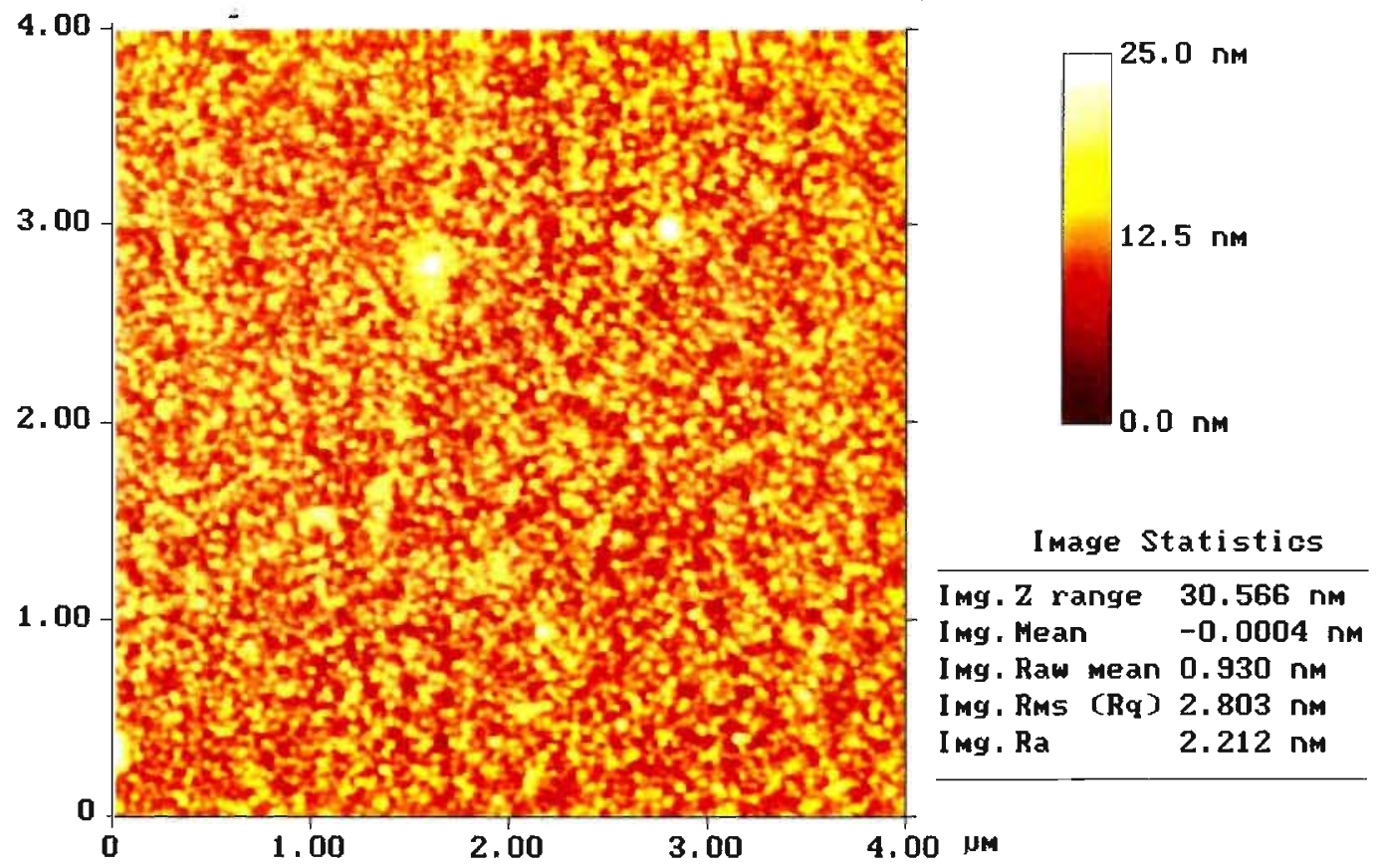

Figuras 3.8 e 3.9. Imagens de AFM e análise da rugosidade da superfície dos eletrodos de filme de $\mathrm{SnO}_{2}(\mathrm{Sb})$ e $\mathrm{SnO}_{2}(\mathrm{~F})$, respectivamente. 
Imagens de AFM para o substrato e o eletrodo transparente de filme de $\mathrm{SnO}_{2}(\mathrm{Cl})$

Figura 3.10. Substrato

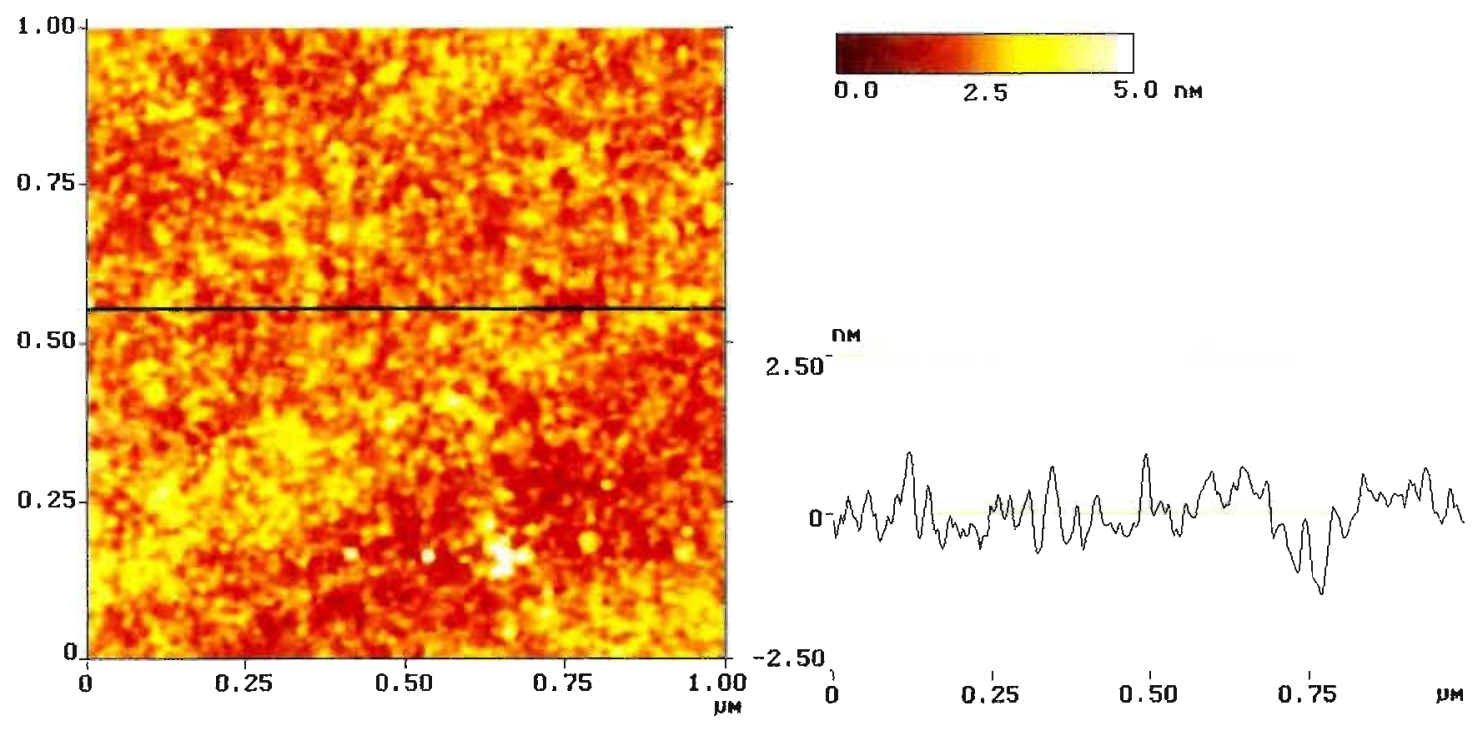

Figura 3.11. $\mathrm{SnO}_{2}(\mathrm{Cl})$

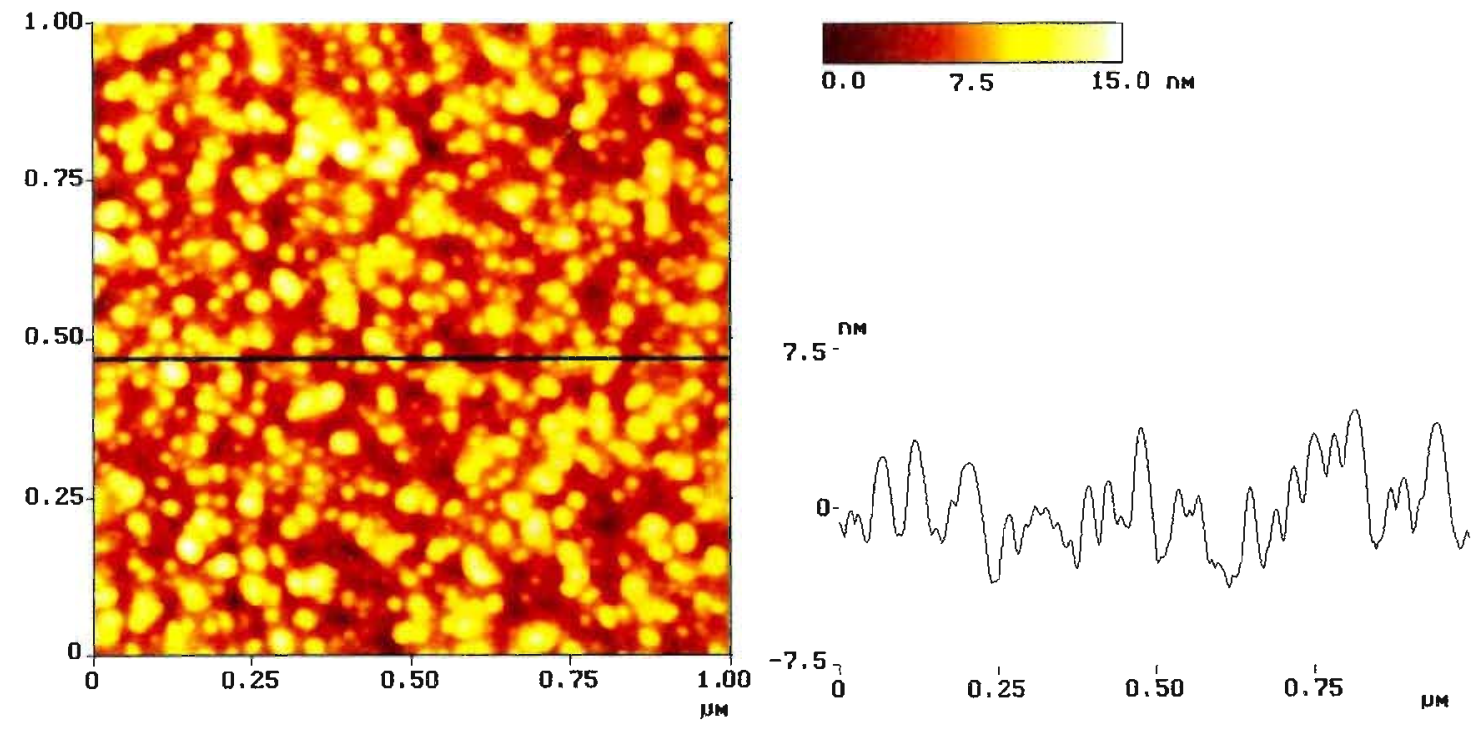

Figuras 3.10 e 3.11. Superfície do substrato e do filme de $\mathrm{SnO}_{2}(\mathrm{Cl})$ : imagens da topografia e perfis correspondentes às seções transversais indicadas nas imagens. 
Imagens de AFM para os eletrodos transparentes de filme de $\mathrm{SnO}_{2}(\mathrm{Sb})$ e $\mathrm{SnO}_{2}(\mathrm{~F})$

Figura 3.12. $\mathrm{SnO}_{2}(\mathrm{Sb})$
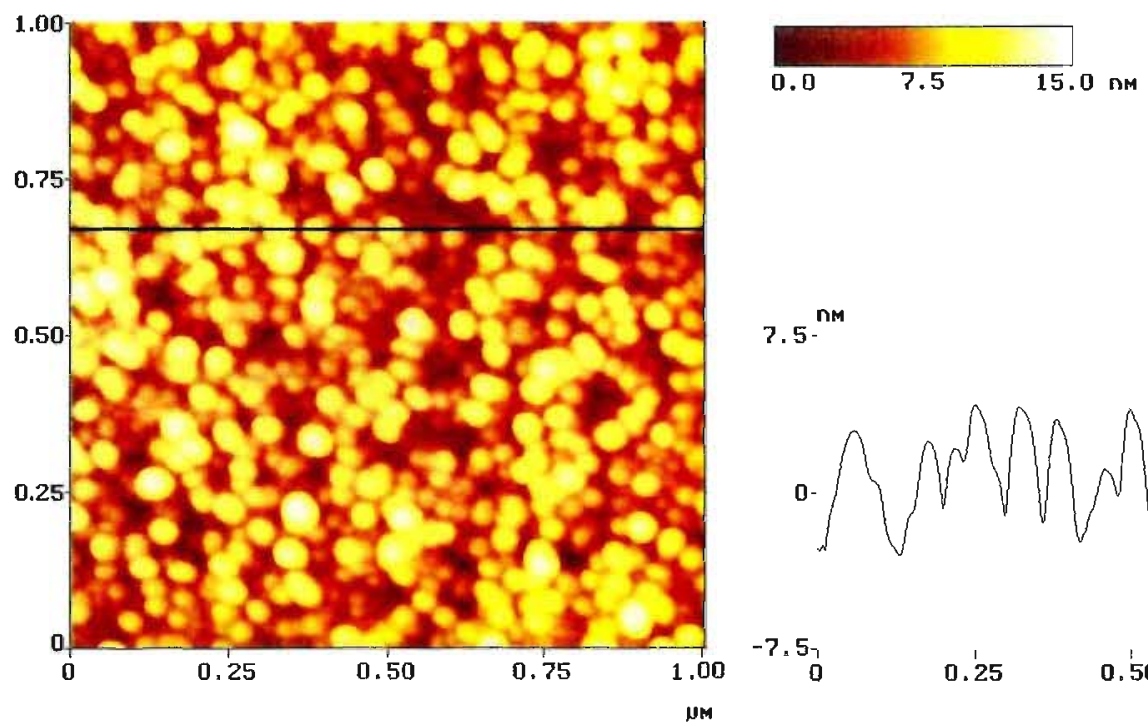

$$
7.5^{\mathrm{nm}}
$$

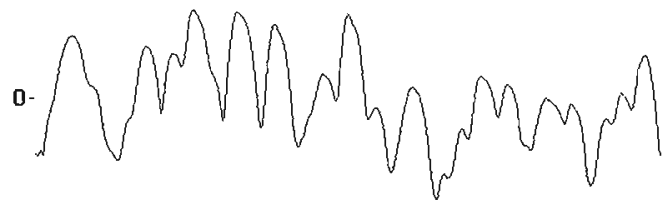

$\begin{array}{rrrrr}-7.57 & 0.1 & 0.1 & 1 . \\ 0 & 0.25 & 0.50 & 0.75 & 1.00\end{array}$

Figura 3.13. $\mathrm{SnO}_{2}(\mathrm{~F})$

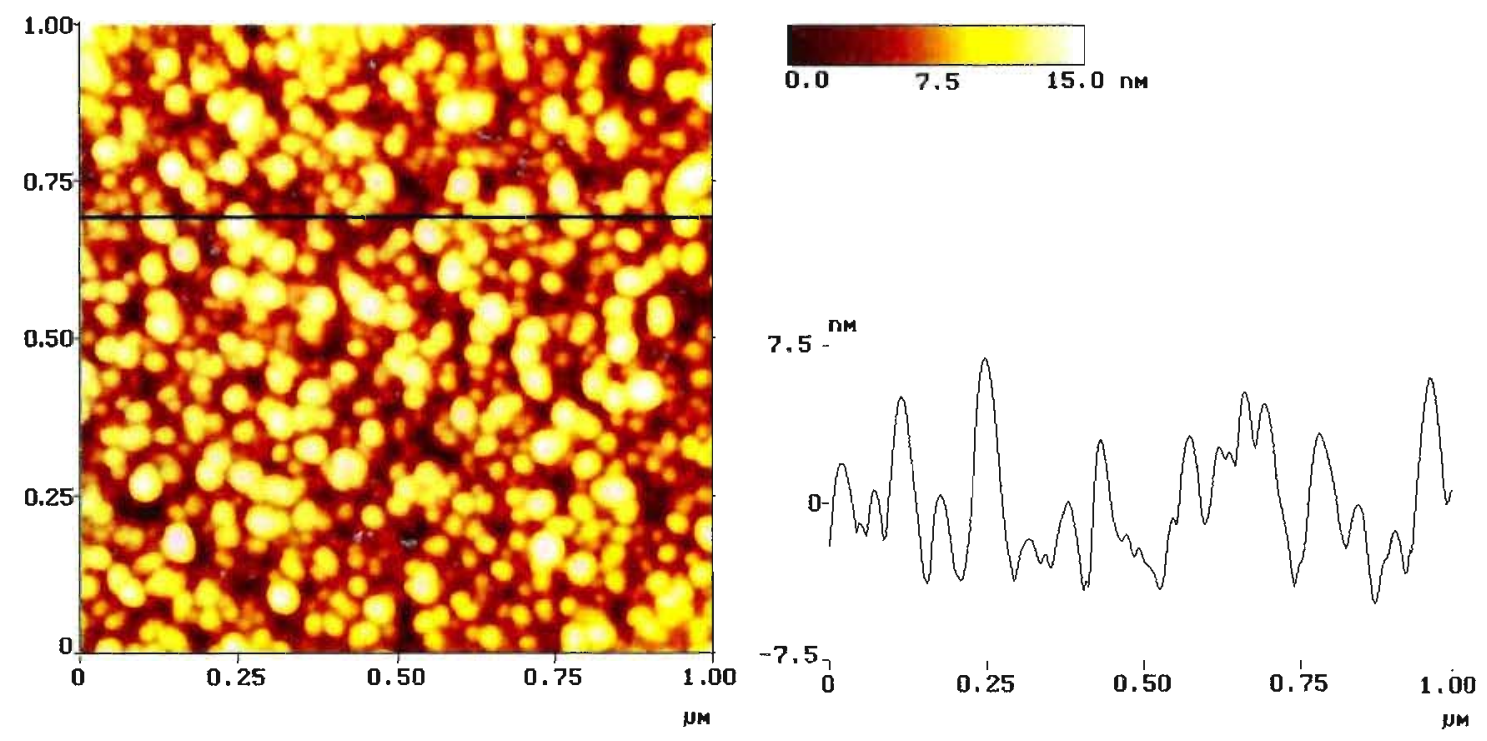

Figuras 3.12 e 3.13. Superfície dos filmes de $\mathrm{SnO}_{2}(\mathrm{Sb})$ e de $\mathrm{SnO}_{2}(\mathrm{~F})$ : imagens da topografia e perfis correspondentes às seções transversais indicadas nas imagens. 
Imagens de AFM - detalhes da morfologia do substrato e do filme de $\mathrm{SnO}_{2}(\mathrm{Cl})$

Figura 3.14. Substrato

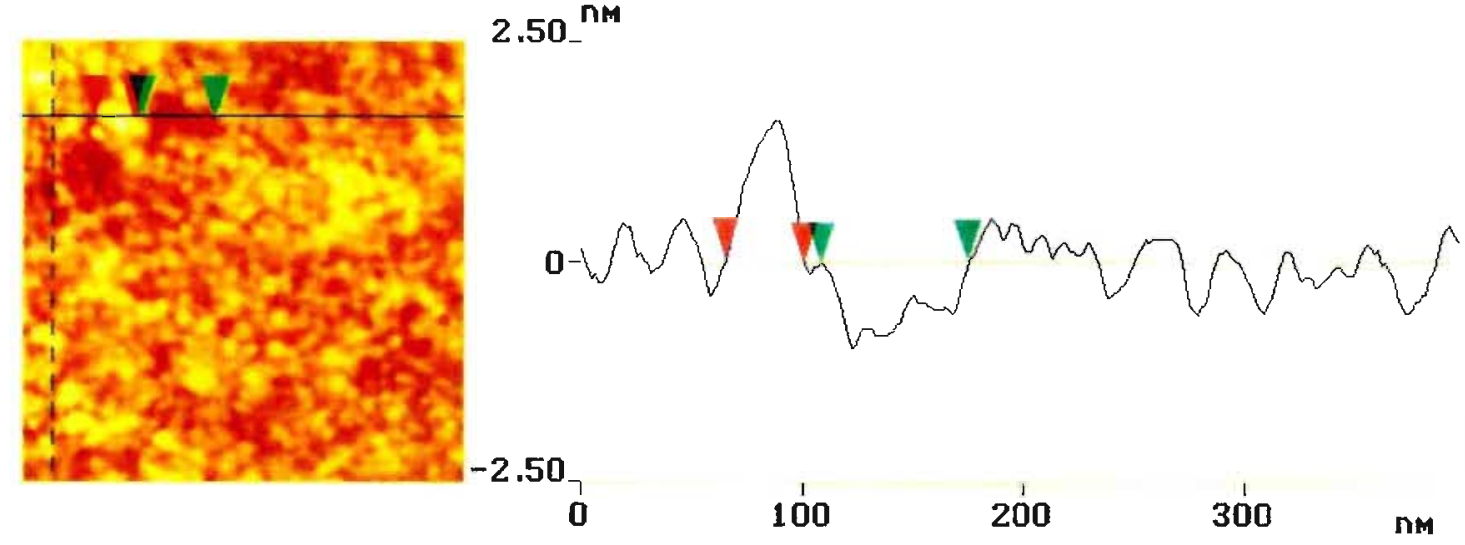

Horiz distance (L) $35.938 \mathrm{~nm}$

Horiz distance $67.188 \mathrm{~nm}$

Figura 3.15. $\mathrm{SnO}_{2}(\mathrm{Cl})$

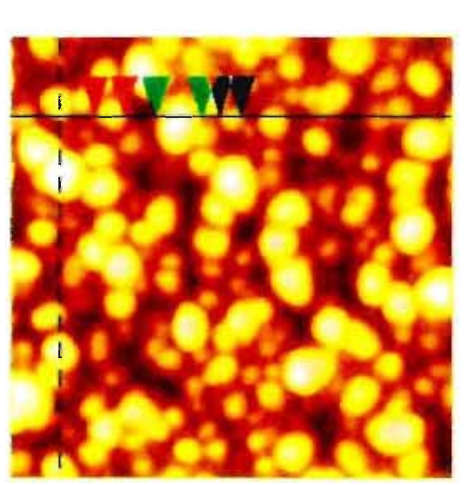

$$
7.5_{-}^{\mathrm{nm}}
$$

$-7.5$

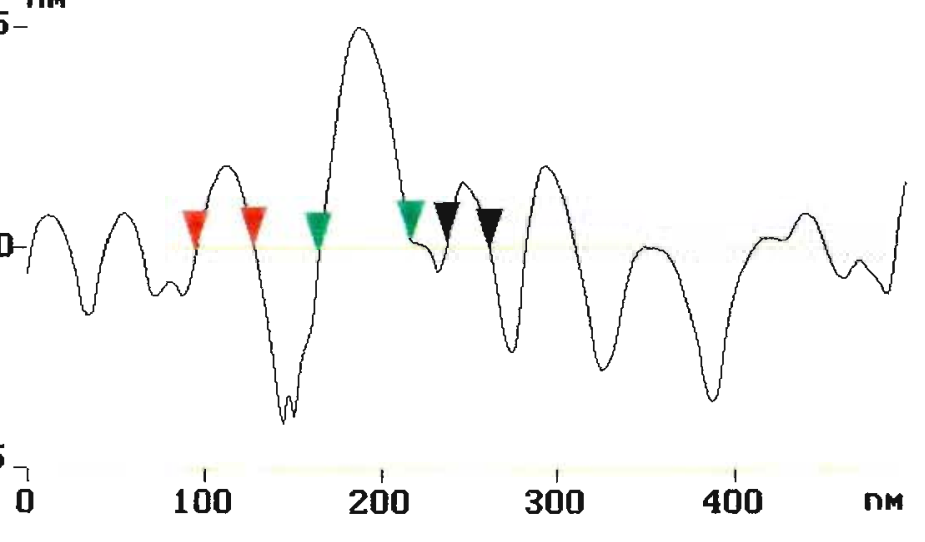

Horiz distance ( $) 33.203 \mathrm{~nm}$

Horiz distance $52.734 \mathrm{~nm}$

Horiz distance $25.391 \mathrm{~nm}$

Figuras 3.14 e 3.15. Superfície do substrato e do filme de $\mathrm{SnO}_{2}(\mathrm{Cl})$ : imagens da topografia e perfis correspondentes às seções transversais indicadas nas imagens. 
Imagens de AFM - detalhes da morfologia dos filmes de $\mathrm{SnO}_{2}(\mathrm{Sb})$ e $\mathrm{SnO}_{2}(\mathrm{~F})$

Figura 3.16. $\mathrm{SnO}_{2}(\mathrm{Sb})$

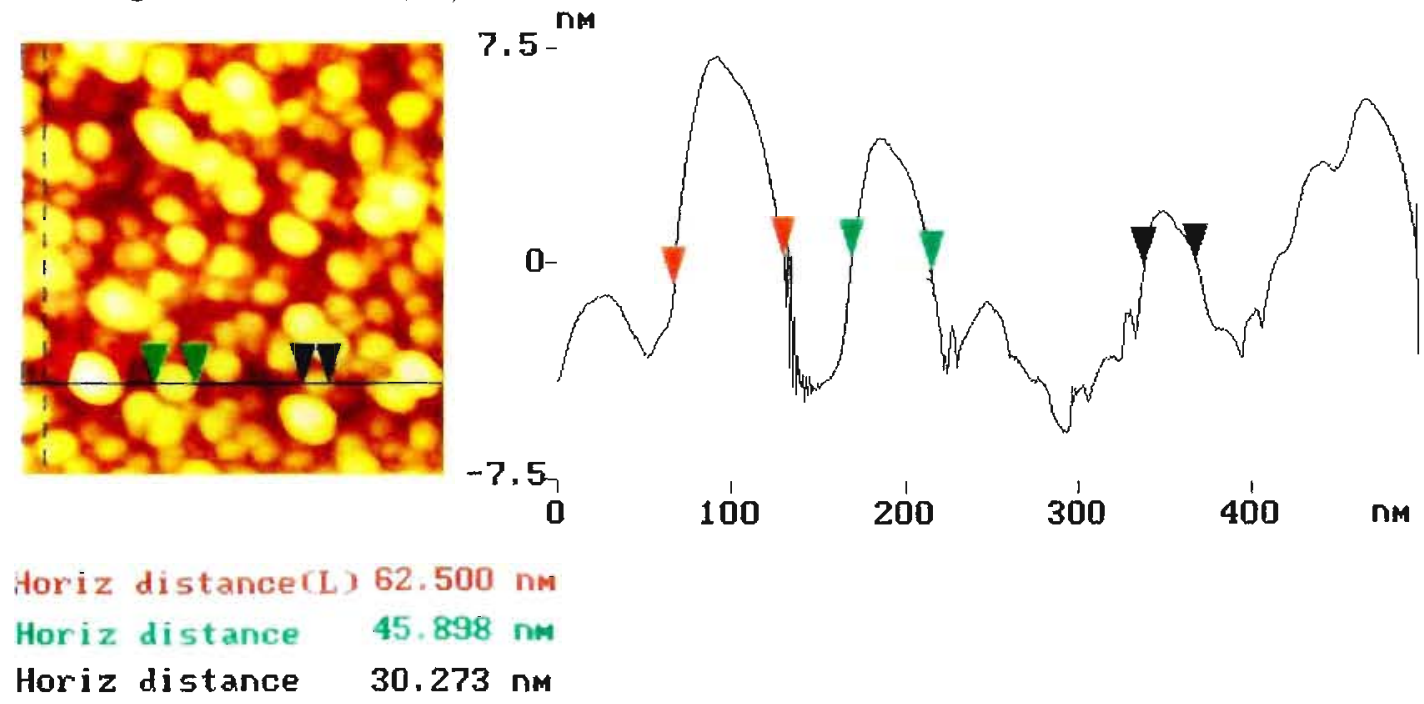

Figura 3.17. $\mathrm{SnO}_{2}(\mathrm{~F})$

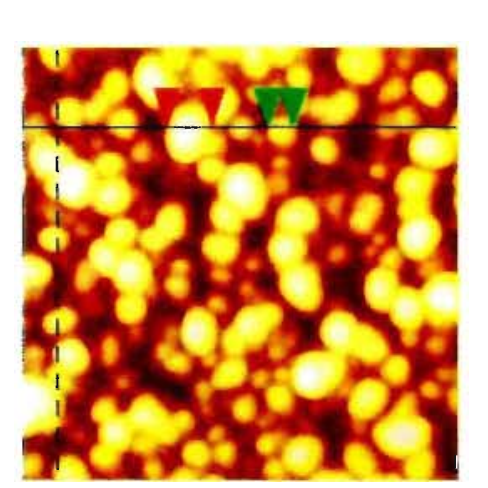

$$
7.5^{\mathrm{nm}}
$$

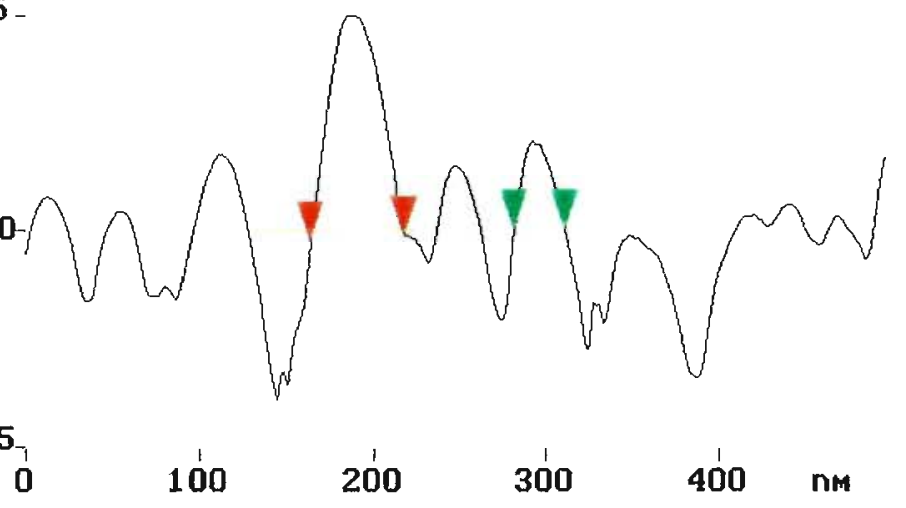

Horiz distance (L) $52.734 \mathrm{~nm}$

Horiz distance $\quad 29.297 \mathrm{~nm}$

Figuras 3.16 e 3.17. Superfície dos filmes de $\mathrm{SnO}_{2}(\mathrm{Sb})$ e de $\mathrm{SnO}_{2}(\mathrm{~F})$ : imagens da topografia e perfis correspondentes às seções transversais indicadas nas imagens. 
Imagens de AFM e STM da superfície do eletrodo de $\mathrm{SnO}_{2}(\mathrm{Sb})$

(a) AFM

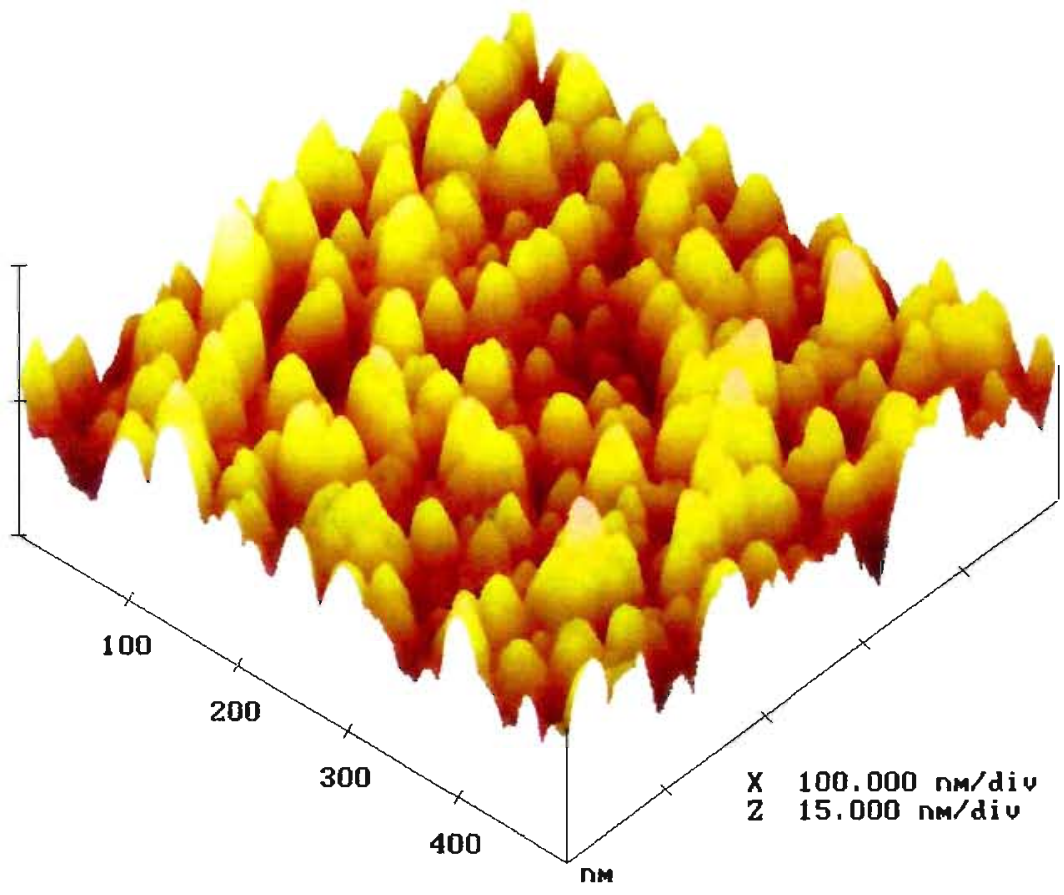

(b) STM

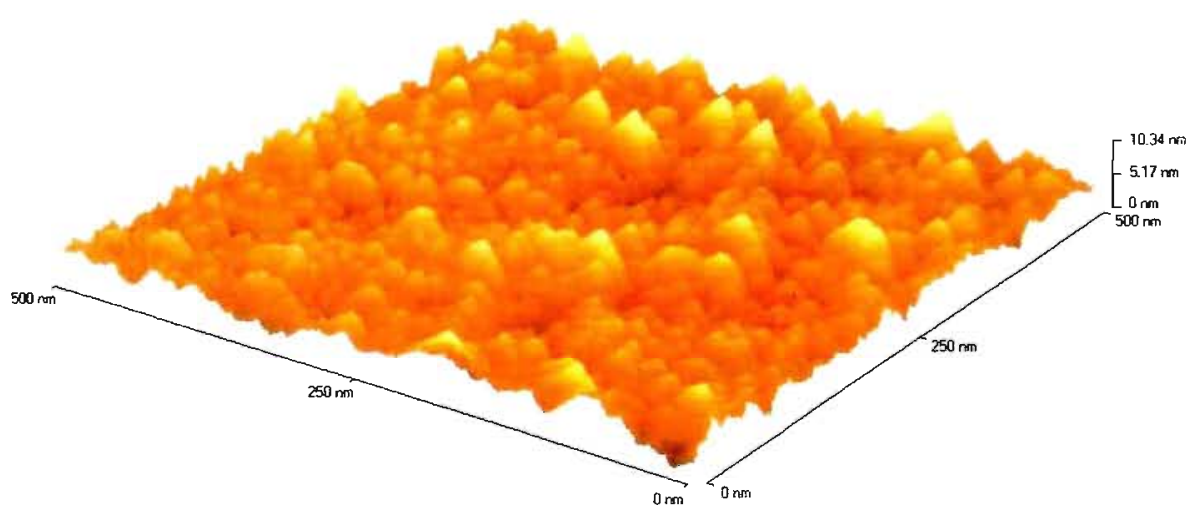

Figura 3.18. Imagens de AFM (a) e STM (b) da superfície do eletrodo transparente de filme de $\mathrm{SnO}_{2}(\mathrm{Sb})$. 
Microscopia Eletrônica de Transmissão - eletrodo transparente de $\mathrm{SnO}_{2}(\mathrm{Cl})$
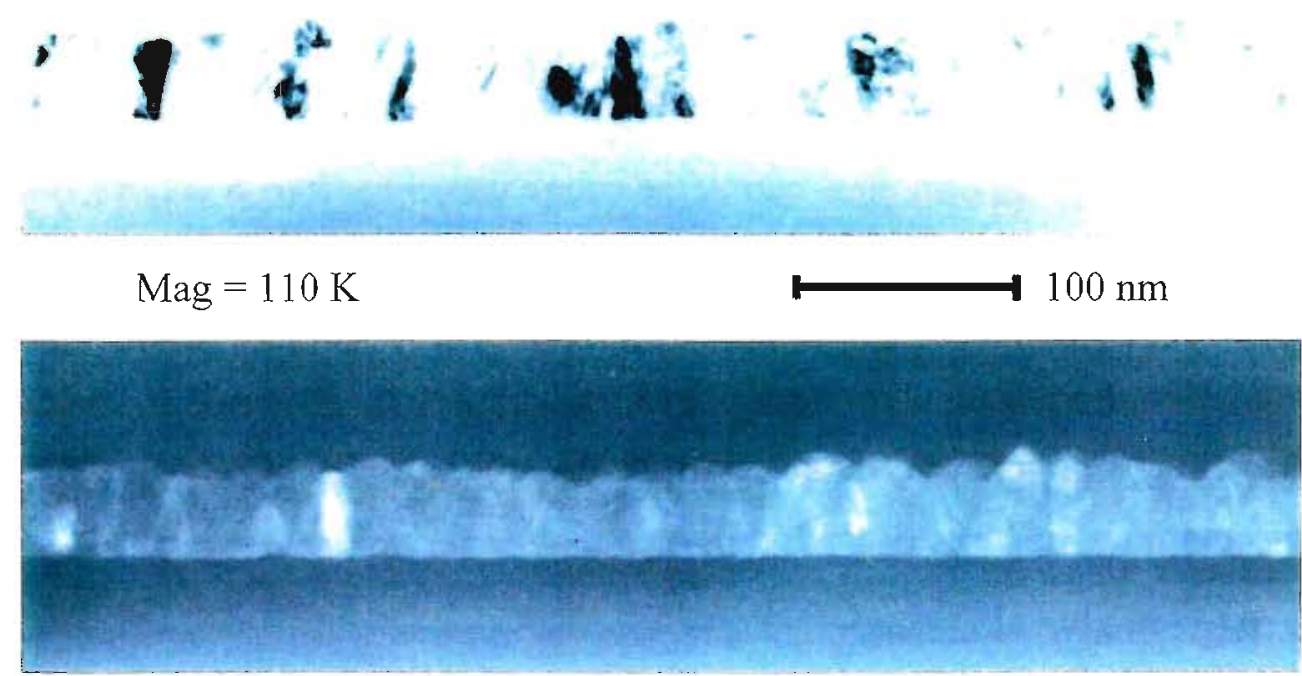

Figura 3.19. Imagens da seção transversal do filme de $\mathrm{SnO}_{2}(\mathrm{Cl})$ obtidas por TEM em campo claro (a) e em campo escuro (b).
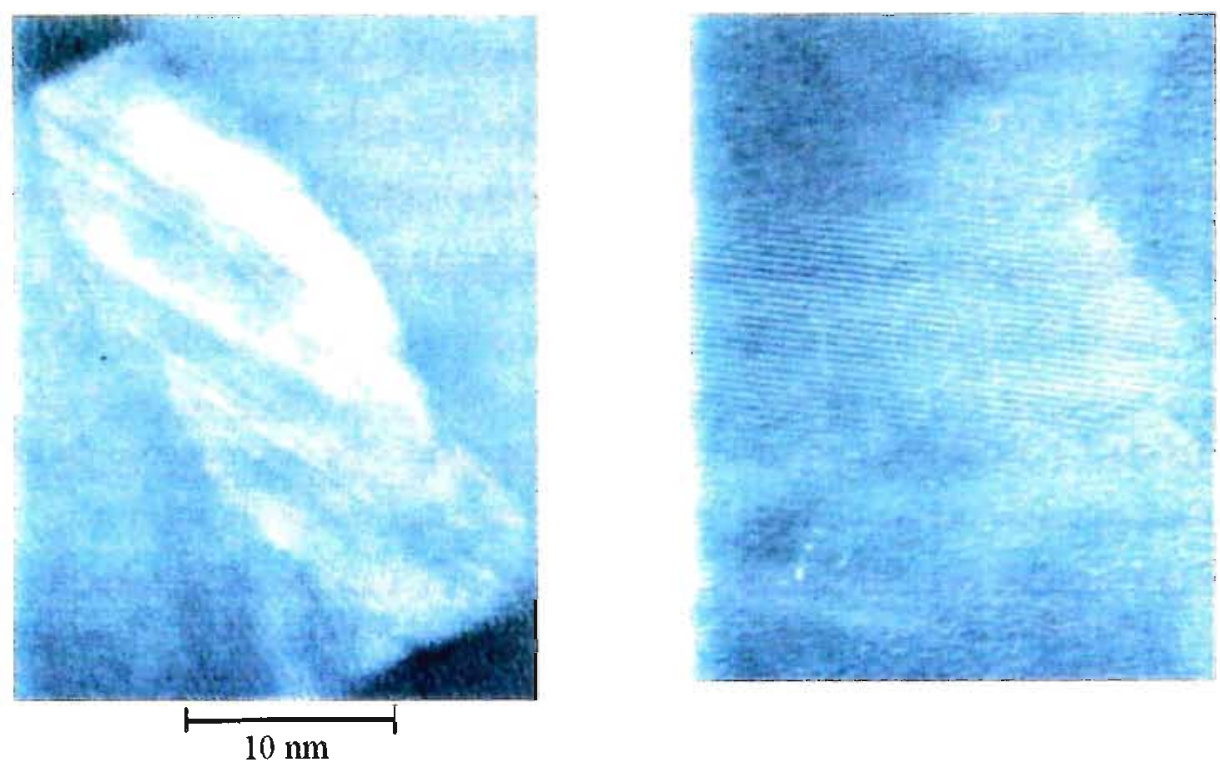

Figura 3.20. Imagens do filme de $\mathrm{SnO}_{\mathrm{s}}(\mathrm{Cl})$ obtidas em alta resolução (HRTEM). 
Difração de Raios- $X$. Os difratogramas obtidos para os três filmes de $\mathrm{SnO}_{2}$ depositado sobre sílica estão representados na Figura 3.22, que inclui ainda os marcadores correspondentes aos picos característicos para a cassiterita [177]. De um modo geral, para os três tipos de eletrodo, os picos de difração coincidiram razoavelmente bem com os picos mais intensos da cassiterita, embora as intensidades relativas fossem distintas.

O pico mais intenso para as três amostras coincidiu com o característico para a cassiterita: localizou-se em $2 \theta=26,61^{\circ}$, correspondendo então à orientação cristalina (110). Para a cassiterita, o segundo pico mais intenso é o correspondente à direção (101) $\left(2 \theta=33,89^{\circ}\right)$. No entanto, para os filmes depositados de $\mathrm{SnO}_{2}(\mathrm{Cl})$ e de $\mathrm{SnO}_{2}(\mathrm{Sb})$, a segunda direção preferencial de crescimento foi a $(211)\left(2 \theta=51,78^{\circ}\right)$, e, para o filme dopado com flúor, o $(200)\left(2 \theta=37,95^{\circ}\right)$.

Para filmes depositados, as direções preferenciais de crescimento podem ser distintas, dependendo do método de deposição e do substrato empregado. De modo geral, a direção preferencial de crescimento para filmes de óxido de estanho é a (110) [76]. No entanto, para os filmes de $\mathrm{SnO}_{2}$ dopados com flúor, frequentemente relata-se o crescimento preferencial na direção $(200)[70,79,87]$.

As análises de difração de raios-X permitiram ainda estimar o tamanho de algumas partículas constituintes do filme, através da equação (3.1). Os cálculos foram realizados apenas para os dois primeiros picos de difração do óxido, correspondentes às direções (110) e (101). Os valores da largura do pico a meia altura $(\beta)$ e a localização exata do pico de difração empregados nos cálculos estão ilustrados na Tabela 3.1 .

Tabela 3.1. Parâmetros utilizados e resultados obtidos na determinação do tamanho das partículas constituintes dos filmes (D) através da Equação de Scherrer.

\begin{tabular}{|c|c|c|c|c|c|c|c|c|c|}
\hline & \multicolumn{3}{|c|}{$\mathrm{SnO}_{2}(\mathrm{Cl})$} & \multicolumn{3}{|c|}{$\mathrm{SnO}_{2}(\mathrm{Sb})$} & \multicolumn{3}{|c|}{$\mathrm{SnO}_{2}(\mathrm{~F})$} \\
\hline & $2 \theta$ & $\beta$ & $\mathrm{D} / \AA$ & $2 \theta$ & $\beta$ & $\mathrm{D} / \AA$ & $2 \theta$ & $\beta$ & $\mathrm{D} / \AA$ \\
\hline [110] & 26,62 & 1,95 & 42 & 26,66 & 2,09 & 39 & 26,69 & 1,60 & 51 \\
\hline [101] & 34,26 & 1,33 & 63 & 34,39 & 1,79 & 76 & 34,15 & 0,73 & 114 \\
\hline
\end{tabular}


De acordo com os valores apresentados na Tabela 3.1, o filme dopado com $\mathrm{Cl}$ (dopagem não intencional) apresentou cristalitos menores que os filmes dopados. Para a direção (110), todos os três tipos de filmes apresentaram valores semelhantes, entre 4 e 5 nm. No entanto, para a direção (101), os filmes dopados com F e Sb apresentaram grãos maiores, principalmente para o $\mathrm{SnO}_{2}(\mathrm{~F})$.

Embora não tenha sido possível estimar a altura dos grãos para as outras direções, a comparação destes resultados com os obtidos por AFM revelou uma interessante coincidência. As imagens de AFM evidenciaram que os filmes eram constituídos por partículas com altura similar a estes valores, além de evidenciarem também que os grãos dos filmes dopados com $\mathrm{F}$ e Sb eram maiores que os do filme de $\mathrm{SnO}_{2}(\mathrm{Cl}$ ) (Figuras 3.11 a 3.13 e 3.15 a 3.17 )

Em geral, nos trabalhos relatados na Literatura, o tamanho das partículas constituintes de filmes de $\mathrm{SnO}_{2}$ depositados através de distintos métodos foi determinado através de técnicas de difração de raios-X (através da equação de Scherrer) $[85,87]$ e de técnicas de microscopia (SEM e TEM) [76, 88, 96]. Frequentemente observaram-se partículas de 20 a $40 \mathrm{~nm}[87,96]$. No entanto, valores inferiores a $7 \mathrm{~nm}$ ou superiores a $100 \mathrm{~nm}$ também foram relatados $[75,85]$.

Embora os valores obtidos possam ser considerados baixos se comparados à maioria dos valores relatados na Literatura, são bastante coerentes considerando-se o método de deposição empregado. Diversas precauções foram cuidadosamente observadas durante a preparação do material, com o objetivo de obter filmes de $\mathrm{SnO}_{2}$ de baixa rugosidade. Estas precauções possivelmente diminuiram a velocidade de nucleação e crescimento das partículas durante o processo de deposição. Consequentemente, embora os filmes obtidos fossem pouco espessos, constituiam-se de partículas pequenas e regulares, resultando em superficies altamente uniformes e pouco rugosas. 


\section{Estrutura Cristalina}

\begin{tabular}{cc}
\hline $\mathrm{d} / \AA$ & $\mathrm{hkl}$ \\
\hline 3,38 & 110 \\
2,30 & 111 \\
1,78 & 211 \\
1,42 & 301 \\
\hline
\end{tabular}

Figuras 3.21. Padrão de difração obtido por TEM para o filme de $\mathrm{SnO}_{2}(\mathrm{Cl})$.

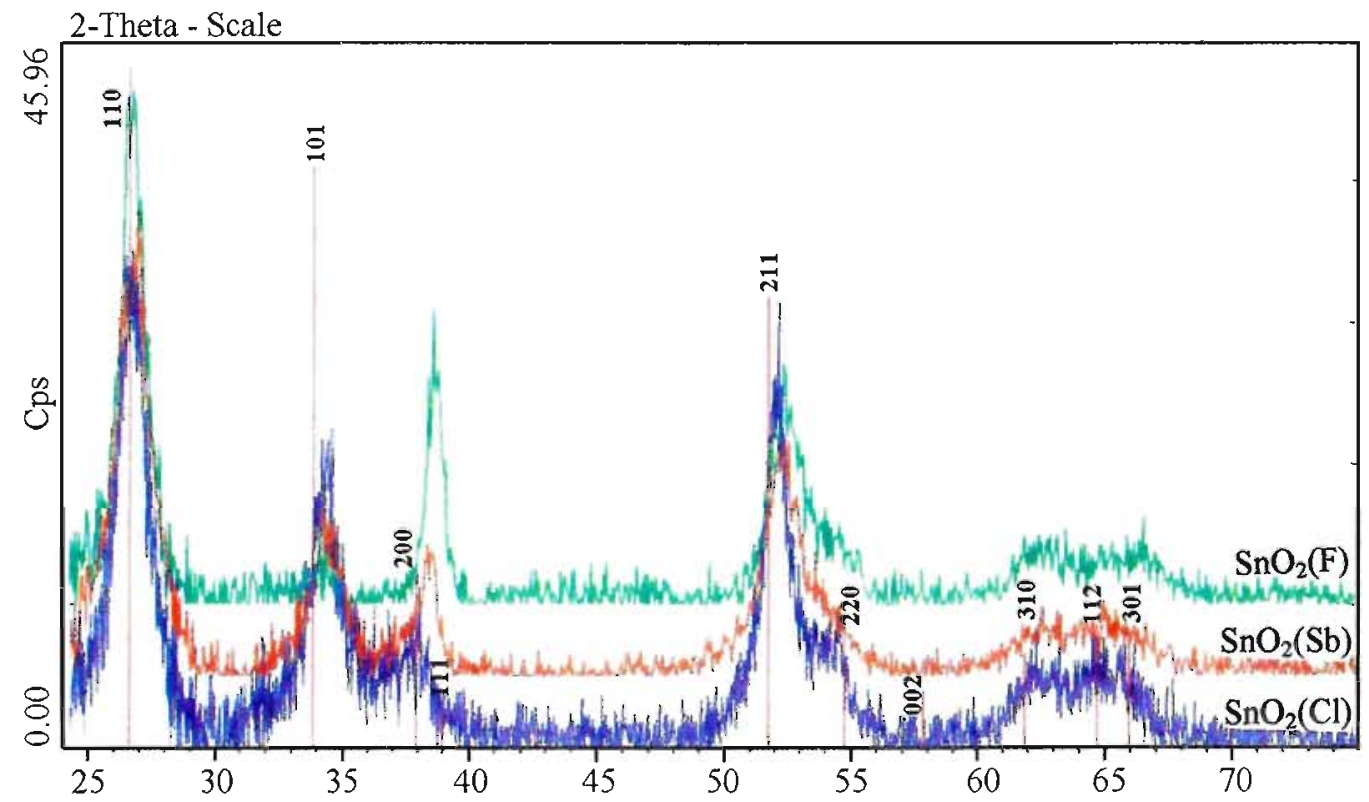

Figuras 3.22. Espectros de difração de raios-X para os filmes transparentes de $\mathrm{SnO}_{2}$. 


\subsubsection{Composição química dos filmes transparentes de $\mathrm{SnO}_{2}$}

Os resultados das análises por XPS realizados para os filmes depositados em sílica estão representados nas Fig. 3.23 a 3.25 . Na Fig. 3.23, estão representadas as diversas regiões analisadas para a superficie (os dois primeiros espectros) e em profundidade, após diversos ciclos de bombardeio com $\mathrm{Ar}^{+}$.

Inicialmente, verificou-se a calibração dos espectros, observando a posição do sinal do $\mathrm{C} 1 \mathrm{~s}$. A presença de $\mathrm{C}$, devido à contaminação com compostos orgânicos e $\mathrm{CO}_{2}$, é um fato comum em análises de XPS e útil para a calibração dos espectros. A $E_{\mathrm{Lig}}$ característica do elétron 1s do C é $284,8 \mathrm{eV}$ [141]. Na Fig. 3.22, verifica-se que, para todas as amostras, o pico do $\mathrm{C}$ está situado aproximadamente nesta região. Portanto, nesta análise preliminar, é razoável considerar que os valores de $E_{\mathrm{Lig}}$ estão corretos para os espectros iniciais. A verificação da calibração também pode ser feita para os últimos espectros obtidos, apesar da ausência do C. Neste caso, podem ser considerados os valores característicos para o Ar ou os esperados para o substrato. Os picos do Si e do O em sílica correspondem a 103,4 e $533 \mathrm{eV}$, respectivamente [141]. Nos espectros obtidos, observaram-se este valores apenas para os filmes de $\mathrm{SnO}_{2}(\mathrm{Cl})$ e $\mathrm{SnO}_{2}(\mathrm{Sb})$. Para o $\mathrm{SnO}_{2}(\mathrm{~F})$, os espectros estavam deslocados em aproximadamente $2 \mathrm{eV}$ para valores mais baixos de energia.

Nos espectros iniciais representados na Fig. 3.23, referentes à análise da superfície, detectaram-se os elementos $\mathrm{C}, \mathrm{O}$ e $\mathrm{Sn}$ para todas as amostras. Na Fig. 3.23a, referente ao filme preparado apenas com $\mathrm{SnCl}_{4}$, identificou-se a presença de $\mathrm{Cl}$, revelando ter ocorrido a dopagem não intencional do filme. Nesta análise, os outros dois dopantes não foram identificados, porém, como será discutido posteriormente, análises mais detalhadas dos espectros permitiram identificar a contribuição do $\mathrm{Sb}$. Para o filme preparado com $\mathrm{NH}_{4} \mathrm{~F}$, detectou-se ainda presença de $\mathrm{Ca}$, também em muito pequena quantidade; a origem desta contaminação não foi conhecida.

Ainda para os espectros iniciais, na região do $\mathrm{O} 1 \mathrm{~s}$, para todas as amostras, os picos situaram-se em aproximadamente $530,5 \mathrm{eV}$, que é o valor de energia característico para os elétrons $1 \mathrm{~s}$ do $\mathrm{O}$ em óxidos metálicos [141]. No decorrer da análise, porém, devido à remoção do filme de $\mathrm{SnO}_{2}$, o sinal do $\mathrm{O}$ deslocou-se gradativamente para o valor característico do $\mathrm{O} 1 \mathrm{~s}$ em sílica. Na Fig. 3.23b, referente ao filme de $\mathrm{SnO}_{2}(\mathrm{Sb})$, observa-se ainda que os espectros da região do $\mathrm{O}$ não foram simétricos. Estes espectros serão analisados e discutidos com maiores detalhes posteriormente. 
$\mathrm{Na}$ região do $\mathrm{Sn}$, os picos referentes aos elétrons $\mathrm{Sn} 3 \mathrm{~d}_{5 / 2}$ e $\mathrm{Sn} 3 \mathrm{~d}_{3 / 2}$ situaram-se nos valores característicos para o $\mathrm{SnO}_{2}$, em aproximadamente 487 e $495 \mathrm{eV}[77,141]$, para todas as três amostras. Como a $E_{\text {Lig }}$ destes elétrons nas espécies $\mathrm{SnO}$ e $\mathrm{SnO}_{2}$ são praticamente coincidentes, não é possível distinguir qual a espécie presente (ou predominante) no filme [141]. Estes sinais foram detectados nas suas $E_{\text {Lig }}$ características apenas nos quatro primeiros espectros; a seguir, deslocaram-se para energias mais baixas e, a partir do sexto espectro, aproximadamente, já não foram detectados. A extinção do Sn ocorreu simultaneamente ao aparecimento do substrato, como mostram os espectros da região do Si. Nesta fase, observou-se ainda o deslocamento dos espectros na região do $\mathrm{O} e$ do Sn. Este fato também pode ter resultado das mudanças de condutividade das amostras durante a análise, decorrentes da extinção do filme condutor.

A Fig. 3.24 representa a variação das concentrações relativas dos elementos detectados no decorrer das análises de XPS, em porcentagem atômica. Para todas as amostras, observou-se que o Si contribuiu em $\sim 5 \%$ na composição relativa dos filmes, o que seria um indício de falhas no recobrimento do substrato. Nas curvas referentes aos filmes de $\mathrm{SnO}_{2}(\mathrm{Cl})$ e $\mathrm{SnO}_{2}(\mathrm{Sb})$, a contribuição do $\mathrm{Si}$ apareceu no primeiro espectro e tornou-se nula no segundo. Este resultado não é coerente porque ambos os espectros de $N^{\text {os }} 1$ e 2 foram registrados antes de iniciar o bombardeio com $\mathrm{Ar}^{+} \mathrm{e}$, portanto, deveriam ser similares. Apenas para a análise realizada para o filme de $\mathrm{SnO}_{2}(\mathrm{~F})$, na Fig. 3.24c, observa-se uma contribuição de aproximadamente $13 \%$ nos dois espectros iniciais. Este resultado não chega a ser surpreendente, considerando as diversas falhas no recobrimento do substrato, observadas por SEM, e a pouca espessura deste filme (que será discutida posteriormente).

Um outro resultado interessante e inesperado foi a relação entre as concentrações de Si e $\mathrm{O}$ apresentadas nos gráficos da Fig. 3.24. Após aproximadamente 4 minutos de bombardeio com $\mathrm{Ar}^{+}$, observam-se aproximadamente $60 \%$ de $\mathrm{Si}$ e $40 \%$ de $\mathrm{O}$, valor inesperado para a composição do substrato (sílica). O substrato também foi analisado por XPS, e identificaram-se apenas Si e O na sua composição, com a relação esperada para a relação $[\mathrm{Si}] /[\mathrm{O}]$, i.e., 0,5 .

Considerando ainda a Fig. 3.24, a partir das concentrações relativas de Sn, Si e O determinadas nos segundo espectro, a relação $[\mathrm{Sn}(+\mathrm{Si})] /[\mathrm{O}]$ para os filmes de $\mathrm{SnO}_{2}(\mathrm{Cl})$, $\mathrm{SnO}_{2}(\mathrm{Sb})$ e $\mathrm{SnO}_{2}(\mathrm{~F})$ foi estimada em 0,$73 ; 0,49$ e 0,70 . Portanto, através das análises de XPS, exceto para o $\mathrm{SnO}_{2}(\mathrm{Sb})$, os filmes de $\mathrm{SnO}_{2}$ foram considerados como "nãoestequiométricos", devido à deficiência de $\mathrm{O}$ na superfície. 
Espectros de XPS para os filmes de $\mathrm{SnO}_{2}$ depositados em sílica

(a) $\mathrm{SnO}_{2}(\mathrm{Cl})$

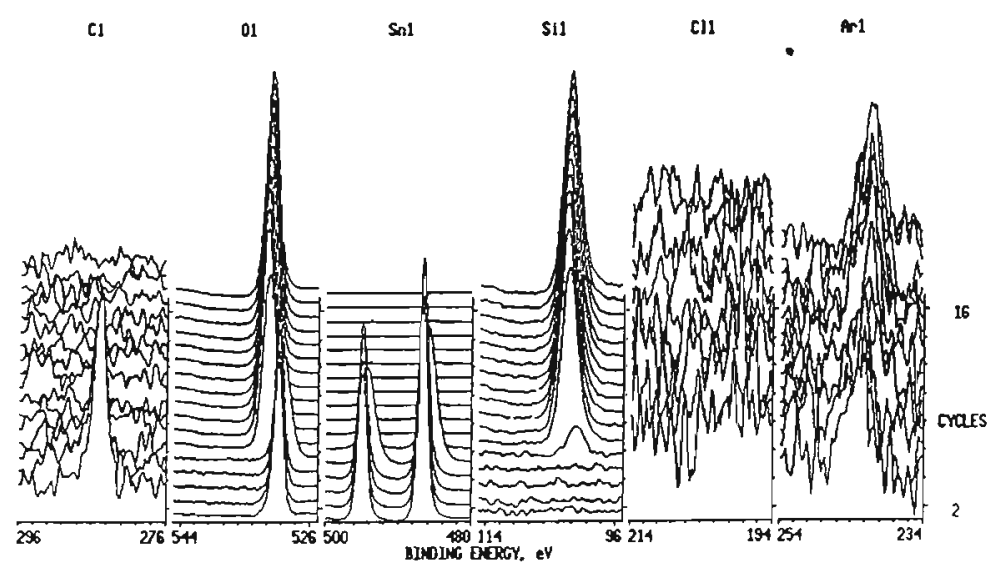

(b) $\mathrm{SnO}_{2}(\mathrm{Sb})$

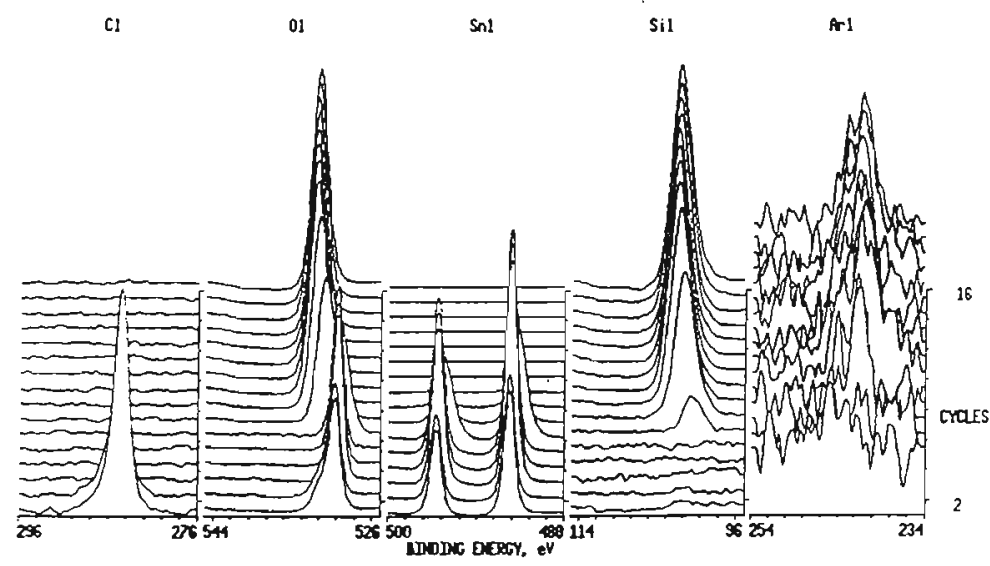

(c) $\mathrm{SnO}_{2}(\mathrm{~F})$

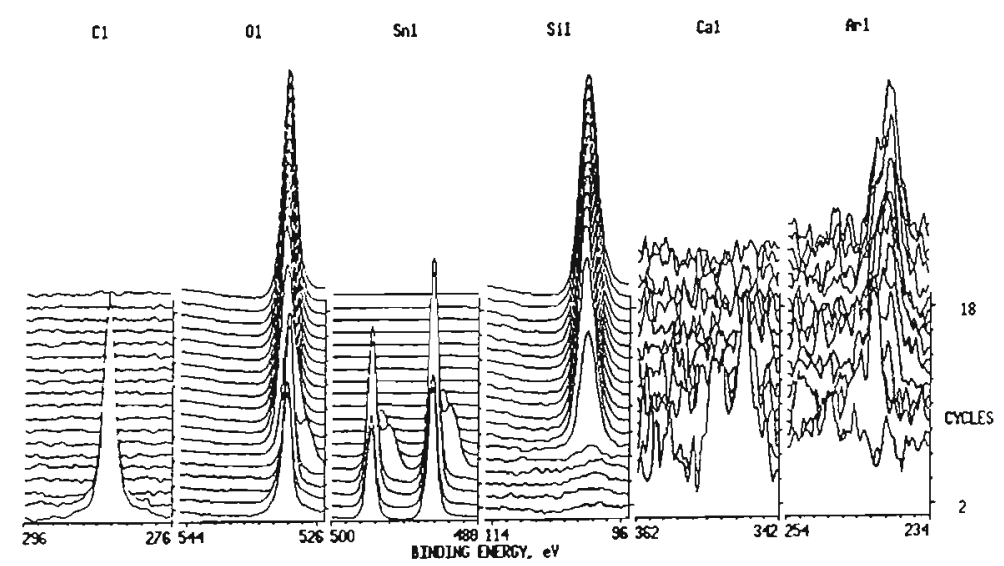

Figura 3.23. Análise da composição química dos filmes de $\mathrm{SnO}_{2}$ depositados sobre sílica: espectros de XPS determinados para a superficie e em profundidade, após diversos ciclos de bombardeio com $\mathrm{Ar}^{+}$. 
Espectros de XPS para os filmes de $\mathrm{SnO}_{2}$ depositados em sílica

(a) $\mathrm{SnO}_{2}(\mathrm{Cl})$

SCALE FACIOR $=0.020 \mathrm{k} \mathrm{c} / \mathrm{s}$, OFFSET $=0.000 \mathrm{k}$ c/s AI 350 \# ION VOL TACE $=3.00 \mathrm{kV}$

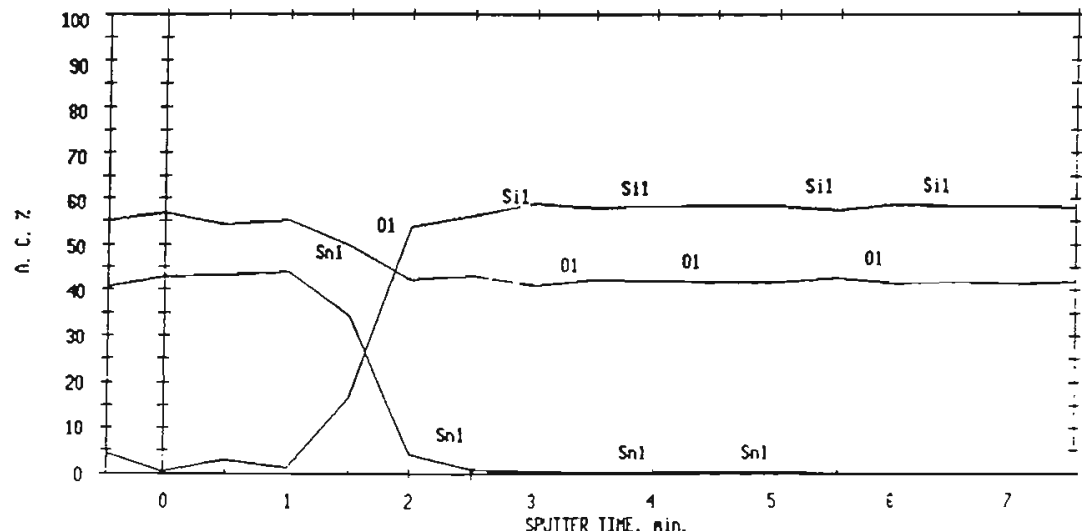

(b) $\mathrm{SnO}_{2}(\mathrm{Sb})$

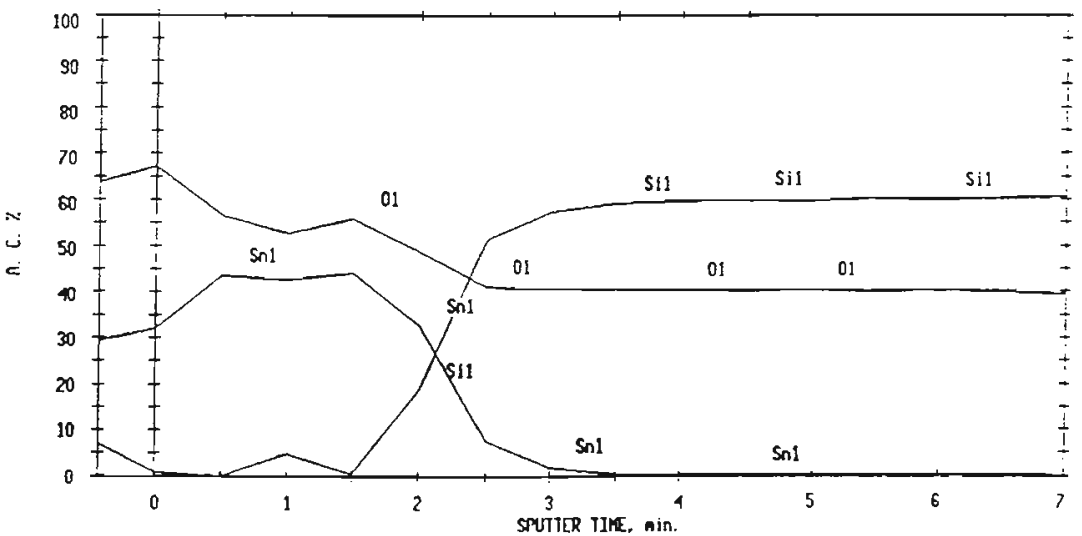

(c) $\mathrm{SnO}_{2}(\mathrm{~F})$

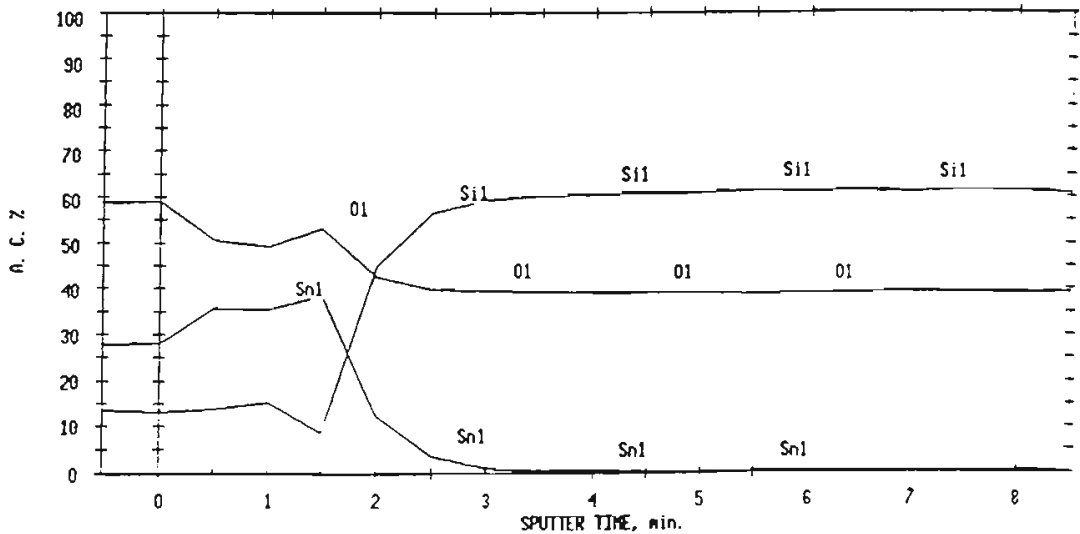

Figura 3.24. Variação das concentraçôes relativas dos elementos detectados por XPS nos espectros registrados durante a remoçào gradativa do filme pelo bombardeio com $\mathrm{AI}^{+}$. 
Os resultados obtidos para o $\mathrm{SnO}_{2}(\mathrm{Sb})$ foram analisados mais detalhadamente, para investigar a falta de simetria apresentada pelo espectro na região do $\mathrm{O} 1 \mathrm{~s}$. Este fenômeno poderia ser resultante da presença de grupos $\mathrm{OH}$ na superfície [21, 25, 77] ou de uma possível contribuição de $\mathrm{Sb}$, considerando que as $E_{\mathrm{Lig}}$ dos elétrons $\mathrm{Sb} 3 \mathrm{~d}_{5 / 2}$ situam-se na região do $\mathrm{O}$, em aproximadamente $528 \mathrm{eV}$ [141]. Se fosse devido à contribuição do $\mathrm{Sb}$, deveriam ser observados também os sinais referentes aos elétrons $\mathrm{Sb} 3 \mathrm{~d}_{3 / 2}$, na posição de aproximadamente $537 \mathrm{eV}$ [21, 77, 141]. Para realizar esta análise com maior rigor, subtraiu-se $0,1 \mathrm{eV}$ da $E_{\mathrm{Lig}}$ dos espectros, considerando a posição do pico do $\mathrm{C} 1 \mathrm{~s}$, discutida anteriormente (Fig. 3.25a).

Os espectros nas regiões do Sn e do O determinados na análise da superficie e após o primeiro ciclo de bombardeio com $\mathrm{Ar}^{+}$estão representados nas Fig. $3.25 \mathrm{~b}$ e $3.25 \mathrm{c} . \mathrm{Na}$ região do $\mathrm{Sn}$, os picos referentes aos sinais dos elétrons $\mathrm{Sn} 3 \mathrm{~d}_{5 / 2}$ e $\mathrm{Sn} 3 \mathrm{~d}_{3 / 2}$ foram observados em 486.5 and $495 \mathrm{eV}$, valores coincidentes aos relatados para o $\mathrm{SnO}_{2}$ [141]. $\mathrm{Na}$ região do $\mathrm{O}$, a Fig. $3.25 \mathrm{c}$ revela as diferenças entre os espectros determinados na superficie e após o bombardeio com $\mathrm{Ar}^{+}$. $\mathrm{O}$ espectro assimétrico do $\mathrm{O}$ 1s obtido na análise da superficie foi decomposto em duas curvas, como mostra a Fig. 3.25d. O pico a 530,4 eV pode ser atribuído ao $\mathrm{O}$ no $\mathrm{SnO}_{2}$ [141], enquanto que o outro pico, a $531.3 \mathrm{eV}$, provavelmente era devido à presença de espécies $\mathrm{OH}$ na superficie $[21,25,77]$. Nos espectros registrados após iniciar o bombardeio com $\mathrm{Ar}^{+}$(Fig. 3.25c) observou-se apenas o pico a $530.4 \mathrm{eV}$, indicando, portanto, que as espécies $\mathrm{OH}$ existiam apenas na superfície e foram removidas com o bombardeio de $\mathrm{Ar}^{+}$. A observação cuidadosa do espectro representado na Figura 3.24d revela que existe um pequeno pico a $540,1 \mathrm{eV}$, e que pode ser associado ao sinal dos elétrons $\mathrm{Sb} 3 \mathrm{~d}_{3 / 2}$ para espécies $\mathrm{Sb}^{5+}[21,77]$.

Para os espectros obtidos nas análises da superficie e após o primeiro ciclo de bombardeio com $\mathrm{Ar}^{+}$, estimaram-se as concentrações relativas para o $\mathrm{Sn}$ e $\mathrm{O}$. A concentração relativa para cada componente $\left(\mathrm{C}_{X}\right)$ foi calculada a partir das áreas dos picos nos espectros (I) e os respectivos fatores de sensibilidade (S), através da relação [141]

$$
C_{X}=\frac{I_{X} / S_{X}}{\sum I_{i} / S_{i}}
$$

$O \mathrm{C}_{\mathrm{Sn}}$ foi calculada a partir da área referente ao sinal do $\mathrm{Sn} 3 \mathrm{~d}_{5 / 2}$. Para estimar o $\mathrm{C}_{\mathrm{Sb}}$, estimou-se o pico que seria esperado para o $\mathrm{Sb}_{3} \mathrm{~d}_{5 / 2}$, considerando a diferença de 9,35 $\mathrm{eV}$ entre os sinais $\mathrm{Sb} 3 \mathrm{~d}_{5 / 2}$ e Sb $3 \mathrm{~d}_{3 / 2}$, e as intensidades relativas de ambos, 3:2 [141]. Para 
estimar o $\mathrm{C}_{\mathrm{O}}$, consideraram-se as áreas dos sinais a 531,3 e a $530,4 \mathrm{eV}$ (após descontar a contribuição prevista para o $\mathrm{Sb3} \mathrm{d}_{5 / 2}$ ). Os valores obtidos estão representados na Tabela 3.2 .

Tabela 3.2. Determinação das concentrações relativas do $\mathrm{Sn}, \mathrm{Sb}$ e $\mathrm{O}$ nos filmes de $\mathrm{SnO}_{2}(\mathrm{Sb})$ na superfície e após o $1^{\circ}$ ciclo de bombardeio com $\mathrm{Ar}^{+}$, através das análises de XPS.

\begin{tabular}{rrrrrrrr}
\hline & \multicolumn{1}{c}{$S$} & \multicolumn{1}{c}{$\mathrm{I}_{(\mathrm{SUP})}$} & \multicolumn{1}{c}{$\mathrm{I} / \mathrm{S}_{(\mathrm{SUP})}$} & \multicolumn{1}{c}{$\mathrm{C}_{\mathrm{X}(\mathrm{SUP})}$} & \multicolumn{1}{c}{$\mathrm{I}_{(10 \mathrm{C})}$} & $\mathrm{I}_{\mathrm{S}} \mathrm{S}_{(10 \mathrm{C})}$ & $\mathrm{C}_{\mathrm{X}(10 \mathrm{C})}$ \\
\hline \hline $\mathrm{Sn}$ & 4,095 & 59322 & 14486 & $35,5 \%$ & 111866 & 27318 & $46,7 \%$ \\
$\mathrm{Sb}$ & 4,473 & 1260 & 282 & $0,7 \%$ & 382 & 86 & $0,15 \%$ \\
$\mathrm{O}$ & 0,711 & 18504 & 26025 & $63,8 \%$ & 22103 & 31143 & $53,3 \%$ \\
\hline
\end{tabular}

Como mostra a Tabela 3.2, a [Sb] na superfície do filme foi estimada em $0,7 \%$, e a razão das concentrações atômicas relativas $[\mathrm{Sn}+\mathrm{Sb}] /[\mathrm{O}]$ e $[\mathrm{Sb}] /[\mathrm{Sn}]$ corresponderam a 57\% e $2 \%$, respectivamente. Estes valores são um pouco distintos dos estimados a partir dos gráficos da Fig. 3.24b, sem considerar a contribuição do Sb. Verifica-se ainda que a razão $[\mathrm{Sb}] /[\mathrm{Sn}]$ na superficie é muito maior que na solução precursora (era de $0.2 \%$ ). Este fenômeno já foi observado para filmes preparados por Spray Pyrolysis [76], e pode ocorrer porque o $\mathrm{SbCl}_{3}$ é menos volátil que o $\mathrm{SnCl}_{4}$; durante o processo de aplicação da solução com o atomizador, $\mathrm{o} \mathrm{SnCl}_{4}$ volatiliza, alterando a composição da solução precursora. Um outro motivo a ser considerado é a tendência do $\mathrm{Sb}$ se apresentar preferencialmente na superficie do filme, como discutido na Revisão Bibliográfica. Os valores da tabela revelam ainda que estas relações mudaram após o início do bombardeio com $\mathrm{Ar}^{+}$, ocorrendo a diminuição na [Sb] e [O]. Estes dados, porém, não merecem maior atenção, considerando que a remoção do filme pode ocorrer de maneira não uniforme e que os raios- $X$ interagem com o $\mathrm{SnO}_{2}$ provocando a sua redução, como tem sido relatado na Literatura [99].

A composição química dos filmes foi analisada também por micro-sonda eletrônica, porém, os resultados obtidos foram muito distintos. As análises revelaram que os filmes eram constituídos por $\mathrm{Sn}, \mathrm{O}$ e $\mathrm{Si}$, não identificando a presença de nenhum dos dopantes. Provavelmente, estas espécies estavam abaixo do limite de deteç̧ão da técnica. Como apenas o Sn e o $\mathrm{O}$ foram considerados na composição relativa, obtiveram-se relações correspondentes a aproximadamente $70 \%$ de Sn e $30 \%$ de $\mathrm{O}$ em peso, para todos os filmes. Estes valores indicariam um excesso de $\mathrm{O}$ no filme, já que a composição esperada para o $\mathrm{SnO}_{2}$ (estequiométrico) seria 78,77\% em $\mathrm{Sn}$ para 21,23\% de O. Como estes filmes eram muito finos, é provável que a incerteza das análises tenha aumentado. 
Espectros de XPS para o filme de $\mathrm{SnO}_{2}(\mathrm{Sb})$ depositado em sílica

(a)

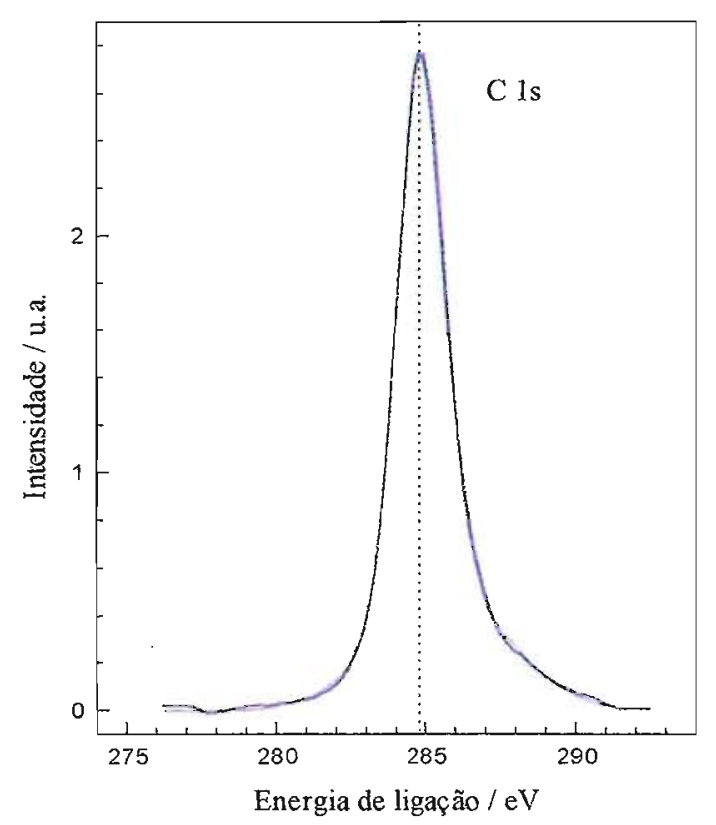

(c)

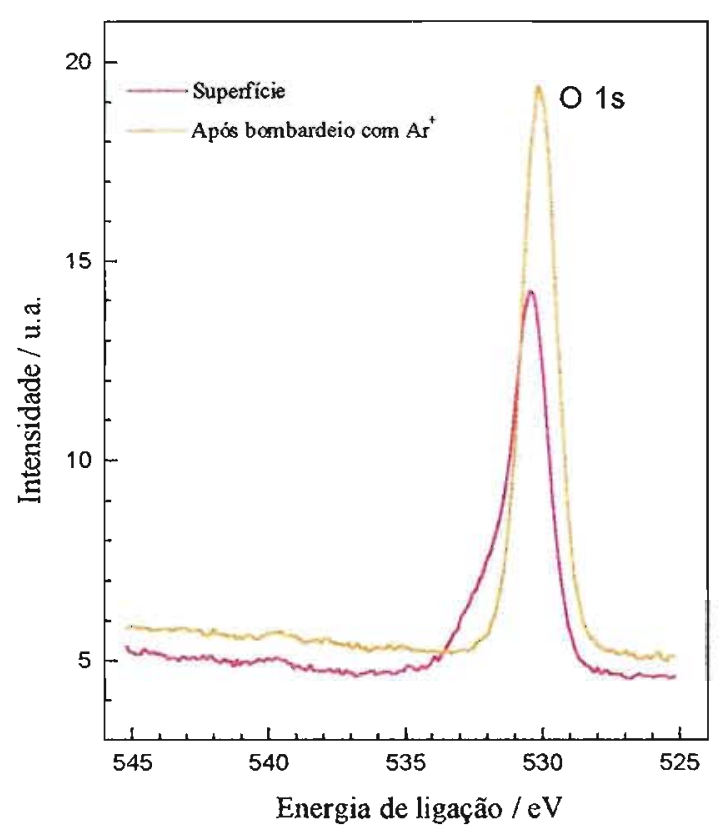

(b)

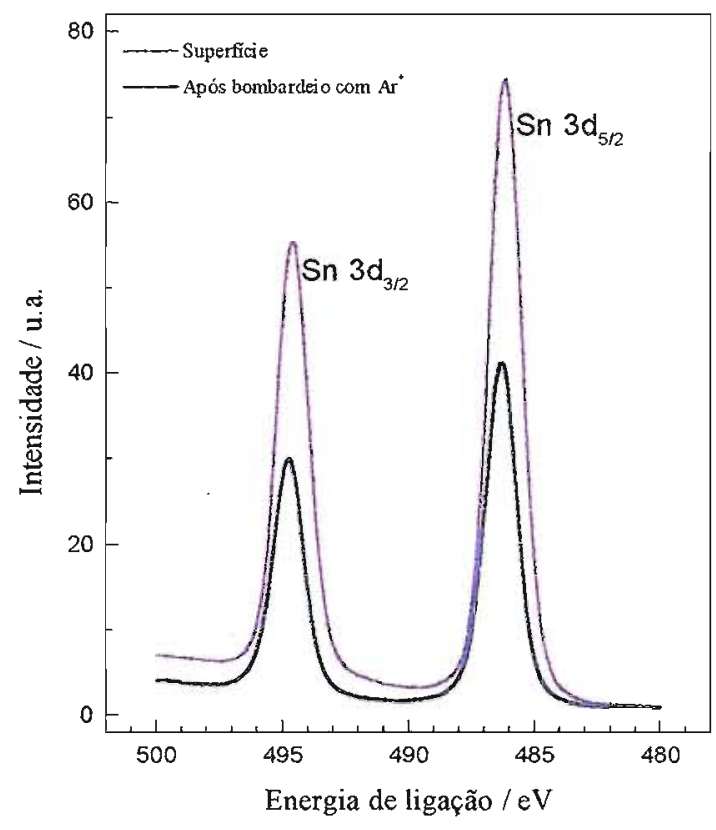

(d)

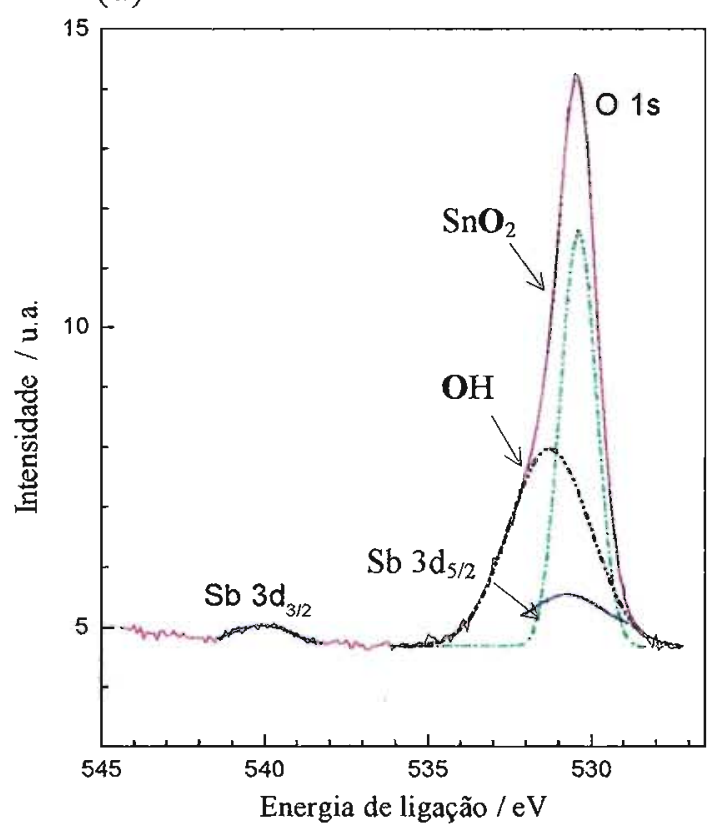

Figura 3.25. Espectros de XPS: região do $\mathrm{C} 1 \mathrm{~s}$, evidenciando que o espectro está deslocado em $0,15 \mathrm{~V}$ (a); regiões do $\mathrm{Sn} 3 \mathrm{~d}(\mathrm{~b}) \mathrm{e}$ do $\mathrm{O} 1 \mathrm{~s}(\mathrm{c})$, referentes às análises da superfície e após o $1^{\circ}$ ciclo de bombardeio com $\operatorname{Ar}^{+}$(corrigidos em $0,15 \mathrm{eV}$ ); decomposição do espectro superficial do O1s nos picos componentes (d). 


\subsubsection{Espessura, condutividade e transparência dos filmes depositados em sílica}

A espessura dos filmes transparentes de $\mathrm{SnO}_{2}$ foi estimada através de diferentes técnicas. Através da refletometria de raios- $\mathrm{X}$, a espessura dos filmes foi determinada através da relação expressa na equação 3.4, considerando a distância entre as franjas de interferência apresentadas nos espectros representados na Fig. 3.26. Para os filmes de $\mathrm{SnO}_{2}(\mathrm{Cl})$ e $\mathrm{SnO}_{2}(\mathrm{Sb})$, considerou-se a distância entre a segunda e a terceira franjas, por estarem melhor definidas; as espessuras estimadas para estes filmes corresponderam a 42 e $53 \mathrm{~nm}$, respectivamente. $\mathrm{O}$ espectro obtido para o filme de $\mathrm{SnO}_{2}(\mathrm{~F})$ apresentou apenas duas franjas. Considerando a distância entre as mesmas, estimou-se a espessura deste filme em $18 \mathrm{~nm}$.

Apenas para o filme de $\mathrm{SnO}_{2}(\mathrm{Cl})$, as análises da seção transversal por TEM revelaram que a espessura deste filme- variava entre 35 e 45 nm (Figura 3.19).

Para obter mais informações sobre este parâmetro, examinou-se também a superficie das amostras submetidas à análise por XPS, para analisar a região onde o filme havia sido removido por bombardeio com $\mathrm{Ar}^{+}$. As análises foram realizadas por interferometria de luz, em áreas de $2 \times 1,5 \mathrm{~mm}^{2}$, e estão representadas na Fig. 3.27. Na fig. 3.27 , foram representadas as imagens da superficie dos filmes e os perfis correspondentes a uma seção transversal obtida para cada imagem. Através dos perfis, determinou-se diferença na altura das áreas onde o filme foi removido e onde a superficie não foi atingida pelo bombardeio com $\mathrm{Ar}^{+}$. Estas alturas correspondem a 30,$4 ; 36,5$ e $26,7 \mathrm{~nm}$ para os filmes de $\mathrm{SnO}_{2}(\mathrm{Cl}), \mathrm{SnO}_{2}(\mathrm{Sb})$ e $\mathrm{SnO}_{2}(\mathrm{~F})$, respectivamente.

Informações adicionais foram obtidas ainda através das análises por micro-sonda eletrônica, onde realizaram-se cálculos interativos para determinar a composição química e a espessura dos filmes. Nestas análises, a espessura dos filmes de $\mathrm{SnO}_{2}(\mathrm{Cl}), \mathrm{SnO}_{2}(\mathrm{Sb})$ e $\mathrm{SnO}_{2}$ (F) foram estimadas em 37,50 e $33 \mathrm{~nm}$, respectivamente.

A comparação qualitativa dos resultados obtidos revela que, entre as três amostras, os filmes de maior e menor espessura são respectivamente, os de $\mathrm{SnO}_{2}(\mathrm{Sb})$ e $\mathrm{SnO}_{2}(\mathrm{~F})$. No entanto, a comparação quantitativa dos resultados revela consideráveis diferenças. Como valores médios, as espessuras foram estimadas em 40;50 e $25 \mathrm{~nm}$, para os eletrodos de $\mathrm{SnO}_{2}(\mathrm{Cl}), \mathrm{SnO}_{2}(\mathrm{Sb})$ e $\mathrm{SnO}_{2}(\mathrm{~F})$, respectivamente. 
Considerando estes valores de espessura, a resistividade dos filmes dopados com $\mathrm{Cl}$, Sb e $\mathrm{F}$ foi estimada em 10; 5 e $4 \mathrm{~m} \Omega \mathrm{cm}$. Estes resultados mostram que os filmes dopados com $\mathrm{F}$ e $\mathrm{Sb}$ eram mais condutores que o filme dopado com $\mathrm{Cl}$.

Analisou-se ainda a transmitância dos filmes de $\mathrm{SnO}_{2}$ depositados sobre sílica. Como mostram os espectros de transmitância da luz representados na Figura 3.28, estes filmes apresentaram alta transparência na região do visível.

Os resultados obtidos na caracterização das propriedades físico-químicas determinadas através das diferentes técnicas de análise para os eletrodos transparentes foram resumidas na Tabela 3.3 .

Tabela 3.3. Propriedades fisico-químicas dos filmes transparentes de $\mathrm{SnO}_{2}$

\begin{tabular}{|c|c|c|c|}
\hline & $\mathrm{SnO}_{2}(\mathrm{Cl})$ & $\mathrm{SnO}_{2}(\mathrm{~F})$ & $\mathrm{SnO}_{2}(\mathrm{Sb})$ \\
\hline $\begin{array}{c}\text { XPS-Composição química } \\
{[\mathrm{Sn}] /[\mathrm{O}]}\end{array}$ & 0,7 & 0,7 & $\begin{array}{c}{[\mathrm{Sn}+\mathrm{Sb}] /[\mathrm{O}]} \\
0,57\end{array}$ \\
\hline Transmissão VIS & $85 \%$ & $75 \%$ & $80 \%$ \\
\hline Espessura / nm & $35-45$ (TEM) & - & - \\
\hline Reflectometria de XRD & 42 & 18 & 53 \\
\hline Perfilometria & 30 & 27 & 37 \\
\hline Micro-sonda eletrônica & 37 & 33 & 50 \\
\hline Resistividade $/ \mathrm{m} \Omega \mathrm{cm}$ & 10 & 4 & 5 \\
\hline \multicolumn{4}{|l|}{ Tamanho dos grãos / nm } \\
\hline AFM-Diâmetro & $25-35$ & $30-50$ & $30-60$ \\
\hline AFM-Altura & $3-7$ & $3-10$ & 5 \\
\hline XRD: (110); (101) & 4,$2 ; 6,3$ & 5,$1 ; 11,4$ & 3,$9 ; 4,6$ \\
\hline \multicolumn{4}{|l|}{ Rugosidade (rms) / nm } \\
\hline $\begin{array}{l}A F M\left(4 \times 4 \mathrm{~mm}^{2}\right) \\
\text { Interferometria de luz }\end{array}$ & $\begin{array}{c}1,5-2,5 \\
1,0\end{array}$ & $\begin{array}{c}1,5-2,6 \\
1,0\end{array}$ & $\begin{array}{c}1,6-2,8 \\
1,0\end{array}$ \\
\hline
\end{tabular}


Reflectometria de Difração de Raios-X - filmes de $\mathrm{SnO}_{2}$ depositados em sílica

(a) $\mathrm{SnO}_{2}(\mathrm{Cl})$

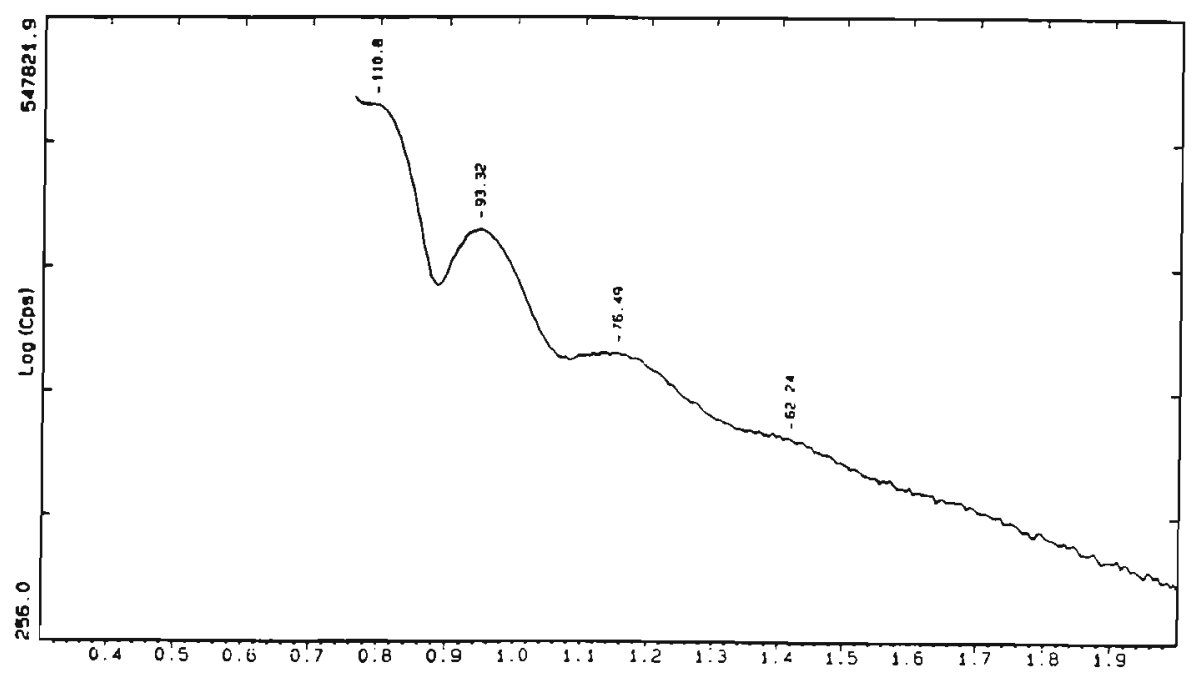

(b) $\mathrm{SnO}_{2}(\mathrm{Sb})$

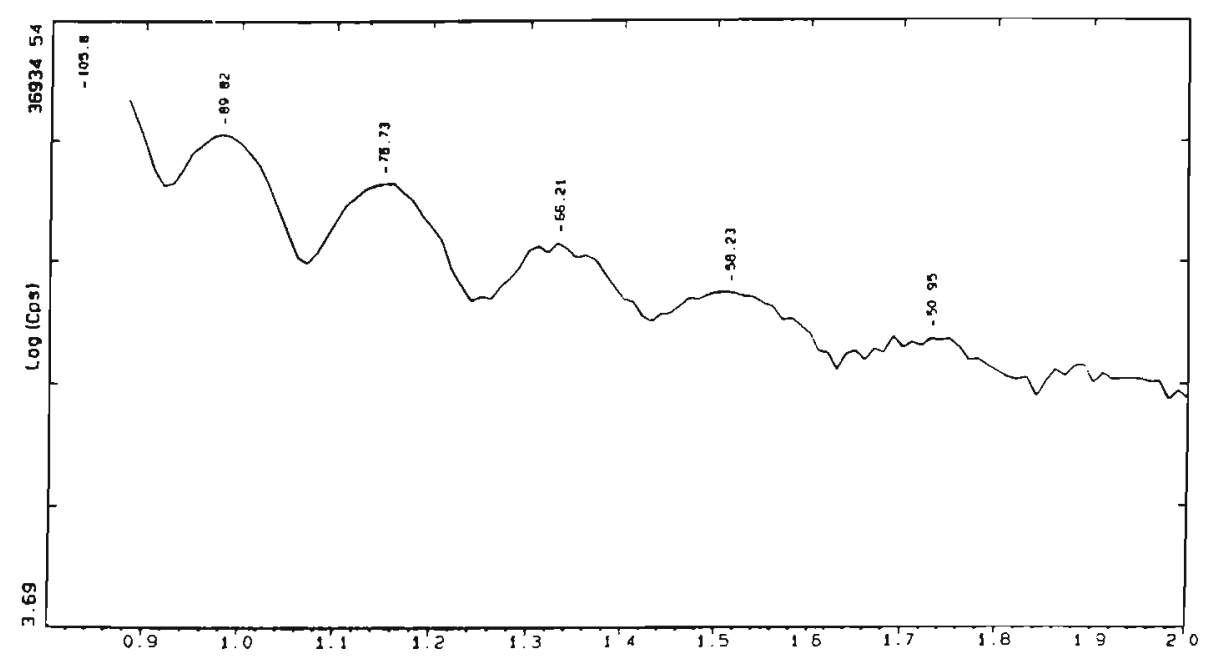

(c) $\mathrm{SnO}_{2}(\mathrm{~F})$

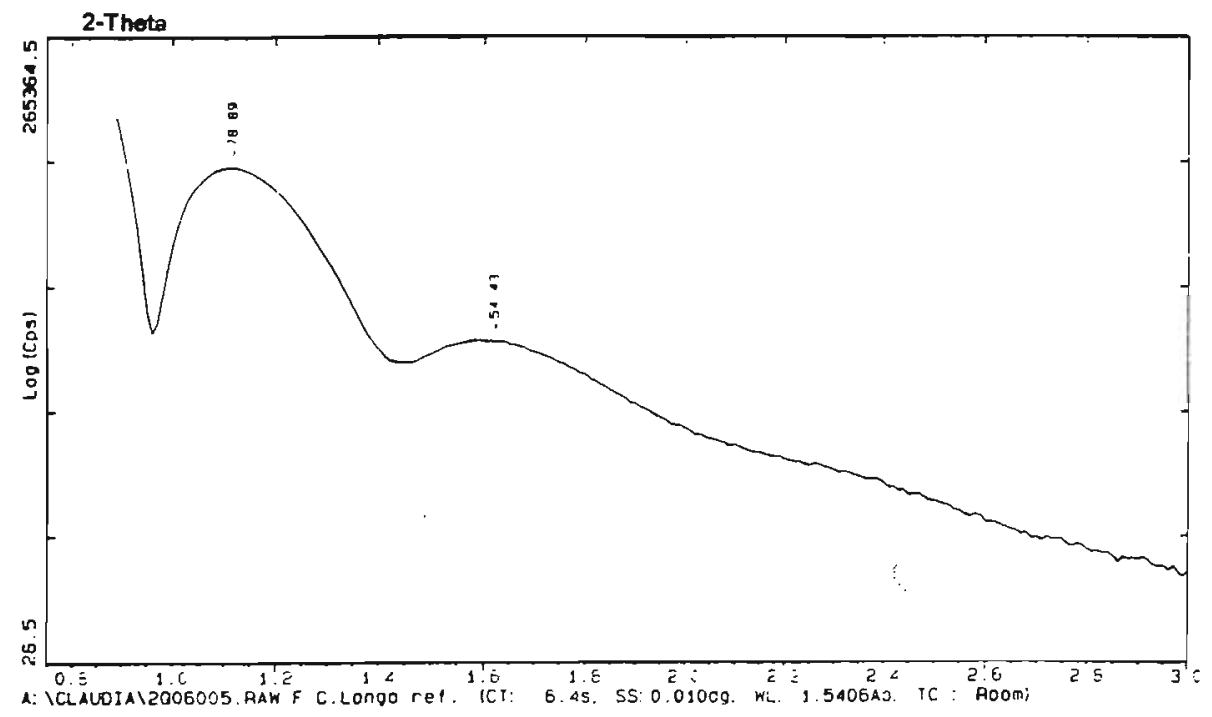

Figura 3.26. Espectros de Reflectometria de Raios-X determinados para estimar a espessura dos filmes de $\mathrm{SnO}_{2}$ depositados sobre sílica. 
Microscopia por Interferometria de Luz

(a) $\mathrm{SnO}_{2}(\mathrm{Cl})$
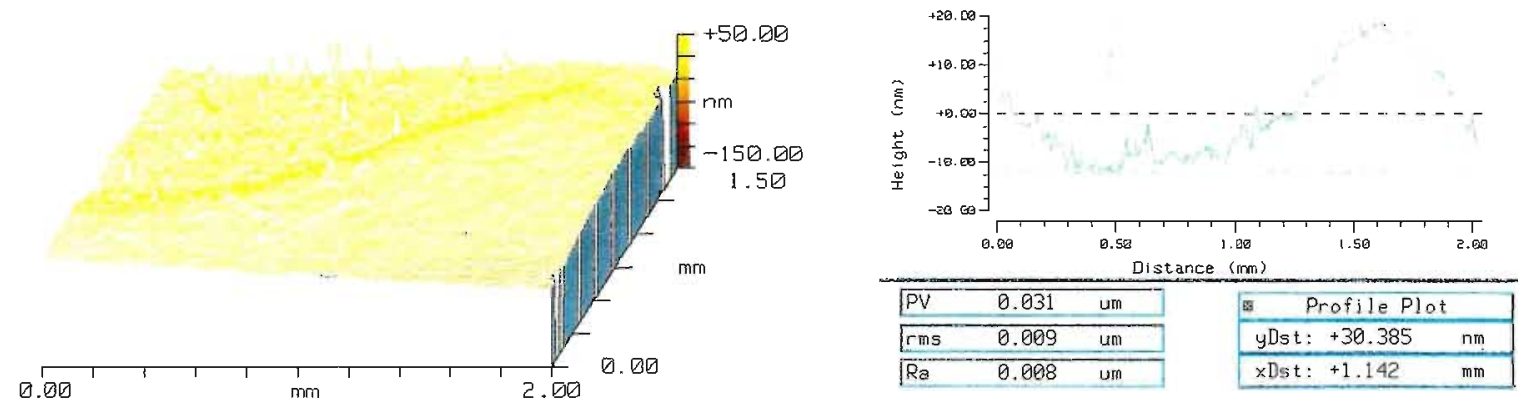

(b) $\mathrm{SnO}_{2}(\mathrm{Sb})$
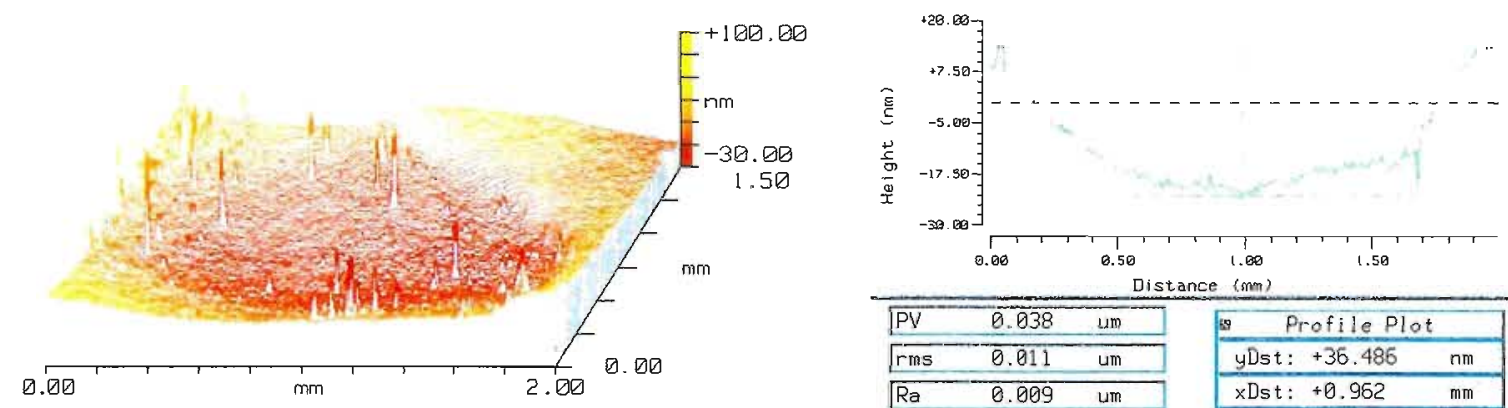

\begin{tabular}{|c|c|c|c|c|}
\hline \multicolumn{5}{|c|}{ Distance (mm) } \\
\hline PV & อ. 038 & $1 \mathrm{~m}$ & Profile P & \\
\hline$\sqrt{r m s}$ & 0.011 & um & yD̂st: +36.486 & $\mathrm{~nm}$ \\
\hline $\mathrm{Ra}$ & 0.009 & um & $x$ Dst: +0.962 & $\mathrm{~mm}$ \\
\hline
\end{tabular}

(c) $\mathrm{SnO}_{2}(\mathrm{~F})$
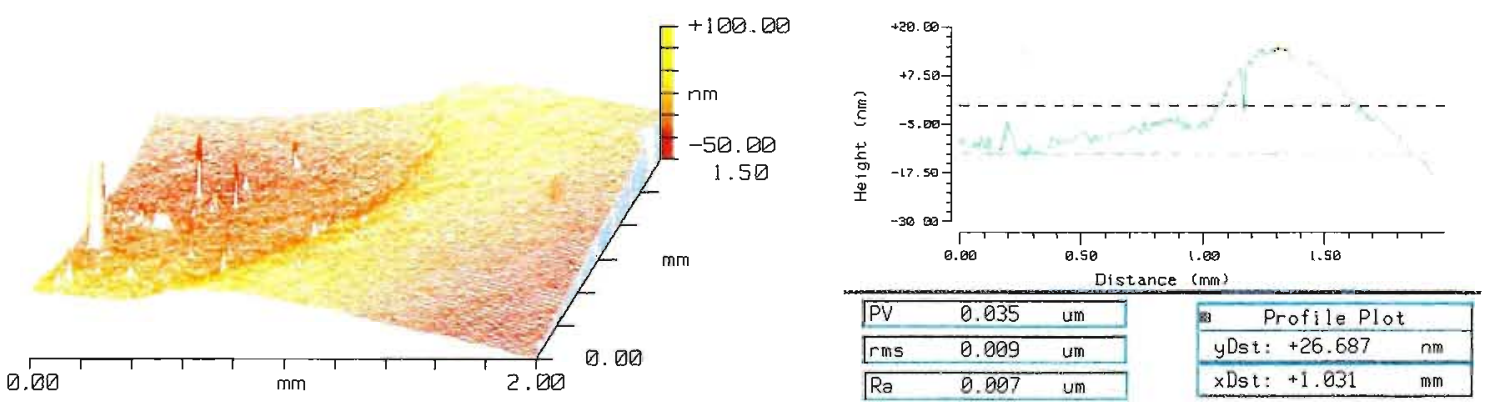

Figura 3.27. Análise por perfilometria nas proximidades das áreas bombardeadas com $\mathrm{Ar}^{+}$ para remoção do filme de $\mathrm{SnO}_{2}$. Imagens da superfície e perfis de seções transversais. 
Transmitância da luz na região do visível

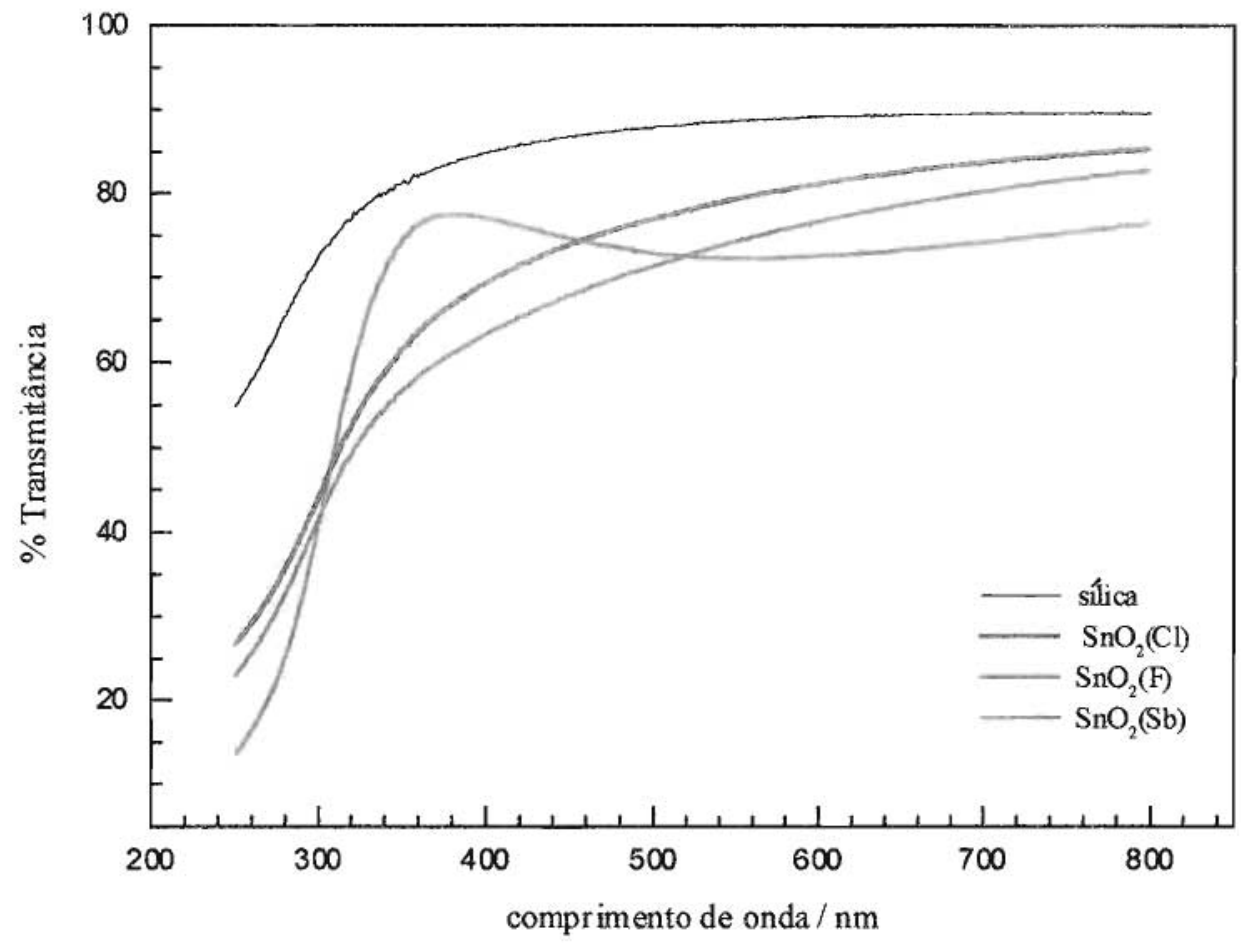

Figura 3.28. Espectros de transmitância de luz dos filmes depositados sobre sílica. 


\section{4 - CARACTERIZAÇAOO DOS ELETRODOS DEPOSITADOS SOBRE TITÂNIO}

Os eletrodos de filme de $\mathrm{SnO}_{2}(\mathrm{Sb})$ depositado sobre titânio foram caracterizados apenas no aspecto morfológico, empregando SEM e microscopia por interferometria de luz. Este tipo de eletrodo foi detalhadamente caracterizado por Fugivara [51] por SEM, $\mathrm{XRD}$ e outras técnicas. As análises por SEM revelaram que a superfície deste eletrodo apresentava uma alta rugosidade, sendo formada por cadeias de aglomerados e partículas com dimensões entre 1 e $3 \mu \mathrm{m}$. Nas análises por XRD, identificou-se a presença de um composto misto de composição $\left(\mathrm{Sn}_{1-\mathrm{x}} \mathrm{Ti}_{\mathrm{x}} \mathrm{O}_{2}\right)$ entre a superfície do titânio e o $\mathrm{SnO}_{2}$ [51].

As micrografias obtidas por SEM para os eletrodos de $\mathrm{Ti} / \mathrm{SnO}_{2}(\mathrm{Sb})$ preparados no presente trabalho estão representadas na Figura 3.29. Esta análise revelou que os eletrodos apresentaram a superfície bastante rugosa, com diversas irregularidades no filme. A Figura 3.29a ilustra uma imagem de aproximadamente $250 \times 150 \mu \mathrm{m}^{2}$, observada em aumentos da ordem de 500 vezes. Esta imagem é bastante representativa da morfologia observada em toda a extensão da amostra. Nesta imagem, verificam-se regiões em que o filme se apresenta de maneira mais uniforme, e outras que apresentam rachaduras, crateras e protuberâncias. Estas regiões podem ser examinadas melhor através das imagens representadas nas Figuras $3.29 \mathrm{~b}$ e $3.29 \mathrm{c}$, que ilustram áreas onde o filme apresentava recobrimento uniforme e aquelas que apresentavam grãos, respectivamente. A Figura $3.29 \mathrm{~d}$ revela em detalhes a microestrutura apresentada nas proximidades dos grãos.

Os resultados obtidos nas análises por microscopia interferométrica estão representados na Figura 3.30. Estão representados uma imagem com o mapa geral obtido para a superficie, em uma área de $\sim 180$ x $140 \mu \mathrm{m}^{2}$, e, ao lado, o perfil correspondente a uma seção transversal definida naquela imagem. Apresenta-se ainda um gráfico que mostra a composição tridimensional dos perfis determinados na análise, e o histograma referente às diferentes alturas determinadas. As análises realizadas em diferentes áreas das amostras

revelaram resultados similares: a superfície deste tipo de eletrodo apresentou alta rugosidade (rms entre 420 e $480 \mathrm{~nm}$ ), e, em algumas regiões, a distância entre pico e vale atingiu $8 \mu \mathrm{m}$. 
$\mathrm{SEM}$ - Morfologia do eletrodo de $\mathrm{Ti} / \mathrm{SnO}_{2}(\mathrm{Sb})$

(a)

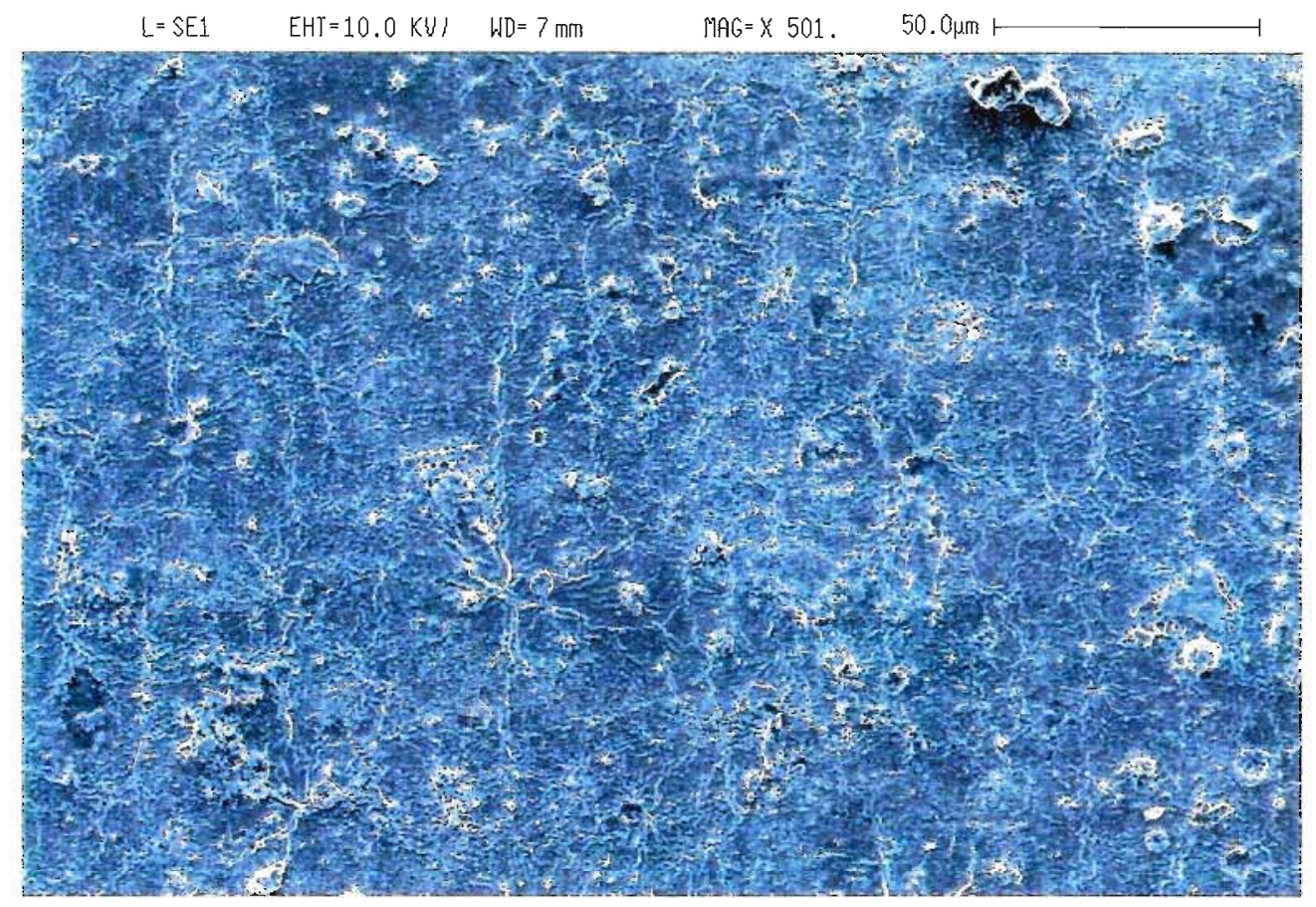

(b)

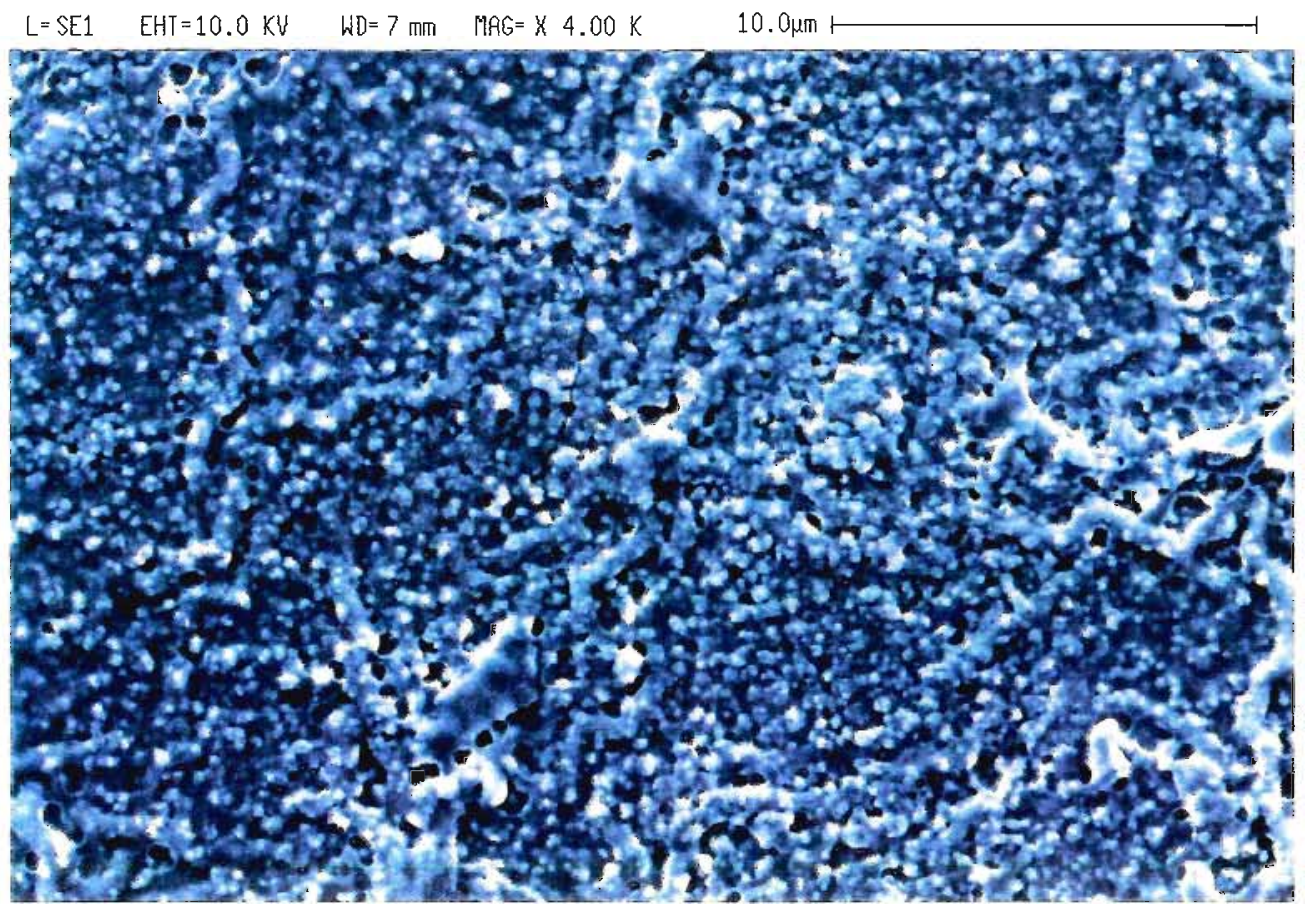

Figura 3.29. Micrografias obtidas por SEM para o eletrodo de filme de $\mathrm{SnO}_{2}(\mathrm{Sb})$ depositado em titânio: aspecto geral da superfície (a) e detalhe das áreas mais uniformes (b). 
$\mathrm{SEM}$ - Detalhes da superfície do eletrodo de $\mathrm{Ti} / \mathrm{SnO}_{2}(\mathrm{Sb})$

(c)

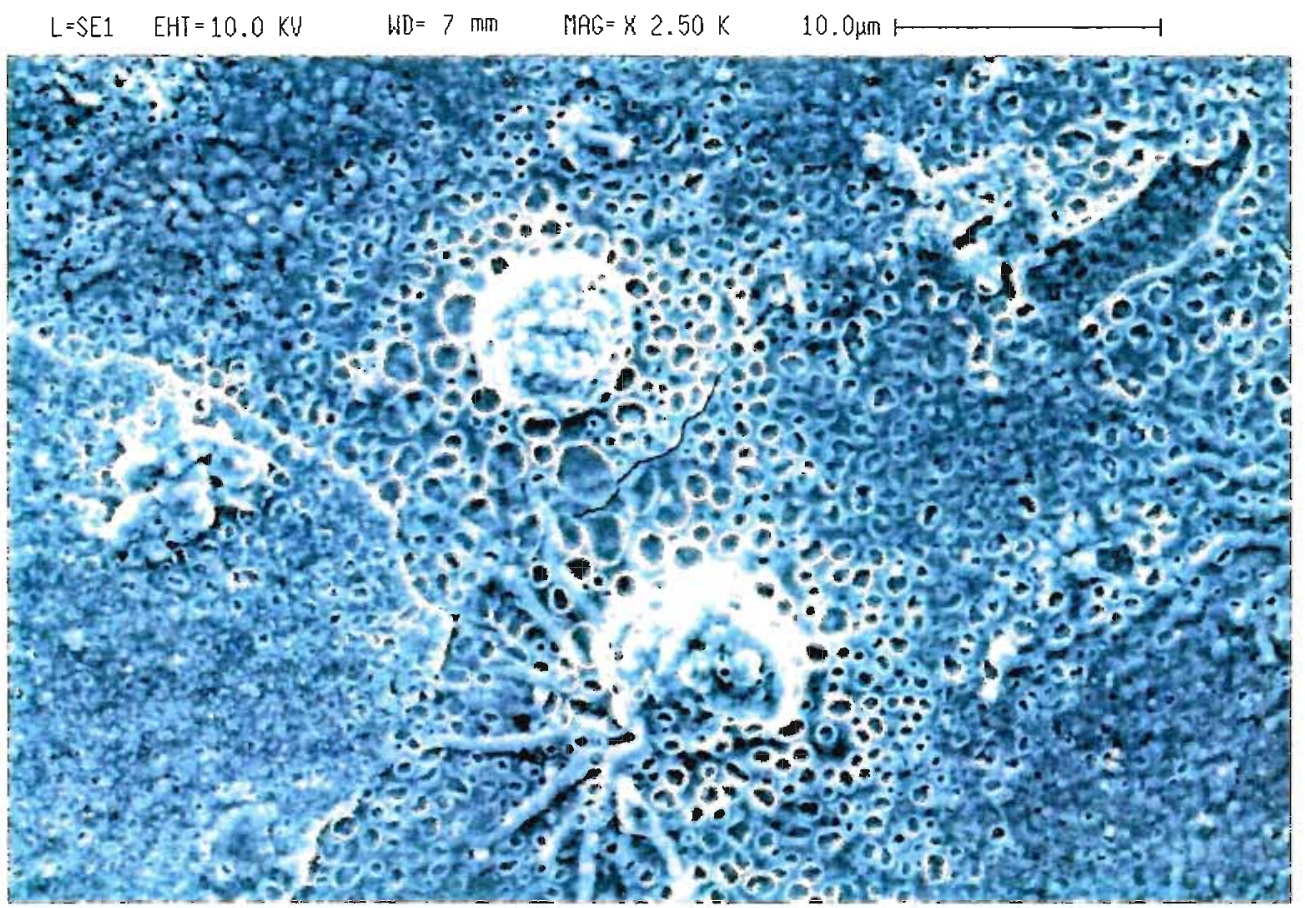

(d)

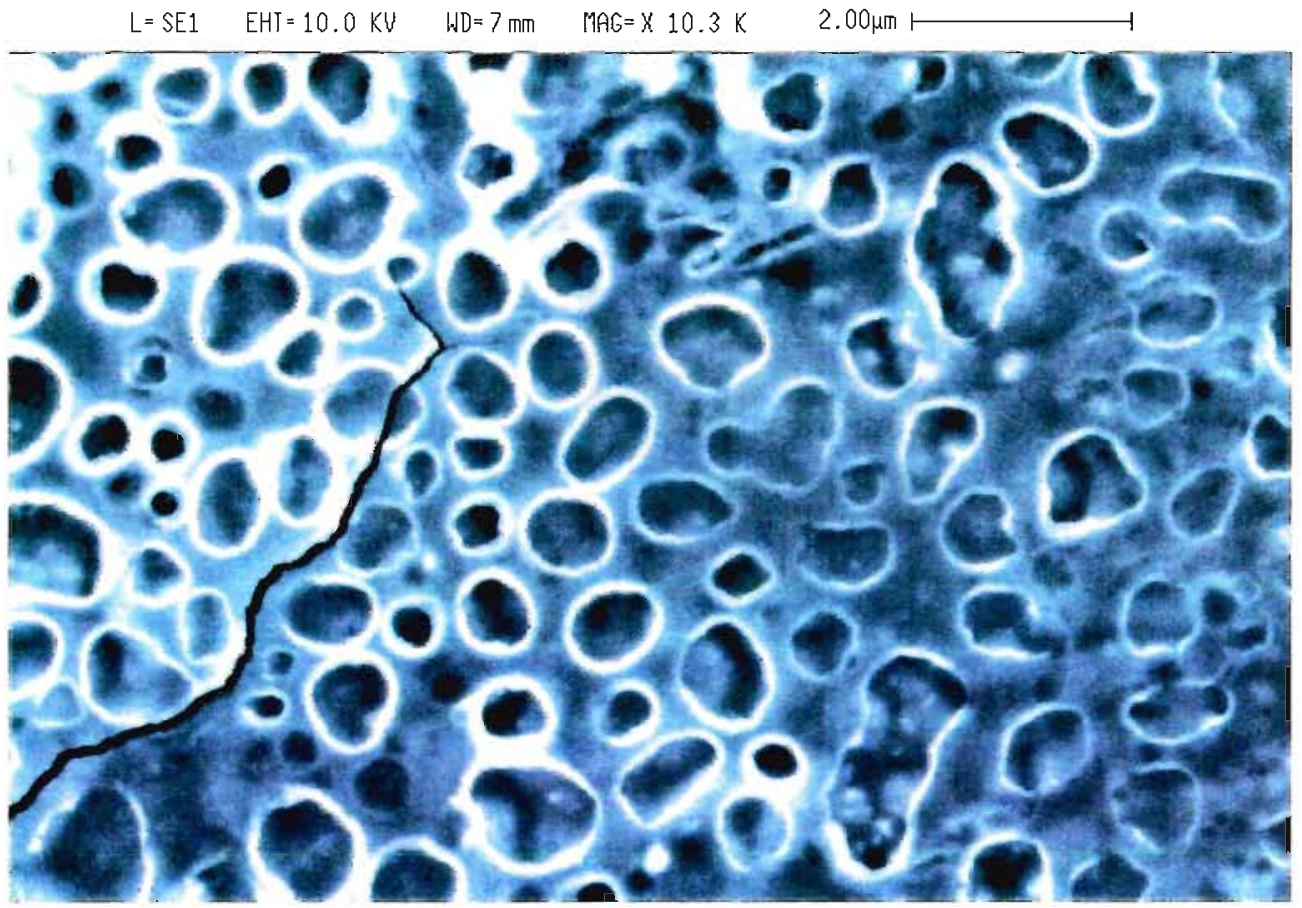

Figura 3.29. Superfície do eletrodo de $\mathrm{Ti} / \mathrm{SnO}_{2}(\mathrm{Sb})$ : detalhes de regiões que apresentaram falhas na cobertura do filme, observadas com aumentos de $\sim 2500$ e 10000 vezes. 
Eletrodo de $\mathrm{Ti} / \mathrm{SnO}_{2}(\mathrm{Sb})$ - Microscopia por Interferometria de Luz
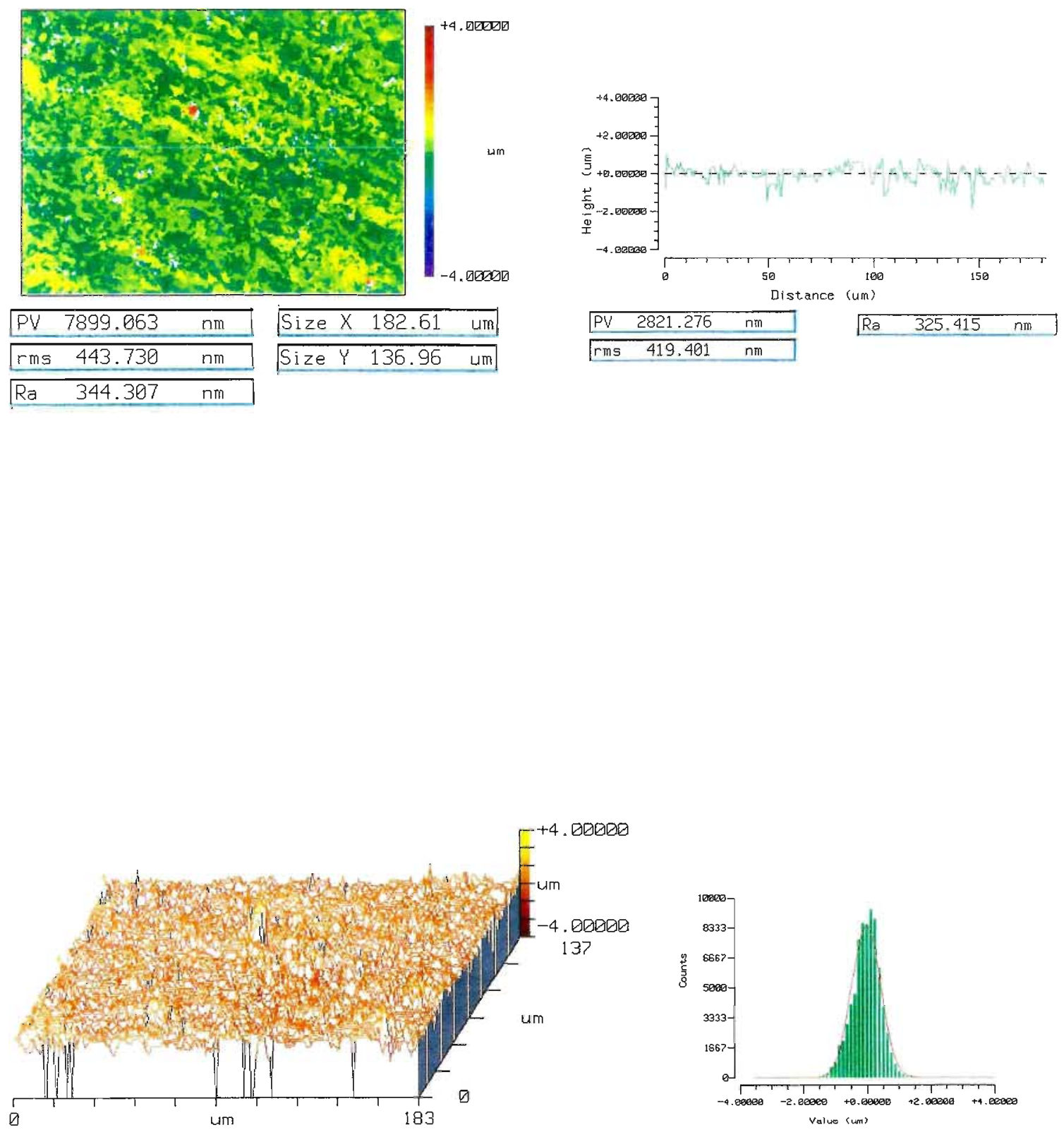

Figura 3.30. Microestrutura do eletrodo de filme de $\mathrm{SnO}_{2}(\mathrm{Sb})$ depositado em titânio: resultados da análise por microscopia interferométrica. 


\section{5 - CARACTERIZAÇÃO DOS ELETRODOS DE SnO TRANSPARENTES E DE THSNO $\mathrm{O}_{2}$ MODIFICADOS COM OTS}

A caracterização dos eletrodos modificados com OTS foi realizada através de análises químicas (XPS) e morfológicas. As análises morfológicas foram efetuadas apenas para os eletrodos transparentes e incluiram o exame da superficie por AFM e a verificação da hidrofobicidade da superficie (apenas qualitativa). Para avaliar a hidrofobicidade da superficie, obtiveram-se, com o auxílio de uma câmera, imagens de gotículas de água de 2,5 e de 5,0 $\mu \mathrm{L}$ colocadas com uma micro-seringa sobre a superficie dos eletrodos.

As imagens obtidas para gotículas de 2,5 $\mu \mathrm{L}$ estão representadas na Fig. 3.31. A análise da forma das gotículas nas imagens (a), (b) e (c) revela que mesmo os eletrodos não modificados apresentaram superfícies consideravelmente hidrofóbicas. A comparação com as imagens obtidas para os eletrodos modificados mostra que os três tipos de eletrodos apresentaram superficies ainda mais hidrofóbicas. $O$ aumento na hidrofobicidade pode ser considerado um indício da presença do filme de organosilano.

As amostras foram analisadas por AFM em diversas áreas, e não foram observadas alterações morfológicas que pudessem indicar a presença dos organosilanos na superfície. Nestas análises, observou-se apenas uma certa dificuldade para a aquisição das imagens, possivelmente provocada por interações entre a ponta e o filme hidrofóbico. Como as imagens obtidas para os eletrodos modificados não diferiram das apresentadas na Seção 3.3.2., não foram incluídas neste capítulo. Algumas destas imagens serão apresentadas no Capítulo 5, nas comparações da morfologia dos eletrodos antes e após a aplicação de tratamentos eletroquímicos.

Através das análises de XPS, também foram obtidos apenas indícios da presença do OTS na superfície dos eletrodos modificados. Os espectros obtidos estão representados nas Fig. $3.32 \mathrm{~b}$ e $3.32 \mathrm{c}$, respectivamente. Para comparação, o espectro obtido para o filme transparente de $\mathrm{SnO}_{2}(\mathrm{Sb})$ não modificado está representado na Fig. 3.32a. Para os eletrodos modificados, verificou-se a presença de $\mathrm{Si}$ e detectou-se que o pico relativo ao $\mathrm{C}$ $1 \mathrm{~s}$ apresentava intensidade muito maior (Figs. $3.32 \mathrm{~b}$ e 3.32c). Para os eletrodos transparentes, a presença do Si poderia ser proveniente do substrato, caso houvessem falhas na cobertura do filme. Porém, essa hipótese não é aplicável para o eletrodo de $\mathrm{Ti} / \mathrm{SnO}_{2}(\mathrm{Sb})$, e, portanto, parece razoável admitir que estes resultados indiquem a adsorção do OTS na superfície destes eletrodos. 
Nas análises realizadas para os eletrodos modificados, observou-se também que os sinais referentes ao $\mathrm{O} 1 \mathrm{~s}$ não eram simétricos. A Figura 3.32 ilustra a decomposição dos espectros nos picos componentes. Na Fig. 3.32a, verifica-se um pico em 530,5 eV, que pode ser atribuído aos elétrons do $\mathrm{O}$ 1s do $\mathrm{SnO}_{2}$. Porém, neste mesmo espectro, o outro pico está localizado em 532,2 eV; embora este valor ainda possa ser atribuído aos grupos $\mathrm{M}-\mathrm{OH}$ superficiais $[77,141]$, é cerca de $1 \mathrm{eV}$ mais alto que o $E_{\mathrm{Lig}}$ observada para o eletrodo não modificado (Fig. 3.25d). É possível que o $E_{\text {Lig }}$ tenha se deslocado para valores mais altos por contribuição dos $\mathrm{O}$ ligados ao OTS, já que o $E_{\mathrm{Lig}}$ do $\mathrm{O} 1 \mathrm{~s}$ em compostos orgânicos situa-se em 532 e 536 eV [77, 141]. Para o eletrodo modificado de $\mathrm{Ti} / \mathrm{SnO}_{2}(\mathrm{Sb})$, ambos os picos foram verificados em $E_{\mathrm{Lig}}$ menores, em 529,5 e em $531,8 \mathrm{eV}$. Possivelmente, estas diferenças foram causadas pelos distintos substratos (sílica e Ti).

Estas análises permitiram caracterizar os eletrodos modificados apenas qualitativamente, mas não forneceram informações a respeito da espessura e da estrutura do filme de OTS na superfície dos eletrodos modificados. Considerando a morfologia dos materiais investigados e os mecanismos propostos para a adsorção do OTS [138-140], seria muito pouco provável que as moléculas do OTS estivessem ordenadas como uma monocamada ideal na superfície dos eletrodos de $\mathrm{SnO}_{2}$, como ilustrado na Fig. 2.5. Para os materiais investigados, a rugosidade da superfície dificilmente possibilitaria a formação de uma camada com uma estrutura tão ordenada e fixa, mesmo antes de considerar se a distância Sn-Sn na superficie seria compativel com a distância Si-O-Si do filme hidrofóbico.

Devido à alta reatividade dos grupos $\mathrm{Si}-\mathrm{Cl}$ (ou ainda $\mathrm{Si}-\mathrm{OH})$ e da tendência a fortes interações hidrofóbicas das cadeias hidrocarbônicas das moléculas do OTS, é muito provável que estas moléculas tenham sofrido hidrólise e polimerização ao entrar em contato com a superfície hidratada do $\mathrm{SnO}_{2}$. Porém, parece mais razoável admitir que as ligações das moléculas de OTS com os sítios $\mathrm{Sn}-\mathrm{OH}$ da superfície não foram efetivas para cada molécula de OTS, mas muito mais esporádicas. A estrutura resultante do filme de OTS poderia ser imaginada como um novelo de lã desenrolado sobre o eletrodo de $\mathrm{SnO}_{2}$. Este filme hidrofóbico, formado pela polimerização das moléculas do OTS, ou por interações hidrofóbicas e de ponte de hidrogênio, poderia estar atado à superficie somente em alguns pontos, através de ligações do tipo -Sn-O-Si- $\left(\mathrm{CH}_{2}\right)_{17} \mathrm{CH}_{3}$.

Este modelo pareceu ser coerente com os resultados obtidos no estudo das propriedades eletroquímicas destes materiais (Capítulo 4) e no estudo das alterações morfológicas induzidas por perturbações eletroquímicas (Capítulo 5). 
Análise qualitativa da hidrofobicidade da superfície dos eletrodos

Eletrodos não modificados

(a) $\mathrm{SnO}_{2}(\mathrm{Cl})$

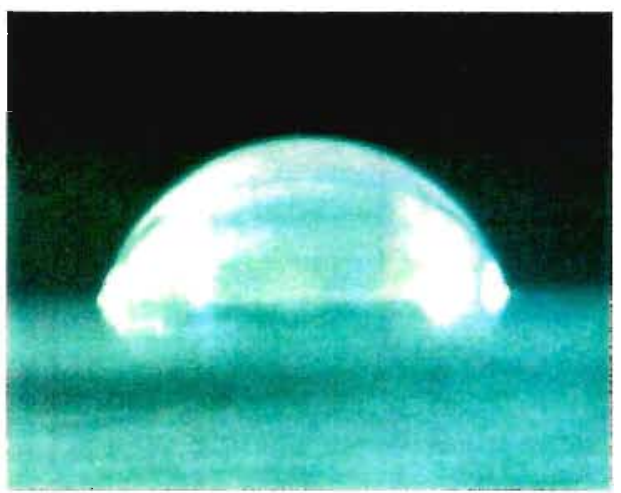

(b) $\mathrm{SnO}_{2}(\mathrm{Sb})$

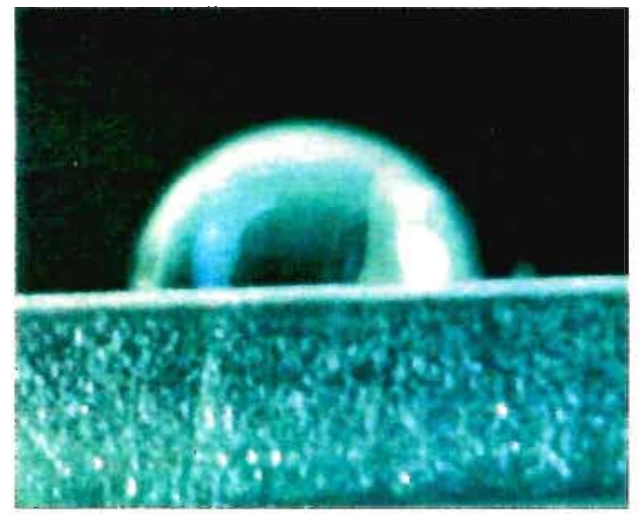

(c) $\mathrm{SnO}_{2}(\mathrm{~F})$

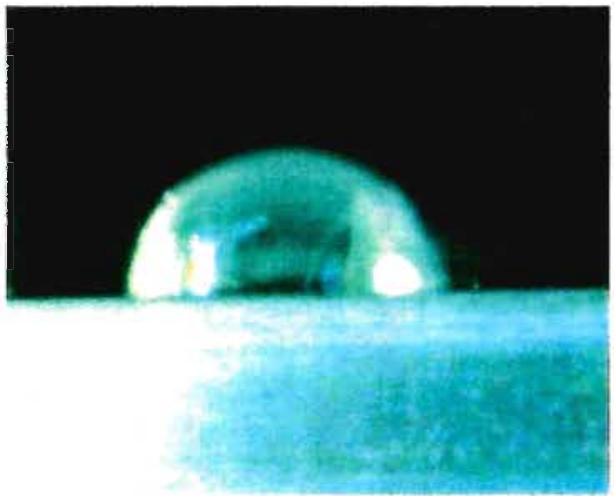

Eletrodos modificados com OTS
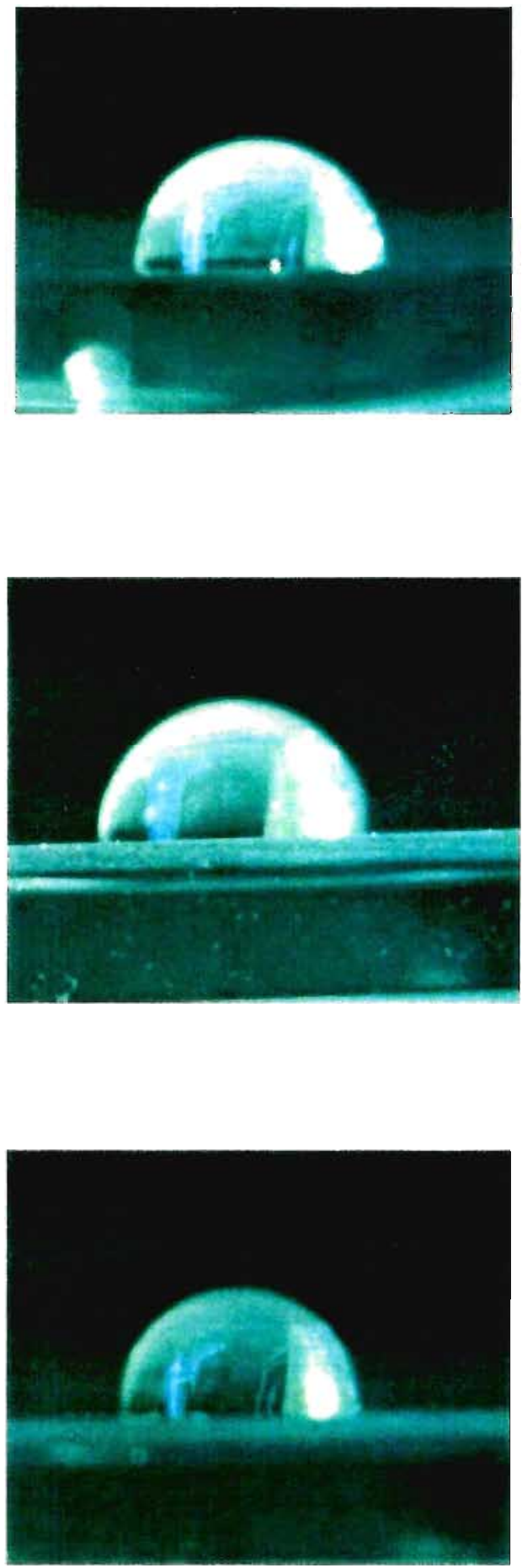

Figura 3.31. Verificação qualitativa da hidrofobicidade da superfície dos eletrodos transparentes: imagens de gotas de $\mathrm{H}_{2} \mathrm{O}(2,5 \mu \mathrm{L})$ sobre os eletrodos modificados ou não com octadeciltriclorosilano. 
Espectros de XPS

(a) Sílica/ $\mathrm{SnO}_{2}(\mathrm{Sb})$

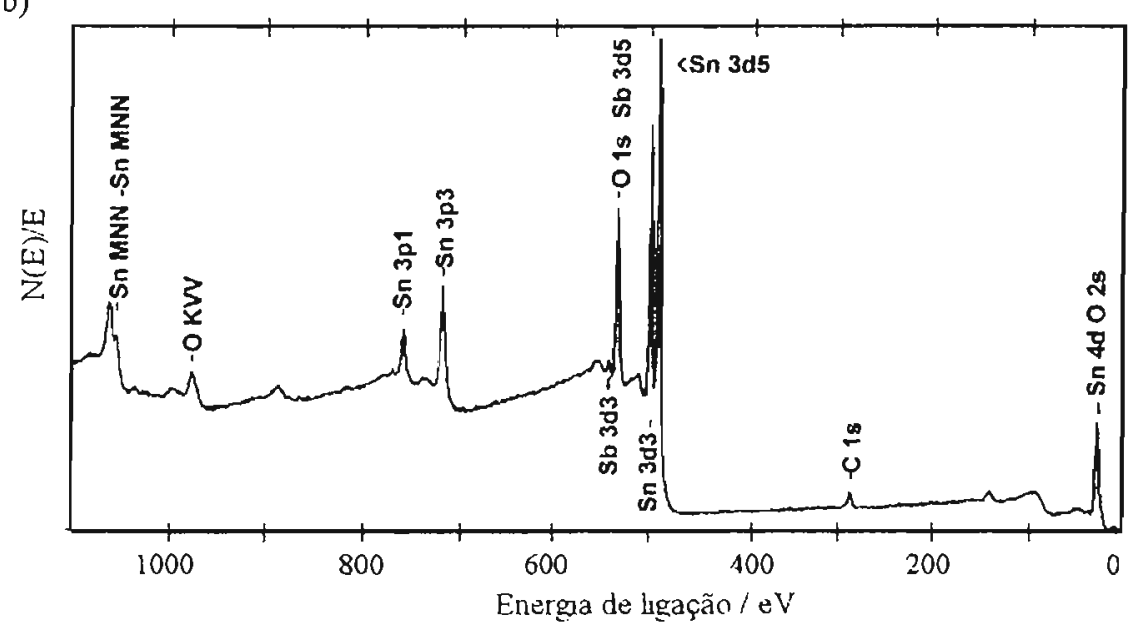

(b) Sílica/ $\mathrm{SnO}_{2}(\mathrm{Sb}) / \mathrm{OTS}$

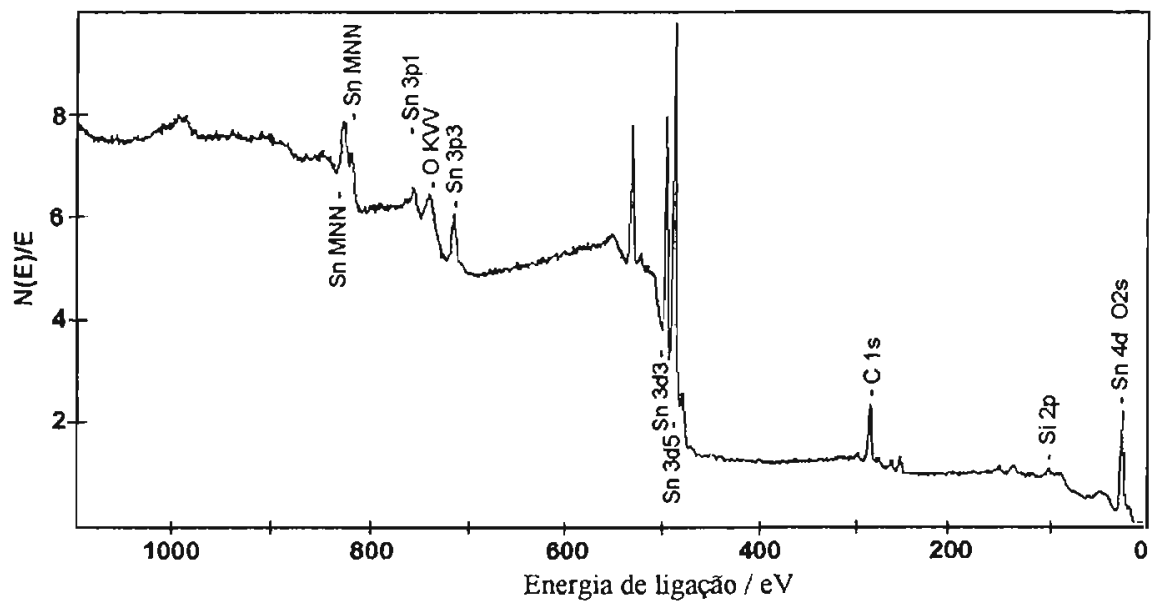

(c) $\mathrm{Ti} / \mathrm{SnO}_{2}(\mathrm{Sb}) / \mathrm{OTS}$

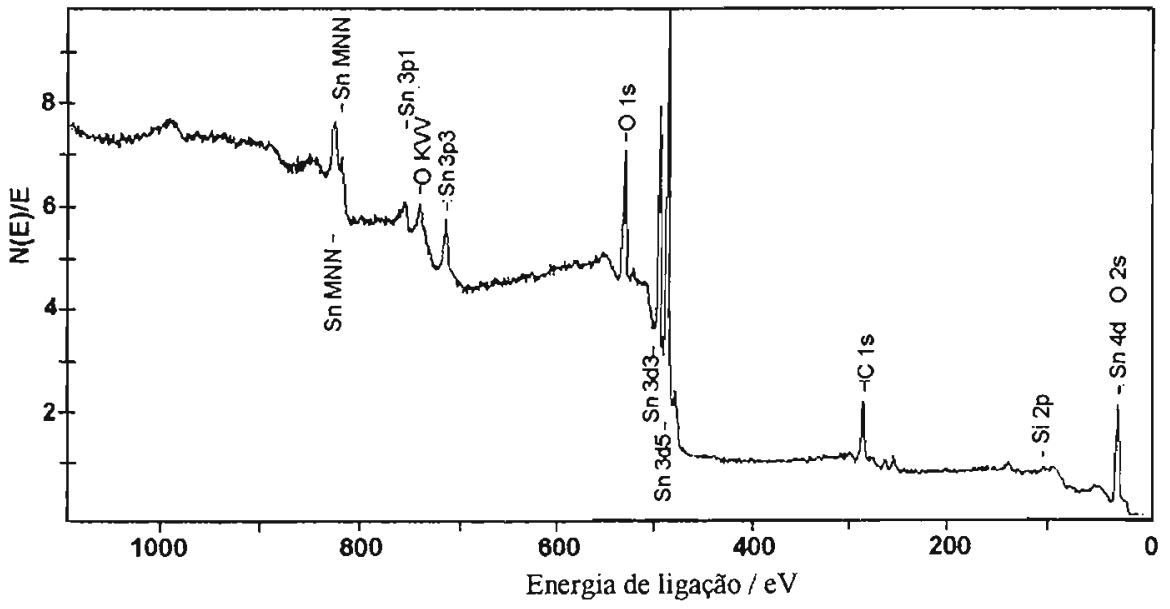

Figura 3.32. Espectros de XPS obtidos para (a) o eletrodo não modificado de $\mathrm{SnO}_{2}$ (Sb) depositado em sílica; (b) para o eletrodo transparente de $\mathrm{SnO}_{2}(\mathrm{Sb})$ modificado com octadeciltriclorosilano e (c) para o eletrodo de $\mathrm{Ti} / \mathrm{SnO}_{2}(\mathrm{Sb})$-OTS. 


\section{XPS - Espectros da região do O $1 \mathrm{~s}$}

(a) Sílica $/ \mathrm{SnO}_{2}(\mathrm{Sb})$-OTS

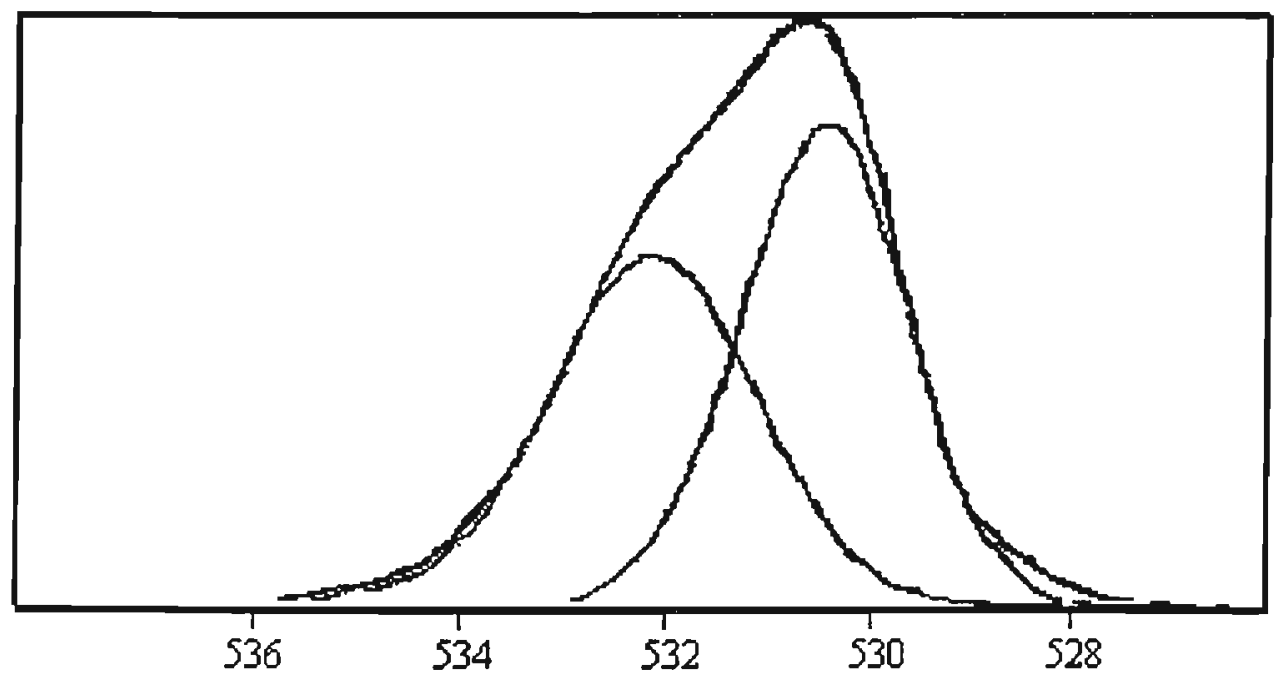

(b) $\mathrm{Ti} / \mathrm{SnO}_{2}(\mathrm{Sb})$-OTS

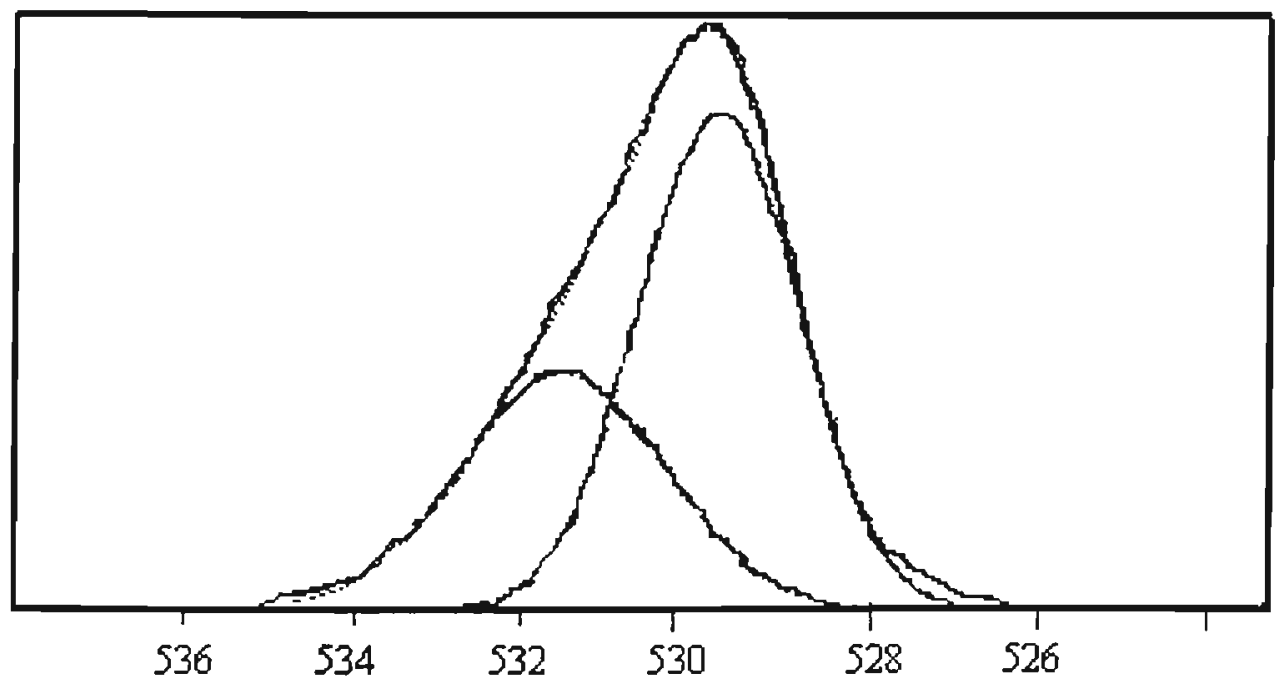

Figura 3.33. Decomposição dos espectros do $\mathrm{O}$ 1s obtidos para os eletrodos de filme de $\mathrm{SnO}_{2}(\mathrm{Sb})$ depositados sobre sílica ou titânio modificados com OTS. 


\section{6 - CONCLUSÖES}

As principais conclusões obtidas do estudo apresentado neste capítulo referem-se ao trabalho desenvolvido para a preparação e caracterização dos eletrodos transparentes, já que estes aspectos praticamente não foram investigados para os eletrodos de $\mathrm{Ti} / \mathrm{SnO}_{2}$.

Depositaram-se filmes de $\mathrm{SnO}_{2}$ dopados com $\mathrm{Cl}, \mathrm{F}$ ou $\mathrm{Sb}$ que eram transparentes, condutores e policristalinos. Os filmes eram constituidos por partículas com dimensões nanométricas (diâmetro e altura médios de 30 e $6 \mathrm{~nm}$, respectivamente) e apresentavam a superficie uniforme, com rugosidade média quadrática de apenas 1 a $2 \mathrm{~nm}$.

A morfologia dos filmes obtidos, principalmente no que se refere à uniformidade, baixa rugosidade e à pequena dimensão e à alta coalescência das partículas, se destaca como um resultado original quando comparado aos resultados obtidos em estudos correlatos apresentados na Literatura.

A técnica de Spray Pyrolysis consiste em um método relativamente simples e de baixo custo para a obtenção dos filmes transparentes de $\mathrm{SnO}_{2}$, porém, exige um controle rigoroso de todos os parâmetros envolvidos no processo de deposição, i.e, concentração da solução precursora e dos dopantes, fluxo do atomizador, morfologia e temperatura do substrato, etc.

As características do substrato têm grande influência na morfologia dos filmes depositados, especialmente para filmes finos. Para a obtenção de filmes uniformes e de baixa rugosidade é imprescindível que a superficie do substrato esteja perfeitamente limpa, para que tanto a nucleação como o crescimento do filme sejam uniformes.

Os dopantes empregados para aumentar a condutividade dos filmes de $\mathrm{SnO}_{2}$, apesar da baixa concentração na solução precursora $(0,2 \%)$, influem na direção preferencial de crescimento dos grãos e, consequentemente, afetam a morfologia das partículas, a espessura do filme, e ainda a composição química e o grau de hidratação da superficie.

Como mostram os próximos capítulos, estas propriedades influem no comportamento eletroquímico destes eletrodos e na susceptibilidade à corrosão induzida por perturbações eletroquímicas. 
CAPITULO 4

\section{CARACTERIZAÇÃO ELETROQUÍMICA DOS ELETRODOS DE FILME DE $\mathrm{SnO}_{2}$ SUPORTADO EM SÍlICA OU TITÂNIO}




\section{1 - INTRODUÇÃO}

Este capítulo apresenta o estudo desenvolvido para caracterizar as propriedades eletroquímicas dos eletrodos transparentes de $\mathrm{SnO}_{2}$ dopados com $\mathrm{Cl}, \mathrm{F}$ ou $\mathrm{Sb}$ e dos eletrodos de $\mathrm{Ti} / \mathrm{SnO}_{2}(\mathrm{Sb})$, modificados ou não com um filme de octadeciltriclorosilano.

Inicialmente, investigou-se o comportamento eletroquímico dos eletrodos em solução aquosa de um eletrólito inerte $\left(\mathrm{NaClO}_{4} 0,1 \mathrm{M}\right)$ e também em $\mathrm{K}_{4} \mathrm{Fe}(\mathrm{CN})_{6} 1 \mathrm{mM}$ por Voltametria Cíclica. Em prosseguimento, como o $\mathrm{SnO}_{2}$ é um material semicondutor, determinaram-se os gráficos de Mott-Schoktty $\left(\mathrm{C}^{-2}\right.$ vs. E) para estimar a densidade de portadores de carga $\left(\mathrm{N}_{\mathrm{D}}\right)$ e o potencial de bandas planas $\left(\mathrm{E}_{\mathrm{FB}}\right)$ para ambos os tipos de eletrodos não modificados. Para determinar as variações da capacidade interfacial em função do potencial aplicado, empregaram-se as técnicas de Espectroscopia de Impedância Eletroquímica (EIS) e Voltametria Cíclica de Baixa Amplitude (SACV).

Para finalizar este estudo, verificaram-se possíveis aplicações para os eletrodos de $\mathrm{Ti} / \mathrm{SnO}_{2}(\mathrm{Sb})$ modificados com OTS para o desenvolvimento de biosensores e como ânodos para a eletroxidação de compostos orgânicos. A primeira alternativa foi motivada pela suposição de que proteínas eletroativas poderiam adsorver na superficie do eletrodo e manter a estrutura inalterada, protegidas pelas cadeias do organosilano $[178,179]$. Para verificar esta possibilidade, realizaram-se testes com o citocromo-C. Para a segunda alternativa, realizaram-se testes com metanol em solução aquosa para verificar se o filme hidrofóbico de OTS poderia atuar como um pré-concentrador e promover a oxidação de compostos orgânicos $[136,137]$. Infelizmente, porém, os resultados obtidos em ambas as tentativas não foram promissores: o citocromo-C não apresentou qualquer resposta eletroquímica, e o metanol, além de ter sido fortemente adsorvido na superficie do eletrodo pareceu até mesmo bloqueá-lo, como será discutido no final deste capítulo. 


\section{2 - DETALHES EXPERIMENTAIS}

\subsubsection{Reagentes e soluções}

As medidas eletroquímicas foram realizadas em soluções aquosas de $\mathrm{NaClO}_{4} \quad 0.1$ $\mathrm{M}$ com pH 2,0 ou 10,0 e em solução de $\mathrm{K}_{4} \mathrm{Fe}(\mathrm{CN})_{6} 1 \mathrm{mM}$ em $\mathrm{NaClO}_{4} 0.1 \mathrm{M}$ com pH 2,0.

$\mathrm{O}$ pH das soluções foi ajustado pela adição de $\mathrm{HClO}_{4}$ ou $\mathrm{NaOH}$, sob agitação magnética, empregando um pHmetro e eletrodo de vidro combinado. Antes de ajustar o $\mathrm{pH}$, as soluções foram desoxigenadas através do borbulhamento de nitrogênio por 30 minutos. Para evitar a presença de agentes oxidantes no gás, empregou-se um sistema de purificação constituído por dois frascos lavadores, o primeiro contendo solução de metavanadato de amônio/amalgama de Zn e o segundo contendo a solução de trabalho.

A água empregada no preparo das soluções e na lavagem final dos eletrodos foi previamente destilada e purificada através de um sistema Milli-pore, Milli-Q.

Utilizaram-se apenas reagentes de grau p.a. e de procedência "Merck" (exceto quando especificado). $\mathrm{O} \mathrm{NaClO}_{4}$ foi previamente recristalizado, para minimizar uma possível contaminação com cloreto (o $\mathrm{NaCl}$ é muito mais solúvel). $\mathrm{O}$ procedimento consistiu em dissolver o sal em água até saturação, filtrar a solução e manter o filtrado sob uma lâmpada de infra-vermelho até que se iniciasse o processo de cristalização. O sistema foi então deixado em repouso por 24 horas. A seguir, o sólido foi retirado com o auxílio de uma espátula e submetido à secagem a vácuo. Para finalizar o processo, o $\mathrm{NaClO}_{4}$ foi colocado em estufa a $100^{\circ} \mathrm{C}$ até que apresentasse peso constante, e, depois, mantido em um dessecador [149].

Nos experimentos realizados para testar possíveis aplicações para os eletrodos, utilizaram-se ainda soluções tampão de $\mathrm{Na}_{2} \mathrm{HPO}_{4} / \mathrm{NaH}_{2} \mathrm{PO}_{4}$ de $\mathrm{pH}$ 7,00 (preparadas com água previamente fervida e purgada com $\mathrm{N}_{2}$ para eliminar o $\mathrm{CO}_{2}$ ), solução $10 \mathrm{mM}$ de citocromo-C (Cyt-C) no tampão fosfato de pH 7,00 (Cyt-C "Aldrich", 99\%) e solução aquosa 2,5 mM de $\mathrm{CH}_{3} \mathrm{OH}$ em meio de $\mathrm{NaClO}_{4}$ 0,1 M de pH 2,0. 


\subsubsection{Preparação dos eletrodos para as medidas eletroquímicas}

Antes de iniciar as medidas eletroquímicas, os eletrodos foram previamente submetidos a um processo de limpeza. Para os eletrodos depositados sobre titânio, realizaram-se dois banhos de ultra-som em acetona, com duração de 5 minutos cada. A seguir, apenas a face com filme de $\mathrm{SnO}_{2}$ depositado foi enxaguada abundantemente com água. A secagem do eletrodo foi feita com jato de gás nitrogênio.

Os eletrodos depositados sobre sílica foram previamente cortados nas dimensões adequadas com lápis de diamante e submetidos a sucessivos banhos de ultra-som em acetona, etanol e água, seguidos de secagem.

Para os eletrodos modificados, utilizou-se apenas enxague abundante com água e secagem, porque estes já haviam sido submetidos ao processo de limpeza antes da adsorção do organosilano, e, desde então, haviam sido manipulados somente através de pinças.

\subsubsection{Células eletroquímicas e equipamentos}

Nas medidas realizadas para os eletrodos depositados sobre titânio, empregou-se uma célula eletroquímica similar às células empregadas para estudos de corrosão, p.ex. como o modelo K0047 da EG\&G/PAR, mas de menor dimensão ( $12 \mathrm{~mL}$ de capacidade). A célula consistia de um cilindro de Pyrex com uma abertura circular em uma das laterais, onde o eletrodo de trabalho foi colocado e fixado com o auxílio de um anel de Viton. A área do eletrodo em contato com a solução correspondia a aproximadamente $0,636 \mathrm{~cm}^{2}$. A parte superior da célula dispunha de diversos orifícios, para adaptação dos outros eletrodos e entrada e saída de gás.

Empregou-se uma espiral de Pt platinizada como contra-eletrodo, e, como eletrodo de referência, utilizou-se um eletrodo de calomelano saturado (ECS), colocado na célula eletroquímica em um compartimento separado através de um capilar de Luggin. O eletrodo de referência foi ainda conectado a um capacitor de $10 \mu \mathrm{F}$ e a um fio de Pt que foi colocado na solução, com o objetivo de minimizar ruídos de frequência da rede elétrica e melhorar a resposta do sistema [51]. As medidas foram realizadas empregando o potenciostato/galvanostato EG\&G PAR modelo 273A, acionado por um microcomputador IBM-PC através dos programas M-270 e M-398. 
Nas medidas realizadas para os eletrodos depositados sobre sílica empregaram-se duas células eletroquímicas distintas. Uma das células era constituída por um copo de Pyrex com capacidade para $50 \mathrm{~mL}$ e tampa de Teflon com orificios para adaptação dos eletrodos e do borbulhador de gás. Nesta célula, os eletrodos de filme de $\mathrm{SnO}_{2}$ depositado sobre sílica foram utilizados na forma de amostras retangulares de aproximadamente $1,0 \times 1,5 \mathrm{~cm}^{2}$. A área do eletrodo exposta à solução correspondeu a aproximadamente $0,6 \mathrm{~cm}^{2}$. Como eletrodo auxiliar e de referência, empregaram-se uma espiral de Pt e o ECS (descritos anteriormente).

A outra célula foi utilizada na fase inicial do trabalho, quando as medidas foram efetuadas com o equipamento de STM. Topometrix acoplado ao bipotenciostato DM-1000, operando no modo para Eletroquímica. A célula eletroquímica consistia de um pequeno corpo de Teflon, colocado sobre o eletrodo de trabalho com o auxílio de um anel de Viton e 4 parafusos para fixar o conjunto. A capacidade desta célula era de aproximadamente 0,15 $\mathrm{mL}$, e a área exposta do eletrodo de trabalho era de $0,385 \mathrm{~cm}^{2}$. Utilizaram-se um anel e um fio de Pt atuando respectivamente como contra-eletrodo e pseudo eletrodo de referência.

A maioria dos experimentos realizados empregando a célula eletroquímica desenhada para os experimentos de STM foram posteriormente refeitos com a célula eletroquímica convencional, utilizando o ECS como referência. As exceções incluem os experimentos em $\mathrm{K}_{4} \mathrm{Fe}(\mathrm{CN})_{6}$ realizados para os eletrodos transparentes e, eventualmente, alguns outros voltamogramas.

A comparação dos voltamogramas obtidos em ambos os sistemas mostraram reprodutibilidade nos resultados, evidenciando que o eletrodo de pseudo-referência de Pt apresentava um potencial estável na solução de $\mathrm{NaClO}_{4} 0,1 \mathrm{M}$ de $\mathrm{pH} 2,0$. O potencial de ambos os eletrodos está relacionado por:

$$
\mathrm{E}_{\mathrm{ECS}}=\mathrm{E}_{\mathrm{Pt}}+0,45 \mathrm{~V}
$$

No entanto, nos experimentos realizados com o eletrodo de Pt como pseudoreferência em solução alcalina $\left(\mathrm{NaClO}_{4} 0,1 \mathrm{M}\right.$ de $\left.\mathrm{pH} 10,0\right)$, verificaram-se resultados pouco coerentes e não reprodutíveis quando repetidos com o ECS. Provavelmente o eletrodo de Pt não apresenta um comportamento estável em soluções alcalinas, e não pode ser empregado como um eletrodo de pseudo referência em tais condições. Na apresentação dos resultados, estará indicado em cada experimento qual foi o eletrodo de referência utilizado. 


\subsubsection{Metodologia}

Para todos os experimentos realizados, a solução de trabalho foi previamente desaerada através do borbulhamento de nitrogênio durante 30 minutos. Antes de iniciar as medidas, os eletrodos foram mantidos na solução durante 2 horas (exceto para as medidas de potencial de circuito aberto, $\mathrm{E}_{\mathrm{CA}}$ ). Os experimentos foram realizados em temperatura ambiente, a $(25 \pm 1)^{\circ} \mathrm{C}$, e sob atmosfera inerte, mantendo-se o $\mathrm{N}_{2}$ sobre a solução.

Em eletrólito inerte, $\mathrm{NaClO}_{4} \quad 0,1 \mathrm{M}$, determinaram-se os potenciais nos quais iniciam-se as reações de desprendimento de hidrogênio e de oxigênio (RDH e RDO) em soluções de $\mathrm{pH}$ 2,0 e 10,0. Para determinar o potencial para a RDO, realizaram-se repetidas varreduras triangulares de potencial, a partir do $\mathrm{E}_{\mathrm{CA}}$ e com aumento progressivo no limite de potencial anódico. Experimentos similares foram realizados para determinar o potencial para a $\mathrm{RDH}$. Para os eletrodos de filme de $\mathrm{SnO}_{2}$ depositado em titânio, realizaram-se ainda curvas de polarização anódica quase estacionária, a $0,166 \mathrm{mVs}^{-1}$, desde um potencial $50 \mathrm{mV}$ abaixo do $\mathrm{E}_{\mathrm{CA}}$ até o potencial para a $\mathrm{RDO}$.

Nos experimentos com ferrocianeto de potássio, registraram-se os perfis $\mathrm{I} / \mathrm{E} \mathrm{em}$ diversas velocidades de varredura $(v)$, para todos os tipos de eletrodos, modificados ou não com OTS.

As medidas de Voltametria Cíclica de Baixa Amplitude e de Espectroscopia de Impedância Eletroquímica foram efetuadas sob a aplicação de potenciais compreendidos entre 0,1 e 1,8 V, somente depois que o sistema apresentasse uma corrente constante. Como eletrólito, empregou-se solução de $\mathrm{NaClO}_{4} 0.1 \mathrm{M}$, com pH 2,0.

Nas medidas de SACV, o procedimento experimental consistiu em aplicar um dado valor de potencial $\mathrm{E}$ ao eletrodo durante pelo menos 120 segundos, e a seguir realizar a varredura triangular de potencial entre $(E-20 \mathrm{mV})$ até $(\mathrm{E}+20 \mathrm{mV})$, iniciada em sentido positivo. Em cada experimento, realizaram-se 2 varreduras repetidas de potencial.

Para estimar as resistências $R_{S}$ e $R_{P}$ do sistema, de acordo com o circuito apresentado na Fig. 2.13, registraram-se os perfis potenciodinâmicos obtidos ao variar linearmente o potencial desde 0,38 até $0,42 \mathrm{~V}$. Empregaram-se diversos valores de $\mathrm{v}$, compreendidos entre 0,001 a $2 \mathrm{Vs}^{-1}$ (exceto para o eletrodo de $\mathrm{SnO}_{2}(\mathrm{Sb}$ ), onde utilizaramse $0,001<v<1 \mathrm{Vs}^{-1}$ ). Para estimar a capacidade da dupla camada elétrica, efetuaram-se 
medidas em diversos intervalos de potencial ( $\mathrm{E}-20 \mathrm{mV}<\mathrm{E}<\mathrm{E}+20 \mathrm{mV}$ ), com valores de $\mathrm{E}$ compreendidos entre 0,2 a $1,2 \mathrm{~V}$, somente em $v$ baixas $\left(1<v<5 \mathrm{mVs}^{-1}\right)$.

Os dados foram tratados de acordo com a metodologia proposta por Macdonald, apresentada na seção 2.6.2 da Revisão Bibliográfica. Deve-se acrescentar ainda que, para determinar $\Delta \mathrm{I}$, utilizaram-se os voltamogramas obtidos na segunda varredura, e, para determinar $1 / R_{a p}$, os valores da derivada foram obtidos graficamente, após traçar uma curva média para a corrente, na região onde a varredura de potencial foi invertida.

Os espectros de impedância eletroquímica foram determinados aplicando sinais de amplitude de $5 \mathrm{mV}$, entre as frequências de 0,1 e $10^{5} \mathrm{~Hz}$. Os espectros de impedância foram analisados usando o programa desenvolvido por Boukcamp [148] para atribuição do circuito elétrico equivalente através do ajuste dos dados experimentais.

Os experimentos de eletro-oxidação de metanol foram realizados com os eletrodos de $\mathrm{Ti} / \mathrm{SnO}_{2}(\mathrm{Sb})$ modificados e não modificados com OTS. Cada eletrodo foi previamente mantido na solução $0,1 \mathrm{M}$ de $\mathrm{NaClO}_{4} \mathrm{com}$ pH 2,0 durante 2 horas, e, a seguir, registraramse os voltamogramas cíclicos (VC) no intervalo compreendido entre 0,8 e $1,6 \mathrm{~V}$ em diferentes velocidades de varredura. A seguir, o mesmo conjunto de experimentos foi realizado com uma solução $2,5 \mathrm{mM}$ de $\mathrm{CH}_{3} \mathrm{OH}$ em $0,1 \mathrm{M}$ de $\mathrm{NaClO}_{4} \mathrm{com}$ pH 2,0.

Os estudos com Citocromo-C foram realizados seguindo um procedimento similar. Inicialmente, o eletrodo foi mantido na solução tampão de $\mathrm{pH} 7,0$, e registraram-se os VC em diversas $v$ no intervalo de $-0,25$ a $+0,25 \mathrm{~V}$. A seguir, a solução tampão foi retirada da célula com o auxílio de uma pipeta, adicionou-se a solução $2,5 \mathrm{mM}$ de Cyt-C em tampão, e acompanhou-se a variação do $\mathrm{E}_{\mathrm{CA}}$. Após 2 horas, registraram-se também os VC. Porém, como já foi mencionado na introdução deste capítulo, não foi obtida qualquer resposta eletroquímica para este sistema e, por esta razão, os resultados obtidos neste estudo não foram incluídos na seção 4.3 . 


\section{3-RESULTADOS E DISCUSSÃO}

\subsubsection{Comportamento eletroquímico dos eletrodos transparentes}

\subsubsection{O potencial de circuito aberto dos eletrodos em solução de $\mathrm{NaClO}_{4}$}

As curvas da variação do $\mathrm{E}_{\mathrm{CA}}$ do eletrodo em função do tempo em contato com a solução de $\mathrm{NaClO}_{4}$ 0,1 M de pH 2,0 estão representadas na Figura 4.1. As curvas foram registradas alguns minutos após a imersão do eletrodo na solução, devido às dificuldades verificadas para a montagem da célula eletroquímica.

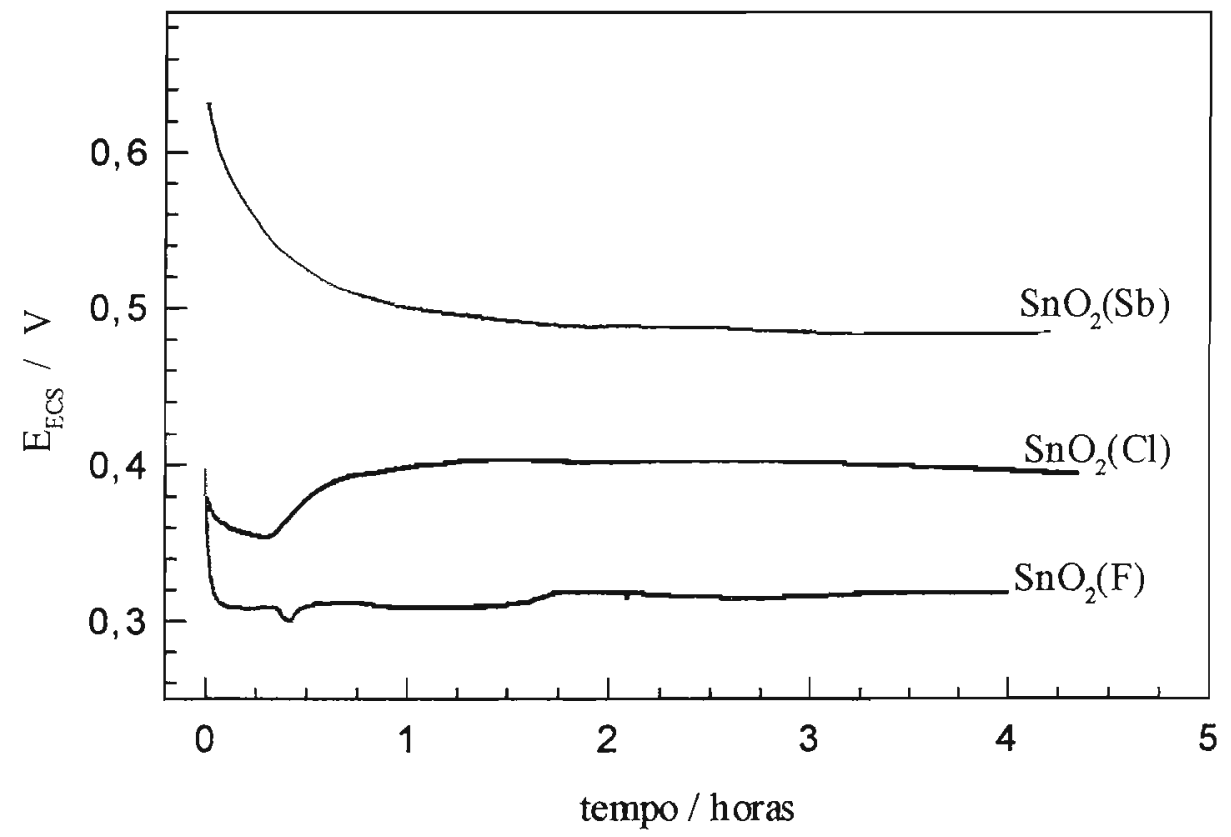

Figura 4.1. Potencial de circuito aberto dos eletrodos transparentes de $\mathrm{SnO}_{2}$ em função do tempo em contato com a solução de $\mathrm{NaClO}_{4} 0,1 \mathrm{M}$ de $\mathrm{pH} 2,0$.

Para todos os eletrodos investigados, verificou-se que o $\mathrm{E}_{\mathrm{CA}}$ atingiu um valor estável após aproximadamente 2 horas em contato com a solução. Para os eletrodos dopados com $\mathrm{Sb}$, o potencial simplesmente diminuiu lentamente até atingir o valor estável em aproximadamente $0,49 \mathrm{~V}$; no entanto, para os outros eletrodos, o potencial inicialmente decresceu para depois aumentar, permanecendo constante em 0,40 e $0,32 \mathrm{~V}$ para os eletrodos dopados com $\mathrm{Cl}$ e com $\mathrm{F}$, respectivamente. 
A observada variação do $E_{C A}$ com o tempo deve estar relacionada aos diversos equilíbrios envolvidos nos processos de adsorção de moléculas de água e hidratação da superfície do $\mathrm{SnO}_{2}$. Para os eletrodos investigados neste trabalho, as análises de XRD evidenciaram que os filmes de $\mathrm{SnO}_{2}$ eram policristalinos com orientação preferencial (110). Como já foi discutido na Revisão Bibliográfica, as moléculas de $\mathrm{H}_{2} \mathrm{O}$ se dissociam quando adsorvidas neste plano cristalino, formando grupos $\mathrm{Sn}-\mathrm{OH}[31,32,62,128]$. A formação destes grupos pode ter alterado o estado de oxidação dos átomos de Sn superficiais, e, consequentemente, o interior do sólido também se reestruturou. Como a formação das espécies Sn-OH produz, no geral, um excesso de cargas negativas, deve ter diminuído o potencial da superfície do eletrodo [31, 32]. Estes processos devem ser relativamente lentos, e, por esta razão, o $\mathrm{E}_{\mathrm{CA}}$ variou até que fosse estabelecido o equilíbrio entre a superfície do eletrodo e a solução.

Na Fig. 4.1, verifica-se que, nas mesmas condições, os eletrodos transparentes de $\mathrm{SnO}_{2}(\mathrm{Cl}), \mathrm{SnO}_{2}(\mathrm{~F})$ e $\mathrm{SnO}_{2}(\mathrm{Sb})$ apresentaram $\mathrm{E}_{\mathrm{CA}}$ distintos. Possivelmente, este resultado está relacionado às diferenças na composição química da superfície e na estrutura cristalina entre os três eletrodos, discutidos no capítulo anterior.

Para todos os eletrodos, a orientação cristalina predominante foi a (110) e, embora as outras orientações predominantes fossem distintas para cada filme, a análise destas propriedades não ofereceu qualquer relação com os valores de $\mathrm{E}_{\mathrm{CA}}$ obtidos. Porém, no que se refere à composição química, os valores do $\mathrm{E}_{\mathrm{CA}}$ determinados foram coerentes com o que seria esperado considerando a eletronegatividade dos dopantes.

De acordo com o modelo da tripla camada elétrica para óxidos, a carga da superficie, e, consequentemente, o $E_{C A}$, dependem dos equilíbrios de dissociação dos grupos $\mathrm{Sn}-\mathrm{OH}[180]$, ou seja,

$$
\begin{aligned}
& \mathrm{Sn}-\mathrm{OH}=\mathrm{Sn}-\mathrm{O}^{-}+\mathrm{H}^{+} \\
& \mathrm{Sn}_{-} \mathrm{OH}_{2}^{+}=\mathrm{Sn}-\mathrm{OH}+\mathrm{H}^{+}
\end{aligned}
$$

Em geral, estes equilíbrios são discutidos em relação às características da solução $(\mathrm{pH}$, força iônica, etc). Porém, parece razoável supor que estes equilíbrios também sejam influenciados pela presença de espécies "estranhas" na estrutura cristalina do óxido, i.e., os dopantes. Sendo assim, seria esperado que, quanto maior a eletronegatividade dos 
dopantes, mais os equilíbrios das reações de dissociação do $\mathrm{SnOH}$ estariam deslocados para a direita. Consequentemente, a carga da superfície seria mais negativa e o valor do $\mathrm{E}_{\mathrm{CA}}$ seria menor, como foi observado para o $\mathrm{E}_{\mathrm{CA}}$ dos eletrodos dopados com, $\mathrm{F}, \mathrm{Cl}$ e Sb.

\subsubsection{Perfis potenciodinâmicos em $\mathrm{NaClO}_{4} 0,1 \mathrm{M}$}

O comportamento eletroquímico dos eletrodos de $\mathrm{SnO}_{2}$ em solução aquosa foi caracterizado através de Voltametria Cíclica. Para cada eletrodo, ao realizar a varredura de potencial partindo do $E_{\mathrm{CA}}$ em direção crescente, verificou-se apenas uma corrente capacitiva baixa em um amplo intervalo de potencial, até que fosse atingido o potencial para a $\mathrm{RDO}$.

Para todos os eletrodos, os experimentos mostraram que, para um eletrodo "novo", i.e., que ainda não tivesse sido empregado em qualquer tipo de investigação, o potencial no qual se iniciava a RDO apresentava alterações nas primeiras varreduras. Obtinham-se curvas I/E reprodutíveis e estáveis somente após 5 ou 6 ciclos de varreduras de potencial ou ainda, após alguns minutos de polarização anódica na região da RDO.

A Figura 4.2. ilustra a variação do perfil potenciodinâmico de um eletrodo novo de $\mathrm{SnO}_{2}(\mathrm{Sb})$ submetido a ciclos repetidos de varredura de potencial. Verifica-se que, na primeira varredura de potencial, a RDO iniciou-se antes de 1,6 V. Nas varreduras seguintes, esta reação iniciou-se em potenciais mais anódicos, até que se obteve um perfil potenciodinâmico reprodutível e estável a partir da $6^{a}$ varredura.

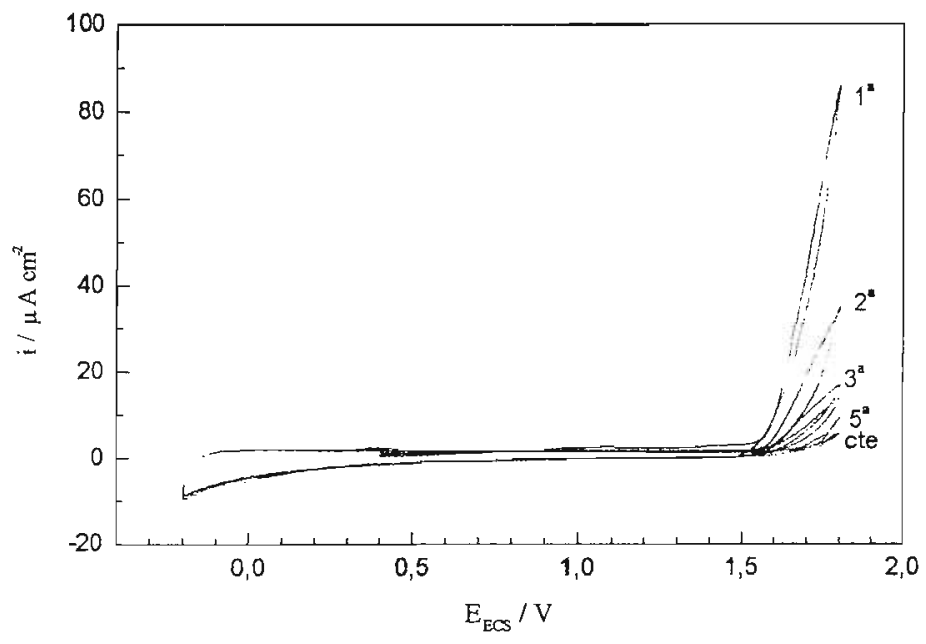

Figura 4.2. Perfis potenciodinâmicos obtidos em repetidas varreduras triangulares de potencial para um eletrodo novo de $\mathrm{SnO}_{2}(\mathrm{Sb})$ depositado em sílica. Eletrólito: $0,1 \mathrm{M} \mathrm{NaClO}_{4}$ de $\mathrm{pH} 2,0 ; v=50 \mathrm{mV} / \mathrm{s}$. 
Na Literatura, há relatos da observação de um comportamento semelhante para eletrodos transparentes de óxido de índio dopado com estanho (ITO) [181], e ainda para eletrodos de $\mathrm{SnO}_{2}(\mathrm{Sb})$ depositados sobre titânio [51, 76].

Para os eletrodos de ITO, Kraft [181] sugeriu que a polarização na região da RDO poderia provocar a oxidação dos átomos de $O$ constituintes da superficie do eletrodo, causando a quebra das ligações Sn-O e In-O. Os íons In $^{3+}$ passariam para a solução, porém, os íons $\mathrm{Sn}^{4+}$ reagiriam com espécies $\mathrm{OH}$ da solução, depositando-se na superficie como $\mathrm{Sn}(\mathrm{OH})_{4}$, que seria menos catalítico para a RDO.

Para os eletrodos de $\mathrm{SnO}_{2}$ depositados em titânio, sugeriram-se diferentes explicações para este fenômeno. $\mathrm{Na}$ sua tese, Fugivara [51] observou ainda que os voltamogramas obtidos na primeira varredura de potencial apresentavam a carga anódica maior, e sugeriu que este fenômeno era devido à oxidação da superficie ativa do titânio que não estivesse recoberto pelo filme de $\mathrm{SnO}_{2}$. Nos trabalhos de Comninellis [76], como já discutido na Revisão Bibliográfica, admitiu-se que os eletrodos novos poderiam apresentar maior número de sítios catalíticos para a RDO, relacionados com a não-estequiometria da superfície do óxido de estanho. Após a aplicação de alguns tratamentos eletroquímicos, a superficie poderia se tornar estequiométrica, perdendo aqueles sítios que haviam atuado para a RDO nas varreduras iniciais.

A princípio, nenhuma destas hipóteses é satisfatória para os eletrodos investigados neste trabalho, considerando a natureza do substrato (sílica) e o fato de que nem todos os eletrodos apresentavam deficiência de $\mathrm{O}$ na superficie (o eletrodo de $\mathrm{SnO}_{2}(\mathrm{Sb}$ ) era praticamente estequiométrico). Admitindo a sugestão de Kraft, se os átomos de $\mathrm{O}$ da superficie participam na RDO, então seria possível que a superficie de um eletrodo novo fosse mais catalítica para a RDO por não estar ainda completamente hidratada. Considerando, porém, apenas os experimentos realizados e os resultados obtidos neste trabalho, não há subsídios para confirmar esta hipótese ou formular outras que expliquem este fenômeno.

Os perfis potenciodinâmicos estáveis obtidos para os três tipos de eletrodos de $\mathrm{SnO}_{2}$ em $\mathrm{NaClO}_{4}$ 0,1 M com pH 2,0 estão representados na Figura 4.3. Para verificar a estabilidade do comportamento eletroquímico dos eletrodos, realizaram-se 20 varreduras repetitivas de potencial entre a $\mathrm{RDH}$ e a RDO. Não se observaram diferenças no perfil voltamétrico nem na superficie dos eletrodos, examinada por SEM e AFM. Realizaram-se 
também 100 varreduras repetitivas de potencial para outras amostras do eletrodo novo, e não detectaram-se alteraçôes significativas no comportamento eletroquímico do eletrodo, mesmo após o $100^{\circ}$ ciclo de varredura registrada. O efeito desta perturbação na morfologia dos eletrodos será apresentado apenas no Capítulo 5.

Para os eletrodos dopados com $\mathrm{Cl}$ e F, a RDO iniciou em aproximadamente $1,55 \mathrm{~V}$, enquanto que, para o eletrodo de $\mathrm{SnO}_{2}(\mathrm{Sb})$, apenas a partir de cerca de 1,8 V. Quando o sentido da varredura foi invertido, a partir de potenciais inferiores ao $E_{\mathrm{CA}}$, todos os eletrodos apresentaram um aumento progressivo na corrente catódica. A carga catódica deve ser resultante da hidratação da superfície do eletrodo seguida pela $\mathrm{RDH}$ e pela redução do filme de $\mathrm{SnO}_{2}$, como discutido na Seção 2.3.7 da Revisão Bibliográfica. A comparação das curvas obtidas mostrou ainda que o aumento da carga catódica foi verificado em potenciais menos negativos para o eletrodo de $\mathrm{SnO}_{2}(\mathrm{Sb})$ que para os outros dois eletrodos. A análise de XPS discutida na seção 3.3.3 havia revelado que, entre os três tipos de eletrodo, era justamente o $\mathrm{SnO}_{2}(\mathrm{Sb})$ que apresentava maior quantidade de grupos $\mathrm{OH}$ na superfície. Possivelmente, a maior carga catódica tenha sido decorrente da maior densidade de grupos $\mathrm{M}-\mathrm{OH}$ na superfície.

$\mathrm{Na}$ curva correspondente ao eletrodo dopado com $\mathrm{Cl}$, verifica-se ainda um pequeno pico de redução em aproximadamente $0,3 \mathrm{~V}$. Este pico foi observado aleatoriamente em alguns voltamogramas e para todos os tipos de eletrodos. No entanto, ainda não foi possível explicar a sua presença; pode-se afirmar apenas que este pico não estava relacionado à contaminação com cloreto. Realizaram-se experimentos de Voltametria Cíclica empregando concentrações crescentes de $\mathrm{NaCl}$ e este pico não foi alterado, nem mesmo para concentração correspondente a $1 \mathrm{M}$.

As diferenças existentes nos perfis potenciondinâmicos determinados para os três tipos de eletrodos podem estar relacionadas às características superficiais ou às propriedades semicondutoras de cada eletrodo. Esta questão será discutida posteriormente, considerando os valores dos parâmetros $\mathrm{E}_{\mathrm{FB}}$ e $\mathrm{N}_{\mathrm{D}}$ determinados para cada eletrodo.

Embora todos os experimentos eletroquímicos tenham sido realizados em meio ácido ( $\mathrm{pH}$ 2,0), realizaram-se também alguns experimentos em meio alcalino, considerando que informações sobre o comportamento dos eletrodos neste meio poderiam ser úteis. As curvas $\mathrm{I} / \mathrm{E}$ dos eletrodos transparentes de $\mathrm{SnO}_{2}$ em solução de $\mathrm{NaClO}_{4} 0,1 \mathrm{M}$ em pH 10,0 estão representados na Fig. 4.4. 
Independente do dopante, todos os eletrodos apresentaram praticamente o mesmo perfil $\mathrm{I} / \mathrm{E}$ em $\mathrm{pH} 10$. A RDO foi observada em aproximadamente $1,0 \mathrm{~V}$ e, quando o sentido da varredura foi invertido, observou-se apenas uma carga capacitiva baixa que aumentou abruptamente a partir de $0,35 \mathrm{~V}$. Nesta situação, não foi verificado o progressivo aumento da carga catódica observado em pH 2,0 (Fig. 4.3), associado com a adsorção de prótons na superfície (inverso da reação $4.2 \mathrm{~b}$ ). Resultados similares já foram relatados para eletrodos transparentes [114] e de $\mathrm{Ti} / \mathrm{SnO}_{2}(\mathrm{Sb})[76]$.

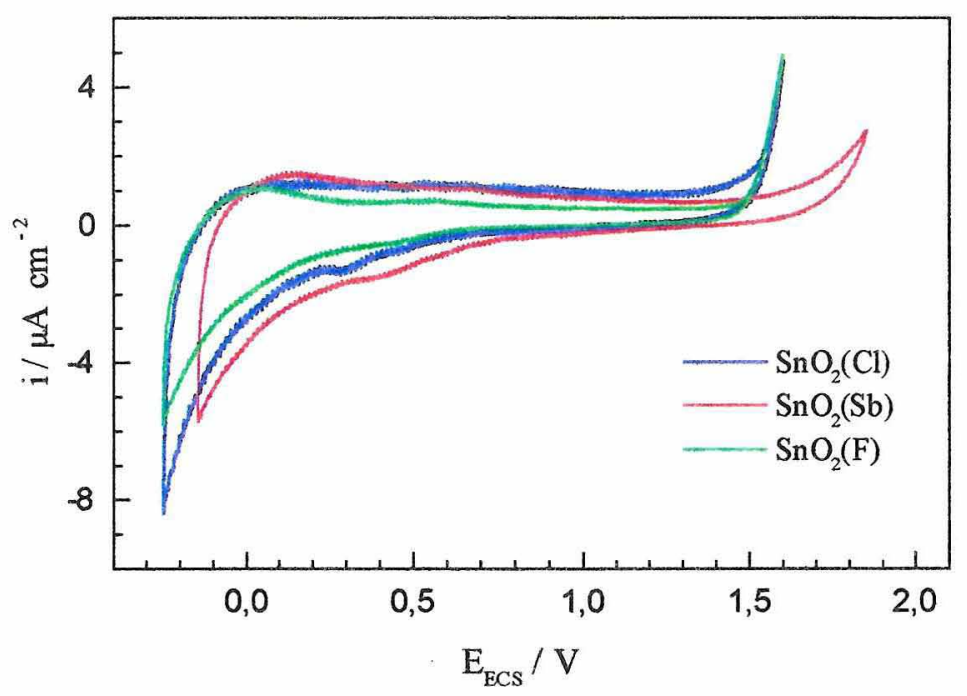

Figura 4.3. Perfis potenciodinâmicos dos eletrodos de filme de $\mathrm{SnO}_{2}$ em solução de $\mathrm{NaClO}_{4}$ 0,1 M de $\mathrm{pH} 2,0$, registrados a $50 \mathrm{mV} / \mathrm{s}$.

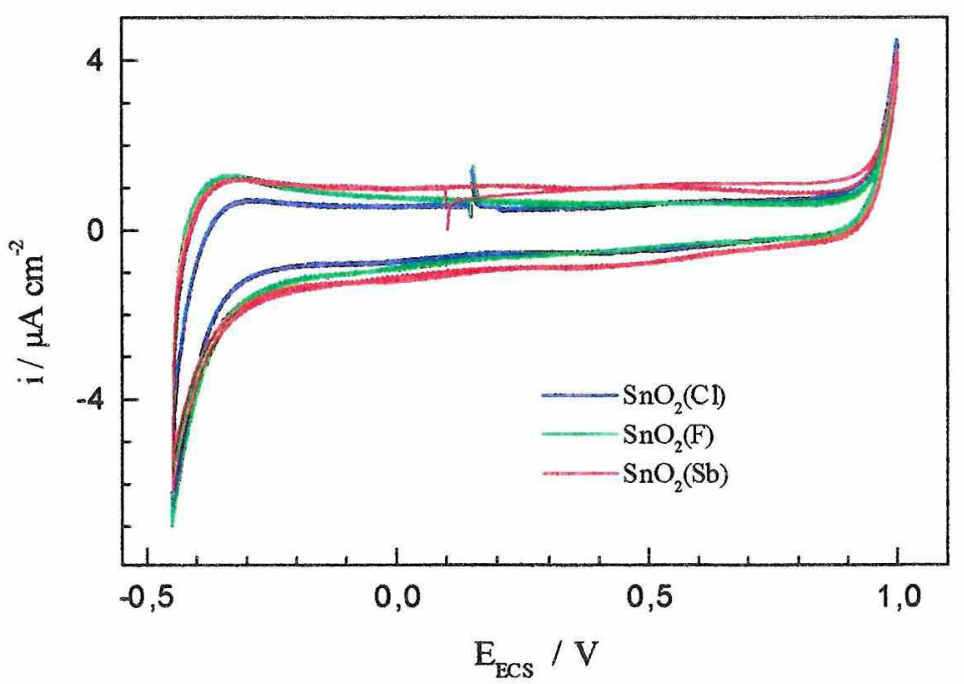

Figura 4.4. Perfis potenciodinâmicos dos eletrodos transparentes de filme de $\mathrm{SnO}_{2}$ em solução de $\mathrm{NaClO}_{4} 0,1 \mathrm{M}$ de $\mathrm{pH} 10,0 . v=50 \mathrm{mV} / \mathrm{s}$. 
Para os eletrodos modificados com OTS, os perfis potenciodinâmicos determinados a $50 \mathrm{mV} / \mathrm{s}$ em solução aquosa de $\mathrm{pH} \mathrm{2,0} \mathrm{estão} \mathrm{representados} \mathrm{na} \mathrm{Fig.} \mathrm{4.5.} \mathrm{Estes} \mathrm{experi-}$ mentos foram realizados no aparelho de STM, empregando Pt como eletrodo de pseudoreferência na célula eletroquímica. Por esta razão, o gráfico apresenta as duas escalas, onde $\mathrm{E}_{\mathrm{ECS}}=\mathrm{E}_{\mathrm{Pt}}+0,45 \mathrm{~V}$, segundo a relação expressa na equação (4.1).

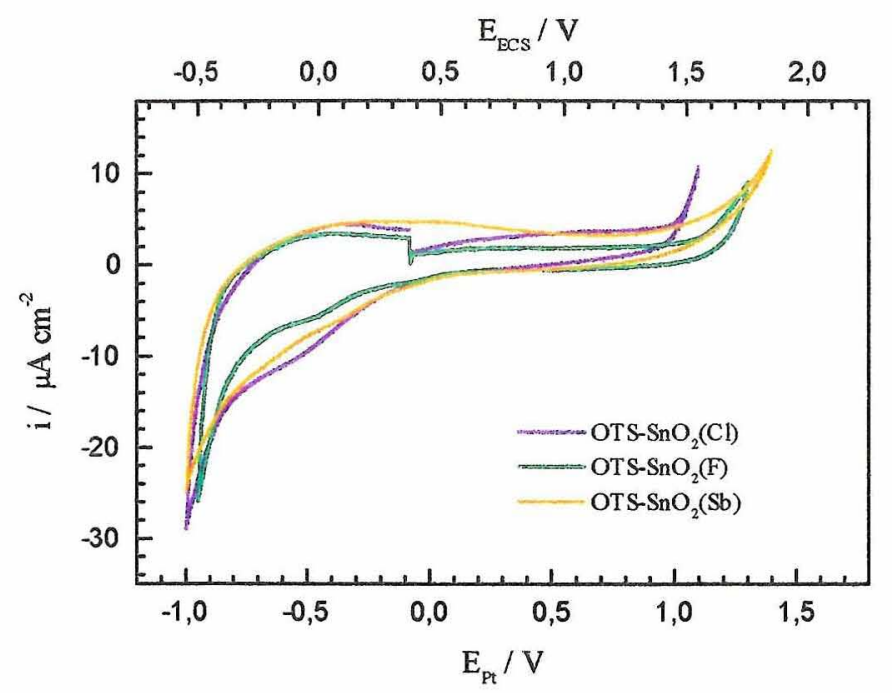

Figura 4.5. Curvas $\mathrm{I} / \mathrm{E}$ para os eletrodos transparentes de filme de $\mathrm{SnO}_{2}$ modificados com OTS. Eletrólito: $\mathrm{NaClO}_{4}$ (aq.) $0,1 \mathrm{M}$ de $\mathrm{pH} \mathrm{2,0.v}=50 \mathrm{mV} / \mathrm{s}$.

De um modo geral, a comparação entre os voltamogramas obtidos para os eletrodos modificados revelou que, do lado anódico, apenas o eletrodo modificado de $\mathrm{SnO}_{2}(\mathrm{~F})$ apresentou a RDO em um potencial mais positivo que o eletrodo não modificado, enquanto que os outros eletrodos não apresentaram alterações significativas. Este fenômeno sugere que a interação do OTS com a superfície do eletrodo de $\mathrm{SnO}_{2}(\mathrm{~F})$ pode ter sido maior que para os outros eletrodos. É possível que, devido à maior eletronegatividade do $\mathrm{F}$, as reações entre os grupos $\mathrm{Sn}-\mathrm{OH}$ e as moléculas de OTS tenham sido favorecidas.

No lado catódico, o aumento da corrente devido à $\mathrm{RDH}$ e aos outros processos catódicos ocorreu em potenciais menos negativos, para todos os eletrodos. P.ex., as densidades de corrente catódica apresentadas em $-0,1 \mathrm{~V}$ (em relação ao ECS) corresponderam a -5 e $-9 \mu \mathrm{Acm}^{-2}$ para os eletrodos de $\mathrm{SnO}_{2}(\mathrm{Sb})$ e OTS-SnO${ }_{2}(\mathrm{Sb})$, respectivamente. A Fig. 4.5 revela que os eletrodos modificados apresentaram densidades de corrente maiores, principalmente no lado catódico. É possível que a presença do filme hidrofóbico de OTS tenha alterado a capacidade da dupla camada dos eletrodos, interferindo nos equilíbrios responsáveis pela carga nesta região de potencial. Este fenômeno também foi observada para os eletrodos depositados em titânio, como será discutido posteriormente. 


\subsubsection{A reversibilidade das reações de óxido-redução de $\mathrm{K}_{4} \mathrm{Fe}(\mathrm{CN})_{6}$}

Para discutir a reversibilidade do sistema $\mathrm{SnO}_{2} \mid \mathrm{K}_{4} \mathrm{Fe}(\mathrm{CN})_{6}$ (aq.), analisaram-se os potenciais de pico anódico $\left(\mathrm{E}_{\mathrm{p}}{ }^{\mathrm{A}}\right)$ e catódico $\left(\mathrm{E}_{\mathrm{p}}{ }^{\mathrm{C}}\right)$ e as intensidades das correntes de pico anódica $\left(\mathrm{I}_{\mathrm{p}}^{\mathrm{A}}\right)$ e catódica $\left(\mathrm{I}_{\mathrm{p}}^{\mathrm{C}}\right)$ em função da velocidade de varredura $(v)$ [126].

Os voltamogramas cíclicos determinados em solução de $\mathrm{K}_{4} \mathrm{Fe}(\mathrm{CN})_{6} 1 \mathrm{mM}$ a $5 \mathrm{mVs}$ ' 1 sobre os eletrodos transparentes de $\mathrm{SnO}_{2}$ não modificados e sobre os eletrodos modificados estão representados na Fig. 4.6a e 4.7a, respectivamente. Estes experimentos também foram realizados empregando o eletrodo de $\mathrm{Pt}$, e, por esta razão, o gráfico apresenta as duas escalas, relacionadas de acordo com a expressão (4.1).

Comparando os perfis I/E obtidos em um mesmo $v$, observaram-se valores distintos para o $\mathrm{E}_{\mathrm{p}}^{\mathrm{A}}$ e o $\mathrm{E}_{\mathrm{p}}^{\mathrm{C}}$ para cada eletrodo. Como mostra a Fig. 4.6a, os $\mathrm{E}_{\mathrm{p}}{ }^{\mathrm{A}}$ observados a $5 \mathrm{mVs}^{-1}$ para os eletrodos não modificados de $\mathrm{SnO}_{2}(\mathrm{Cl}), \mathrm{SnO}_{2}(\mathrm{~F})$ e $\mathrm{SnO}_{2}(\mathrm{Sb})$ foram respectivamente 0,$6 ; 0,65$ e $0,7 \mathrm{~V}$, e os valores de $E_{p}{ }^{C}$ foram 0,$3 ; 0,27$ e $0,23 \mathrm{~V}$. Para os eletrodos modificados, na Fig. 4.7a, os valores de $E_{p}{ }^{A}$ foram 0,$6 ; 0,5$ e $0,5 \mathrm{~V}$, e os de $E_{p}{ }^{C}$ corresponderam a 0,$25 ; 0,30$ e $0,32 \mathrm{~V}$ (valores referentes ao ECS).

Para todos os eletrodos, a diferença entre $\mathrm{E}_{\mathrm{p}}{ }^{\mathrm{A}}$ e $\mathrm{E}_{\mathrm{p}}{ }^{\mathrm{C}}$ foi, portanto, superior ao valor previsto para esta reação reversível $(59 \mathrm{mV})$. Verificou-se também que esta diferença aumentou ainda mais com o aumento da velocidade de varredura. No que se refere às intensidades da $\mathrm{I}_{\mathrm{p}}{ }^{\mathrm{A}}$ e $\mathrm{I}_{\mathrm{p}}{ }_{\mathrm{p}}^{\mathrm{C}}$, obtiveram-se valores praticamente idênticos e que variaram linearmente com $v^{1 / 2}$ passando pela origem somente para $v$ muito baixos, entre 5 e $15 \mathrm{mVs}$ 1, como mostram as Fig. $4.6 \mathrm{~b}$ e $4.7 \mathrm{~b}$.

Este conjunto de características leva a concluir que o sistema $\mathrm{SnO}_{2} \mid \mathrm{K}_{4} \mathrm{Fe}(\mathrm{CN})_{6}$ (aq.) não era reversível. A irreversibilidade das reações de óxido-redução investigadas pode ser resultante da baixa velocidade de transferência de elétrons sobre estes eletrodos, insuficiente para manter o equilíbrio na superficie, e ainda por problemas relacionados a uma alta resistência do sistema [126].

Em geral, a resistência do sistema é causada pela resistência da solução entre os eletrodos de trabalho e o de referência, porém, pode incluir também quaisquer outras resistências provenientes de contatos, da formação de filmes resistivos na superfície do eletrodo e ainda de eletrodos pouco condutores [182]. Como estes eletrodos eram constituídos por filmes condutores muito finos (entre 25 e $50 \mathrm{~nm}$ ) depositados em um 
substrato não condutor (sílica), o contato elétrico pode não ter sido adequado, resultando em uma resistência bastante elevada, o que foi confirmado nos experimentos de EIS e $\mathrm{SACV}$. Durante os experimentos de VC, tal resistência poderia alterar o potencial que estivesse sendo aplicado ao eletrodo. Consequentemente, provocaria a diminuição da altura dos picos e o aumento da separação entre os mesmos, como foi verificado [182]

Como o $\mathrm{SnO}_{2}$ é um semicondutor, é muito provável também que a transferência de elétrons na interfase não seja suficientemente rápida para o sistema investigado. Considerando os valores de $\mathrm{E}_{\mathrm{p}}{ }^{\mathrm{A}}$ e $\mathrm{E}_{\mathrm{p}}{ }^{\mathrm{C}}$ obtidos, verifica-se que os maiores desvios referem-se aos potenciais para a reação de oxidação, já que os $\mathrm{E}_{\mathrm{p}}{ }^{\mathrm{C}}$ obtidos não são tão distintos do potencial característico para a redução do $\mathrm{K}_{3} \mathrm{Fe}(\mathrm{CN})_{6}$ sobre eletrodos de $\mathrm{Pt}(\sim 0,2 \mathrm{~V})$ [126].

Este fenômeno sugere que as reações de oxidação foram dificultadas, o que é um comportamento típico de eletrodos semicondutores do tipo-n e frequentemente observado para eletrodos transparentes de $\mathrm{SnO}_{2}$, já discutido na Revisão Bibliográfica. Como o potencial redox do $\mathrm{K}_{4} \mathrm{Fe}(\mathrm{CN})_{6}$ é mais positivo que o $\mathrm{E}_{\mathrm{FB}}$ (estimado em $\sim 0,1 \mathrm{~V}$, como será discutido posteriormente), a região de carga espacial se encontra em condições de depleção de elétrons e a transferência de carga está, portanto, bloqueada. As reações de oxidação são possíveis (supõe-se que através de um mecanismo de tunelamento), mas ocorrem apenas em potenciais muito mais anódicos e dependem do $\mathrm{N}_{\mathrm{D}}$ [30]. Estes resultados serão ainda discutidos posteriormente, considerando os valores de $\mathrm{N}_{D}$ determinados para cada eletrodo. 
Perfis potenciodinâmicos em $\mathrm{K}_{4} \mathrm{Fe}(\mathrm{CN})_{6}$ para os eletrodos transparentes modificados e não modificados com OTS
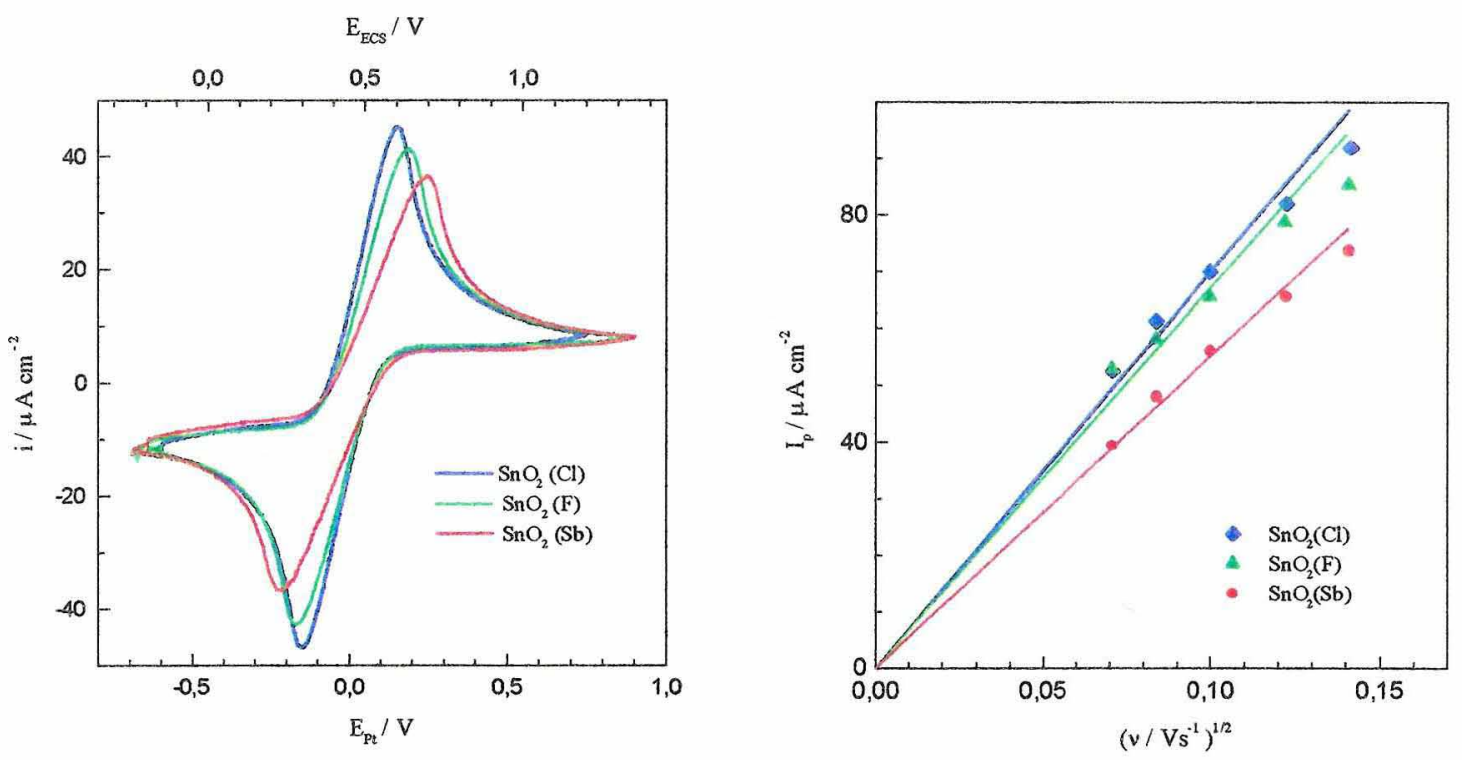

Figura 4.6. (a) Curvas $\mathrm{I} / \mathrm{E}$ em $\mathrm{K}_{4} \mathrm{Fe}(\mathrm{CN})_{6} 1 \mathrm{mM}, \mathrm{NaClO}_{4} 0,1 \mathrm{M}$ com pH 2,0 a 5 $\mathrm{mV} / \mathrm{s}$ para os eletrodos transparentes de $\mathrm{SnO}_{2}$; (b) variação do $\mathrm{I}_{\mathrm{p}} \operatorname{com} v^{1 / 2}$.
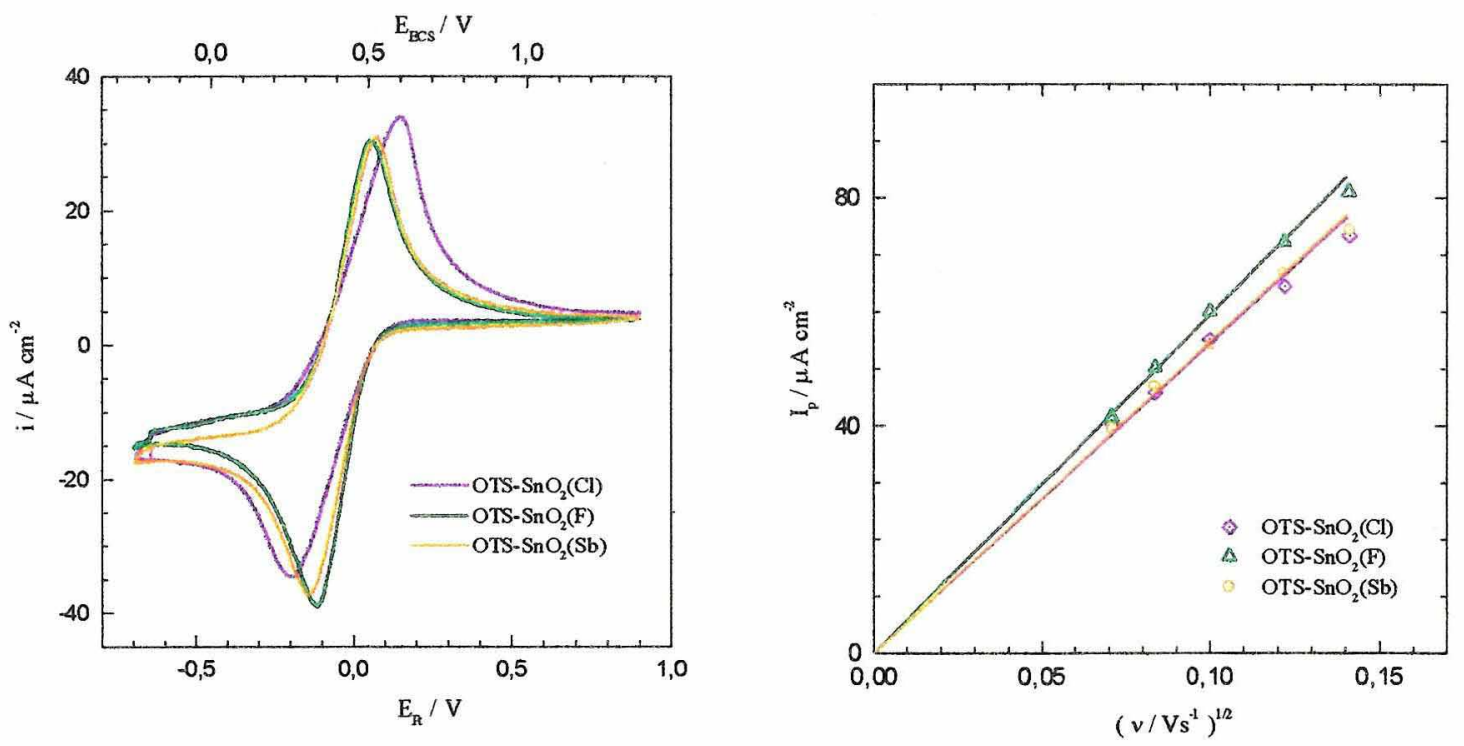

Figura 4.7. (a) Curvas $\mathrm{I} / \mathrm{E}$ em $\mathrm{K}_{4} \mathrm{Fe}(\mathrm{CN})_{6} 1 \mathrm{mM}$ a $5 \mathrm{mV} / \mathrm{s}$ para os eletrodos transparentes de $\mathrm{SnO}_{2}$ modificados com OTS; (b) variação do $\mathrm{I}_{\mathrm{p}}$ com $v^{1 / 2}$. 


\subsubsection{Comportamento eletroquímico dos eletrodos de $\mathrm{Ti} / \mathrm{SnO} \mathrm{O}_{2}(\mathrm{Sb})$}

\subsubsection{1. $\mathrm{O}$ potencial de circuito aberto em $\mathrm{NaClO}_{4} 0,1 \mathrm{M}$ de $\mathrm{pH} 2,0$}

As curvas da variação do potencial de circuito aberto em função do tempo para o eletrodo de $\mathrm{Ti} / \mathrm{SnO}_{2}(\mathrm{Sb})$ modificado ou não com OTS estão representadas na Fig. 4.8.

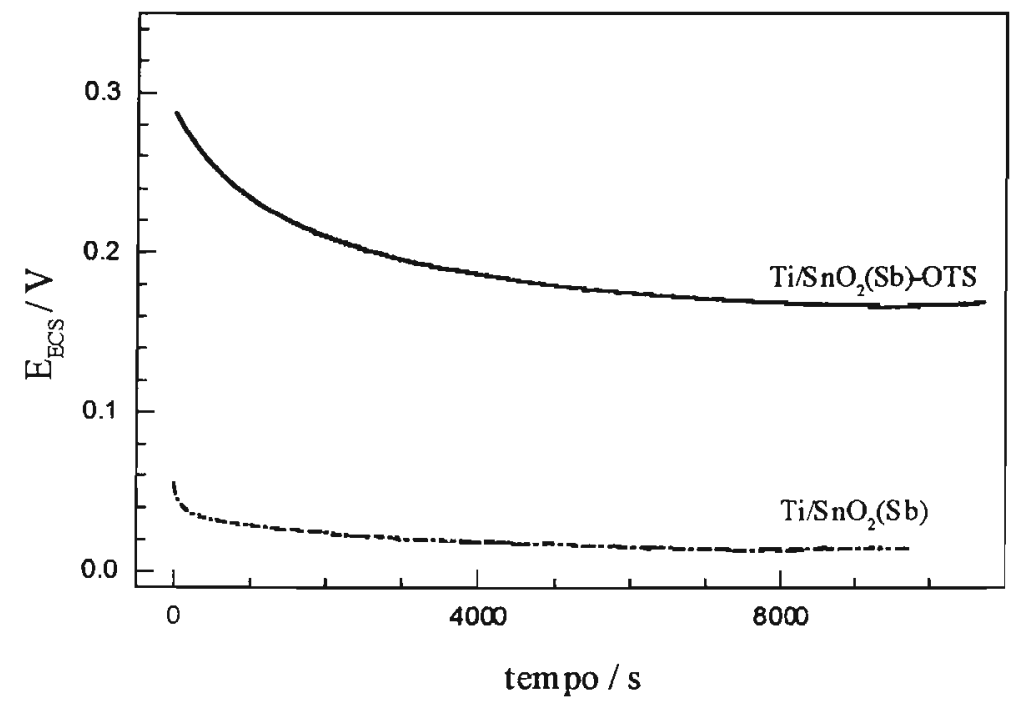

Figura 4.8. Variação do potencial de circuito aberto com o tempo para o eletrodo de $\mathrm{Ti} / \mathrm{SnO}_{2}(\mathrm{Sb})$, modificado ou não com OTS, em $\mathrm{NaClO}_{4} 0,1 \mathrm{M}$ de pH 2,0.

A diminuição do $\mathrm{E}_{\mathrm{CA}}$ no decorrer do tempo em contato com a solução também deve estar relacionada aos processos de hidratação da superficie, como discutido para os eletrodos transparentes. Para o eletrodo não modificado de $\mathrm{Ti} / \mathrm{SnO}_{2}(\mathrm{Sb})$, o $\mathrm{E}_{\mathrm{CA}}$ estabilizou em $20 \mathrm{mV}$. Nos estudos anteriormente desenvolvidos no Grupo, para um eletrodo preparado através do mesmo procedimento, Fugivara [51] obteve um $\mathrm{E}_{\mathrm{CA}}$ de $140 \mathrm{mV}$ em $\mathrm{H}_{2} \mathrm{SO}_{4}$ 0,5 M. Estes valores não podem ser comparados diretamente porque empregaramse eletrólitos distintos. Porém, em uma análise qualitativa, estes valores são coerentes já que, para um mesmo material, o $\mathrm{E}_{\mathrm{CA}}$ deve aumentar com a diminuição do $\mathrm{pH}$, de acordo com as reações expressas na equação 4.2

Comparando as curvas da Fig.4.8 com as da Fig. 4.1, verifica-se que o $E_{C A}$ dos eletrodos depositados sobre Ti era muito mais baixo que $o \mathrm{E}_{\mathrm{CA}}$ dos eletrodos transparentes. Para os eletrodos não modificados de $\mathrm{SnO}_{2}(\mathrm{Sb})$, o $\mathrm{E}_{\mathrm{CA}}$ correspondeu a 500 e $20 \mathrm{mV}$ para os filmes depositados em sílica e em $\mathrm{Ti}$, respectivamente. As características físicoquímicas de ambos os tipos de material foram analisadas e comparadas, mas não foi possível encontrar os possíveis causadores deste fenômeno 
Da comparação das curvas da Fig. 4.8, observa-se que a variação do $E_{C A}$ foi muito mais lenta para o eletrodo modificado com OTS. Possivelmente, o estabelecimento do equilíbrio da superfície do eletrodo com a solução deve ter sido dificultado pela presença do filme hidrofóbico. Observa-se ainda que o $\mathrm{E}_{\mathrm{CA}}$ do $\mathrm{Ti} / \mathrm{SnO}_{2}(\mathrm{Sb})-\mathrm{OTS}$ era aproximadamente $200 \mathrm{mV}$ mais alto que o do $\mathrm{Ti} / \mathrm{SnO}_{2}(\mathrm{Sb})$. Os prováveis motivos para esta diferença podem estar relacionados ao comprometimento de uma fração dos sítios Sn-OH com as moléculas de OTS adsorvidas e a alterações nos equilíbrios de dissociação destes grupos, representados pela equação 4.2 .

\subsubsection{2. $\mathrm{O}$ comportamento eletroquímico em eletrólito inerte $\left(\mathrm{NaClO}_{4} \mathrm{0,1} \mathrm{M}, \mathrm{pH} \mathrm{2,0}\right)$}

As curvas de polarização anódica determinadas para os eletrodos depositados em titânio estão representadas na Fig. 4.9. As curvas de polarização revelaram que a RDO iniciou-se a partir de aproximadamente 1,7 e $1,9 \mathrm{~V}$ para os eletrodos de $\mathrm{Ti} / \mathrm{SnO}_{2}(\mathrm{Sb})$ e $\mathrm{Ti} / \mathrm{SnO}_{2}(\mathrm{Sb})$-OTS, respectivamente.

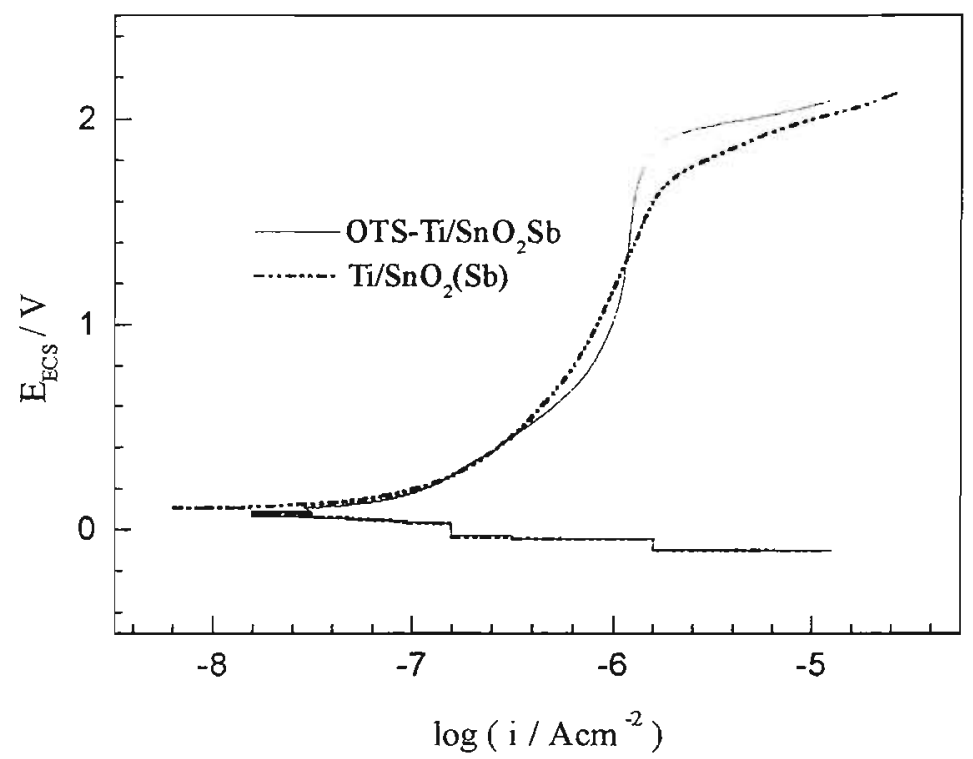

Figura 4.9. Curvas de polarização anódica determinadas a $0,166 \mathrm{mV} / \mathrm{s}$ em $\mathrm{NaClO}_{4}$ $0,1 \mathrm{M}$ de $\mathrm{pH}$ 2,0 para o eletrodo de $\mathrm{Ti} / \mathrm{SnO}_{2}(\mathrm{Sb})$, modificado ou não com OTS.

Na região da $\mathrm{RDO}$, a corrente variou exponencialmente com o potencial de acordo com a Lei de Tafel, i.e., $\mathrm{E}=\mathrm{a}+\mathrm{b} \log \mathrm{i}$, onde $\mathrm{b}=2,3 \mathrm{RT} / \mathrm{F}\left(\sim 59 \mathrm{mV}\right.$ a $\left.25^{\circ} \mathrm{C}\right)$ [183]. Os coeficientes de Tafel (b) estimados corresponderam a 291 e $236 \mathrm{mV}$, para os eletrodos não modificado e modificado com OTS, respectivamente. 
Estes altos valores para o coeficiente de Tafel revelam que estes materiais foram pouco catalíticos para a RDO. Os coeficientes obtidos são comparáveis a diversos valores publicados na Literatura para eletrodos a base de $\mathrm{SnO}_{2}$ suportado em Ti. Para um eletrodo de $\mathrm{Ti} / \mathrm{SnO}_{2}(\mathrm{Sb})$ preparado pelo mesmo procedimento, Fugivara [51] obteve $230 \mathrm{mV}$ em $\mathrm{H}_{2} \mathrm{SO}_{4}$ 0,5 M. Das medidas realizadas no mesmo eletrólito, para eletrodos depositados em Ti por Spray Pyrolysis, Kötz [21] obteve coeficientes de Tafel de $290 \pm 50 \mathrm{mV}$, enquanto que Chertykovtseva [108] obteve $300 \mathrm{mV}$. Outros autores, porém, obtiveram valores mais baixos, de 40 a $50 \mathrm{mV}[105,107]$ e ainda de $120 \mathrm{mV}$ [112].

Nos estudos desenvolvidos com eletrodos de $\mathrm{SnO}_{2}$, especificamente naqueles onde obtiveram-se coeficientes de Tafel similares aos obtidos neste trabalho, não há sugestões de mecanismos para a $\mathrm{RDO}$. Para os eletrodos de $\mathrm{Ti} / \mathrm{SnO}_{2}(\mathrm{Sb})$ que apresentaram coeficientes de $120 \mathrm{mV}$, Correa-Lazano [76] admitiu o mecanismo geral sugerido para a RDO sobre eletrodos de óxidos em meio ácido, considerando pequenas alterações $[76,112$, 184]. Este mecanismo geral admite uma etapa inicial de oxidação do sítio ativo durante a adsorção dissociativa de moléculas de água (4.3a), na qual são adsorvidos radicais ${ }^{\circ} \mathrm{OH}$, seguida pela estabilização do intermediário formado na etapa anterior (4.3b), ou seja,

$$
\begin{aligned}
& -\mathrm{M}-\mathrm{O}_{\mathrm{X}}+\mathrm{H}_{2} \mathrm{O} \rightarrow-\mathrm{MO}_{\mathrm{X}}\left({ }^{\circ} \mathrm{OH}\right)+\mathrm{H}^{+}+\mathrm{e} \\
& -\mathrm{MO}_{\mathrm{X}}\left({ }^{\circ} \mathrm{OH}\right) \rightarrow-\mathrm{MO}_{\mathrm{X}+1}+\mathrm{H}^{+}+\mathrm{e}
\end{aligned}
$$

Portanto, a superficie poderia apresentar dois estados de $\mathrm{O}$ ativo: o que está adsorvido fisicamente como " $\mathrm{OH}$ " e o que está quimicamente adsorvido, fazendo parte da estrutura do óxido, presente nos sítios $\mathrm{MO}_{\mathrm{X}+1}$ [76]. Na ausência de outros compostos oxidáveis, (p.ex. os poluentes orgânicos), ambos os tipos de $\mathrm{O}$ ativo produziriam $\mathrm{O}_{2}$ de acordo com as reações

$$
\begin{aligned}
& -\mathrm{MO}_{\mathrm{X}}\left({ }^{\bullet} \mathrm{OH}\right) \rightarrow 1 / 2 \mathrm{O}_{2}+\mathrm{H}^{+}+\mathrm{e}+-\mathrm{MO}_{\mathrm{X}} \\
& -\mathrm{MO}_{\mathrm{X}+1} \rightarrow-\mathrm{MO}_{\mathrm{X}}+1 / 2 \mathrm{O}_{2}
\end{aligned}
$$

Dependendo de qual das etapas é a determinante da velocidade (edv), são esperados diferentes valores para o coeficiente de Tafel e para a dependência com o pH da solução. Para o mecanismo proposto no conjunto de reações acima, se a edv fosse a etapa (a), ou a (b), os coeficientes esperados corresponderiam respectivamente a 120 , ou $60 \mathrm{mV}$ [184]. 
$\mathrm{Na}$ Literatura consultada, verificaram-se relatos de coeficientes de Tafel de $240 \mathrm{mV}$ para a RDO apenas sobre metais e em meio alcalino [185]. Para os mecanismos propostos em tais condições, os coeficientes altos estariam associados a uma etapa lenta onde o desprendimento do $\mathrm{O}_{2}$ ocorreria em sítios vizinhos $\mathrm{M}-\mathrm{O}$ através da reação

$$
\mathrm{M} \ldots \mathrm{O}+\mathrm{M} \ldots \mathrm{O} \rightarrow \mathrm{O}_{2}+2 \mathrm{M}
$$

Considerando estes mecanismos, seria provável que, para os eletrodos de $\mathrm{Ti} / \mathrm{SnO}_{2}$ modificados ou não com OTS investigados neste trabalho, a edv para a RDO estivesse mais relacionada ao processo de formação do $\mathrm{O}_{2}$, do que com as etapas de adsorção dissociativa da água descritas pelas equações 4.3a e 4.3b. Porém, como não foram desenvolvidos quaisquer outros estudos referentes a este tema, não é possível sugerir um mecanismo que explique os resultados obtidos neste trabalho.

Como uma observação final, a comparação dos coeficientes de Tafel, relativamente similares, e das curvas de polarização anódica obtidas para os eletrodos de $\mathrm{Ti} / \mathrm{SnO}_{2}(\mathrm{Sb})$ e de OTS-Ti $/ \mathrm{SnO}_{2}(\mathrm{Sb})$ revela que os mecanismos para a $\mathrm{RDO}$ sobre ambos os tipos de eletrodos não devem apresentar diferenças consideráveis. Como será apresentado posteriormente, a presença do OTS na superficie do eletrodo também afetou os espectros de impedância determinados, porém, um mesmo circuito pôde ser empregado para representar os espectros obtidos em ambos os sistemas. A princípio, sobre eletrodos modificados, os processos envolvidos na RDO apenas iniciaram-se em potenciais mais positivos que sobre os eletrodos não modificados. A presença do organosilano não deve portanto, ter bloqueado o acesso das moléculas de água aos sítios $\mathrm{Sn}-\mathrm{OH}$.

Os perfis potenciodinâmicos determinados para os eletrodos de $\mathrm{Ti} / \mathrm{SnO}_{2}$ também revelaram que a presença do OTS deslocou o potencial para a RDO para valores mais positivos, como mostra a Figura 4.10. Na Fig. 4.10, observa-se ainda que o eletrodo de $\mathrm{Ti} / \mathrm{SnO}_{2}$ apresentou uma pequena carga anódica desde o potencial de $0,7 \mathrm{~V}$ até os valores próximos à RDO. Este comportamento inesperado foi observado diversas vezes, como, p.ex., nos voltamogramas registrados durante as medidas empregando a SACV (Fig. 4.20), mas não foi encontrado qualquer motivo para este fenômeno.

Na Fig. 4.10, verifica-se também que os eletrodos modificados apresentaram a carga voltamétrica maior, como já havia sido observado para os eletrodos transparentes. Esta característica também foi observada nos voltamogramas determinados na solução tampão de pH 7,0, como mostra a Figura 4.11. 
Perfis potenciodinâmicos obtidos para os eletrodos de $\mathrm{Ti} / \mathrm{SnO}_{2}(\mathrm{Sb})$

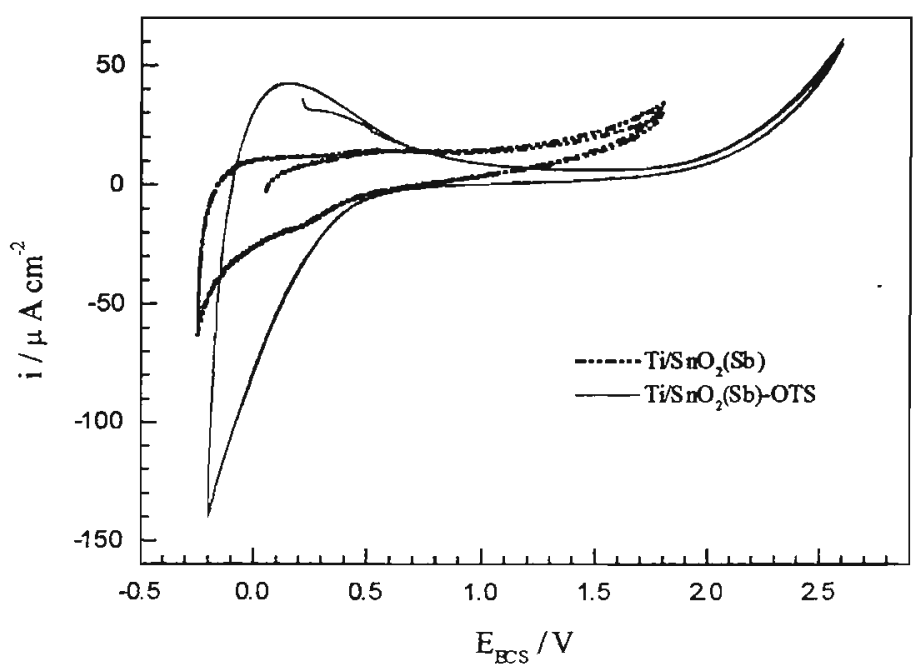

Figura 4.10. Perfis $\mathrm{I} / \mathrm{E}$ obtidos para o eletrodo de $\mathrm{Ti} / \mathrm{SnO}_{2}(\mathrm{Sb})$, modificado ou não com OTS, em $\mathrm{NaClO}_{4} 0,1 \mathrm{M}$ de pH 2,0. $\nu=50 \mathrm{mV} / \mathrm{s}$

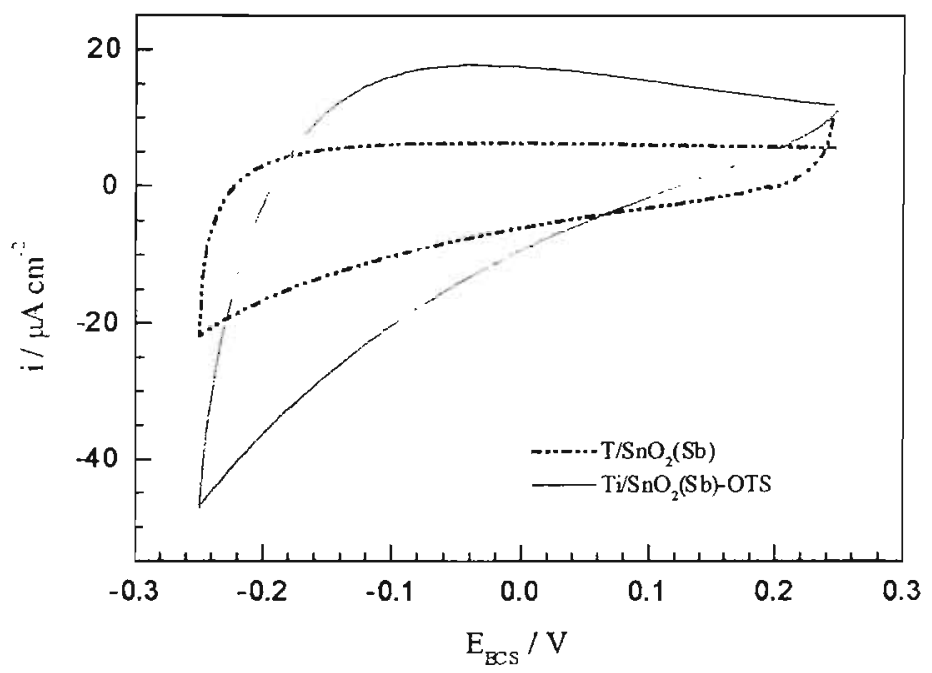

Figura 4.11. Perfis $\mathrm{I} / \mathrm{E}$ obtidos para o eletrodo de $\mathrm{Ti} / \mathrm{SnO}_{2}(\mathrm{Sb})$, modificado ou não com OTS, em solução tampão de $\mathrm{NaH}_{2} \mathrm{PO}_{4}$ e $\mathrm{Na}_{2} \mathrm{HPO}_{4}$ de $\mathrm{pH} 7,0 . v=10 \mathrm{mV} / \mathrm{s}$.

A análise dos voltamogramas obtidos a diferentes $v$ entre $-0,25$ e $+0,25 \mathrm{~V}$, como ilustrado na Fig. 4.11, revelou que a carga apresentada pelo eletrodo modificado não era puramente capacitiva, embora também não estivesse associada à antecipação da RDH. Provavelmente, esta carga poderia estar relacionada a uma pseudo-capacitância decorrente da presença do OTS na superficie do eletrodo modificado. A presença deste filme hidrofóbico nas proximidades dos sítios $\mathrm{Sn}-\mathrm{OH}$ deve ter alterado os equilíbrios de dissociação destes grupos e provocado um maior acúmulo de carga na interfase. 


\subsubsection{A reversibilidade das reações de óxido-redução do $\mathrm{K}_{4} \mathrm{Fe}(\mathrm{CN})_{6}$}

O comportamento eletroquímico dos eletrodos de $\mathrm{Ti} / \mathrm{SnO}_{2}(\mathrm{Sb})$ em $\mathrm{K}_{4} \mathrm{Fe}(\mathrm{CN})_{6}$ está representado na Fig. 4.12. Para facilitar a comparação dos dois tipos de material investigados, representou-se a curva I/E obtida para o eletrodo transparente no mesmo gráfico.

$\mathrm{Na}$ Fig. 4.12a, considerando inicialmente o voltamograma obtido para o eletrodo de $\mathrm{Ti} / \mathrm{SnO}_{2}(\mathrm{Sb})$ não modificado, verifica-se que os valores de $\mathrm{E}_{\mathrm{p}}{ }^{\mathrm{A}}$ e $\mathrm{E}_{\mathrm{p}}{ }^{\mathrm{C}}$ corresponderam a 360 e a $280 \mathrm{mV}$, respectivamente. Nos experimentos realizados, verificou-se que a separação entre os picos também aumentou com $v$ para este eletrodo, porém de maneira menos pronunciada que a observada para o eletrodo transparente. Para o eletrodo modificado, o OTS-Ti/ $\mathrm{SnO}_{2}$, os perfis I/E apresentaram o pico anódico pouco definido e menos intenso que o pico catódico. Na análise realizada para as Fig. 4.10 e 4.11, verificou-se que a carga apresentada não era puramente capacitiva, indicando que outros processos deveriam estar acontecendo na interfase. Estes processos devem ter afetado a reversibilidade da reação de óxido-redução do $\mathrm{K}_{4} \mathrm{Fe}(\mathrm{CN})_{6}$. P.ex., é possível que a corrente catódica verificada no $\mathrm{VC}$ da Fig. 4.12a tenha manifestado não apenas a redução do $\mathrm{K}_{3} \mathrm{Fe}(\mathrm{CN})_{6}$ como também a contribuição daqueles processos catódicos observados em eletrólito inerte, e, como resultado, a corrente catódica apresentou maior intensidade que a anódica.
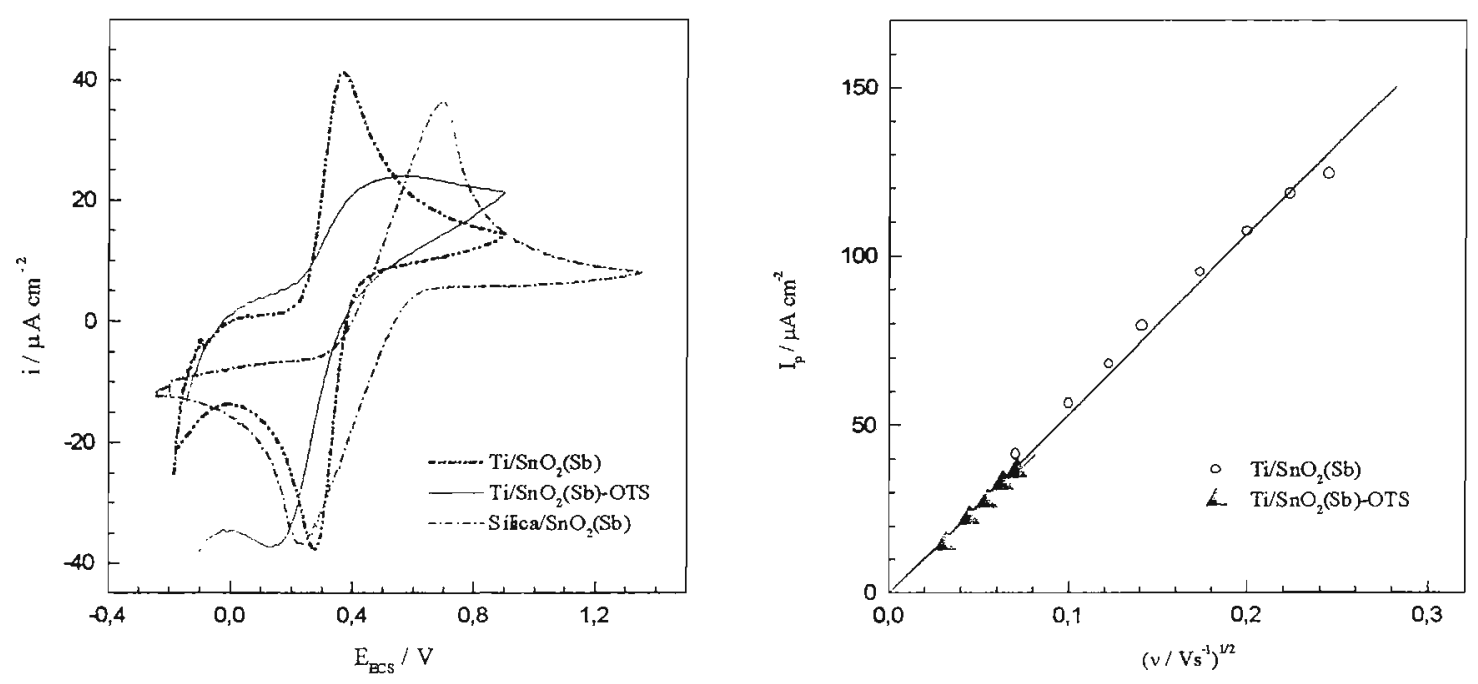

Figuras 4.12a e 4.12b. Curvas I/E em $\mathrm{K}_{4} \mathrm{Fe}(\mathrm{CN})_{6} 1 \mathrm{mM}, \mathrm{NaClO}_{4} 0,1 \mathrm{M}$ com pH 2,0 determinadas para os eletrodos de filme de $\mathrm{SnO}_{2}(\mathrm{Sb})$ depositado em sílica ou titânio. 
Na Fig. 4.12b está representada a variação da $\mathrm{I}_{\mathrm{p}}^{\mathrm{c}} \operatorname{com} v^{1 / 2}$ para os eletrodos depositados em Ti modificados ou não com OTS. Para os eletrodos não modificados, observa-se uma relação linear em um amplo intervalo de $v$; para os eletrodos modificados, porém, as medidas puderam ser realizadas apenas em $v<7 \mathrm{mV} / \mathrm{s}$, devido às distorções apresentadas nos voltamogramas obtidos em $v$ maiores.

Apesar do comportamento eletroquímico apresentado pelo eletrodo não modificado de $\mathrm{Ti} / \mathrm{SnO}_{2}(\mathrm{Sb})$ neste sistema ainda não ter sido o esperado para um eletrodo metálico, já foi muito melhor que o apresentado pelos eletrodos transparentes de $\mathrm{SnO}_{2}(\mathrm{Sb})$. Estas diferenças podem estar relacionadas ao fato destes eletrodos apresentarem menor efeito de queda ôhmica devido à $\mathrm{R}_{\mathrm{u}}$, como também por apresentarem um maior número de portadores de carga. Como a quantidade de dopante adicionada à solução precursora para preparar o eletrodo depositado em Ti foi cerca de 10 vezes superior à empregada para preparar o eletrodo transparente, provavelmente o eletrodo de $\mathrm{Ti} / \mathrm{SnO}_{2}(\mathrm{Sb})$ apresentou maior densidade de portadores de carga.

Para poder avaliar melhor o comportamento eletroquímico apresentado por ambos os tipos de material, determinaram-se as capacidades da interfase em diversos valores de potencial, para analisar o comportamento do gráfico de Mott-Schotkky e estimar a densidade de portadores de cargas para cada material. 


\subsubsection{Voltametria Cíclica de Baixa Amplitude}

\subsubsection{Aspecto geral dos perfis $\mathrm{I} / \mathrm{E}$ dos eletrodos transparentes e de $\mathrm{Ti} / \mathrm{SnO} \mathrm{O}_{2}(\mathrm{Sb})$}

As medidas de SACV foram efetuadas somente para os eletrodos não modificados de $\mathrm{SnO}_{2}$ transparentes e de $\mathrm{Ti} / \mathrm{SnO}_{2}(\mathrm{Sb})$. Para cada eletrodo, obtiveram-se numerosos voltamogramas que foram analisados segundo a metodologia apresentada na seção 2.6.2, observando os detalhes apresentados na seção 4.2 .4 para a determinação dos parâmetros $1 / R_{D}, 1 / R_{a p}$ e $\Delta I$ e estimar $R_{S}, R_{P}$ e $C_{d l}$.

Alguns dos perfis potenciodinâmicos obtidos no intervalo de 0,38 a $0,42 \mathrm{~V}$ para os eletrodos de $\mathrm{SnO}_{2}(\mathrm{Sb})$ depositados sobre sílica e titânio foram representados nas Figuras 4.13 e 4.14 , respectivamente.

Figura 4.13

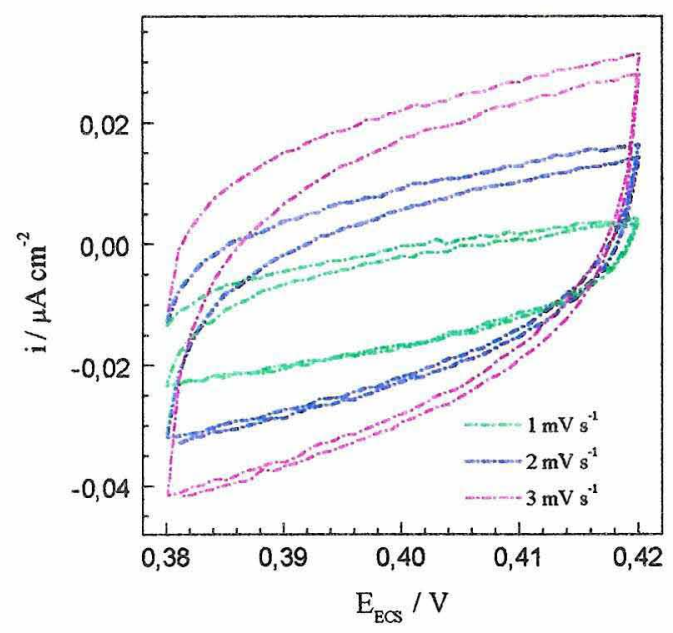

Figura 4.14

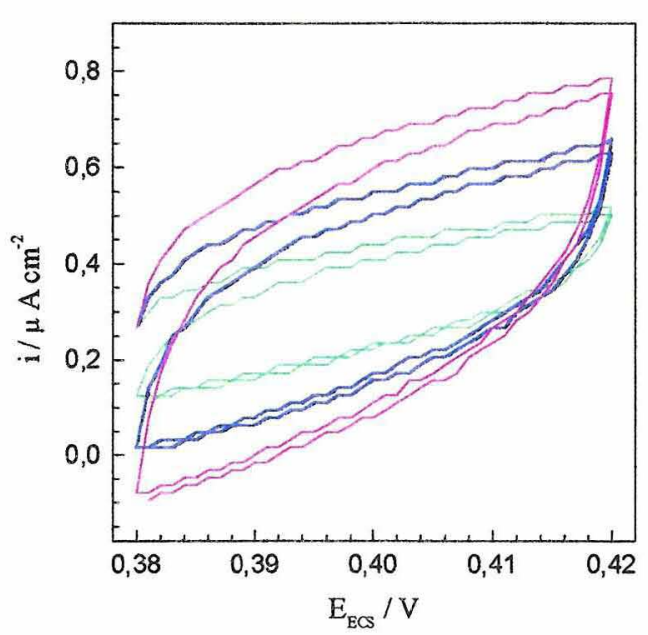

Figuras 4.13 e 4.14. Curvas I/E obtidas em $v$ baixas para o eletrodo transparente de $\mathrm{SnO}_{2}(\mathrm{Sb})$ e o de $\mathrm{Ti} / \mathrm{SnO}_{2}(\mathrm{Sb})$ em solução $0,1 \mathrm{M}$ de $\mathrm{NaClO}_{4} \operatorname{com} \mathrm{pH} 2,0$.

A comparação entre as curvas obtidas para os eletrodos depositados sobre sílica e titânio mostra que, para o eletrodo transparente, obtiveram-se correntes muito mais baixas para a perturbação de potencial aplicada. Os outros eletrodos transparentes apresentaram voltamogramas similares ao da Fig. 4.13.

As correntes muito baixas apresentadas pelos eletrodos transparentes se constituíram em um fator limitante à aplicação deste método, por aumentar o erro relativo das medidas realizadas sobre os voltamogramas. 


\subsubsection{Determinação da $\mathbf{R}_{\mathrm{S}}$ para os eletrodos transparentes e de $\mathrm{Ti} / \mathrm{SnO} \mathrm{O}_{2}(\mathrm{Sb})$}

Os parâmetros $1 / R_{D}$ e $1 / R_{a p}$ determinados a partir das diversas curvas $I / E$ registradas em diferentes condições de velocidade de varredura estão representados nas Figuras 4.15 e 4.16, para os eletrodos transparentes e de $\mathrm{Ti} / \mathrm{SnO}_{2}(\mathrm{Sb})$, respectivamente.

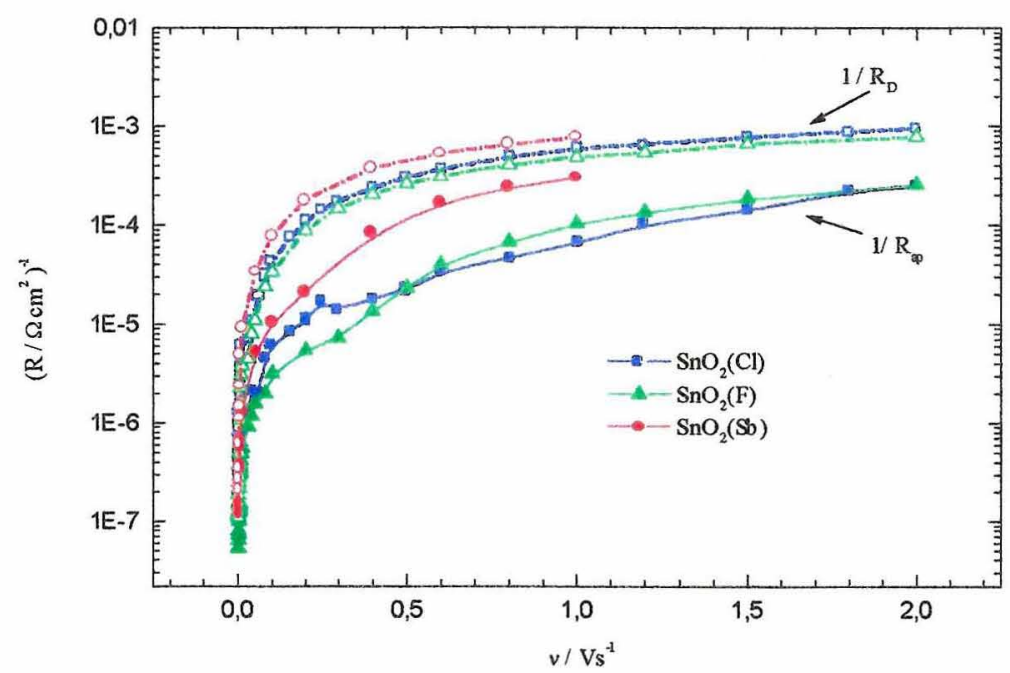

Figura 4.15. 1/R $R_{D}$ e $1 / R_{a p}$ em função da velocidade de varredura para os eletrodos transparentes de $\mathrm{SnO}_{2}$ em solução $0,1 \mathrm{M}$ de $\mathrm{NaClO}_{4}$ com pH 2,0.

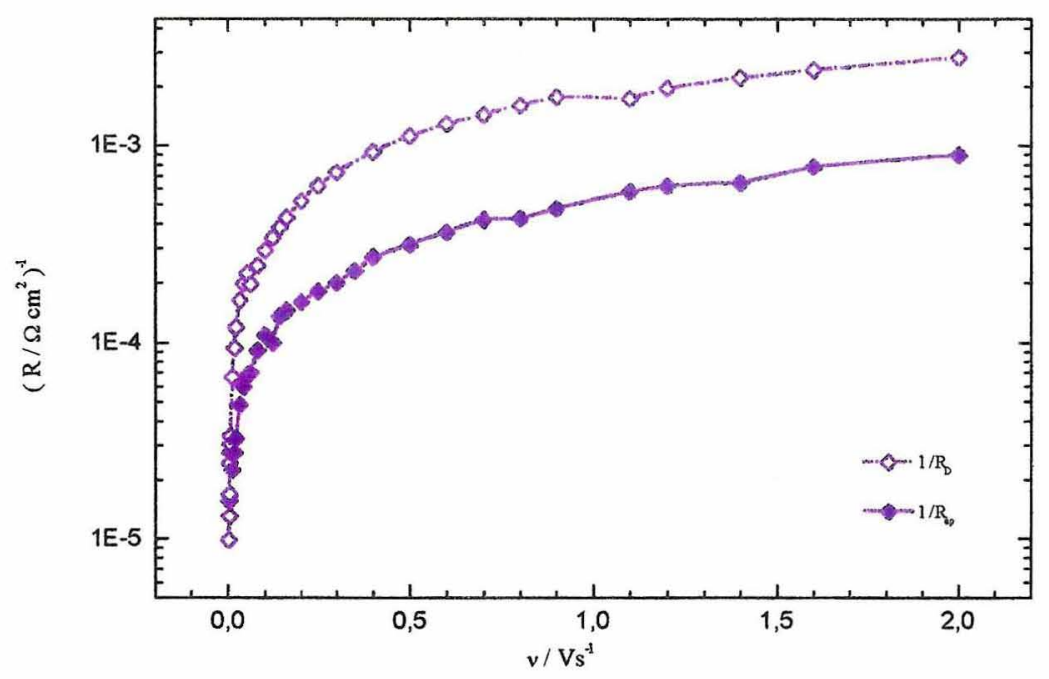

Figura 4.16. $1 / R_{D}$ e $1 / R_{\text {ap }}$ em função da velocidade de varredura para o eletrodo de $\mathrm{Ti} / \mathrm{SnO}_{2}(\mathrm{Sb})$ em solução $0,1 \mathrm{M}$ de $\mathrm{NaClO}_{4}$ com pH 2,0.

Como previsto através do desenvolvimento teórico da técnica de $\mathrm{SACV}$, os valores de $1 / R_{D}$ e $1 / R_{a p}$ se aproximaram de um valor constante a velocidades de varredura altas. No entanto, ambas as curvas deveriam se aproximar a um mesmo valor (correspondente $a R_{S}$ ), 
o que não foi verificado. Tal comportamento seria esperado para $v$ ainda mais altas, mas as medidas não foram efetuadas porque os voltamogramas já se apresentavam distorcidos desde aproximadamente $1,5 \mathrm{Vs}^{-1}$.

As Fig. 4.15 e 4.16 revelam que, a $2 \mathrm{Vs}^{-1}$, enquanto os valores de $1 / \mathrm{R}_{\mathrm{D}}$ corresponderam a 0,$943 ; 0,784 ; 0,768$ e $2,93 \mathrm{~m} \Omega^{-1} \mathrm{~cm}^{-2}$ para os eletrodos transparentes dopados com $\mathrm{Cl}, \mathrm{F}$, e $\mathrm{Sb}$ e de $\mathrm{Ti} / \mathrm{SnO}_{2}(\mathrm{Sb}), 1 / \mathrm{R}_{\mathrm{ap}}$ foi cerca de três vezes menor para cada eletrodo, correspondendo a 0,$245 ; 0,256 ; 0,3$ e $1 \mathrm{~m}^{-1} \mathrm{~cm}^{-2}$, respectivamente.

Considerando os valores médios de $1 / R_{D}$ e $1 / R_{a p}$ para estimar $1 / R_{S}$, se a interfase $\mathrm{SnO}_{2} \mid \mathrm{NaClO}_{4}$ (aq.) pudesse ser representada por um circuito $\mathrm{R}_{\mathrm{S}}\left(\mathrm{R}_{\mathrm{P}} \mathrm{C}\right)$, como previsto pela técnica da SACV, as resistências em série corresponderiam a 1684; 1925 e $1872 \Omega \mathrm{cm}^{2}$ para os eletrodos dopados com $\mathrm{Cl}, \mathrm{F}$, e $\mathrm{Sb}$ respectivamente, e, para o eletrodo depositado sobre titânio, $R_{S}$ corresponderia a $509 \Omega \mathrm{cm}^{2}$. Os altos $R_{S}$ determinados para os eletrodos transparentes confirmaram a hipótese sugerida na Seção 4.3.1.3 para explicar o comportamento eletroquímico destes eletrodos. Portanto, o maior responsável pela não reversibilidade das reações de óxido-redução do $\mathrm{K}_{4} \mathrm{Fe}(\mathrm{CN})_{6}$ deve ter sido a alta resistência do sistema.

\subsubsection{Determinação de $R_{P}$ para os eletrodos transparentes e de $\mathrm{Ti} / \mathrm{SnO}_{2}(\mathrm{Sb})$}

A resistência à transferência de carga, $R_{P}$, foi determinada para cada um dos eletrodos considerando que $1 / R_{D}$ e $1 / R_{a p}$ se aproximaram de $\left(1 / R_{S}+1 / R_{P}\right)$ quando $v \rightarrow 0$. As Figuras 4.17 e 4.18 ilustram como foram determinados os valores de $\left(1 / R_{S}+1 / R_{P}\right)$ para os eletrodos depositados em sílica e titânio.
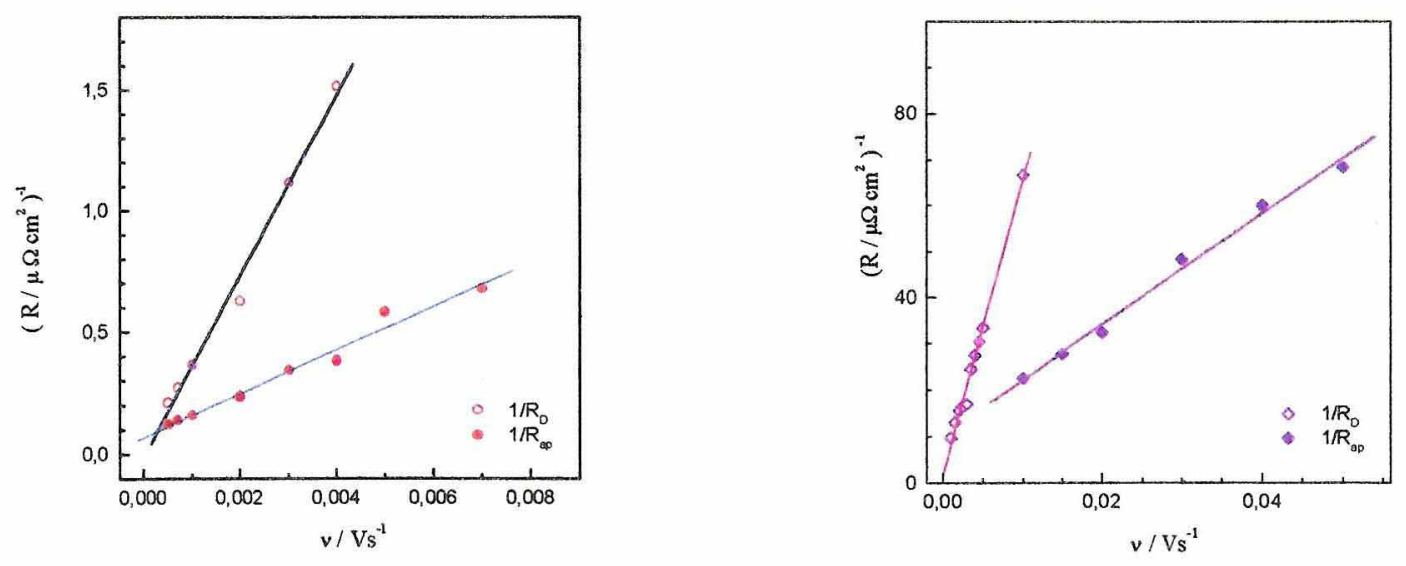

Figuras 4.17 e 4.18 . Determinação de $\left(1 / \mathrm{R}_{\mathrm{P}}+1 / \mathrm{R}_{\mathrm{S}}\right)$ para os eletrodos de $\mathrm{SnO}_{2}(\mathrm{Sb})$ transparente e depositado sobre titânio, respectivamente. 
$O$ valor de $\mathrm{R}_{\mathrm{P}}$ estimado para o eletrodo de $\mathrm{Ti} / \mathrm{SnO}_{2}$ correspondeu a $8,2 \times 10^{4} \Omega \mathrm{cm}^{2}$, e, para os eletrodos transparentes de filme de $\mathrm{SnO}_{2}$ dopados com $\mathrm{Cl}, \mathrm{F}$ e $\mathrm{Sb}$ corresponderam a $5 \times 10^{7} ; 3,3 \times 10^{7} \mathrm{e} 1,1 \times 10^{7} \Omega \mathrm{cm}^{2}$, respectivamente

Os valores de $R_{S}$ e $R_{P}$ estimados pela $S A C V$ evidenciam, novamente, diferenças consideráveis entre ambos os tipos de material; para o eletrodo depositado em $\mathrm{Ti}$, os valores para a resistência do eletrodo e a resistência à transferência de carga foram muito menores que as estimadas para os eletrodos transparentes. Seguindo esta tendência, os valores estimados para a capacidade interfacial também foram muito distintos.

\subsubsection{Determinação da capacidade interfacial}

$O C_{d l}$ foi estimada a partir dos $\Delta \mathrm{I}$ determinados nos voltamogramas cíclicos registrados em $v$ baixas (entre 1 e $5 \mathrm{mVs}^{-1}$ ). As medidas foram realizadas em diversos valores de potencial, para que pudessem ser obtidos os gráficos de Mott-Schottky.

Os voltamogramas obtidos a $4 \mathrm{mVs}^{-1}$ em diversos valores de potencial para os eletrodos de $\mathrm{SnO}_{2}(\mathrm{Sb})$ depositado sobre sílica e titânio estão representados nas Figuras 4.19 e 4.20 , respectivamente.

$\mathrm{Na}$ Fig. 4.19, o aspecto dos voltamogramas obtidos em $\mathrm{E}<0,2 \mathrm{~V}$ e em $\mathrm{E}>1,3 \mathrm{~V}$ evidenciou a existência de processos faradaicos nestas condições, e, por esta razão, o método não seria aplicável $[162,165-169]$. Por outro lado, as curvas obtidas no intervalo de $0,4<\mathrm{E}<1,3 \mathrm{~V}$ para o eletrodo transparente apresentaram o comportamento previsto para condições nas quais as reações faradaicas estão ausentes e a resposta do sistema devese somente a contribuições de caráter capacitivo [162]. A diminuição da carga com o aumento do potencial pode ser relacionada à formação da camada de depleção [169].

$\mathrm{Na}$ fig. 4.20, os perfis L/E determinados para o eletrodo depositado sobre titânio apresentaram novamente a contribuição anódica a partir de $0,7 \mathrm{~V}$. A origem desta contribuição anódica, observada também na Fig. 4.10, não foi conhecida. 
SACV - Perfis potenciodinâmicos determinados para os eletrodos de $\mathrm{SnO}_{2}(\mathrm{Sb})$

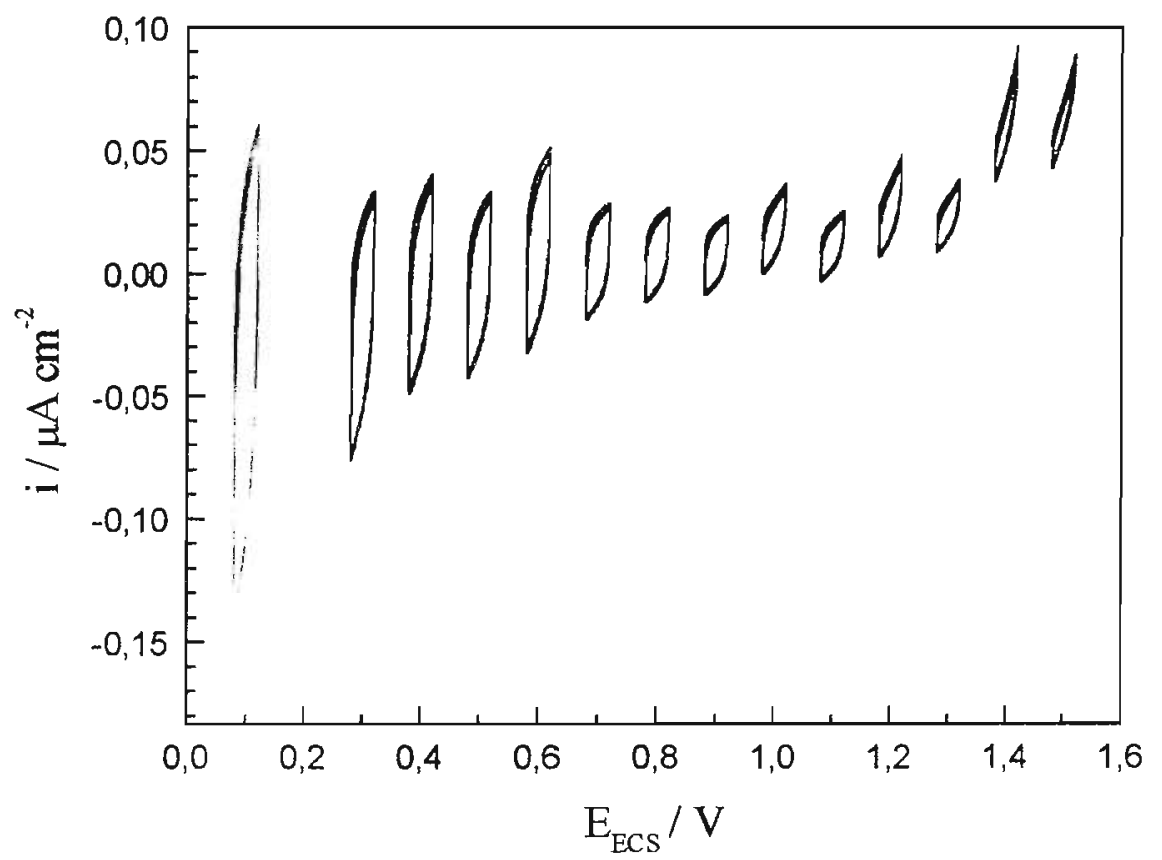

Figura 4.19. Curvas I/E obtidas a $4 \mathrm{mVs}^{-1}$ para o eletrodo transparente de $\mathrm{SnO}_{2}(\mathrm{Sb})$ em $\mathrm{NaClO}_{4} 0,1 \mathrm{M}$ com pH 2,0.

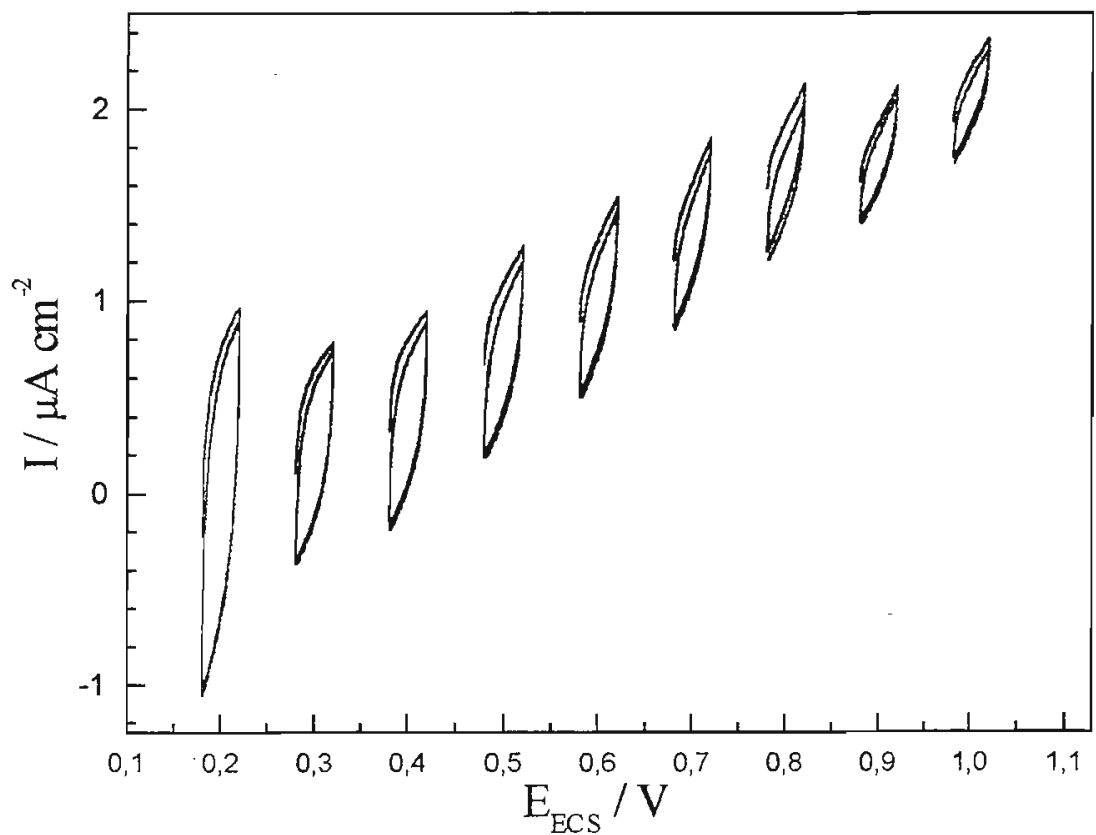

Figura 4.20. Curvas I/E obtidas para o eletrodo $\mathrm{Ti} / \mathrm{SnO}_{2}(\mathrm{Sb})$ em $0,1 \mathrm{M}$ de $\mathrm{NaClO}_{4}$ com pH 2,0. 
Na Figura 4.21 estão representados alguns gráficos obtidos para o eletrodo de $\mathrm{Ti} / \mathrm{SnO}_{2}(\mathrm{Sb})$ que mostram como foi feita a determinação da $\mathrm{C}_{\mathrm{dc}}$ a partir das medidas de $\Delta \mathrm{I}$ em função de $v$. Obtiveram-se gráficos similares para os outros eletrodos investigados.

Como $\Delta \mathrm{I}$ variou linearmente com $v$ e $R_{P} \gg R_{S}$, a capacidade da dupla camada elétrica da interfase foi estimada através da expressão 2.41 , ou seja, $C_{d l}=1 / 2(\Delta V / d v)_{v \rightarrow 0}$.

O conjunto dos resultados obtidos através da SACV para cada um dos eletrodos investigados está representado na Tabela 4.1.

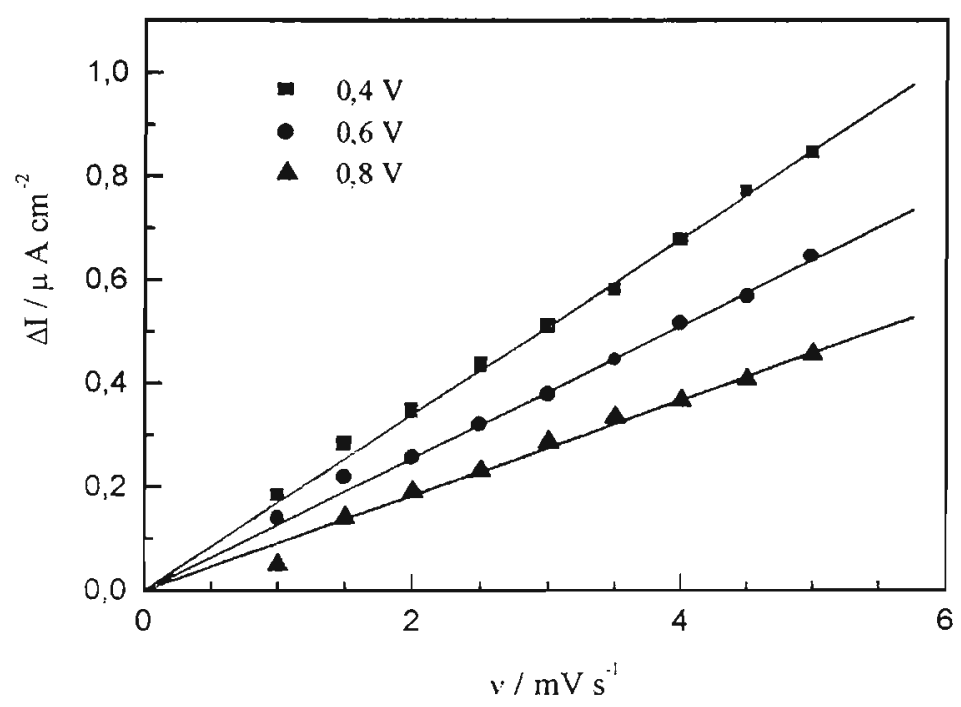

Figura 4.21. Variação dos $\Delta \mathrm{I} \operatorname{com} v$. Determinação da $\mathrm{C}_{\mathrm{d} l}$ em 0,$4 ; 0,6 \mathrm{e}$ $0,8 \mathrm{~V}$ para o eletrodo de $\mathrm{Ti} / \mathrm{SnO}_{2}(\mathrm{Sb})$ em $\mathrm{NaClO}_{4} 0,1 \mathrm{M}$ (aq.), pH 2,0.

Tabela 4.1. Parâmetros determinados a $0,4 \mathrm{~V}$ através da técnica SACV para os eletrodos de filme de $\mathrm{SnO}_{2}$ transparentes e de $\mathrm{Ti} / \mathrm{SnO}_{2}(\mathrm{Sb})$, considerando que a interfase $\mathrm{SnO}_{2} \mid \mathrm{NaClO}_{4} \quad 0,1 \mathrm{M}$, pH 2,0 pode ser representada por um circuito $\mathrm{R}_{\mathrm{S}}\left(\mathrm{R}_{\mathrm{P}} \mathrm{C}_{\mathrm{dl}}\right)$.

\begin{tabular}{lcccc}
\hline & $\mathrm{SnO}_{2}(\mathrm{Cl})$ & $\mathrm{SnO}_{2}(\mathrm{~F})$ & $\mathrm{SnO}_{2}(\mathrm{Sb})$ & $\mathrm{Ti} / \mathrm{SnO}_{2}(\mathrm{Sb})$ \\
\hline $\mathrm{R}_{\mathrm{S}} / \mathrm{k} \Omega \mathrm{cm}^{2}$ & 1,7 & 1,9 & 1,9 & 0,5 \\
$\mathrm{R}_{\mathrm{P}} / \mathrm{M} \Omega \mathrm{cm}^{2}$ & 50 & 33 & 11 & 0,08 \\
$\mathrm{C}_{\mathrm{dl}} / \mu \mathrm{F} \mathrm{cm}^{-2}$ & 2,9 & 1,2 & 8,4 & 85 \\
\hline
\end{tabular}




\subsubsection{Variação da capacidade interfacial com o potencial aplicado}

Os valores de $C_{d l}$ obtidos em diversos valores de potencial para os 4 eletrodos investigados estão representados nas Figuras 4.22 e 4.23 .

Como previsto, a capacidade da dupla camada da interfase diminuiu com o aumento de potencial, devido à depleção dos portadores majoritários de carga. A variação de $\mathrm{C}^{-2}$ será analisada posteriormente. Verifica-se ainda que o eletrodo depositado em $\mathrm{Ti}$ apresentou a capacidade interfacial muito maior que a dos eletrodos transparentes, provavelmente devido à maior área de superfície (todos os cálculos foram realizados considerando apenas a área geométrica dos eletrodos).

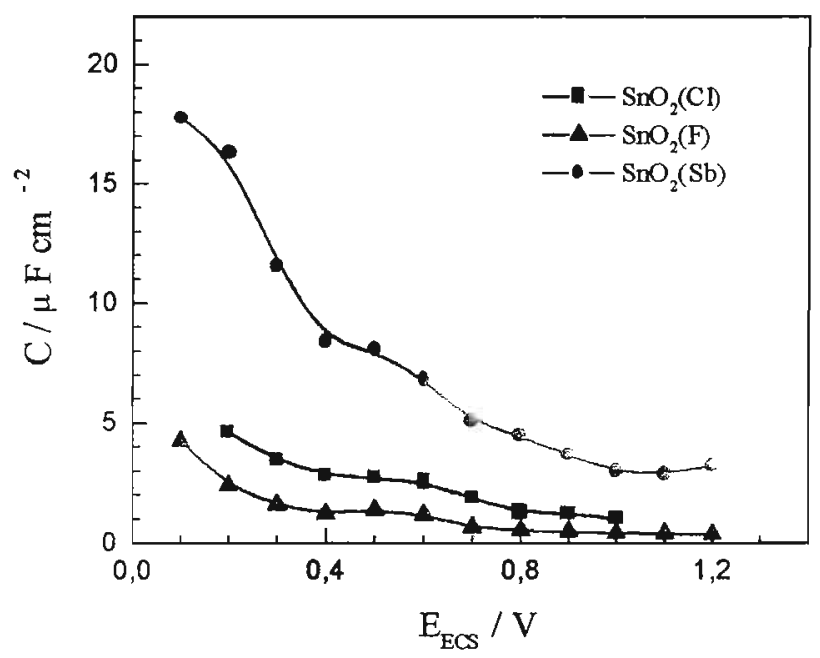

Figura 4.22. Variação da capacidade da dupla camada elétrica com o potencial para os eletrodos transparentes de $\mathrm{SnO}_{2}$ em $0,1 \mathrm{M}$ de $\mathrm{NaClO}_{4}$ (aq.), com pH 2,0.

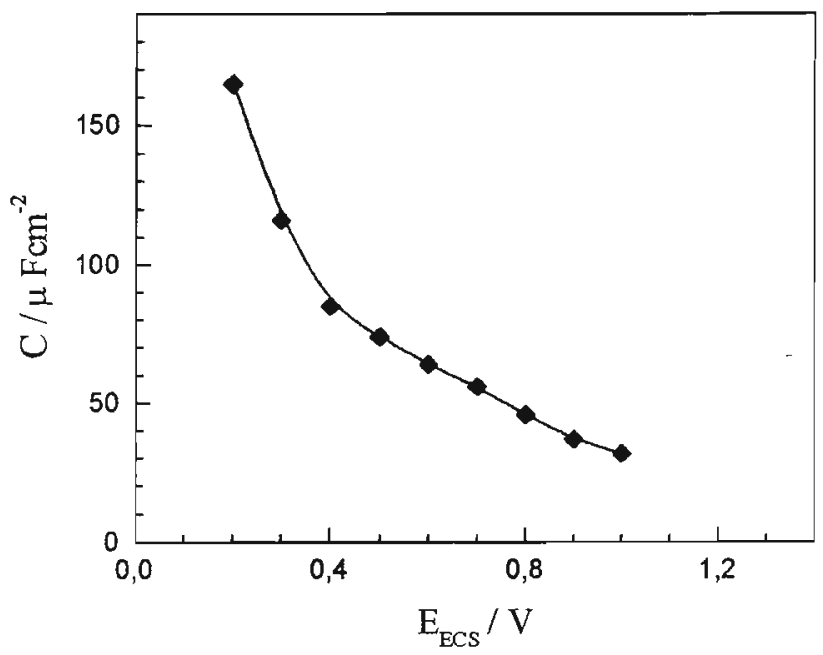

Figura 4.23. Variação da capacidade da dupla camada elétrica com o potencial para o eletrodo $\mathrm{Ti} / \mathrm{SnO}_{2}(\mathrm{Sb}) \mathrm{SnO}_{2} \mid \mathrm{NaClO}_{4}$ (aq.). 


\subsubsection{Espectroscopia de Impedância Eletroquímica}

\subsubsection{Espectros de EIS obtidos para os eletrodos transparentes}

Os espectros de Impedância Eletroquímica obtidos para os eletrodos transparentes em $400 \mathrm{mV}$ e em potenciais da região da RDO, a 1,8 V, estão representados na Fig. 4.24. Considerando o aspecto geral destes espectros, verifica-se que o comportamento destes sistemas se altera consideravelmente nos potenciais da região da $\mathrm{RDO}$.

Nos espectros determinados a $0,4 \mathrm{~V}$, nas frequências $(\omega)$ mais baixas, a inclinação de $-0,9$ observada na Fig. $4.24 a$, assim como o ângulo de fase $(\varphi)$ de $\sim 90^{\circ}$ verificado na Fig. $4.24 \mathrm{~b}$, indicam a presença de uma capacidade que contribuiu predominantemente na impedância total $(Z)$ do sistema nestas condições de $\omega$. Na região de altos $\omega$, a Fig. 4.24b revela que o $\varphi$ foi aproximadamente nulo, indicando que a impedância do sistema foi dominada pela resistência em série. Os valores para este $R_{S}$, que predominou no $|Z|$ a partir de $500 \mathrm{~Hz}$, foram bastante elevados: cerca de 600; 1050 e $800 \Omega$ para os eletrodos transparentes de $\mathrm{SnO}_{2}(\mathrm{Cl}) ; \mathrm{SnO}_{2}(\mathrm{~F})$ e $\mathrm{SnO}_{2}(\mathrm{Sb})$, respectivamente. Se a área dos eletrodos for considerada, os valores de $R_{S}$ corresponderam a $420 ; 735$ e $560 \Omega \mathrm{cm}^{2}$

Os espectros determinados em 1,8 V apresentaram um comportamento bastante distinto, principalmente na região de baixas $\omega$. Neste potencial, verificou-se a forte contribuição de uma resistência (pois $\varphi \sim 0^{\circ}$ ) próximo de $0,1 \mathrm{~Hz}$, e que pode ser associada à resistência à transferência de carga para a RDO. Nesta condição, $|Z|$ variou entre $10^{4} \mathrm{e}$

$10^{5} \Omega$, dependendo do eletrodo. Em $\omega$ altas, verificou-se novamente a forte contribuição da

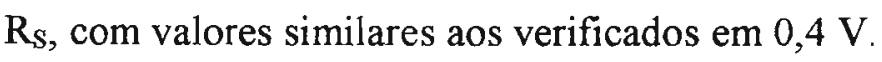

Estes espectros foram analisados empregando o programa de Boukcamp para atribuição dos circuitos equivalentes e análise das simulações. Neste estudo, utilizaram-se diversos circuitos na tentativa de obter algum que fosse coerente com as características do sistema e que simulasse satisfatoriamente os espectros obtidos. Como, de fato, não foi possível obter nenhum que representasse adequadamente os sistemas investigados, serão apenas brevemente discutidos alguns dos circuitos utilizados.

Em ordem crescente de complexidade, admitiu-se inicialmente um circuito $\mathrm{R}_{S} \mathrm{C}_{\mathrm{dl}}$ (em série), considerando os argumentos apresentados para a Fig. 2.10 na Revisão Bibliográfica. Este circuito não foi capaz de representar os resultados obtidos para nenhum dos eletrodos transparentes; as simulações não apresentaram semelhança com os espectros 
experimentais e resultaram em $\chi^{2}$ muito altos, superiores a $10^{-2}$. A substituição da capacidade $\mathrm{C}$ pelo elemento de fase constante $\mathrm{Q}$ apenas diminuiu um pouco as discrepâncias entre os espectros simulados e os obtidos experimentalmente. Em geral, os ajustes continuaram sendo muito pouco satisfatórios, principalmente para os espectros obtidos em $\mathrm{E}>800 \mathrm{mV}$, possivelmente porque a partir deste potencial iniciaram-se as contribuições faradaicas da RDO.

A utilização de um circuito $\mathrm{R}_{S}\left(\mathrm{R}_{\mathrm{P}} \mathrm{C}_{\mathrm{d}}\right)$, como representado na Fig. 2.8, também não foi capaz de representar os sistemas investigados. Nas simulações, os $\chi^{2}$ continuaram muito elevados $\left(\sim 1 \times 10^{-2}\right)$. Com circuitos $R_{S}\left(R_{P} Q\right)$, obtiveram-se resultados um pouco melhores quanto ao aspecto das curvas simuladas e ao $\chi^{2}\left(\sim 7 \times 10^{-3}\right)$, mas não para todos os espectros. Além de não ser razoavelmente satisfatório em todas as condições, obtiveram-se valores absurdamente altos para $R_{P}$, da ordem de $10^{21} \Omega$.

Com a adição de um elemento capacitivo $C$, para representar a presença da capacidade de Helmholtz, fixada em $15 \mu \mathrm{F}$, atribuíram-se circuitos do tipo $\mathrm{R}_{S} \mathrm{C}_{\mathrm{H}}\left(\mathrm{R}_{\mathrm{P}} \mathrm{C}_{\mathrm{d} 1}\right)$ ou ainda $R_{S}\left(R_{P}\left[C_{H} C_{d l}\right]\right)$. Estes novos circuito também não trouxeram melhoras em relação aos discutidos anteriormente.

Considerando o circuito sugerido por Fugivara [51], ou seja, $R_{S}\left(R_{P} Q_{d 1}\right)\left(R_{F} Q_{F}\right)$ (Fig. 2.14), obtiveram-se ajustes muito melhores, com $\chi^{2} \sim 3 \times 10^{-3}$. Porém, fisicamente, este circuito não teria sentido para estes sistemas, já que, para os eletrodos transparentes, não seria possível atribuir o segundo conjunto (RQ) à interfase filme de $\mathrm{SnO}_{2} \mid$ substrato.

Por fim, para considerar a presença dos estados superficiais, empregou-se um circuito $\mathrm{R}_{\mathrm{S}} \mathrm{C}_{\mathrm{H}}\left(\mathrm{C}_{\mathrm{SC}}\left[\mathrm{C}_{\mathrm{if}} \mathrm{R}_{\mathrm{CT}}\right]\right)$, como sugerido na Fig. 2.12, e obtiveram-se também ajustes muito bons, com $\chi^{2}<2 \times 10^{-3}$ para os espectros obtidos em quase todos os potenciais (exceto para os da RDO). Da mesma forma, boas simulações foram obtidas com o circuito sugerido na Fig. 2.11, i.e., $R_{S}\left(R_{P}\left[C_{H}\left(C_{S C}\left[C_{S S} R_{S S}\right]\right)\right.\right.$ ), porém, como não foram realizadas quaisquer medidas que informassem sobre este grande número de parâmetros, não há como verificar se estes circuitos seriam coerentes com os sistemas investigados

As dificuldades encontradas para a análise destes resultados provavelmente estão relacionadas não só com os problemas normalmente encontrados para eletrodos semicondutores (presença de estados superficiais, etc), como também com a alta resistência apresentada pelos eletrodos transparentes, que já havia apresentado problemas nas medidas efetuadas através de outras técnicas. 
Espectros de impedância eletroquímica para os eletrodos transparentes

(a)

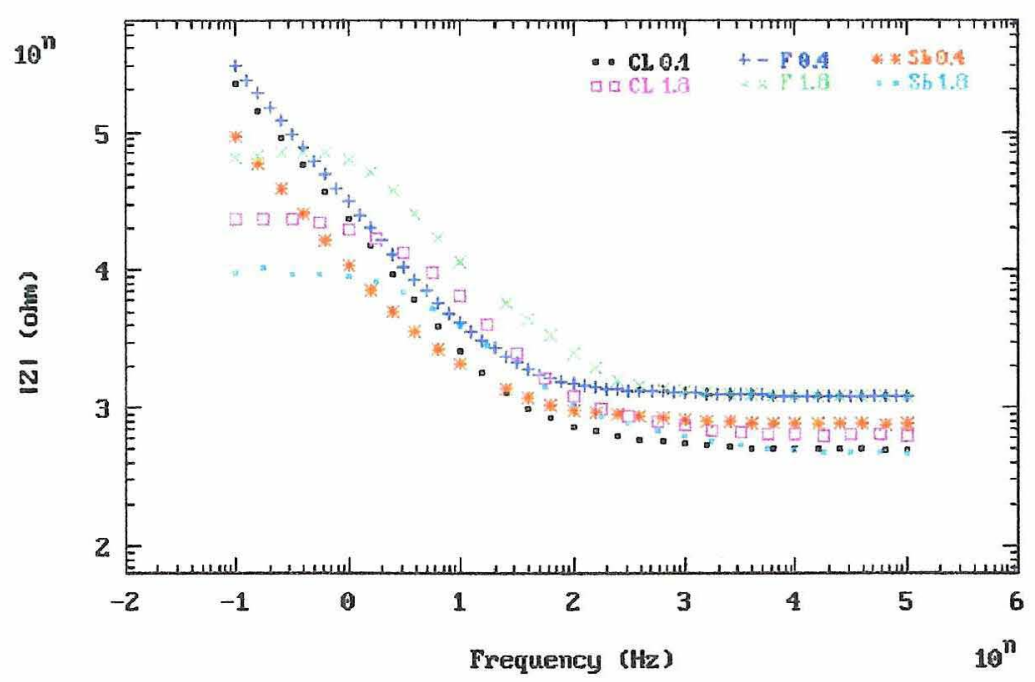

(b)

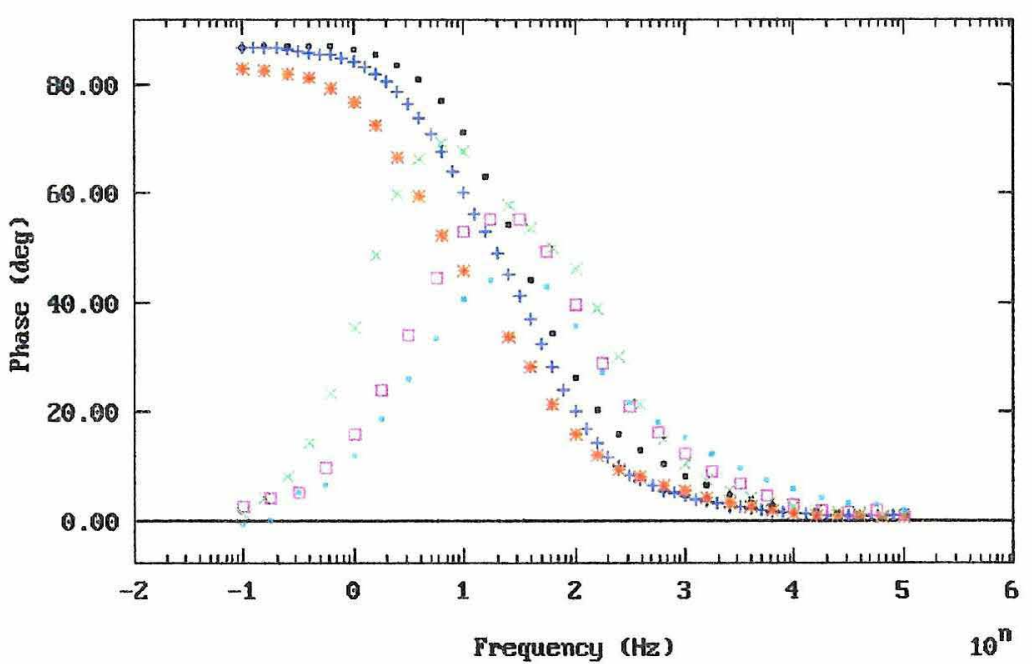

(c)

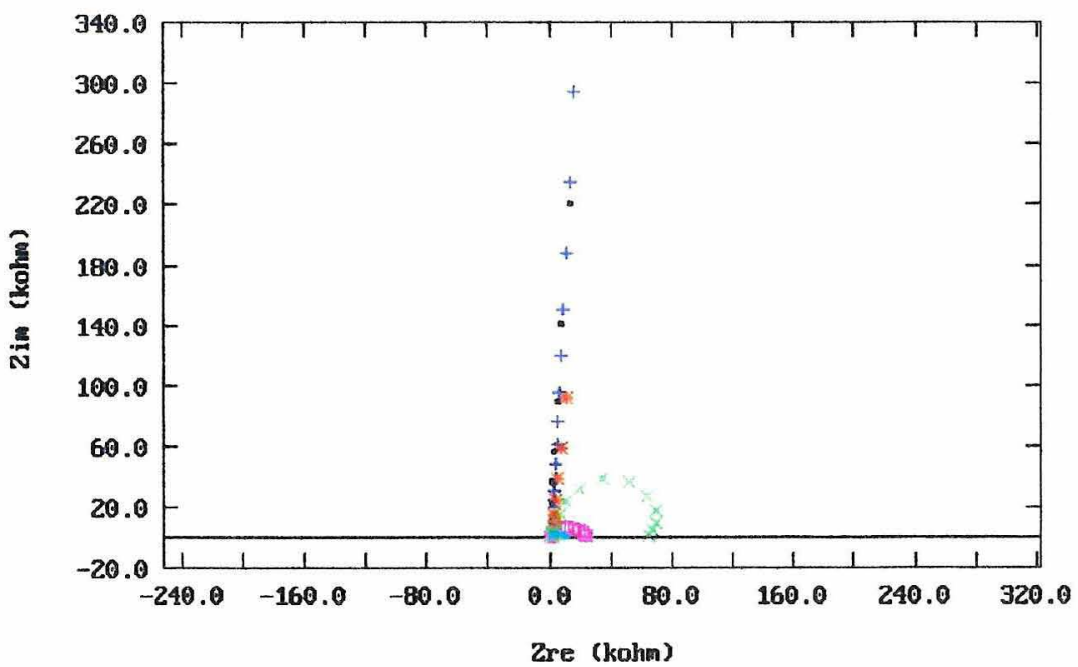

Figura 4.24. Espectros de impedância determinados para os eletrodos de $\mathrm{SnO}_{2}(\mathrm{Cl})$, $\mathrm{SnO}_{2}(\mathrm{~F})$ e $\mathrm{SnO}_{2}(\mathrm{Sb})$ em 0,4 e 1,8 V representados como gráficos de Bode e de Nyquist. 


\subsubsection{Espectros de EIS obtidos para os eletrodos depositados em titânio}

A Figura 4.25 apresenta os espectros de impedância dos eletrodos de $\mathrm{Ti}_{\mathrm{SnO}}(\mathrm{Sb})$ modificados ou não com OTS, obtidos em $0,4 \mathrm{~V}$ e em $2,6 \mathrm{~V}$. Este último valor foi escolhido por ser um potencial da região da RDO comum para ambos os tipos de eletrodo. Para determiná-lo, considerou-se como critério a obtenção de um arco fechado nos diagramas de Nyquist, o que foi verificado apenas em 2,6 V para o eletrodo modificado.

A comparação destes espectros com os espectros obtidos para os eletrodos transparentes (Fig. 4.24) revela grandes diferenças entre ambos os sistemas. De modo geral, a impedância total dos sistemas de eletrodos transparentes foi muito maior que a do $\mathrm{Ti} / \mathrm{SnO}_{2}(\mathrm{Sb})$. P.ex., na região de altas $\omega$ na Fig. $4.25 \mathrm{a}$, verifica-se que o valor do $\mathrm{R}_{\mathrm{S}}$ para o $\mathrm{Ti} / \mathrm{SnO}_{2}(\mathrm{Sb})$ (modificado ou não com OTS) foi de aproximadamente $200 \Omega$ no diagrama, o que correspondeu a $130 \Omega \mathrm{cm}^{2}$. Esta resistência é muito menor, portanto, que a observada para os eletrodos depositados em sílica. Porém, este valor é bastante alto quando comparado ao $\mathrm{R}_{\mathrm{S}}$ de $2 \Omega$ determinada por Fugivara [51] para este mesmo material (em $\mathrm{H}_{2} \mathrm{SO}_{4}$ 0,5 M). Provavelmente, o $\mathrm{R}_{\mathrm{S}}$ obtido no presente estudo foi maior porque o eletrólito empregado, i.e., $0,1 \mathrm{M}$ de $\mathrm{NaClO}_{4}$, apresenta menor condutividade.

A comparação dos espectros da Fig. 4.25 revela que a presença do OTS na superfície do eletrodo de $\mathrm{Ti} / \mathrm{SnO}_{2}(\mathrm{Sb})$ alterou consideravelmente a impedância do sistema. As maiores diferenças foram verificadas na região da $\mathrm{RDO}$, onde os valores de $|\mathrm{Z}|$ para ambos os tipos de eletrodo diferiram em uma ordem de grandeza (corresponderam a cerca de 7 e $70 \mathrm{k} \Omega$ para os eletrodos de $\mathrm{Ti} / \mathrm{SnO}_{2}(\mathrm{Sb})$ e de $\mathrm{Ti} / \mathrm{SnO}_{2}(\mathrm{Sb})$-OTS, respectivamente).

As análises realizadas para atribuição de circuitos equivalentes através do programa de Boukamp revelaram que os melhores ajustes foram obtidos com os circuitos $\mathrm{R}_{S}\left(\mathrm{R}^{\prime} \mathrm{Q}^{\prime}\right)\left(\mathrm{R}^{\prime} \mathrm{Q}\right.$ ”) e $\mathrm{R}_{S}\left(\mathrm{C}^{\prime}\left[\mathrm{R}^{\prime}\left(\mathrm{R}^{\prime \prime} \mathrm{Q}\right.\right.\right.$ ')] $)$. Nestes circuitos, representados nas Fig. 2.12 e 4.26, os elementos de fase constante $Q$ foram associados às capacitâncias do sistema.

Inicialmente, realizaram-se simulações considerando um circuito do tipo $\mathrm{R}\left(\mathrm{R}^{\prime} \mathrm{C}^{\prime}\right)(\mathrm{R}$ 'C”) e obtiveram-se grandes desvios em relação aos espectros experimentais. A substituição de uma das capacitâncias por um elemento de fase constante $Q$, resultando em um circuito $R\left(R^{\prime} Q^{\prime}\right)\left(R^{\prime \prime} C^{\prime \prime}\right)$, proporcionou simulações bastante coincidentes com os espectros experimentais $\left(\chi^{2} \sim 4 E-4\right)$, porém, somente para os espectros obtidos para os eletrodos não modificados e em $E<E_{R D O}$. Por outro lado, para um circuito $R\left(R^{\prime} C^{\prime}\right)\left(R^{\prime \prime} Q\right.$ ") obtiveram-se bons ajustes apenas para os espectros obtidos em $E>E_{R D O}$ e para os 
eletrodos modificados. A utilização de $Q$ no lugar de ambas os $\mathrm{C}$, porém, proporcionou bons ajustes para ambos os tipos de eletrodos e em todos os potenciais investigados.

O circuito $R\left(R^{\prime} Q^{\prime}\right)\left(R^{\prime} Q^{\prime \prime}\right)$ foi utilizado por Fugivara [51] para representar um eletrodo de $\mathrm{Ti} / \mathrm{SnO}_{2}(\mathrm{Sb})$ em potenciais da região do $\mathrm{E}_{\mathrm{CA}}$ e da $\mathrm{RDO}$. O primeiro conjunto (R'Q') foi utilizado para representar a resistência à transferência de carga $\left(R_{C T}\right)$ e a capacidade da dupla camada elétrica da interfase $\left(C_{d l}\right)$, enquanto que o segundo conjunto (R"Q") foi empregado para representar as características do filme $\left(R_{F}\right.$ e $\left.C_{F}\right)$.

A Tabela 4.2 apresenta os valores obtidos para o $\chi^{2}$ e para os elementos deste circuito quando empregado nas simulações realizadas através do programa de Boukamp. Nesta tabela, o parâmetro $n$ e a admitância $Y_{Q}$ referem-se ao $Q$. O valor de $\mathrm{R}_{\mathrm{S}}$, que se manteve constante em aproximadamente $180 \Omega$, não foi incluído.

Tabela 4.2. Parâmetros obtidos por simulação para o circuito equivalente $R_{S}\left(R^{\prime} Q^{\prime}\right)\left(R^{\prime \prime} Q^{\prime \prime}\right)$, da Fig. 2.14, proposto para representar os eletrodos $\mathrm{Ti} / \mathrm{SnO}_{2}(\mathrm{Sb})$ e $\mathrm{Ti} / \mathrm{SnO}_{2}(\mathrm{Sb})$-OTS em solução aquosa $0,1 \mathrm{M}$ de $\mathrm{NaClO}_{4}$ com $\mathrm{pH} 2,0$ em diversos valores de potencial.

\begin{tabular}{cccccccc}
\hline & $\chi^{2} / \mathrm{E}-4$ & $\mathrm{R}^{\prime} / \mathrm{k} \Omega$ & $\mathrm{Y}_{\mathrm{Q}}{ }^{\prime} / \mu \Omega^{-1}$ & $\mathrm{n}^{\prime}$ & $\mathrm{R}^{\prime \prime} / \Omega$ & $\mathrm{Y}^{\prime \prime} \mathrm{Q} / \mu \Omega^{-1}$ & $\mathrm{n}^{\prime \prime}$ \\
\hline $\mathrm{Ti} / \mathrm{SnO}_{2}(\mathrm{Sb})$ & & & & & & & \\
$0,4 \mathrm{~V}$ & 7,0 & 98 & 59,7 & 0,74 & 64 & 12,4 & 0,80 \\
$0,6 \mathrm{~V}$ & 1,4 & 125 & 41,6 & 0,71 & 78 & 15,4 & 0,78 \\
$0,8 \mathrm{~V}$ & 1,3 & 140 & 31,6 & 0,69 & 90 & 22,1 & 0,76 \\
$1,0 \mathrm{~V}$ & 2,2 & 138 & 25,7 & 0,68 & 179 & 44,9 & 0,69 \\
$1,6 \mathrm{~V}$ & 2,4 & 59 & 21,7 & 0,67 & 979 & 21,4 & 0,74 \\
$1,8 \mathrm{~V}$ & 2,3 & 54 & 20,3 & 0,69 & 1603 & 17,7 & 0,72 \\
$2,0 \mathrm{~V}$ & 2,7 & 8,7 & 19,3 & 0,75 & 1940 & 15,3 & 0,69 \\
$2,6 \mathrm{~V}$ & 4,7 & 5,5 & 8,7 & 0,87 & 983 & 25,9 & 0,61
\end{tabular}

$\mathrm{Ti} / \mathrm{SnO}_{2}(\mathrm{Sb})$-OTS

\begin{tabular}{rrrrrrrr}
$0,4 \mathrm{~V}$ & 1,5 & 350 & 23,8 & 0,73 & $3,6 \mathrm{k}$ & 38,3 & 0,77 \\
$2,6 \mathrm{~V}$ & 1,7 & 5,9 & 93,3 & 0,60 & $55,8 \mathrm{k}$ & 3,3 & 0,94 \\
\hline
\end{tabular}


Os dados da Tabela 4.2 mostram que, ao aumentar o potencial aplicado ao eletrodo, o $\mathrm{Y}_{\mathrm{Q}}$, que estava associado ao $\mathrm{C}_{\mathrm{dl}}$, diminuiu gradativamente, enquanto que $\mathrm{R}$ ", associado à resistência do filme, aumentou (exceto para $\mathrm{E}=2,6 \mathrm{~V}$ ). Para os outros elementos do circuito, verificou-se uma mudança de comportamento entre 1 e $1,6 \mathrm{~V}$ : os valores para R' e Q", que inicialmente aumentavam com o E, passaram a diminuir.

Se $\mathrm{Y}_{\mathrm{Q}}$ ' representar o $\mathrm{C}_{\mathrm{dl}}$, sua diminuição com o potencial pode estar relacionada à depleção dos elétrons na região da carga espacial, como seria esperado. Para os outros elementos do circuito, no entanto, os resultados não foram tão coerentes. P.ex., a Tabela 4.2 mostra que o $\mathrm{R}_{\mathrm{F}}$ aumentou em mil vezes na região da $\mathrm{RDO}$, enquanto que a admitância $\left(\mathrm{Y}_{\mathrm{Q}}\right)$ associada à capacidade do filme, começou a diminuir. $\mathrm{O} \mathrm{R}_{\mathrm{CT}}$, que aumentava para valores crescentes de potencial, diminuiu para apenas a metade na região da RDO, e apresentou um valor muito elevado quando comparado aos obtidos por outros investigadores $\left(\sim 10^{2}\right)[34]$

Esta análise mostra que o comportamento dos elementos do circuito em função do potencial não pareceu coerente ao que seria previsto, de acordo com a identidade que lhes foi atribuída. Portanto, apesar dos bons ajustes obtidos, este circuito não pareceu adequado para representar a interfase $\mathrm{Ti} / \mathrm{SnO}_{2}(\mathrm{Sb}) \mid \mathrm{NaClO}_{4}$ (aq.).

Um outro circuito que proporcionou bons ajustes para os espectros obtidos para estes eletrodos está representado na Fig. 4.26. Este circuito, proposto por Lillard [186] para representar a interfase de filmes de $\mathrm{WO}_{3}$ sobre $\mathrm{W}$, inclui elementos que expressariam uma pseudo-capacitância relacionada aos processos de adsorção que ocorreriam na camada mais externa do filme, onde o $\mathrm{WO}_{3}$ estaria hidratado.

Neste circuito, a capacidade total da dupla camada foi representada por um único elemento $\mathrm{C}_{\mathrm{dl}}$ disposto em paralelo com a resistência à transferência de cargas. Em série com o $\mathrm{R}_{\mathrm{CT}}$, incluiu-se o conjunto (R'Q) para representar a pseudo-capacitância associada aos processos de adsorção que ocorreram na superficie do eletrodo

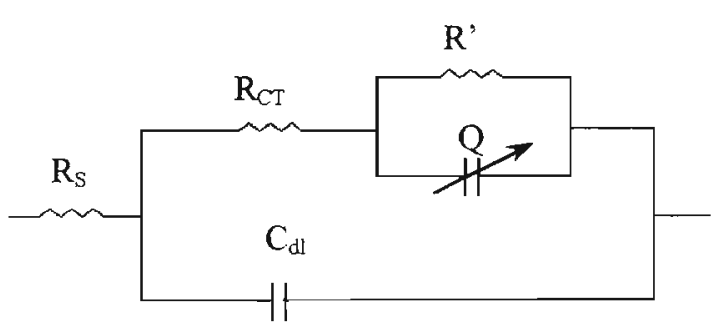

Fig. 4.26. Circuito proposto para representar a interfase dos eletrodos de $\mathrm{Ti} / \mathrm{SnO}_{2}(\mathrm{Sb})$ modificados ou não com OTS em $\mathrm{NaClO}_{4}$ (aq.) de pH 2,0. [186]. 
Os dados experimentais e as simulações realizadas através do programa de Boukamp empregando o circuito da Fig. 4.26 estão representadas nas Fig. 4.27 a 4.30 . As Fig. 4.27 e 4.28 apresentam os espectros experimentais e as correspondentes simulações obtidas para o eletrodo não modificado, determinados respectivamente em 0,4 e $2,6 \mathrm{~V}$. As Fig. 4.29 e 4.30 referem-se aos resultados obtidos para os eletrodos modificados com OTS. Em cada condição, os espectros foram representados como diagramas de Bode, de Nyquist e de admitância, para que os resultados das simulações pudessem ser melhor avaliados.

Para estimar o valor de capacidade $\mathrm{C}$ associada ao elemento de fase constante do circuito 4.26, utilizou-se a expressão [156]

$$
Y_{Q}=C^{n}\left[R_{C T}^{-1}+R^{1-1}\right]^{1-n}
$$

Os parâmetros obtidos nas simulações através do programa de Boukamp estão representados nas Tabela 4.3, e já foram corrigidos considerando a área do eletrodo (exceto para o valor de $Y_{Q}$ ). Esta tabela também não apresenta os valores determinados para a resistência em série, determinada em $(120 \pm 5) \Omega \mathrm{cm}^{2}$.

Os dados da Tabela 4.3 mostram que, para $E<1,6 \mathrm{~V}$, ou seja, antes que fosse atingido o potencial para a RDO, o aumento do potencial aplicado ao eletrodo provocou a diminuição do $\mathrm{C}_{\mathrm{d} l}$ e o aumento do $\mathrm{R}_{\mathrm{CT}}$. Para os elementos associados aos processos de adsorção na superficie do eletrodo, também se verificou o aumento na resistência $R^{\prime}$ e a diminuição do $\mathrm{C}_{\mathrm{ads}}$.

De acordo com os valores obtidos para o $\mathrm{C}_{\mathrm{dl}}$, é bastante razoável admitir que esta capacitância tenha manifestado predominantemente a contribuição do $\mathrm{C}_{\mathrm{SC}}$. Como discutido na Revisão Bibliográfica, a polarização em $\mathrm{E}>\mathrm{E}_{\mathrm{FB}}$ provocou a diminuição do $\mathrm{C}$ devido à depleção dos elétrons na região de carga espacial. Os valores obtidos para o $\mathrm{R}_{\mathrm{Cr}}$, porém, foram muito menores que os apresentados na Literatura. Utilizando também medidas por EIS e utilizando um circuito $R_{S}\left(R_{C T} Q\right)$ (Fig. 2.13) para representar a interfase, Cachet [34] obteve $R_{C T}$ da ordem de $10^{5}$ em $E<E_{R D O}$ e $10^{2}$ na região da $R D O$

As simulações revelaram que, quando o sistema foi polarizado em potenciais da região da $\mathrm{RDO}$ (exceto para $2,6 \mathrm{~V}$ ), o $\mathrm{C}_{\mathrm{dl}}$ continuou a diminuir e o $\mathrm{R}_{\mathrm{CT}}$ foi praticamente nula. Nestas condições, os valores obtidos para $C_{a d}$ também foram muito pequenos, o que indica que o acúmulo de cargas na interfase foi muito baixo. Considerando o sistema investigado, esta pseudo-capacitância pode estar associada aos processos de adsorção e 
dissociação de prótons e hidroxilas na superficie. Durante a RDO, as espécies adsorvidas podem ter sido consumidas, diminuindo o acúmulo de cargas na superfície e o valor do $\mathrm{C}_{\mathrm{ad}}$.

A Tabela 4.3 revela ainda que, para o eletrodo não modificado, a capacitância e a resistência associados aos processos de adsorção foram muito maiores que o $\mathrm{C}_{\mathrm{dl}}$ e o $\mathrm{R}_{\mathrm{CT}}$ em condições nas quais $E<E_{R D O}$. Lillard [186] também observou esta tendência para o eletrodo de $\mathrm{W} / \mathrm{WO}_{3}$. Esta situação se inverteu na região da $\mathrm{RDO}$, exceto para o $\mathrm{C}_{\mathrm{ads}}$ determinado em 2,6 V. Em geral, os parâmetros determinados a 2,6 V para o $\mathrm{Ti} / \mathrm{SnO}_{2}(\mathrm{Sb})$ diferiram dos obtidos em outros potenciais da região da $\mathrm{RDO}$, i.e., em 1,6;1,8 e 2,0 V. É possível que, em $2,6 \mathrm{~V}$, tenham ocorrido outros processos além da reação de geração de $\mathrm{O}_{2}$, como p.ex., a destruição do filme de $\mathrm{SnO}_{2}$, como foi investigado por Cachet [34].

Para os eletrodos modificados, i.e., Ti/ $\mathrm{SnO}_{2}(\mathrm{Sb})-\mathrm{OTS}$, o $\mathrm{C}_{\mathrm{dl}}$ e o $\mathrm{R}_{\mathrm{CT}}$ apresentaram a mesma ordem de grandeza e seguiram a mesma tendência apresentada pelo eletrodo não modificado. No entanto, os valores para o $\mathrm{C}_{\mathrm{ads}}$ e o $\mathrm{R}^{\prime}$ foram muito maiores e variaram com o potencial de um modo distinto: para $E$ crescentes, $R$ ' diminuiu e $C_{a d s}$ aumentou. Portanto, considerando este modelo, as maiores diferenças entre os eletrodos modificados ou não com OTS foram verificadas justamente para os elementos associados à pseudocapacitância de adsorção, principalmente nos potenciais inferiores aos da região da RDO.

De modo geral, o conjunto dos resultados expostos na Tabela 4.3 parecem bastante razoáveis e coerentes, embora os ajustes não tenham sido tão bons quanto os obtidos com o circuito da Fig. 2.12. Portanto, o circuito equivalente proposto na Fig. 4.26 parece ser adequado para representar a interfase $\mathrm{Ti} / \mathrm{SnO}_{2}(\mathrm{Sb}) \mid \mathrm{NaClO}_{4}$ (aq.) para eletrodos modificados ou não com OTS. 
Tabela 4.3. Parâmetros obtidos por simulação para o circuito equivalente da Fig. 4.26, proposto para representar os eletrodos $\mathrm{Ti} / \mathrm{SnO}_{2}(\mathrm{Sb})$ e Ti/SnO $2(\mathrm{Sb})$-OTS em solução aquosa $0,1 \mathrm{M}$ de $\mathrm{NaClO}_{4}$ com $\mathrm{pH} 2,0$ em diversos valores de potencial.

\begin{tabular}{|c|c|c|c|c|c|c|}
\hline & $\chi^{2} / \mathrm{E}-4$ & $\mathrm{C}_{\mathrm{d} 1} / \mu \mathrm{Fcm}^{-2}$ & $\mathrm{R}_{\mathrm{CT}} / \Omega \mathrm{cm}^{2}$ & $\mathrm{R}^{\prime} / \mathrm{k} \Omega \mathrm{cm}^{2}$ & $\mathrm{Y}_{\mathrm{Q}} / \mu \Omega^{-1}, \mathbf{n}$ & $\mathrm{C}_{\mathrm{ads}} / \mu \mathrm{Fcm}^{-2}$ \\
\hline \multicolumn{7}{|l|}{$\mathrm{Ti} / \mathrm{SnO}_{2}(\mathrm{Sb})$} \\
\hline $0,4 \mathrm{~V}$ & 8,0 & 2,1 & 49 & 66,8 & $59 ; 0,73$ & 13,0 \\
\hline $0,6 \mathrm{~V}$ & 3,6 & 1,5 & 67 & 87,8 & $41 ; 0,69$ & 5,85 \\
\hline $0,8 \mathrm{~V}$ & 5,2 & 1,3 & 86 & 102 & $32 ; 0,67$ & 3,31 \\
\hline $1,0 \mathrm{~V}$ & 10 & 1,1 & 111 & 113 & $26 ; 0,64$ & 2,17 \\
\hline $1,6 \mathrm{~V}$ & 9,1 & 0,37 & $1,6 \times 10^{-14}$ & 51,8 & $24 ; 0,57$ & $6,9 \times 10^{-13}$ \\
\hline $1,8 \mathrm{~V}$ & 1,3 & 0,38 & $1,6 \times 10^{-14}$ & 49,8 & $.23 ; 0,56$ & $2,9 \times 10^{-13}$ \\
\hline $2,0 \mathrm{~V}$ & 7,9 & 0,31 & 2,9 & 7,3 & $19 ; 0,60$ & 0,057 \\
\hline $2,6 \mathrm{~V}$ & 19 & 0,58 & 147 & 4,2 & $11 ; 0,79$ & 1,63 \\
\hline \multicolumn{7}{|c|}{$\mathrm{Ti} / \mathrm{SnO}_{2}(\mathrm{Sb})$-OTS } \\
\hline $0,4 \mathrm{~V}$ & 6,5 & 1,65 & 30,6 & 668 & 22,$4 ; 0,62$ & 0,53 \\
\hline $0,6 \mathrm{~V}$ & 3,5 & 1,47 & 53,8 & 271 & 10,$3 ; 0,71$ & 0,85 \\
\hline $0,8 \mathrm{~V}$ & 1,7 & 1,42 & 80,1 & 234 & 6,$3 ; 0,77$ & 1,10 \\
\hline $2,4 \mathrm{~V}$ & 6,2 & 1,39 & 136,0 & 35 & 2,$9 ; 0,85$ & 1,20 \\
\hline $2,6 \mathrm{~V}$ & 6 & 1,45 & 165 & 41,3 & 2,$5 ; 0,86$ & 1,14 \\
\hline
\end{tabular}


Espectros de impedância eletroquímica para os eletrodos de $\mathrm{Ti} / \mathrm{SnO}_{2}(\mathrm{Sb})$

(a)

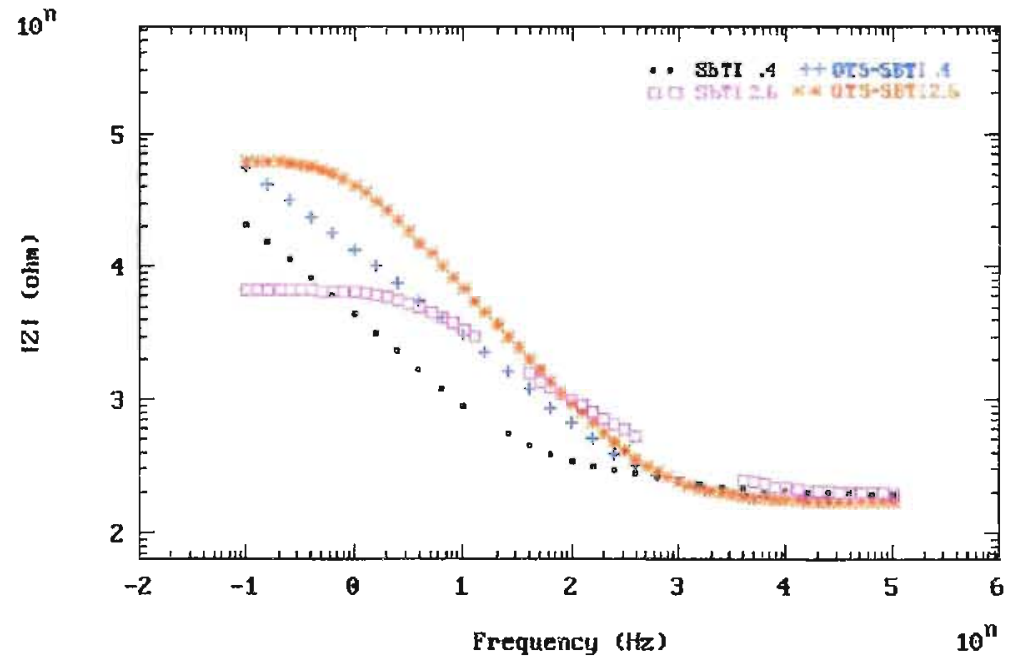

(b)

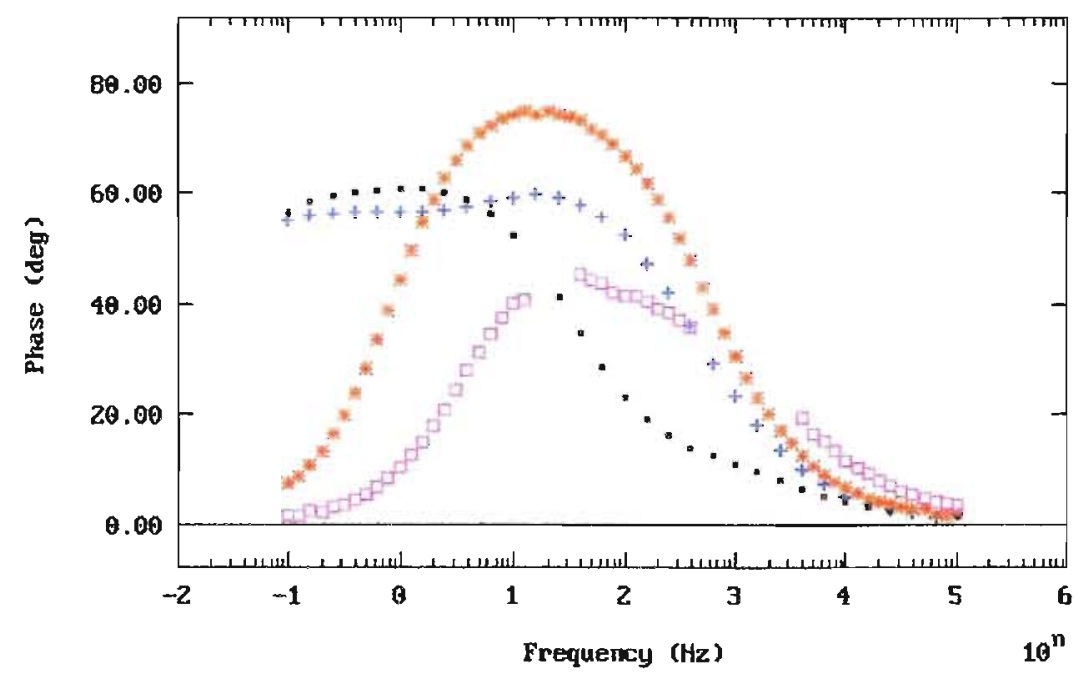

(c)

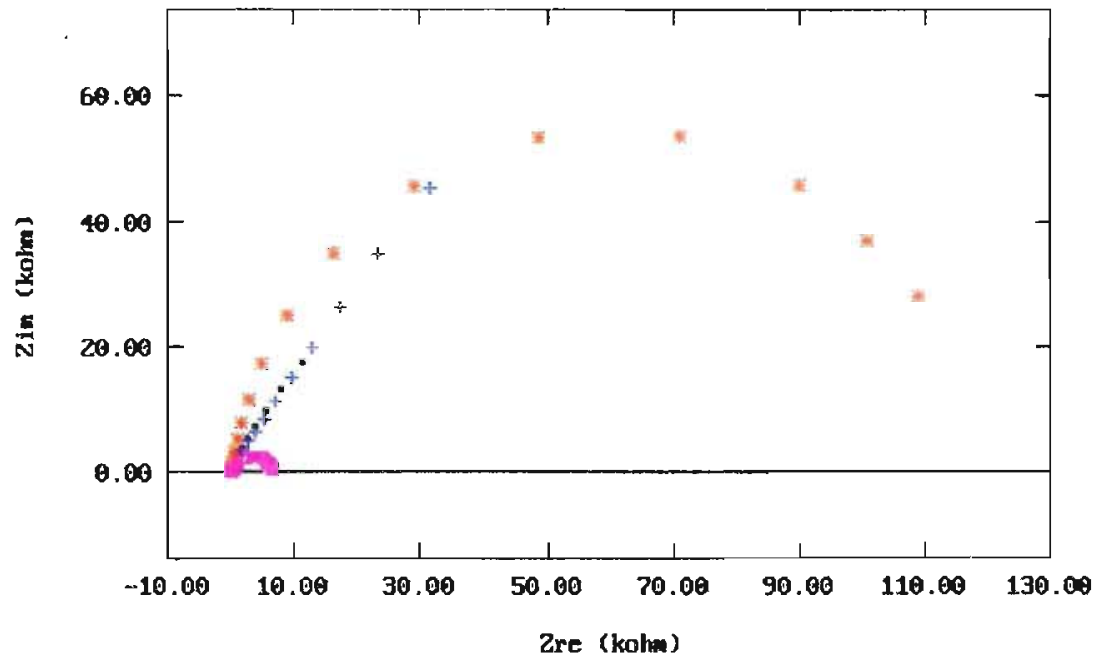

Figura 4.25. Espectros de impedância determinados para os eletrodos de $\mathrm{Ti} / \mathrm{SnO}_{2}(\mathrm{Sb})$ e $\mathrm{Ti} / \mathrm{SnO}_{2}(\mathrm{Sb})$-OTS em 0,4 e 2,6 V, representados como gráficos de Bode e de Nyquist. 
Espectro de impedância eletroquímica para o eletrodo de $\mathrm{Ti} / \mathrm{SnO}_{2}(\mathrm{Sb})$

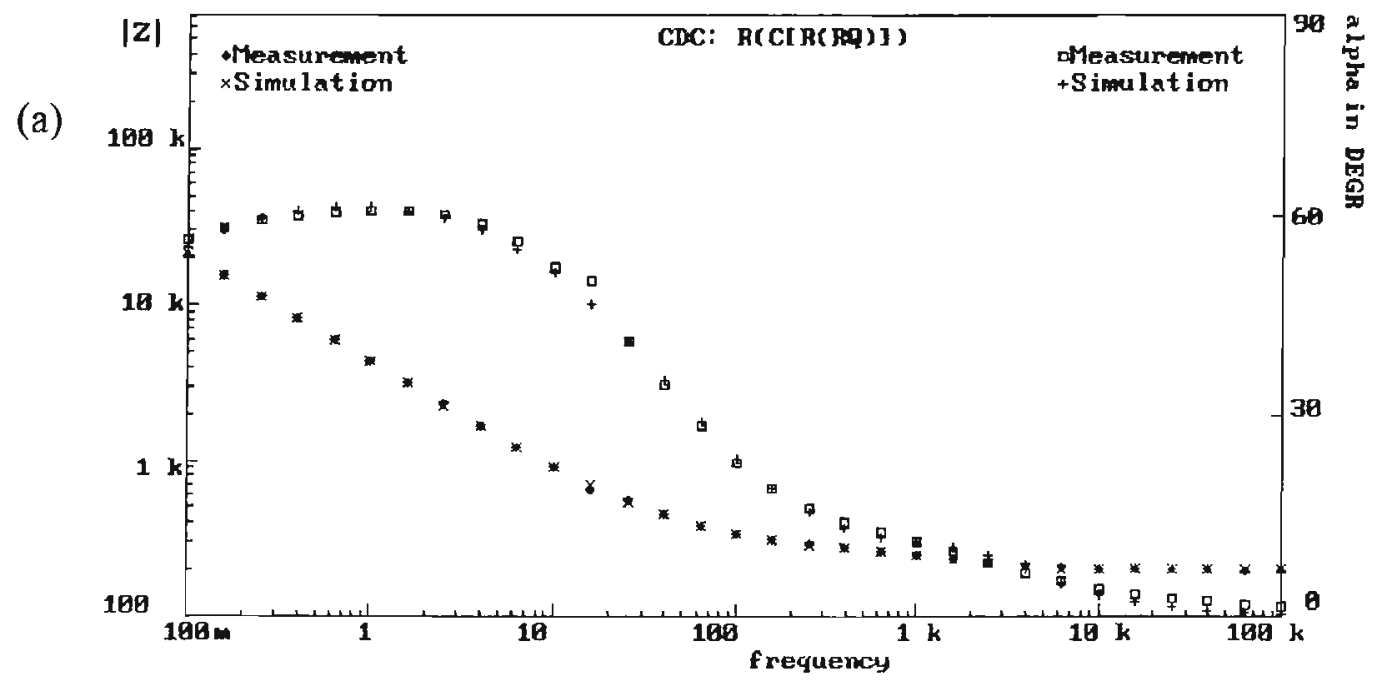

(b)

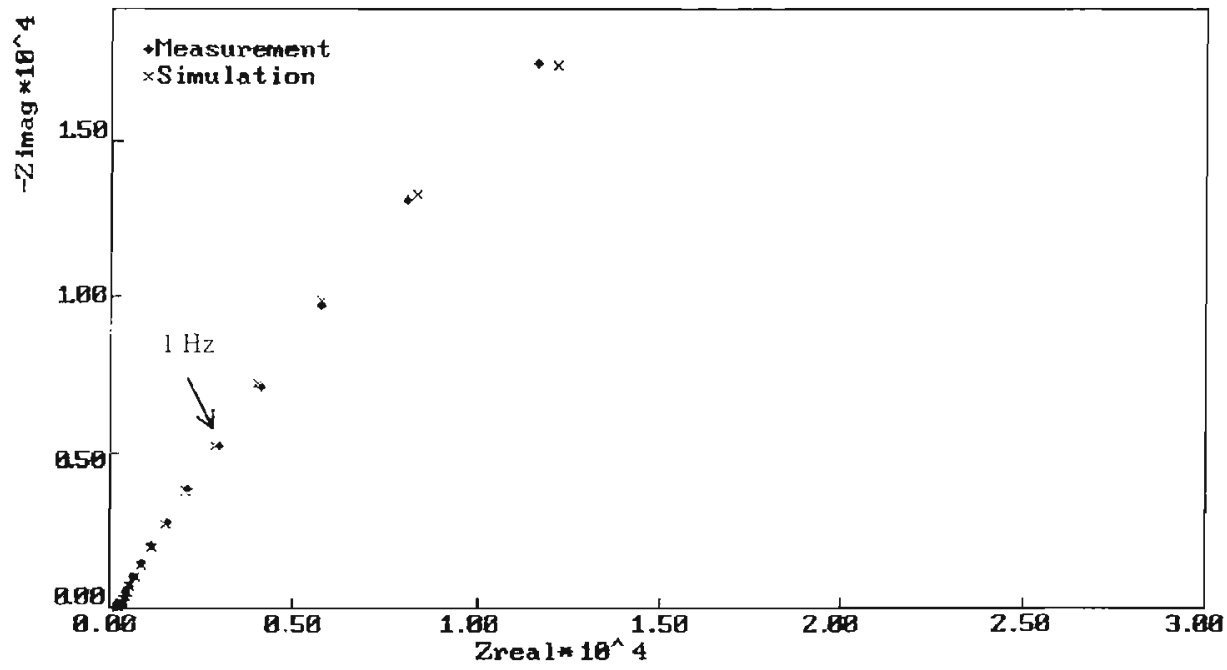

(c)

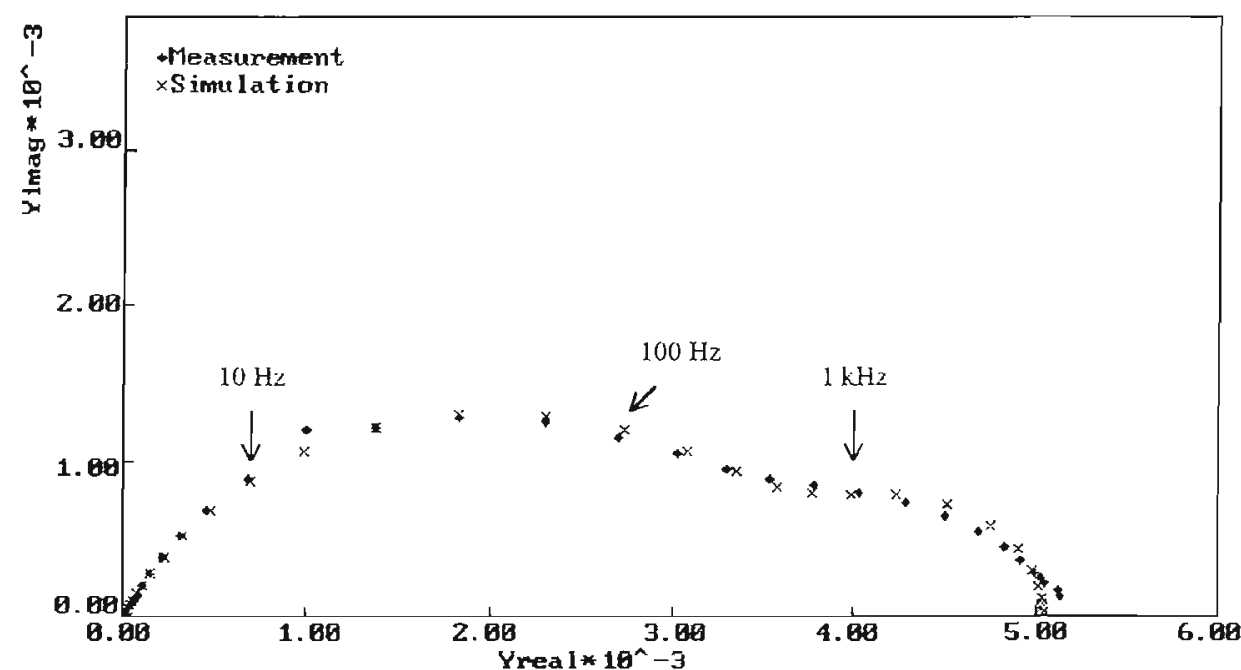

Figura 4.27. Espectro de impedância para o eletrodo de $\mathrm{Ti}_{\mathrm{SnO}}(\mathrm{Sb}) \mid \mathrm{NaClO}_{4}$ (aq.) determinado em $0,4 \mathrm{~V}$, representado como gráfico de Bode, de Nyquist e de admitância. 
Espectro de impedância eletroquímica - eletrodo de $\mathrm{Ti} / \mathrm{SnO}_{2}(\mathrm{Sb}) \mathrm{em} 2,6 \mathrm{~V}$
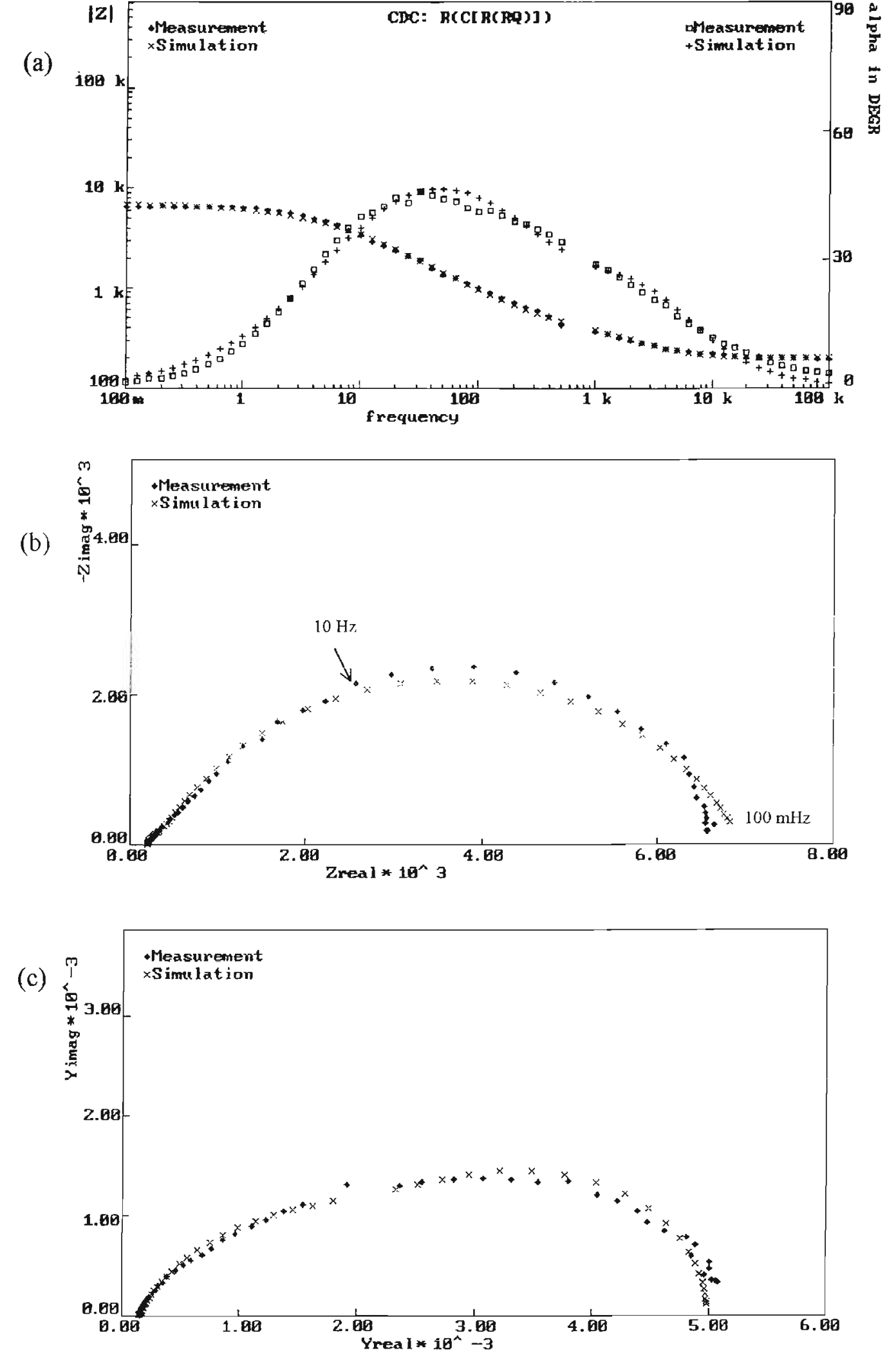

Figura 4.28. Espectro de impedância para o eletrodo de $\mathrm{Ti} / \mathrm{SnO}_{2}(\mathrm{Sb}) \mid \mathrm{NaClO}_{4}$ (aq.) obtido em 2,6 V, representado como diagramas de Bode (a), de Nyquist (b) e de admitância (c). 
Espectro de impedância eletroquímica - eletrodo de $\mathrm{OTS}-\mathrm{Ti} / \mathrm{SnO}_{2}(\mathrm{Sb})$ em $0,4 \mathrm{~V}$
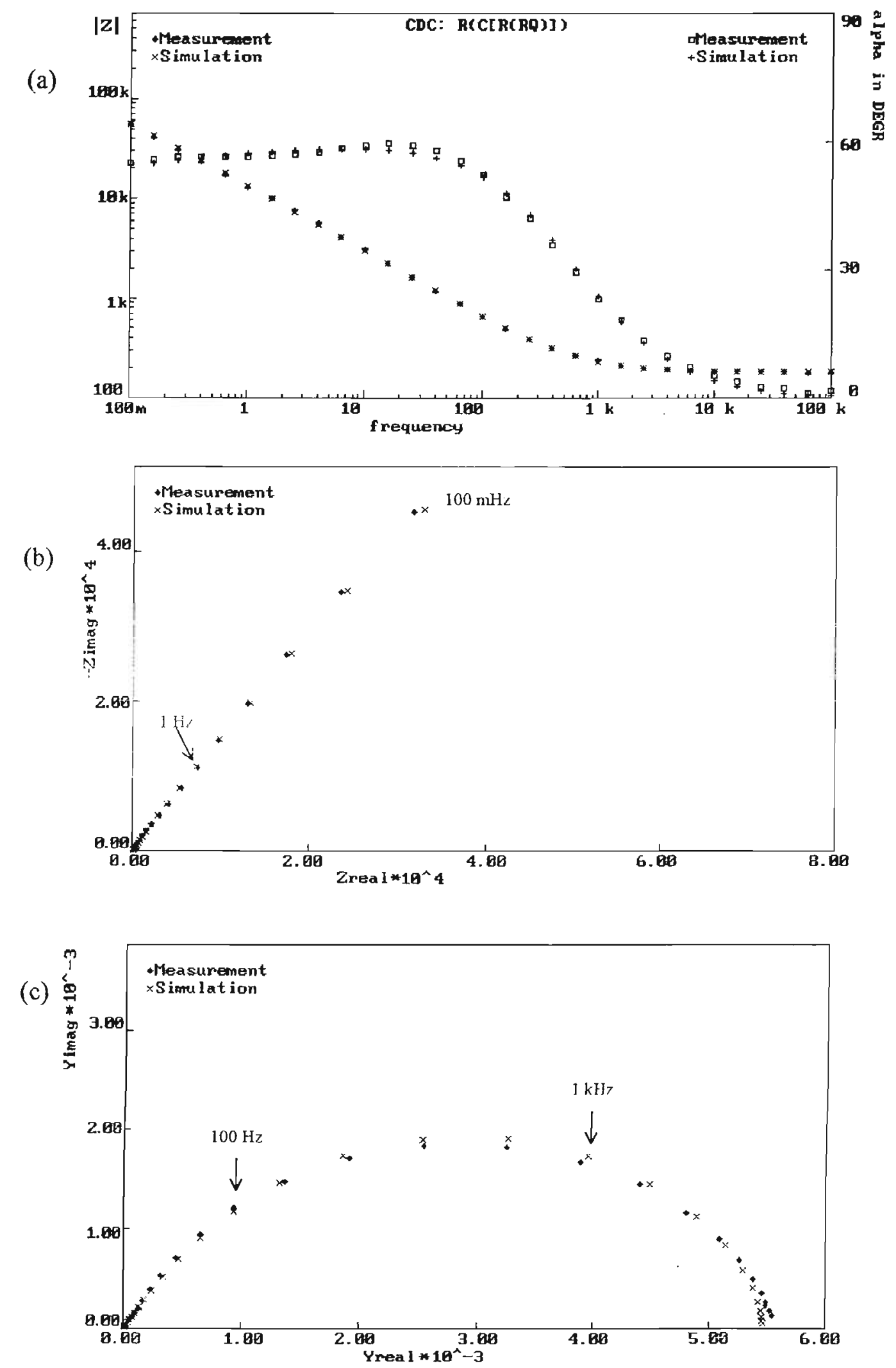

Figura 4.29. Espectro de impedância para o eletrodo de OTS-Ti/ $\mathrm{SnO}_{2}(\mathrm{Sb}) \mathrm{NaClO}_{4}$ (aq.) determinado em $0,4 \mathrm{~V}$, representado como gráfico de Bode, de Nyquist e de admitância. 
Espectro de impedância eletroquímica - eletrodo de OTS-Ti/ $/ \mathrm{SnO}_{2}(\mathrm{Sb})$ em $2,6 \mathrm{~V}$
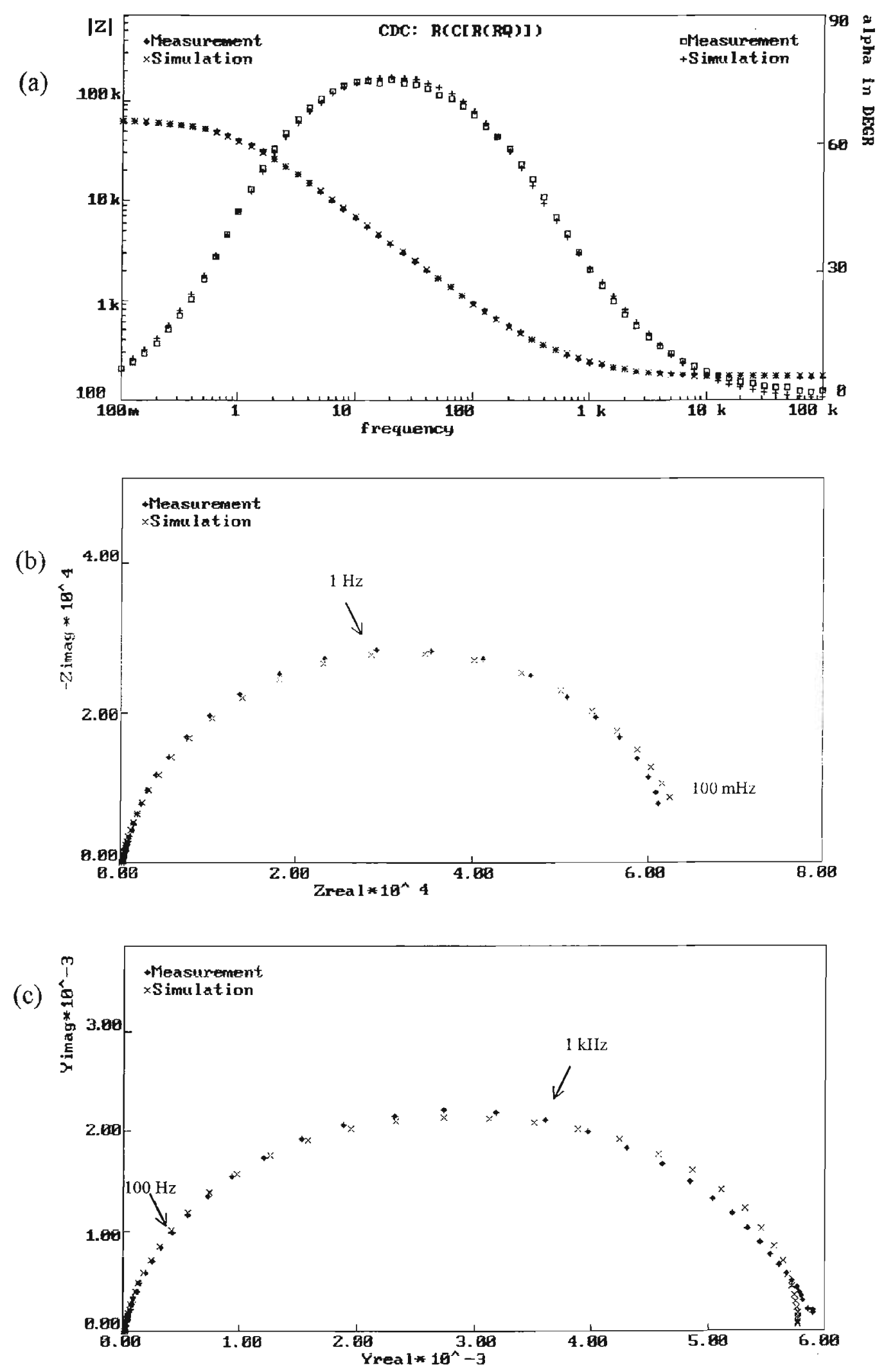

Figura 4.30. Espectro de impedância para o eletrodo de OTS-Ti/SnO determinado em $2,6 \mathrm{~V}$, representado como gráfico de Bode, de Nyquist e de admitância. 


\subsubsection{A capacidade interfacial em função do potencial estimada por EIS}

As medidas de EIS foram ainda utilizadas para estimar a variação da capacidade interfacial em função do potencial aplicado. Como foi sugerido em alguns trabalhos, os valores foram determinados a 100 [20] e a $1000 \mathrm{~Hz}$ [21]. Os gráficos obtidos para os eletrodos transparentes e suportado em Ti estão representados nas Figuras 4.31 e 4.32 , respectivamente.

Figura 4.31

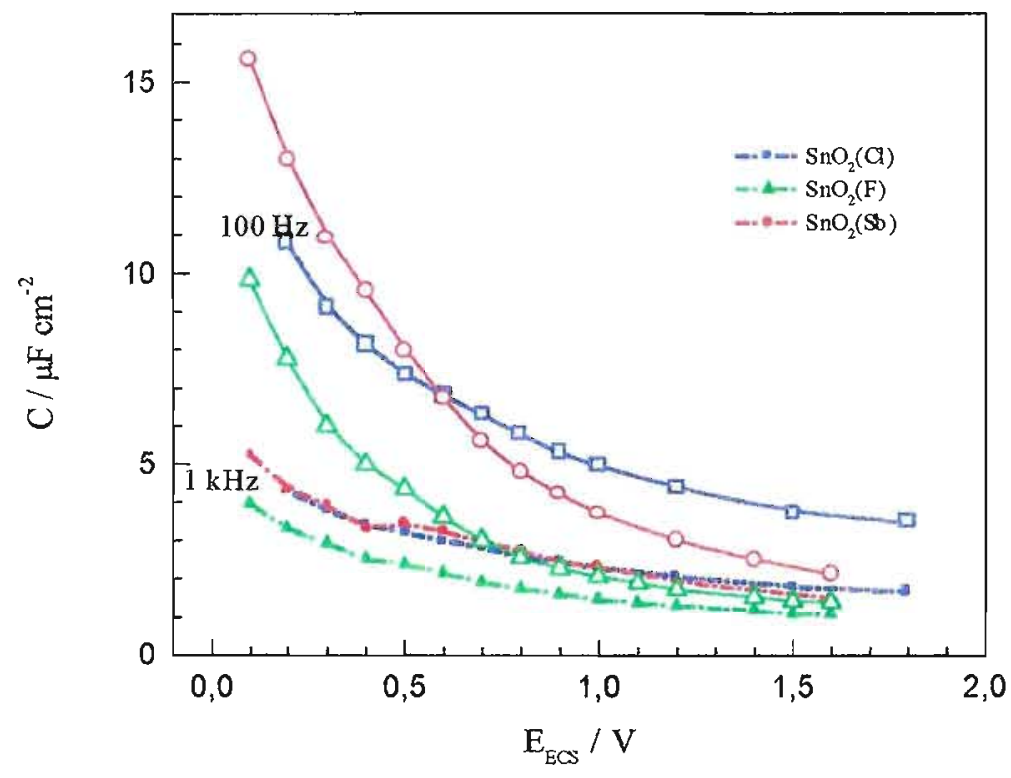

Figura 4.32

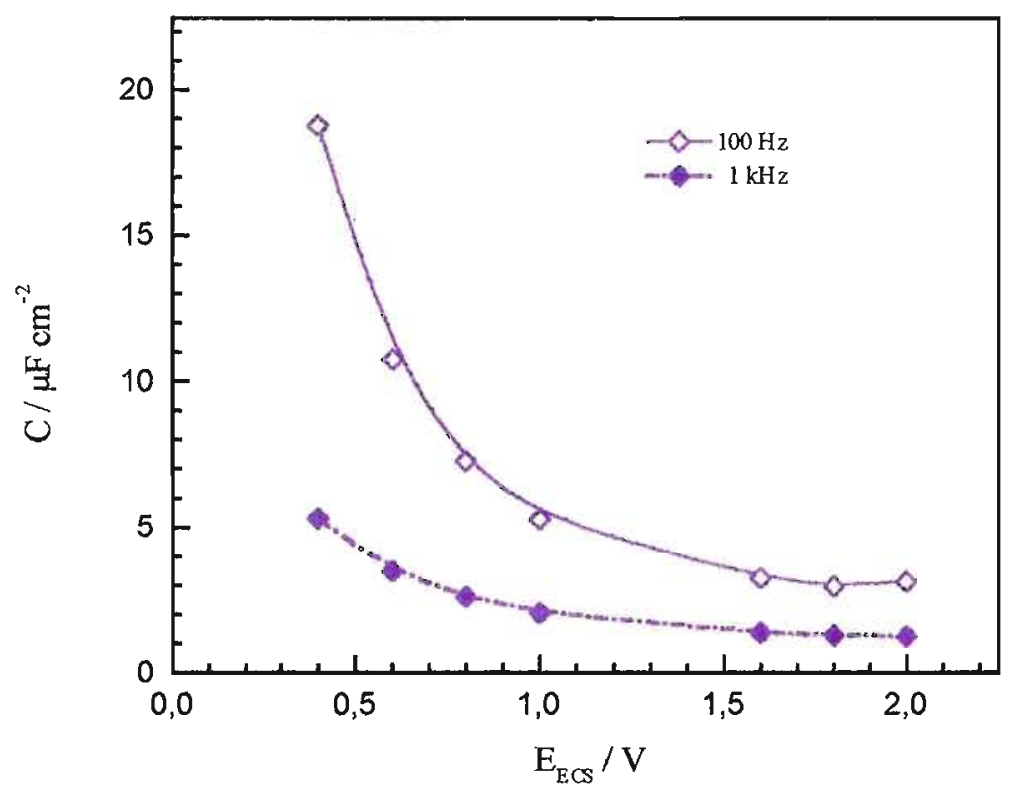

Figuras 4.31 e 4.32 . Variação da capacidade interfacial em função do potencial aplicado para os eletrodos transparentes e para o eletrodo de $\mathrm{Ti} / \mathrm{SnO}_{2}(\mathrm{Sb})$ em $0,1 \mathrm{M}$ de $\mathrm{NaClO}_{4}$ (aq.) com pH 2,0. Valores de C determinados por EIS em 100 e $1000 \mathrm{~Hz}$. 


\subsubsection{Gráficos de Mott-Schoktty}

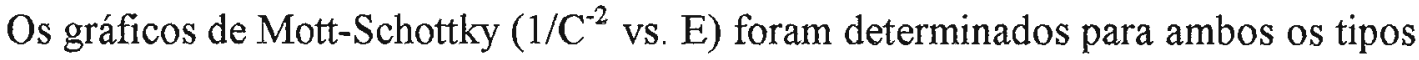
de eletrodos não modificados considerando os valores de capacidade estimados pelas técnicas de SACV e EIS nos diversos valores de potencial (apresentados nas Fig. 4.22, $4.23,4.31$ e 4.32). Em ambos os casos, admitiu-se que os valores de $\mathrm{C}$ medidos, referentes à capacidade total da interfase, refletia essencialmente a capacidade da região da carga espacial $\left(\mathrm{C}_{\mathrm{SC}}\right)$.

De acordo com a equação 2.4 apresentada na revisão bibliográfica, se $1 / \mathrm{C}_{\mathrm{SC}}$ variar linearmente com $\mathrm{E}$, a densidade de portadores de carga $\left(\mathrm{N}_{\mathrm{D}}\right)$ e o potencial de bandas planas $\left(E_{\mathrm{FB}}\right)$ podem ser estimados para o eletrodo através das equações:

$$
\begin{aligned}
& N_{D}=\left(\frac{2}{\varepsilon \varepsilon_{0} e}\right)\left(\frac{d E}{d C^{-2}}\right) \\
& E_{F B}=E_{\left(C^{-2} \rightarrow 0\right)}-\frac{k T}{e}
\end{aligned}
$$

Utilizando estas expressões, estimaram-se $N_{D}$ e E EB para os eletrodos depositados em sílica e titânio. Para a constante dielétrica do $\mathrm{SnO}_{2}$ utilizou-se o valor $\varepsilon=10$ [21].

Os gráficos de Mott-Schottky determinados para os eletrodos transparentes estão representados nas Fig. 4.33 e 4.34 .

Nos gráficos determinados através da EIS, na Fig. 4.33, observam-se diferenças notáveis entre as curvas obtidas em $100 \mathrm{~Hz}$ e em $1 \mathrm{kHz}$, como já observado por outros autores [120]. Para ambas as condições de frequência, obteve-se uma relação linear de $\mathrm{C}^{-2}$ com E no intervalo entre 0,3 e $1,2 \mathrm{~V}$ para os eletrodos transparentes de $\mathrm{SnO}_{2}(\mathrm{Cl})$ e $\mathrm{SnO}_{2}(\mathrm{Sb})$, e somente até $0,9 \mathrm{~V}$ para o eletrodo de $\mathrm{SnO}_{2}(\mathrm{~F})$. A mudança na inclinação das curvas a partir destes potenciais deve ter sido causada pelo início da RDO. Considerando apenas os pontos referentes a tais intervalos de potencial, determinaram-se $N_{D}$ e $E_{F B}$ para os eletrodos investigados. Os valores obtidos foram apresentados na Tabela 4.4.

Na Figura 4.34, verifica-se que as curvas determinadas a partir das medidas efetuadas através da SACV apresentaram uma considerável dispersão nos dados. Neste caso, o desvio da linearidade deve ter sido causado não apenas pelos problemas discutidos nos itens 2.1 .3 e 2.1 .4 da Revisão Bibliográfica, como também por limitações da técnica. 
A primeira limitação para a utilização da SACV nestas medidas refere-se ao próprio princípio do método. $\mathrm{Na} S A C V$, admite-se que a interfase pode ser representada por um circuito do tipo $\mathrm{R}_{S}\left(\mathrm{R}_{\mathrm{P}} \mathrm{C}_{\mathrm{dl}}\right)$. No entanto, a análise dos espectros de impedância mostrou que tal circuito não foi adequado para representar este sistema. Uma outra limitação é de ordem experimental. Como as densidades de corrente observadas para estes eletrodos foram extremamente baixas, os erros relativos das medidas foram muito grandes. Apesar da dispersão dos dados, estimaram -se também o $N_{D}$ e o $E_{F B}$ a partir das curvas de $\mathrm{C}^{-2}$ vs. E da Fig. 4.34

Os gráficos de Mott-Schoktty determinados para o eletrodo de $\mathrm{Ti} / \mathrm{SnO}_{2}(\mathrm{Sb})$ através de medidas efetuadas por EIS e por SACV estão representados nas Fig. 4.35 e 4.36. Por limitação de tempo, os valores da capacidade foram determinados em um número bastante reduzido de potenciais, como mostra a Fig. 4.35. Neste gráfico, verificam-se novamente grandes diferenças entre as medidas obtidas em 100 e em $1000 \mathrm{~Hz}$. Para ambas as condições de frequência, $\mathrm{C}^{-2}$ variou linearmente com $\mathrm{E}$ em quase toda a extensão de potenciais aplicados ao eletrodo, i.e., até aproximadamente 1,8 V. Porém, consideraram-se apenas os $\mathrm{C}$ medidas até $1.6 \mathrm{~V}$ para determinar $\mathrm{N}_{\mathrm{D}}$ e o $\mathrm{E}_{\mathrm{FB}}$, apresentados na Tabela 4.4 .

$\mathrm{Na}$ Fig. 4.36, observa-se que o gráfico determinado a partir dos $\mathrm{C}$ estimados pela SACV apresentou um comportamento linear somente até $0,7 \mathrm{~V}$. Os valores de $\mathrm{N}_{\mathrm{D}}$ e o $\mathrm{E}_{\mathrm{FB}}$ estimados considerando as capacidades obtidas até este potencial também foram apresentados na tabela.

O gráfico obtido para este eletrodo não apresentou a grande dispersão de dados verificada para os eletrodos transparentes (Fig. 4.34). Como obtiveram-se densidades de corrente muito maiores para o $\mathrm{Ti} / \mathrm{SnO}_{2}(\mathrm{Sb})$, as limitações experimentais apontadas para os eletrodos transparentes devem ter sido consideravelmente minimizadas. Porém, neste caso, a validade do método continuou sendo questionável porque, como revelaram as análises dos espectros de impedância, esta interfase também não pode ser representada pelo circuito admitido na SACV.

A Tabela 4.4 apresenta os parâmetros determinados para ambos os tipos de eletrodos através das equações $4.6 \mathrm{a}$ e $4.6 \mathrm{~b}$ para os gráficos de Mott-Schoktty obtidos a partir dos C medidas por EIS e por SACV. 
Tabela 4.4. Valores de $\mathrm{N}_{\mathrm{D}}$ e $\mathrm{E}_{\mathrm{FB}}$ para os eletrodos transparentes e de $\mathrm{Ti} / \mathrm{SnO}_{2}(\mathrm{Sb})$ em $0,1 \mathrm{M}$ de $\mathrm{NaClO}_{4}$ (aq.) com pH 2,0, estimados a partir das capacidades interfaciais determinadas por EIS e SACV (referentes aos gráficos 4.33 a 4.36).

\begin{tabular}{clcccc}
\hline & & $\mathrm{SnO}_{2}(\mathrm{Cl})$ & $\mathrm{SnO}_{2}(\mathrm{~F})$ & $\mathrm{SnO}_{2}(\mathrm{Sb})$ & $\mathrm{Ti} / \mathrm{SnO}_{2}(\mathrm{Sb})$ \\
\hline \hline EIS-100 Hz & $\mathrm{N}_{\mathrm{D}} / \mathrm{cm}^{-3}$ & $3,4 \times 10^{20}$ & $5,6 \times 10^{19}$ & $1,6 \times 10^{20}$ & $2,6 \times 10^{20}$ \\
& $\mathrm{E}_{\mathrm{FB}} / \mathrm{V}$ (vs. ECS) & 0,05 & 0,1 & 0,1 & 0,3 \\
$\mathrm{EIS-1} \mathrm{kHz}$ & $\mathrm{N}_{\mathrm{D}} / \mathrm{cm}^{-3}$ & $8,2 \times 10^{19}$ & $3,4 \times 10^{19}$ & $7,8 \times 10^{19}$ & $4,2 \times 10^{19}$ \\
& $\mathrm{E}_{\mathrm{FB}} / \mathrm{V}$ (vs. ECS) & 0,15 & 0 & $-0,1$ & 0,3 \\
& & & & & \\
$\mathrm{SACV}$ & $\mathrm{N}_{\mathrm{D}} / \mathrm{cm}^{-3}$ & $1,6 \times 10^{19}$ & $1,3 \times 10^{19}$ & $1,1 \times 10^{20}$ & $2,5 \times 10^{22}$ \\
& $\mathrm{E}_{\mathrm{FB}} / \mathrm{V}$ (vs. ECS $)$ & 0,1 & 0,0 & 0,05 & 0,15 \\
\hline
\end{tabular}

Considerando inicialmente os valores determinados para o potencial de bandas planas, observa-se que as diferentes determinações realizadas resultaram em $E_{F B}$ bastante similares. Os valores médios obtidos corresponderam a $100 ; 50$ e $0 \mathrm{mV}$ para os eletrodos transparentes dopados com $\mathrm{Cl}, \mathrm{F}$ e Sb e $250 \mathrm{mV}$ para o de $\mathrm{Ti} / \mathrm{SnO}_{2}(\mathrm{Sb})$, e são comparáveis aos apresentados na Literatura para este material.

Como mostra a Tabela 4.3, para cada eletrodo obtiveram-se, portanto, três valores de $\mathrm{N}_{\mathrm{D}}$. Para os eletrodos transparentes de $\mathrm{SnO}_{2}(\mathrm{~F})$ e $\mathrm{SnO}_{2}(\mathrm{Sb})$, se os três resultados forem considerados, o valor médio de $N_{D}$ corresponderia a $(3 \pm 2) \times 10^{19}$ e a $(9 \pm 2) \times 10^{19} \mathrm{~cm}^{-3}$, respectivamente. $\mathrm{O}$ valor estimado para o eletrodo dopado com $\mathrm{F}$ é bastante razoável, porém, o estimado para o eletrodo de filme transparente de $\mathrm{SnO}_{2}(\mathrm{Sb})$, apesar de ser comparável a outros relatados na Literatura $[30,115]$, pareceu demasiadamente elevado, considerando o comportamento eletroquímico apresentado por este eletrodo. Para o eletrodo transparente de $\mathrm{SnO}_{2}(\mathrm{Cl})$ e para o $\mathrm{Ti} / \mathrm{SnO}_{2}(\mathrm{Sb})$, no entanto, os três valores apresentaram diferenças muito grandes para que se determinasse um valor médio.

Considerando as características físico-quimicas gerais do eletrodo de $\mathrm{SnO}_{2}(\mathrm{Cl})$, sua alta resistividade e o comportamento eletroquímico apresentado, é mais razoável dar preferência ao resultado obtido por $\mathrm{SACV}$, i.e., $\mathrm{N}_{\mathrm{D}} \sim 2 \times 10^{19} \mathrm{~cm}^{-3}$. A alta densidade de portadores estimada por EIS seria incoerente para um material semicondutor dopado não intencionalmente, e que apresentou as características acima mencionadas. 
Para o eletrodo depositado em Ti, embora fosse esperado uma alta densidade de portadores, considerando a quantidade de Sb empregada na preparação ( $[\mathrm{Sb}] /[\mathrm{Sn}]=3 \%)$ e o comportamento eletroquímico apresentado por este eletrodo, o $\mathrm{N}_{\mathrm{D}}$ estimado por SACV pareceu ser demasiadamente elevado. Por outro lado, os resultados obtidos por EIS foram muito baixos, além de diferirem em uma ordem de grandeza dependendo da frequência considerada para a medida da capacidade. Para comparação, Kötz obteve $\mathrm{N}_{\mathrm{D}} \sim 5 \times 10^{21} \mathrm{~cm}^{-3}$ para um eletrodo de $\mathrm{Ti} / \mathrm{SnO}_{2}(\mathrm{Sb})$ obtido por Spray Pyrolysis com ([Sb]/[Sn] $=7 \%$ ) [21]. Como os três valores obtidos foram muito distintos para calcular um valor médio, considerou-se apenas o valor obtido por SACV.

Para finalizar, considerando os valores de $N_{D}$ dos eletrodo transparentes e o comportamento eletroquímico apresentado por cada um em eletrólito inerte e em $\mathrm{K}_{4} \mathrm{Fe}(\mathrm{CN})_{6}$, verifica-se que não há uma relação coerente entre estes aspectos que, como foi discutido na Revisão Bibliográfica, deveriam estar relacionados. O eletrodo dopado com $\mathrm{Sb}$, p.ex., apesar de apresentar o pior desempenho para a trasferência de elétrons em $\mathrm{K}_{4} \mathrm{Fe}(\mathrm{CN})_{6}$, e ainda o maior sobrepotencial para a RDO, foi justamente o que apresentou os maiores valores de $\mathrm{N}_{\mathrm{D}}$.

Como já foi discutido anteriormente, é muito provável que a irreversibilidade observada para os eletrodos transparentes nos sistemas investigados, assim como a grande dificuldade encontrada na determinação das medidas de SACV e EIS, sejam decorrentes dos problemas relacionados a contatos pouco adequados e à alta resistência apresentada por estes materiais. Consequentemente, os resultados obtidos são bastante questionáveis. 
Gráficos de Mott-Schottky para os eletrodos transparentes
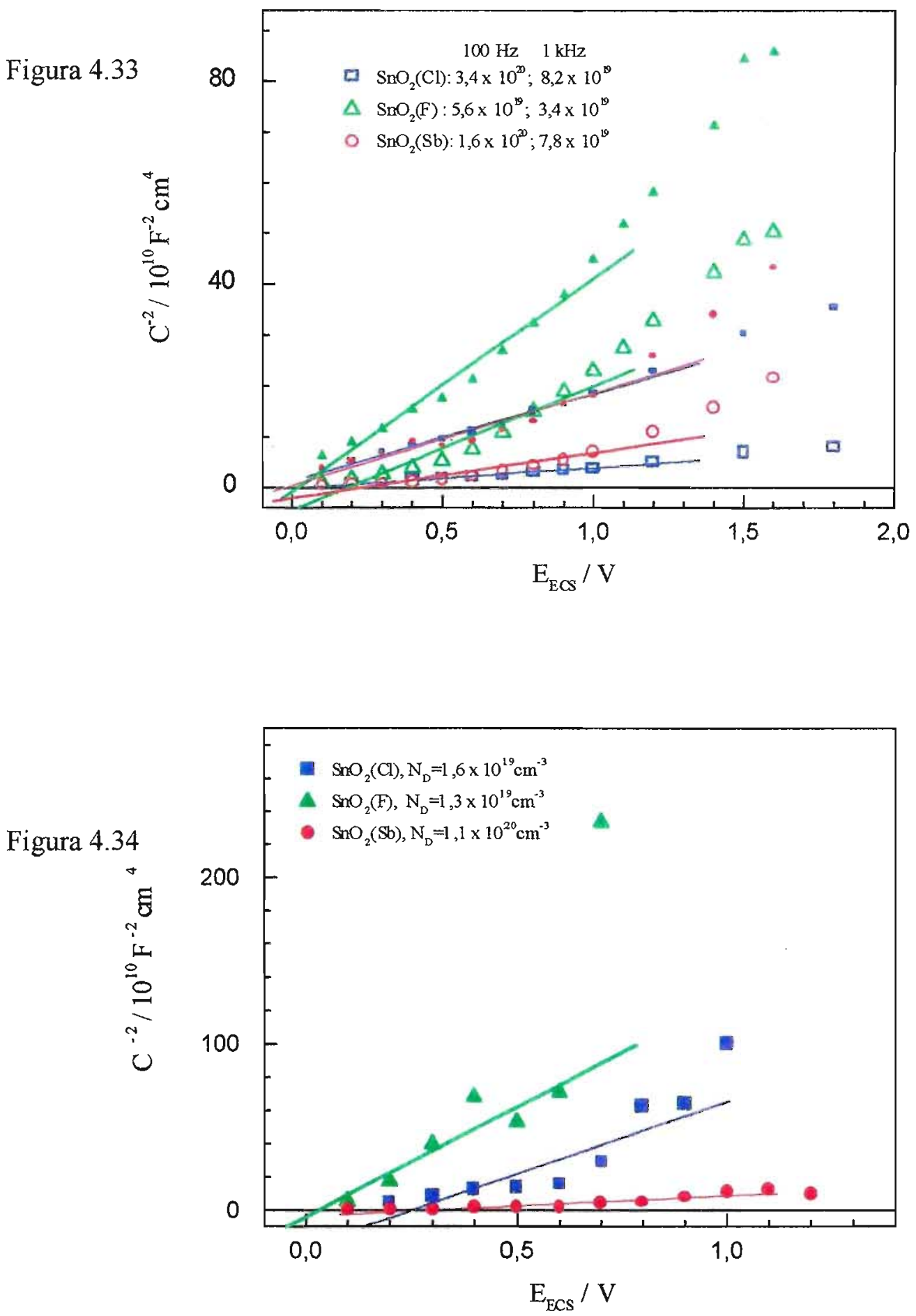

Figuras 4.33 e 4.34. Gráficos de Mott-Schottky para os eletrodos transparentes, obtidos respectivamente com as capacidades determinadas através de medidas de EIS e SACV, em solução aquosa $0,1 \mathrm{M}$ de $\mathrm{NaClO}_{4}$ de $\mathrm{pH} 2,0$. 
Gráficos de Mott-Schottky para o eletrodo de $\mathrm{Ti} / \mathrm{SnO}_{2}(\mathrm{Sb})$

Figura 4.35
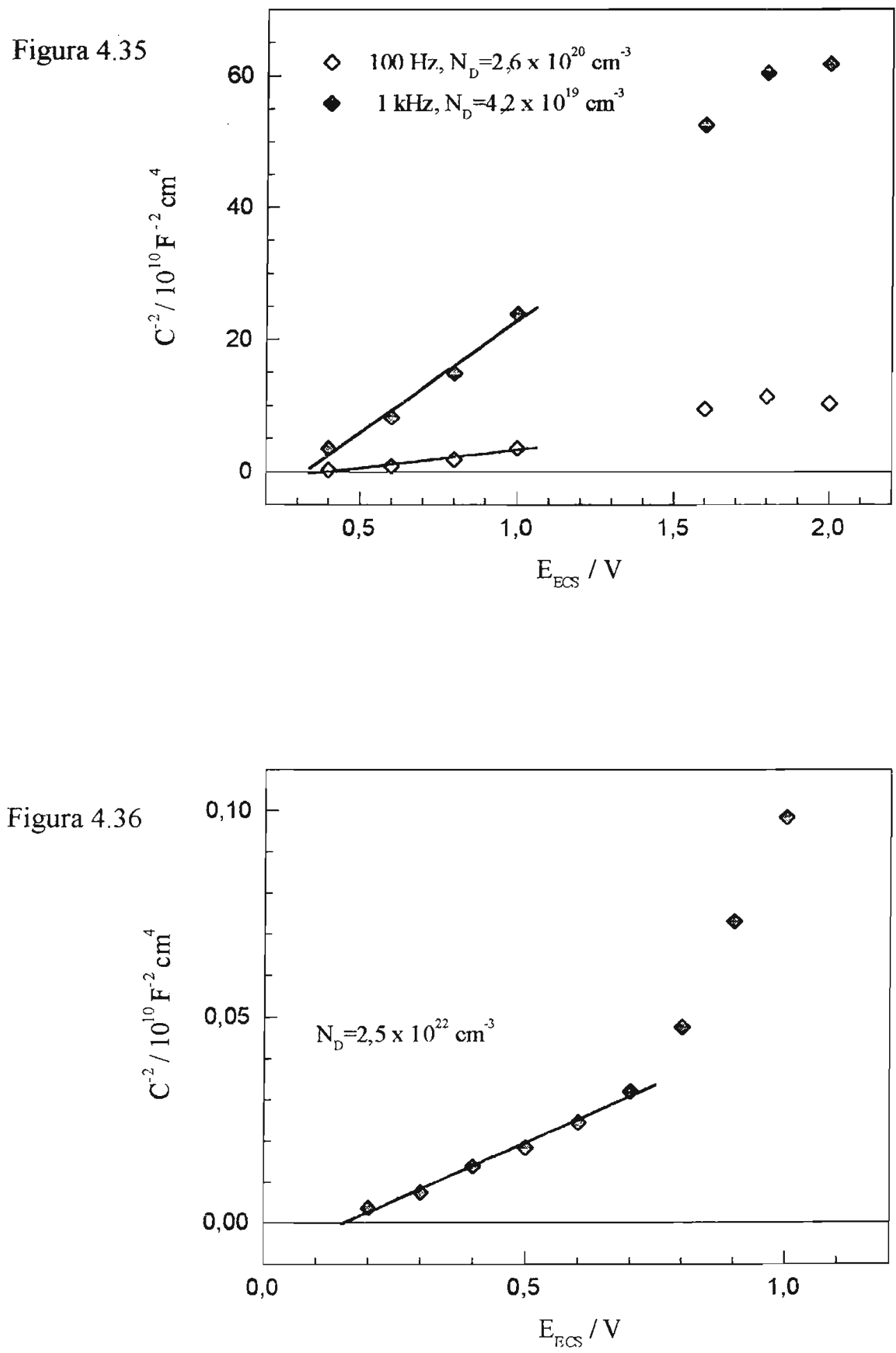

Figuras 4.35 e 4.36. Gráficos de Mott-Schottky para o eletrodo de $\mathrm{Ti} / \mathrm{SnO}_{2}(\mathrm{Sb})$, obtidos com as capacidades determinadas através de EIS e SACV, respectivamente. 


\subsubsection{Testes realizados para avaliar possíveis aplicações para os eletrodos de $\mathrm{Ti} / \mathrm{SnO}_{2}(\mathrm{Sb})$ modificados com OTS: oxidação do metanol}

Como já foi brevemente mencionado na introdução deste capítulo, considerando que os eletrodos de $\mathrm{Ti} / \mathrm{SnO}_{2}$ em geral apresentam um bom desempenho para a eletrooxidação de poluentes orgânicos $[21,23,125]$ e de cianeto [24], investigou-se o desempenho dos eletrodos modificados em aplicações correlatas. No eletrodo modificado, o filme hidrofóbico de OTS adsorvido na superfície poderia atuar como um préconcentrador de substâncias orgânicas presentes em solução aquosa e assim, promover a oxidação das mesmas $[136,137]$. Para verificar a viabilidade desta aplicação, investigou-se oxidação do metanol sobre estes eletrodos.

Como descrito na seção 4.2, para os eletrodos de $\mathrm{Ti} / \mathrm{SnO}_{2}(\mathrm{Sb})$ modificados ou não com OTS, registraram-se inicialmente as curvas $\mathrm{I} / \mathrm{E}$ em $\mathrm{NaClO}_{4} 0,1 \mathrm{M}$ de pH 2,0 e, posteriormente, realizaram-se estes ensaios em solução $2,5 \mathrm{mM}$ de metanol neste mesmo eletrólito. Para o eletrodo não modificado, obtiveram-se curvas praticamente idênticas em ambas as soluções, indicando que o metanol não havia sofrido oxidação sobre o eletrodo de $\mathrm{SnO}_{2}$. Este resultado ia havia sido observado por outros integrantes do Grupo. Para o eletrodo de $\mathrm{Ti} / \mathrm{SnO}_{2}(\mathrm{Sb})$-OTS, porém, a curva obtida apresentou densidades de corrente mais elevadas e um comportamento um tanto peculiar, como mostra a Fig. 4.37.

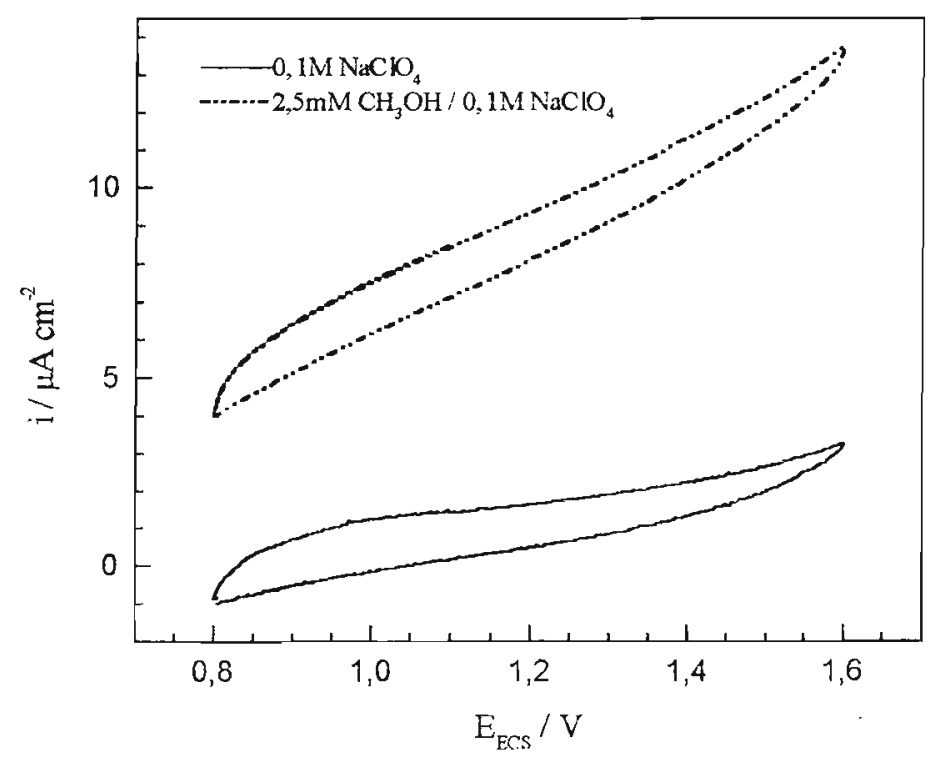

Figura 4.37. Curvas I/E obtidas a $50 \mathrm{mVs}^{-1}$ para o eletrodo de $\mathrm{Ti} / \mathrm{SnO}_{2}(\mathrm{Sb})-\mathrm{OTS}$ em soluções aquosas com pH 2,0 de $0,1 \mathrm{M} \mathrm{NaClO}_{4}$ e $2,5 \mathrm{mM} \mathrm{CH}_{3} \mathrm{OH} / 0,1 \mathrm{M} \mathrm{NaClO}_{4}$. 
$\mathrm{O}$ aspecto apresentado pelo VC determinado na solução de metanol assemelha-se muito ao de uma resistência, indicando que as espécies adsorvidas podiam ter bloqueado a superficie do eletrodo. Registraram-se outros três VC e este comportamento permaneceu inalterado. A solução da célula foi então substituída pela solução de $\mathrm{NaClO}_{4}$ (sem metanol). Mesmo na solução nova, o eletrodo continuou apresentando o comportamento do VC da Fig 3.47. Concluiu-se então que as espécies estavam fortemente adsorvidas sobre o eletrodo.

Para tentar eliminar estas espécies, aplicou-se um potencial de 1,6 V durante 5 minutos, registrando a seguir um VC em condições idênticas às da Fig. 4.37. Como resultado, observou-se apenas uma pequena diminuição na carga voltamétrica. Este procedimento foi repetido outras três vezes e os VC registrados permaneceram praticamente inalterados. Em prosseguimento, o eletrodo foi submetido a uma polarização anódica com aumento progressivo de potencial até $2,4 \mathrm{~V}$, e a seguir registrou-se um outro VC. Somente então o eletrodo apresentou um comportamento similar ao inicial. Este resultado foi considerado como um indício de que as espécies que haviam adsorvido sobre o eletrodo haviam sido eliminadas

É possivel que as espécies que estavam bloqueando o eletrodo tenham sido formadas pela polimerização dos produtos da oxidação do metanol. Em uma etapa inicial, o metanol poderia ter sido oxidado ao cátion-radical e, em seguida, poderia ter polimerizado sobre o eletrodo modificado. A presença do OTS na superficie do eletrodo deve ter favorecido este processo, já que o mesmo não foi verificado para o eletrodo não modificado. Também pode ser considerada a hipótese de que as moléculas de OTS ainda apresentassem grupos $\mathrm{Si}-\mathrm{OH}$ não comprometidos em ligações covalentes (como mostrou a Fig. 2.5, os grupos Si-OH das moléculas do OTS também poderiam interagir apenas por pontes de hidrogênio). Neste caso, o metanol poderia reagir facilmente com estes grupos, resultando na formação de uma rede polimérica que também poderia estar bloqueando a superficie do eletrodo. Como este eletrodo não foi submetido a qualquer outra análise, estas suposições não foram confirmadas.

Para investigar mais detalhadamente os efeitos de todo este processo no comportamento eletroquímico do eletrodo, registraram-se os VC em solução $1 \mathrm{mM}$ de $\mathrm{K}_{4} \mathrm{Fe}(\mathrm{CN})_{6}$. O voltamograma cíclico obtido está representado na Figura 4.38. Para comparação, apresenta-se também a curva obtida para um eletrodo de $\mathrm{Ti} / \mathrm{SnO}_{2}(\mathrm{Sb})$-OTS novo. 
Os VC apresentados na Fig. 4.38 revelam que, mesmo depois da suposta eliminação das espécies que haviam sido adsorvidas, o comportamento do eletrodo foi consideravelmente alterado. Após estes experimentos, verificou-se uma considerável diminuição na carga voltamétrica apresentada pelo eletrodo. Este fato pode ser um indício de que uma grande parte da superficie do eletrodo ainda continuava bloqueada.

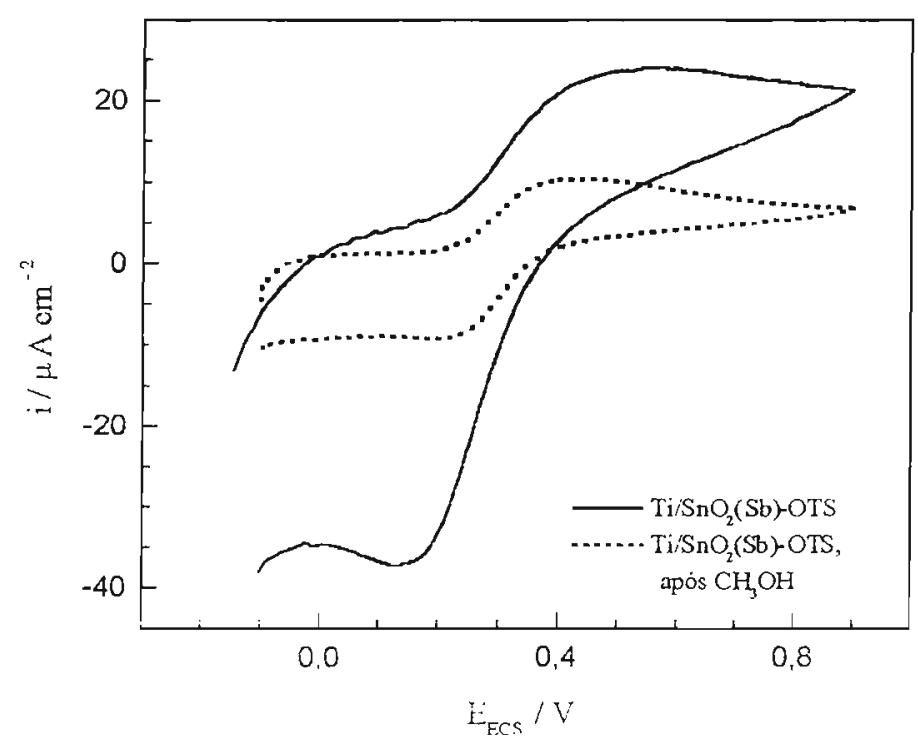

Figura 4.38. Perfis potenciodinâmicos obtidos a $5 \mathrm{mVs}^{-1} \mathrm{em} 1 \mathrm{mM}$ de $\mathrm{K}_{4} \mathrm{Fe}(\mathrm{CN})_{6} \mathrm{e}$ $\mathrm{NaClO}_{4}$, $1 \mathrm{M}$ de pH 2,0 para um eletrodo novo de $\mathrm{Ti} / \mathrm{SnO}_{2}(\mathrm{Sb})$-OTS e para o eletrodo empregadio nos experimentos de eletro-oxidação de metanol.

Estes experimentos revelaram que o eletrodo de $\mathrm{SnO}_{2}$ modificado com OTS não poderia ser empregado como ânodo na oxidação de componentes orgânicos, por facilitar a formação de espécies poliméricas na sua superficie. 


\section{4 - CONCLUSÕES}

O estudo apresentado neste capitulo tinha por objetivo investigar o comportamento eletroquímico apresentado pelos eletrodos à base de $\mathrm{SnO}_{2}$, modificados ou não com OTS, depositados em sílica ou titânio. Para os eletrodos transparentes, pretendia-se também relacionar o desempenho dos três tipos de eletrodos com as suas propriedades físicoquímicas (apresentadas no capítulo anterior).

Para os eletrodos transparentes, a presença dos diferentes dopantes ( $\mathrm{Cl}, \mathrm{F}$ ou $\mathrm{Sb}$ ) influenciou o potencial de circuito aberto dos eletrodos porque os equilíbrios de dissociação dos grupos $\mathrm{Sn}-\mathrm{OH}$ da superfície devem ter sido alterados em função da eletronegatividade de cada dopante.

Os eletrodos de $\mathrm{Ti} / \mathrm{SnO}_{2}(\mathrm{Sb})$ apresentaram um comportamento eletroquímico bastante distinto do observado para os eletrodos transparentes. Para a reações redox do $\mathrm{K}_{4} \mathrm{Fe}(\mathrm{CN})_{6}$, p.ex., a transferência de elétrons foi muito mais rápida sobre o $\mathrm{Ti} / \mathrm{SnO}_{2}(\mathrm{Sb})$ possivelmente porque este eletrodo apresentava maior número de portadores de carga e menor resistência ôhmica que os eletrodos transparentes

- A análise dos perfis potenciodinâmicos e dos espectros de EIS em $\mathrm{NaClO}_{4}$ (aq.) revelaram que o comportamento eletroquímico dos eletrodos de $\mathrm{Ti} / \mathrm{SnO}_{2}(\mathrm{Sb})$ foi fortemente influenciado pelos equilíbrios de adsorção e dissociação dos grupos $\mathrm{Sn}-\mathrm{OH}$ da superficie.

> A interfase $\mathrm{Ti} / \mathrm{SnO}_{2}\left(\mathrm{Sb}\right.$ ) $\mid \mathrm{NaClO}_{4}$ (aq.) pôde ser representada por um circuito elétrico equivalente do tipo $R_{S}\left(C_{d 1}\left[R_{C T}\left(R^{\prime} Q\right)\right]\right)$, onde os elementos ( $\left.R^{\prime} Q\right)$ foram incluídos para expressar os processos de adsorção na superficie, obtendo-se uma boa correspondência entre as simulações e os espectros de impedância eletroquímica obtidos experimentalmente em diversos valores de potencial.

Para os eletrodos modificados com OTS, principalmente os eletrodos depositados em titânio, a presença do organosilano deve ter alterado os equilíbrios de dissociação dos grupos $\mathrm{Sn}-\mathrm{OH}$ da superficie e provocado um maior acúmulo de carga na interfase, já 
que, sob o mesmo potencial, os eletrodos modificados apresentaram densidades de carga maiores que os eletrodos não modificados.

Os eletrodos modificados foram representados pelo mesmo circuito elétrico equivalente; as simulações indicaram que a presença do organosilano alterou apenas os processos de adsorção na superficie.

As curvas de polarização anódica indicaram que o OTS não alterou, porém, o mecanismo para a reação de geração de $\mathrm{O}_{2}$. Os altos valores obtidos para os coeficientes de Tafel obtidos indicaram ainda que a etapa lenta da RDO não deveria estar associada a processos de adsorção na superfície sendo, portanto, coerentes com o circuito sugerido considerando as medidas de EIS.

O eletrodo modificado com OTS não apresentou, no entanto, um bom desempenho nos testes realizados para avaliar possíveis aplicações para este material. Este eletrodo não é indicado para atuar como ânodo na eletro-oxidação de compostos orgânicos, porque, aparentemente, a presenca ceste filme hidrofóbico promove a adsorção e a polimerização destas espécies. o que pode bloquear a sua superficie. 
CAPÍTULO 5

\section{EFEITO DAS PERTURBAÇÕES}

ELETROQUÍMICAS NA MICROESTRUTURA DOS ELETRODOS TRANSPARENTES DE $\mathrm{SnO}_{2}$ 


\section{1 - INTRODUÇÃO}

Como já foi discutido na Revisão Bibliográfica, a utilização do $\mathrm{SnO}_{2}$ como eletrodo é limitada por processos de corrosão que ocorrem sob potenciais catódicos ou anódicos. $\mathrm{Na}$ primeira condição, a destruição do filme ocorre devido às reações de redução do $\mathrm{SnO}_{2}$ a SnO ou a Sn metálico, que ocorrem em potenciais próximos ao da RDH [1-3, 18, 29-34]. Sob polarização anódica, o processo de corrosão é atribuído aos radicais $\mathrm{OH}^{\circ}$ ou $\mathrm{Cl}^{*}$ (dependendo do eletrólito) que se formam nestas condições e atacam as ligações $\mathrm{Sn}-\mathrm{O}$ da superficie [34].

$\mathrm{O}$ entendimento destes processos é de grande interesse, devido às numerosas aplicações atribuidas aos filmes de $\mathrm{SnO}_{2}$. Para os eletrodos de $\mathrm{Ti} / \mathrm{SnO}_{2}$, Correa-Lazano [86] utilizou a SEM para observar as alterações estruturais induzidas pela realização de varreduras triangulares de potencial. Para filmes transparentes de $\mathrm{SnO}_{2}$, as alterações morfológicas causadas por polarização anódica em meio de $\mathrm{HCl}$ foram investigadas por Cachet [34] através de TEM e SEM. A Literatura apresenta também um relato da utilização da AFM para a caracterização da superficie de eletrodos transparentes submetidos à polarização catódica. Porém, estas análises foram empregadas apenas para estimar as alterações da rugosidade da superfície [3].

Neste trabalho, admitiu-se que a AFM poderia ser melhor explorada em tais estudos e fornecer informações detalhadas da superficie destes eletrodos desde os estágios iniciais dos processos de corrosão. Utilizou-se então esta técnica, complementada por SEM, para investigar as alterações micro-estruturais induzidas por perturbações eletroquímicas na superfície dos eletrodos de $\mathrm{SnO}_{2}$ preparados com diferentes dopantes. A STM também foi utilizada para realizar os estudos $i n$-situ, mas apenas para o eletrodo de $\mathrm{SnO}_{2}(\mathrm{Sb})$. Este capítulo apresenta os experimentos realizados e os resultados obtidos neste estudo. 


\section{2-DETALHES EXPERIMENTAIS}

O estudo das alterações morfológicas induzidas por perturbações eletroquímicas foi realizado para os três tipos de eletrodos transparentes não modificados e para os eletrodos modificados com OTS, através de análises ex-situ por AFM e SEM. Para o eletrodo não modificado de $\mathrm{SnO}_{2}(\mathrm{Sb})$, realizaram-se também análises in-situ por STM.

As perturbações eletroquímicas foram impostas aos eletrodos em meio de $\mathrm{NaClO}_{4}$ 0,1 M (aq.) com pH 2,0. Utilizou-se o equipamento de STM Topometrix operando no modo para Eletroquímica e a mesma célula descrita na seção 4.2.3. Os potenciais citados neste capítulo estão referidos ao $\mathrm{Pt}$, utilizado como pseudo eletrodo de referência nestes ensaios.

Para os eletrodos não modificados, realizaram-se três conjuntos de experimentos. $O$ primeiro conjunto de experimentos consistiu em polarizar o eletrodo em potenciais anódicos da região da RDO. Inicialmente, o potencial foi mantido durante 6 minutos em um valor " $\mathrm{E}_{1}$ " no qual verificou-se o início da $\mathrm{RDO}$, i.e., $1,0 \mathrm{~V}$ para os eletrodos de $\mathrm{SnO}_{2}(\mathrm{Cl})$ e $\mathrm{SnO}_{2}(\mathrm{~F})$ e $1.2 \mathrm{~V}$ para o $\mathrm{SnO}_{2}(\mathrm{Sb})$. A seguir, o potencial foi mantido por 6 min em um valor $\left(E_{2}=E_{1}+200 \mathrm{mV}\right)$, seguidos por $6 \mathrm{~min}$ em $\left(E_{3}=E_{1}+400 \mathrm{mV}\right)$, e, por fim, $6 \mathrm{~min}$ em um potencial de valor $\left(E_{4}=E_{1}+600 \mathrm{mV}\right)$. Na segunda série, o eletrodo foi mantido sob um potencial catódico de $-900 \mathrm{mV}$ durante 15 minutos. A outra perturbação eletroquímica aplicada consistiu em realizar 100 repetitivas varreduras triangulares de potencial, entre os limites anódico e catódico nos quais verificaram-se a RDO e a RDH. Os limites de potencial aplicados foram $+1,3$ e $-0,95 \mathrm{~V}$ (vs. Pt).

Para os eletrodos modificados, realizaram-se apenas a primeira e a última séries de experimentos. Porém, aplicaram-se condições um pouco mais agressivas no lado catódico: as 100 varreduras triangulares de potencial foram realizadas entre $-1,5 \mathrm{e}+1,3 \mathrm{~V}$, e, para investigar o efeito da polarização catódica, aplicou-se um potencial de $-1,5 \mathrm{~V}$ durante 15 minutos.

O procedimento geral adotado nestes experimentos consistia em montar a célula eletroquímica e manter uma amostra ainda não utilizada ("nova") do eletrodo na solução por 2 horas. Em seguida, registrava-se um voltamograma cíclico, aplicava-se a perturbação de potencial, e registrava-se novamente um voltamograma, para avaliar qualquer alteração no comportamento eletroquímico do eletrodo. A amostra do eletrodo era então 
abundantemente enxaguada com água, submetida à secagem com fluxo de Ar, e analisada inicialmente por AFM e posteriormente por SEM. Nestas análises, empregaram-se os mesmos equipamentos descritos na seção 3.3.1.

As análises de AFM foram realizadas em 4 ou 5 regiões distintas da superfície de cada eletrodo, empregando as mesmas condições descritas na seção 3.3.1. Para a descrição e discussão dos resultados obtidos, utilizaram-se apenas 2 imagens de cada eletrodo, obtidas em varreduras de $1 \times 1 \mu \mathrm{m}^{2}$ e $500 \times 500 \mathrm{~nm}^{2}$ e apresentadas como visão topográfica (top view) e tridimensional.

Nas análises por STM, realizadas com uma ponta de ouro, as imagens foram obtidas no modo de corrente constante, com um valor de "set point" de $1 \mathrm{nA}$. Durante a aquisição das imagens, obtidas a $800 \mathrm{~nm} \mathrm{~s}^{-1}$, os potenciais aplicados à ponta de Au e ao eletrodo de trabalho foram de $-0,20$ e $+0,80 \mathrm{~V}$ (vs. Pt). Nestes experimentos, as imagens foram obtidas em uma mesma região da superfície do eletrodo, antes e após a aplicação das perturbações eletroquímicas. As perturbações eletroquímicas aplicadas ao eletrodo foram, na sequência: $1,2 \mathrm{~V}$ durante $1 \mathrm{~min} ; 1,4 \mathrm{~V}$ por $1 \mathrm{~min} ; 1,4 \mathrm{~V}$ por $5 \mathrm{~min}$; $-0,95 \mathrm{~V}$ por $5 \mathrm{~min}$; $1,4 \mathrm{~V}$ por 2 min $\mathrm{e}-0.95 \mathrm{~V}$ por 5 minutos. 


\section{3-RESULTADOS E DISCUSSÃO}

As imagens de AFM obtidas neste estudo foram apresentadas em uma só figura para cada tipo de eletrodo, para facilitar a comparação das características iniciais da sua morfologia com as resultantes da aplicação de cada perturbação. Na discussão dos resultados, porém, consideraram-se os efeitos verificados para cada tratamento eletroquímico.

\subsubsection{Alterações morfológicas induzidas pela polarização anódica em potenciais da região da RDO}

As alterações morfológicas induzidas na superficie dos eletrodos não modificados pela aplicação de potenciais anódicos da região da RDO podem ser analisadas considerando as imagens designadas por "a" e por "b" apresentadas nas Fig. 5.1, 5.2, 5.4, 5.5, 5.7 e 5.8. Os efeitos desta perturbação eletroquímica sobre as características morfológico-estruturais dos eletrodos modificados com OTS não foi investigado.

De um modo geral, a comparação das Fig 5.1a e 5.2a com as imagens $5.1 \mathrm{~b}$ e $5.2 \mathrm{~b}$ revela que a superficie do eletrodo de $\mathrm{SnO}_{2}(\mathrm{~F})$ não sofreu alterações muito significativas devido à imposição desta perturbação eletroquímica, ocorrendo apenas um pequeno aumento no tamanho dos grãos. Para o eletrodo de $\mathrm{SnO}_{2}(\mathrm{Sb})$, as imagens das Fig. 5.4a e $5.4 \mathrm{~b}$, e ainda $5.5 \mathrm{a}$ e $5.5 \mathrm{~b}$ indicam o mesmo resultado. $\mathrm{O}$ mesmo efeito foi observado através da análise dos perfis das seções transversais determinadas em diversas áreas destes eletrodos (não apresentados). Para o eletrodo de $\mathrm{SnO}_{2}(\mathrm{Cl})$, este efeito foi ainda mais pronunciado: o aumento do tamanho dos grãos pode ser claramente observado através da comparação das imagens de $1 \times 1 \mu^{2}$, nas Fig. 5.7a e 5.7b, e das imagens tridimensionais de $500 \times 500 \mathrm{~nm}^{2}$, nas Fig. $5.8 \mathrm{a}$ e $5.8 \mathrm{~b}$.

As análises de AFM revelaram, portanto, que este inesperado resultado foi apresentado para todos os três tipos de eletrodos transparentes. $\mathrm{O}$ efeito desta perturbação também foi investigado por Cachet [34] para filmes de $\mathrm{SnO}_{2}$ dopado com $\mathrm{F}$ ou $\mathrm{Sb}$ em meio de $\mathrm{HCl}$ e os resultados obtidos foram completamente distintos. As análises por SEM e TEM revelaram que a superficie havia sofrido um severo processo de corrosão devido a um ataque intergranular. Este processo de corrosão, confirmado por análises de perda de 
massa em micro-balança à cristal de quartzo, foi atribuído ao ataque de radicais $\mathrm{Cl}^{\bullet}$ e $\mathrm{OH}^{*}$ (formados sob a polarização anódica) às ligações $\mathrm{Sn}-\mathrm{O}$ da superficie.

$\mathrm{Na}$ Literatura, não foram encontrados outros relatos sobre os efeitos da polarização anódica na morfologia dos eletrodos de $\mathrm{SnO}_{2}$ ou materiais correlatos. Os resultados obtidos neste trabalho indicam, a princípio, que esta perturbação eletroquímica proporcionou o crescimento do filme de $\mathrm{SnO}_{2}$. Mesmo considerando que estes materiais apresentavam deficiência de $O$ na superfície quando novos (seção 3.3.3), e a aplicação da polarização anódica poderia promover a oxidação do $\mathrm{SnO}$ a $\mathrm{SnO}_{2}$, parece altamente improvável que tal efeito tivesse ocorrido em tão grande extensão a ponto de ser perceptível nas análises por AFM. Portanto, considerando as análises realizadas e os resultados obtidos, não é possível propor, no momento, explicações plausíveis para este fenômeno.

\subsubsection{Alterações morfológicas induzidas pela polarização catódica em potenciais da região da $\mathrm{RDH}$}

O efeito da aplicação de potenciais catódicos na superficie dos eletrodos transparentes de filmes de $\mathrm{SnO}_{2}$ modificados ou não com OTS pode ser avaliado através da comparação das imagens "a" e "c" apresentadas nas Fig. 5.1 a 5.10. A superficie dos eletrodos submetidos a este tratamento também foram analisados por SEM; alguns detalhes observados na superficie destes eletrodos estão ilustrados na Fig. 5.11.

Eletrodo de $\mathrm{SnO}_{2}(\mathrm{~F})$. A comparação das imagens de AFM apresentadas nas Fig. 5.1a e 5.1c revela que a imposição desta perturbação eletroquímica não provocou alterações muito significativas na microestrutura do eletrodo de $\mathrm{SnO}_{2}(\mathrm{~F})$. A análise das imagens tridimensionais de $500 \times 500 \mathrm{~nm}^{2}$ (Fig. $5.2 \mathrm{a}$ e $5.2 \mathrm{c}$ ) revela uma pequena diminuição na altura e no diâmetro das partículas, confirmada através da análise dos perfis de seções transversais definidas em várias imagens (não apresentados). De modo geral, a distribuição do tamanho das partículas se tornou até mais uniforme que a apresentada pelo eletrodo novo. Este resultado sugere, a princípio, que houve um ataque preferencial justamente sobre aquelas partículas muito maiores que haviam sido detectadas nas análises para o eletrodo novo (Fig. 3.13 e 3.17). Na investigação dos efeitos da polarização catódica sobre a estrutura cristalina de eletrodos de $\mathrm{SnO}_{2}(\mathrm{~F})$, Feng [3] observou que os cristalitos de orientação (200) eram preferencialmente reduzidos. É possível, então, que aquelas 
partículas de maior tamanho do eletrodo novo, já não visualizadas nas imagens obtidas após a polarização catódica, apresentassem esta orientação cristalina.

$\mathrm{Na}$ análise por SEM, observou-se a presença de falhas de grande profundidade no recobrimento do filme, e em maior densidade que a observada sobre o eletrodo novo. Uma destas falhas está representada na Fig. 5.11c. É possível que aquelas falhas que haviam sido identificadas na superficie do eletrodo novo (Fig. 3.2 e 3.3), que então apresentavam pequena profundidade, tenham sido intensamente atingidas por esta perturbação eletroquímica, aumentando em profundidade. Para o eletrodo modificado de $\mathrm{SnO}_{2}$ (F)-OTS submetido a um tratamento semelhante, porém um pouco mais agressivo, estas alterações foram ainda mais pronunciadas, como mostram as imagens de AFM ilustradas na Fig. 5.10c. Portanto, para este eletrodo, a presença do OTS não protegeu a superfície dos efeitos da corrosão induzida pela polarização catódica.

Eletrodo de $\mathrm{SnO}_{2}(\mathrm{Sb})$. A imposição de potenciais catódicos da região da $\mathrm{RDH}$ provocou alterações micro-estruturais muito pronunciadas na superfície do eletrodo de filme de $\mathrm{SnO}_{2}(\mathrm{Sb})$. A comparação das imagens de $1 \times 1 \mu \mathrm{m}^{2}$, nas Fig. 5.7a e 5.7c, revela que a estrutura do filme foi bastante danificada por esta perturbação eletroquímica. Em geral, a superficie se tornou muito mais rugosa: a rugosidade média quadrática (rms) determinada para as Fig. 5.4a e 5.4c aumentou de 1,7 para 2,8 nm. Nas imagens tridimensionais de $500 \times 500 \mathrm{~nm}^{2}$, observa-se claramente que imposição da polarização catódica provocou a diminuição do diâmetro e da altura das partículas, indicando que o processo de corrosão atuou nos contornos dos grãos (Fig. 5.5a e 5.5c). Este ataque também não deve ter sido uniforme sobre todas as partículas, considerando que a distribuição da altura das mesmas, que era bastante uniforme para o eletrodo novo, tornou-se muito irregular. O exame desta mesma superficie por SEM não revelou, porém, alterações significativas na estrutura do filme. Apenas raramente observaram-se falhas na superficie, como a apresentada na Fig. 5.11b. Em geral, dentro ou nas proximidades destas falhas no recobrimento da superfície, observou-se a presença de partículas que apresentavam tamanhos variados da ordem de centenas de nm. Muitas vezes, estas partículas eram perfeitamente quadradas, como as observadas na Fig. 5.12 para eletrodos que haviam sido submetidos a 20 repetitivas varreduras triangulares de potencial. Laitinen [29] também observou a presença de partículas quadradas após submeter um eletrodo transparente de $\mathrm{SnO}_{2}$ à polarização catódica, e as considerou como um indício de $\alpha-\mathrm{Sn}$, que cristaliza no sistema cúbico. 
De modo geral, os efeitos da corrosão observados por AFM nas Fig. 5.7 e 5.8 dificilmente seriam identificados por SEM (considerando a resolução do equipamento empregado). As características morfológicas apresentadas nas análises por SEM após a polarização catódica podem ser consideradas bastante razoáveis, já que as análises realizadas para o eletrodo novo revelaram raras falhas no recobrimento (Fig. 3.2), e, portanto, a princípio, a superfície não apresentava regiões que pudessem ser mais susceptíveis à corrosão.

Para o eletrodo modificado com OTS, os efeitos da polarização catódica nas características micro-estruturais da superficie do filme de $\mathrm{SnO}_{2}(\mathrm{Sb})$ foram muito menos pronunciados, apesar de terem sido empregadas condições ainda mais agressivas. Neste caso, as imagens $5.6 \mathrm{c}$ revelam que as partículas também diminuíram em diâmetro e em altura, porém, de maneira muito mais regular que a observada para o eletrodo não modificado. Este resultado indica que, para o eletrodo de $\mathrm{SnO}_{2}(\mathrm{Sb})$, o filme do organosilano protegeu a superficie da corrosão.

Eletrodo de $\mathrm{SnO}_{2}(\mathrm{Cl})$. De modo geral, a imposição de potenciais catódicos da região da $\mathrm{RDH}$ também provocou a diminuição da altura e do diâmetro das partículas constituintes do filme de $\mathrm{SnO}_{2}(\mathrm{Cl})$, como revela a comparação das Fig.5.7a com $5.7 \mathrm{c}$ e 5.8a com 5.8c. Porém, como a distribuição de tamanho das partículas foi razoavelmente uniforme, é provável que o ataque provocado por esta perturbação eletroquímica tenha ocorrido de maneira uniforme sobre todos os grãos presentes na superficie. Este mesmo efeito foi verificado para o eletrodo modificado com OTS, como revelam as imagens representadas na Fig. 5.9c. Nas análises realizadas por SEM para o eletrodo não modificado submetido a este tratamento, observaram-se diversas falhas, quase sempre acompanhadas pela presença de grãos nas proximidades.

Das cinco análises realizadas em diferentes regiões da superficie deste eletrodo, quatro apresentaram características morfológico-estruturais muito semelhantes às das imagens apresentadas nas Fig. 5.7c e 5.8c. Porém, em uma das regiões analisadas, observaram-se características bastante distintas. As imagens obtidas nesta região estão representadas na Fig. 5.10.

A Fig. 5.10 ilustra as imagens da topografia (a) e do correspondente contraste de fase (b), obtidas em varreduras de $1 \times 1 \mu^{2}$. Em geral, as imagens do contraste de fase podem fornecer informações adicionais a respeito do material analisado, porque dependem, 
além da topografia e de outros fatores, da textura da superficie analisada. As imagens do contraste da fase foram registradas em grande parte das análises realizadas por AFM neste trabalho; no entanto, não foram apresentadas anteriormente por não acrescentarem informações relevantes às mencionadas. Neste caso, porém, a imagem do contraste da fase permite distinguir com maior clareza algumas diferenças observadas entre as regiões do lado esquerdo superior e do lado direito inferior da Fig. 5.10a.

Para comprovar se as diferenças verificadas na imagem 5.10a não eram artefatos de imagem provocados, p.ex., por uma possível danificação da ponta, realizou-se uma outra varredura de $500 \times 500 \mathrm{~nm}^{2}$ justamente no centro da área analisada na Fig. 5.10a. A imagem obtida nesta nova varredura, representada na Fig. 5.10c, ilustra justamente a transição entre ambas as regiões. A boa qualidade desta imagem e a reprodução das características apresentadas na imagem anterior, permite descartar a hipótese de danificação da ponta. No lado superior esquerdo da imagem 5.10, observam-se partículas de contorno bem definido, enquanto que, no lado inferior direito, a estrutura é muito pouco definida. O perfil correspondente à seção transversal (Fig. 5.3d) revela claramente como o contorno das partículas é distinto em ambas as regiões.

Aparentemente, a imagem $5.10 \mathrm{a}$ foi registrada justamente nas proximidades de uma área do filme que deve ter sido preferencialmente danificada devido à perturbação eletroquímica aplicada. Nas análises realizadas por SEM, identificaram-se diversas áreas que apresentavam falhas de pouca profundidade, como já havia sido observado para o eletrodo novo (Fig. 3.2 e 3.3), além de algumas falhas de maior profundidade, como as representadas nas Fig. 5.11 a e $5.12 \mathrm{a}$.

Como já foi discutido na Revisão Bibliográfica, a superficie dos eletrodos de $\mathrm{SnO}_{2}$ deve ter sido danificada pela aplicação da polarização catódica na região da $\mathrm{RDH}$ em consequência da redução do filme de $\mathrm{SnO}_{2}$. Como os potenciais de eletrodo dos sistemas redox $\mathrm{H}^{+} / \mathrm{H}_{2}, \mathrm{Sn}^{4+} / \mathrm{Sn}^{2+}$, e $\mathrm{SnO}_{2} / \mathrm{Sn}^{0}$ são muito próximos (entre $-0,3$ e $-0,4 \mathrm{~V}$ vs ECS), a polarização catódica aplicada $(-0,95 \mathrm{~V}$ vs $\mathrm{Pt} \approx-0,5 \mathrm{~V}$ vs ECS), pode ter induzido a formação de estanho metálico [29], de $\mathrm{SnO}$, que é um óxido muito mais solúvel [31, 32], ou de ambos. A redução pode ainda ter sido provocada pelo $\mathrm{H}_{2}$ gerado [11] ou pela presença de $H$ na superficie [3], como expresso nas equações 2.19 e 2.20 do Cap.2. Qualquer um destes processos poderia promover a corrosão do filme de $\mathrm{SnO}_{2}$ e até a sua completa destruição, como já foi relatado por alguns autores [29-31]. 


\subsubsection{Alterações morfológicas induzidas pela realização de 100 varreduras triangulares entre potenciais da região da $\mathrm{RDO}$ e da $\mathrm{RDH}$}

$O$ efeito desta perturbação eletroquímica na morfologia dos eletrodos pode ser avaliado através da comparação das imagens designadas por " $a$ " $e$ " $d$ " apresentadas nas Figuras 5.1 a 5.9 .

Eletrodo de $\mathrm{SnO}_{2}(\mathrm{~F})$. Para o eletrodo de $\mathrm{SnO}_{2}(\mathrm{~F})$ não modificado, a imagem apresentada nas Fig. 5.1d, obtida de uma varredura de $1 \times 1 \mu \mathrm{m}^{2}$, revela que este tratamento eletroquímico provocou apenas um pequeno aumento no tamanho das partículas que constituem o filme. Este efeito também foi observado nas análises dos perfis das seções transversais obtidos para esta e para as outras imagens adquiridas para este eletrodo. De modo geral, a superfície se tornou um pouco mais rugosa: a rugosidade rms aumentou de 1,5 (Fig. 5.1a) para 2,8 nm (Fig. 5.1d). Este efeito de aumento das partículas foi muito mais evidente para o eletrodo modificado de $\mathrm{SnO}_{2}(\mathrm{~F})$-OTS. A comparação das imagens apresentadas nas Fig. 5.3a e 5.3b, principalmente para as imagens tridimensionais, revela claramente o aumento do diâmetro e da altura das partículas em consequência da realização das repetidas varreduras de potencial entre a $\mathrm{RDH}$ e a RDO.

Eletrodo de $\mathrm{SnO}_{2}(\mathrm{Sb})$. Para o eletrodo dopado com $\mathrm{Sb}$, as imagens apresentadas nas Fig. $5.4 \mathrm{~d}$ e $5.5 \mathrm{~d}$ revelam que esta perturbação eletroquímica danificou seriamente a superficie deste tipo de eletrodo. A comparação das imagens da topografia de $1 \times 1 \mu^{2}$ (Fig. 5.4a e 5.4d) revelam que o eletrodo submetido a este tratamento eletroquímico sofreu um grave processo de corrosão. Este efeito pode ser verificado com maiores detalhes nas imagens tridimensionais (Fig. 5.5a e 5.5d), que revelam ainda as alterações no contorno das partículas. De modo geral, a distribuição de tamanho das mesmas se tornou muito menos uniforme, aumentando a rugosidade da superfície de 1,7 para $3,0 \mathrm{~nm}$, nas imagens $5.4 \mathrm{a}$ e $5.4 \mathrm{~d}$, respectivamente. A aplicação de uma perturbação ainda mais agressiva a um eletrodo de $\mathrm{SnO}_{2}(\mathrm{Sb})$ modificado com OTS provocou efeitos muito menos pronunciados, como mostra a comparação entre as imagens das Fig. 5.6a e 5.6b. A superficie deste eletrodo modificado apresentou grãos com altura menor e de tamanho mais uniforme que os observados na superfície deste eletrodo antes que este tratamento eletroquímico fosse realizado. 
Eletrodo de $\mathrm{SnO}_{2}(\mathrm{Cl})$. Para o eletrodo dopado com $\mathrm{Cl}$, as imagens obtidas por AFM, ilustradas nas Fig. $5.7 \mathrm{~d}$ e $5.8 \mathrm{~d}$ também revelaram que a realização das 100 varreduras de potencial danificou a superficie deste material, porém, os efeitos foram muito menos pronunciados que os observados para o eletrodo dopado com $\mathrm{Sb}$. De modo geral, a distribuição de tamanho das partículas, que era bastante uniforme na superfície do eletrodo novo (Fig. 5.7a), apresentou uma pequena alteração (Fig. 5.7d). Após esta perturbação eletroquímica, a maior parte das partículas da superficie diminuíram em altura e diâmetro, enquanto que outras aumentaram. Como resultado geral, a rugosidade média da superficie aumentou de 1,8 para $2,8 \mathrm{~nm}$. Para o eletrodo modificado, a aplicação deste tratamento eletroquímico (mas em condições um pouco mais drásticas) induziu a diminuição do tamanho das partículas de maneira aproximadamente uniforme, como mostra a comparação entre as imagens ilustradas nas Fig. 5.9a e 5.9b.

A varredura triangular entre os potenciais para a $\mathrm{RDH}$ e a $\mathrm{RDO}$ deve ter induzido a reconstrução da superficie do $\mathrm{SnO}_{2}$, como foi observado por Correa-Lazano para eletrodos de $\mathrm{Ti} / \mathrm{SnO}_{2}(\mathrm{Sb})$ através de análises por SEM. Durante a varredura em potenciais catódicos da região da $\mathrm{RDH}$, devem ocorrer aqueles processos de redução anteriormente citados; ao prosseguir a varredura na direção anódica, é possivel que os produtos das reações de redução sejam re-oxidados sobre a superficie. A repetição continuada destes processos provocou a alteração da morfologia inicial do eletrodo porque, como já foi discutido, ambos os processos de redução e de re-oxidação dependem da orientação cristalina e portanto, devem ter ocorrido preferencialmente sobre determinados grãos. Como cada tipo de eletrodo apresentou, em função do dopante empregado, características físico-químicas diferentes, a aplicação desta perturbação produziu efeitos distintos na micro-estrutura de cada material. 
AFM - Topografia da superfície do eletrodo de $\mathrm{SnO}_{2}(\mathrm{~F})$

antes e após a aplicação das perturbações eletroquímicas

(a)

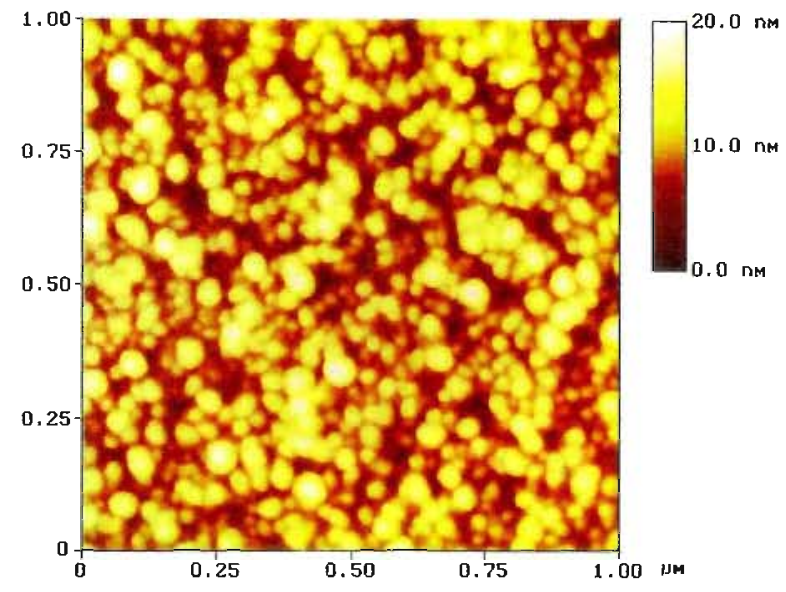

(c)

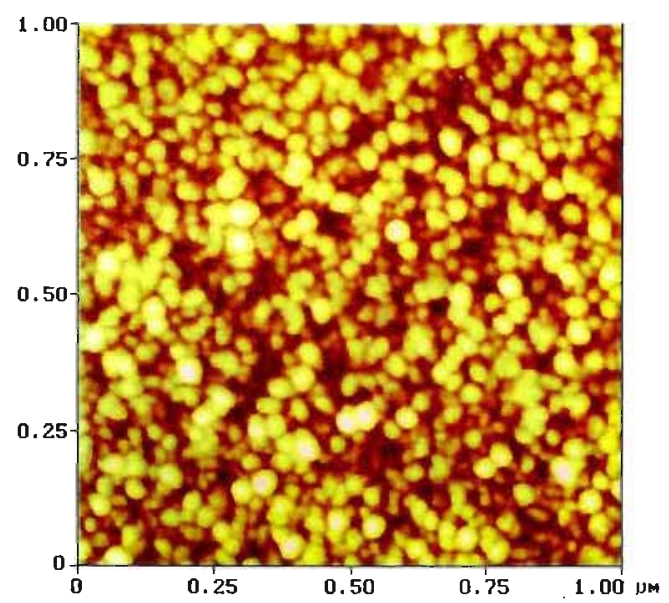

(b)

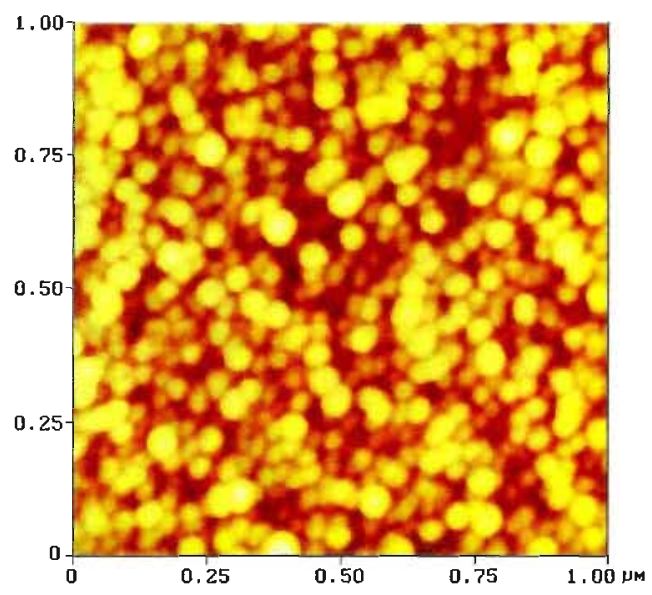

(d)

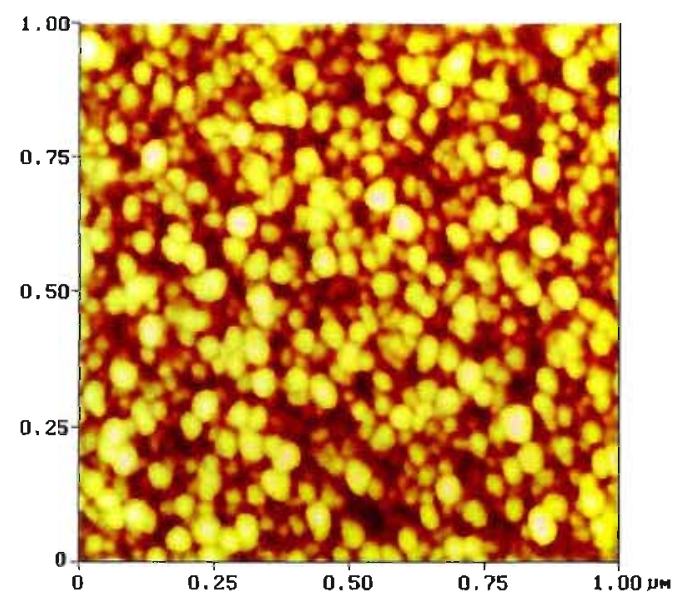

Figura 5.1. (a) Superfície do eletrodo novo;

(b) Após polarização anódica durante 24 minutos;

(c) Após polarização catódica (-0,90 V/Pt por $15 \mathrm{~min})$;

(d) Após 100 varreduras triangulares de potencial repetitivas. 
Efeito das perturbações eletroquímicas na superfície do eletrodo de $\mathrm{SnO}_{2}(\mathrm{~F})$
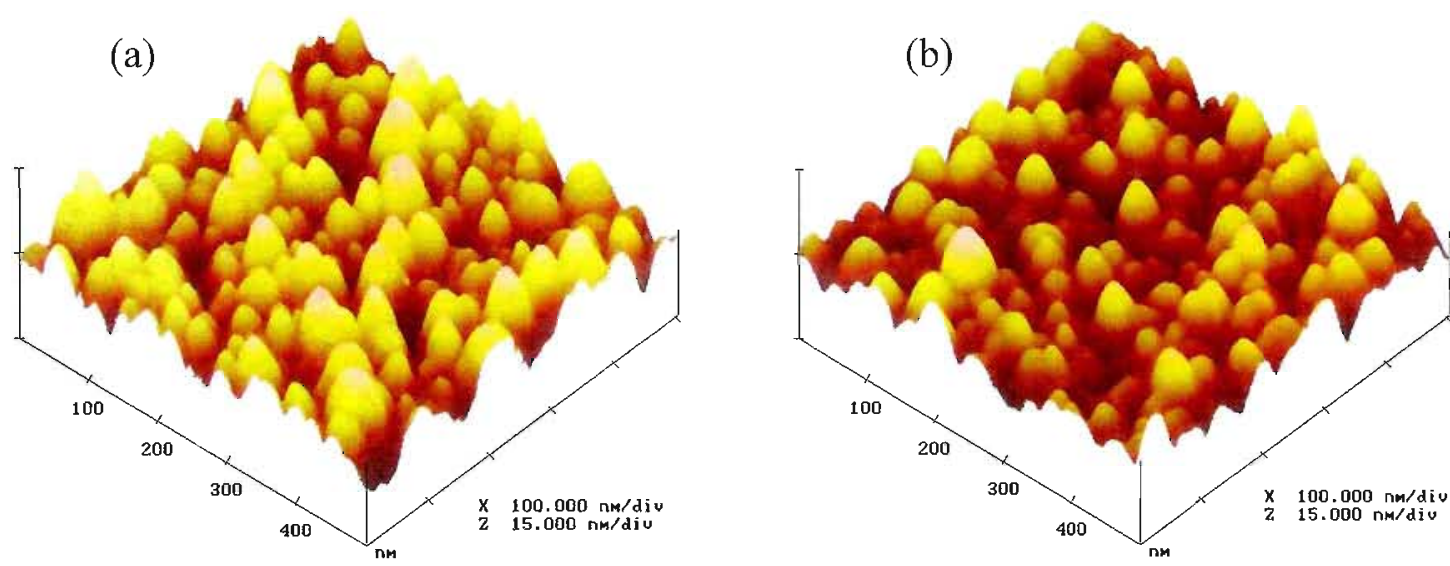

(c)

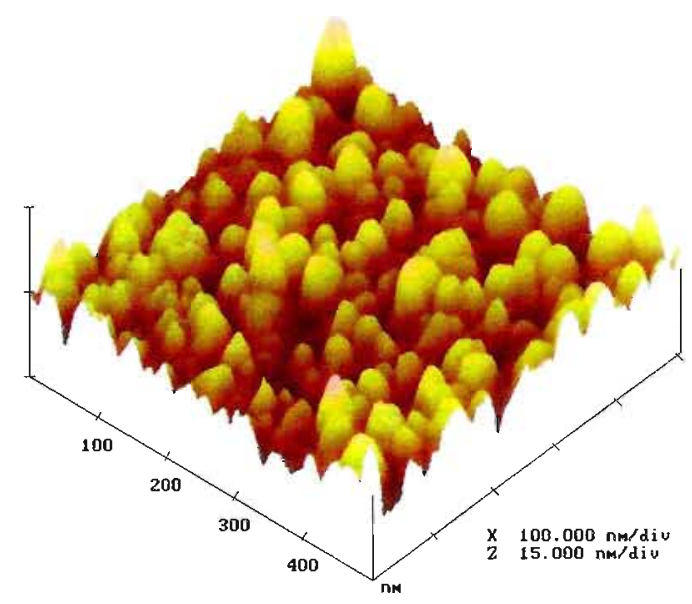

(d)

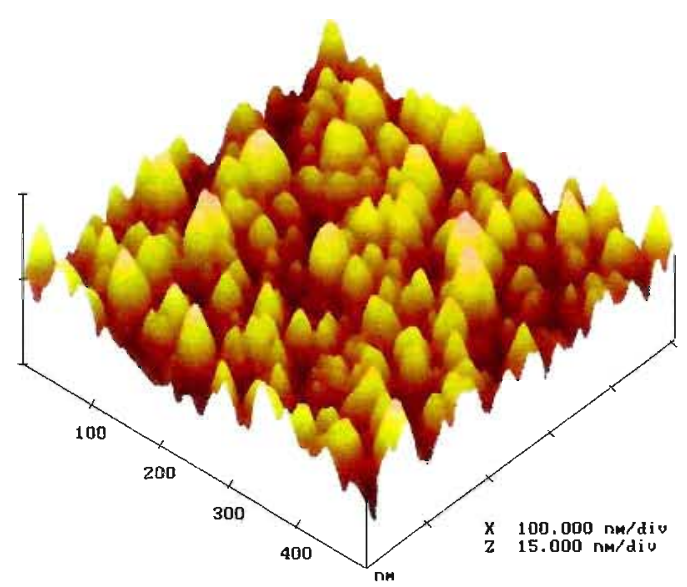

Figura 5.2. (a) Superfície do eletrodo novo;

(b) Após polarização anódica durante 24 minutos;

(c) Após polarização catódica (-0,90 V/Pt por $15 \mathrm{~min})$;

(d) Após 100 varreduras triangulares de potencial repetitivas. 
Efeito das perturbações eletroquímicas na superfície do eletrodo de $\mathrm{SnO}_{2}$ (F)-OTS

(a)
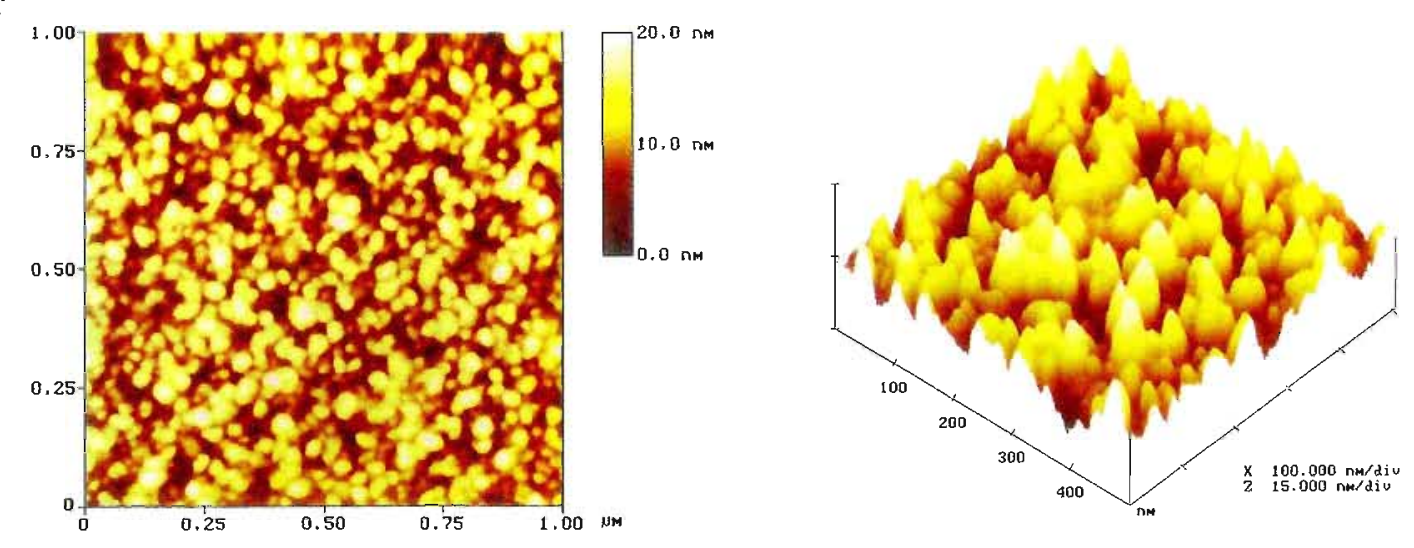

(b)
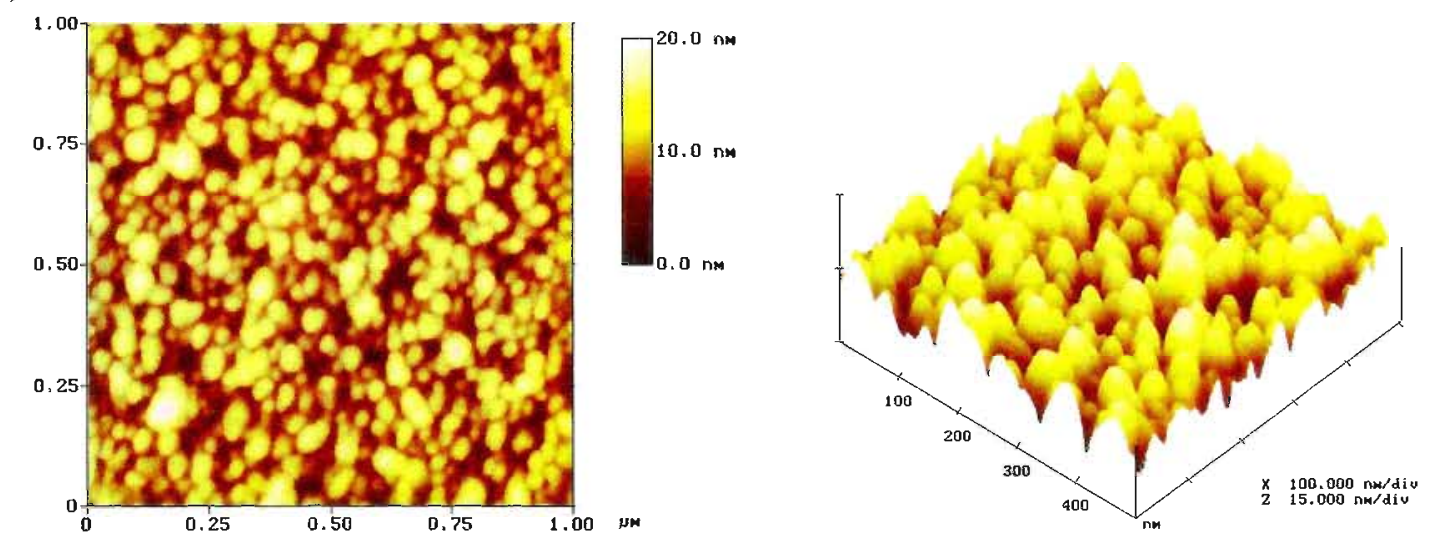

(c)
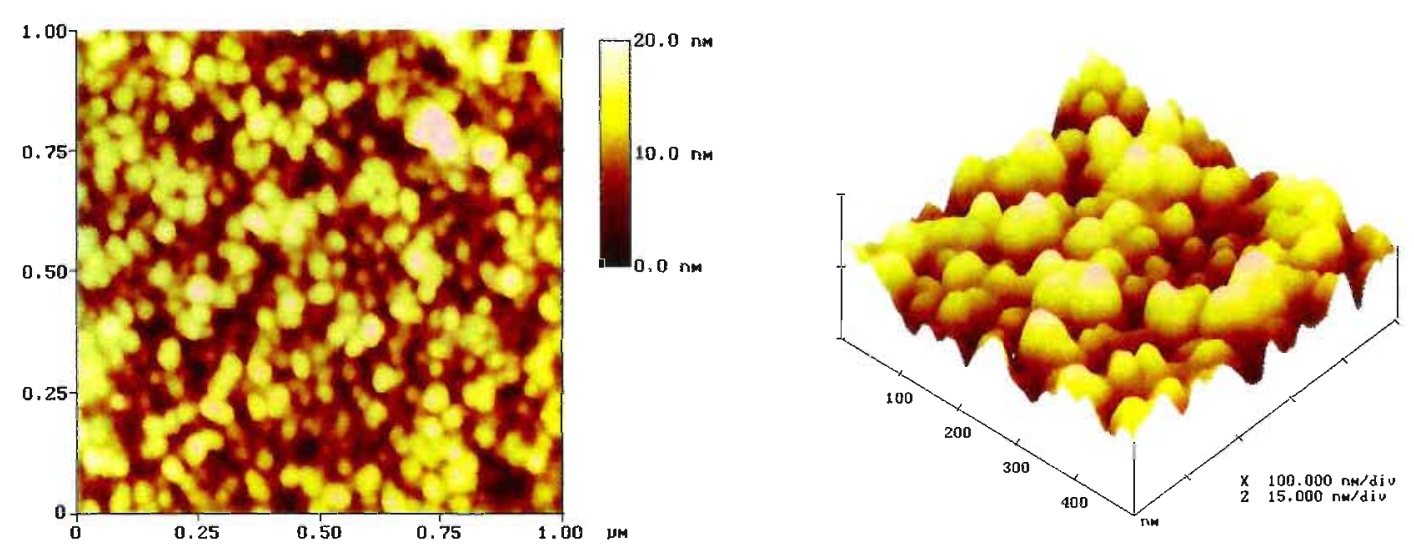

Figura 5.3. (a) Superfície do eletrodo novo;

(b) Após 100 varreduras triangulares de potencial repetitivas;

(c) Após polarização catódica ( 15 min a $-1,5 \mathrm{~V} / \mathrm{Pt})$. 
AFM - Topografia da superfície do eletrodo de $\mathrm{SnO}_{2}(\mathrm{Sb})$ antes e após a aplicação das perturbações eletroquímicas

(a)

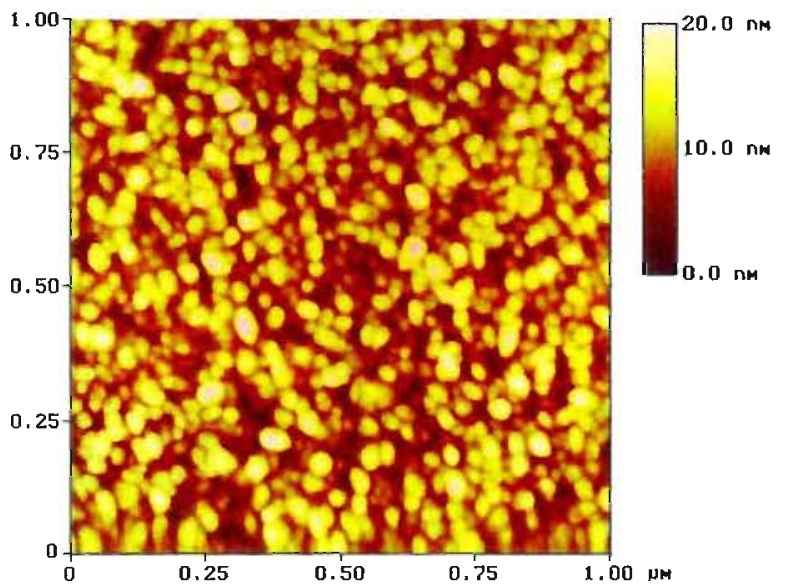

(c)

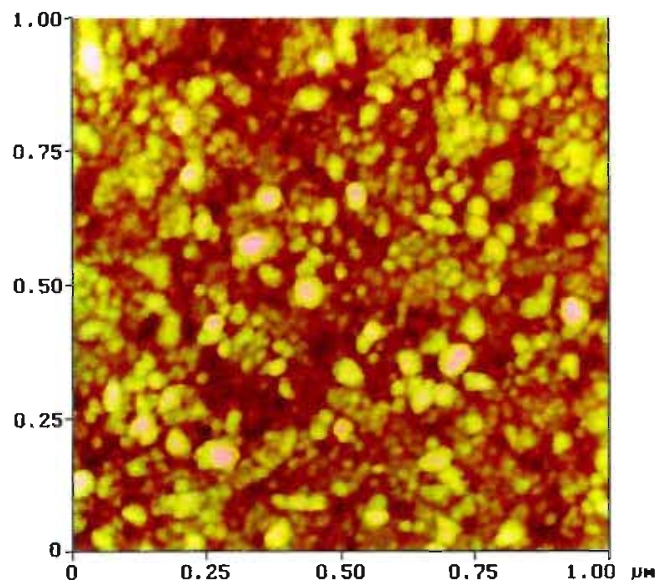

(b)

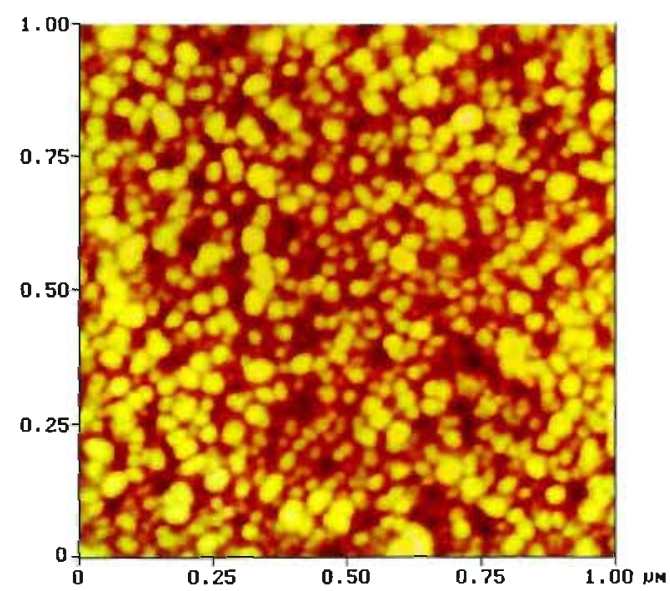

(d)

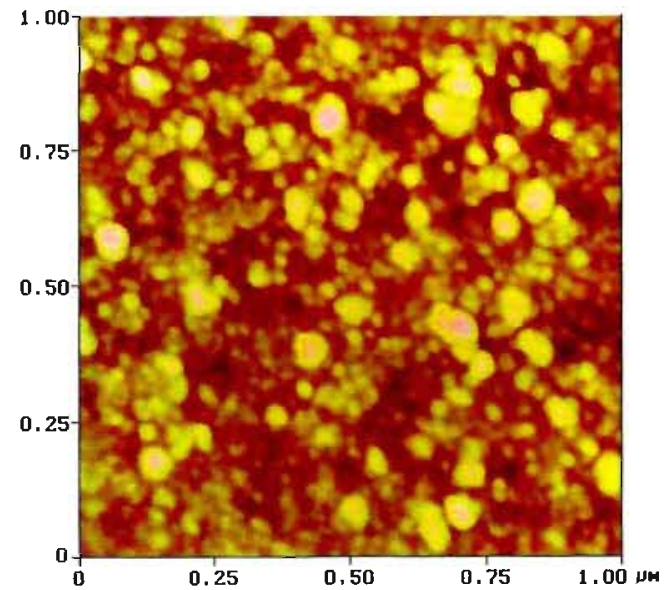

Figura 5.4. (a) Superfície do eletrodo novo;

(b) Após polarização anódica durante 24 minutos;

(c) Após polarização catódica (-0,90 V/Pt por $15 \mathrm{~min})$;

(d) Após 100 varreduras triangulares de potencial repetitivas. 
Efeito das perturbações eletroquímicas na superfície do eletrodo de $\mathrm{SnO}_{2}(\mathrm{Sb})$
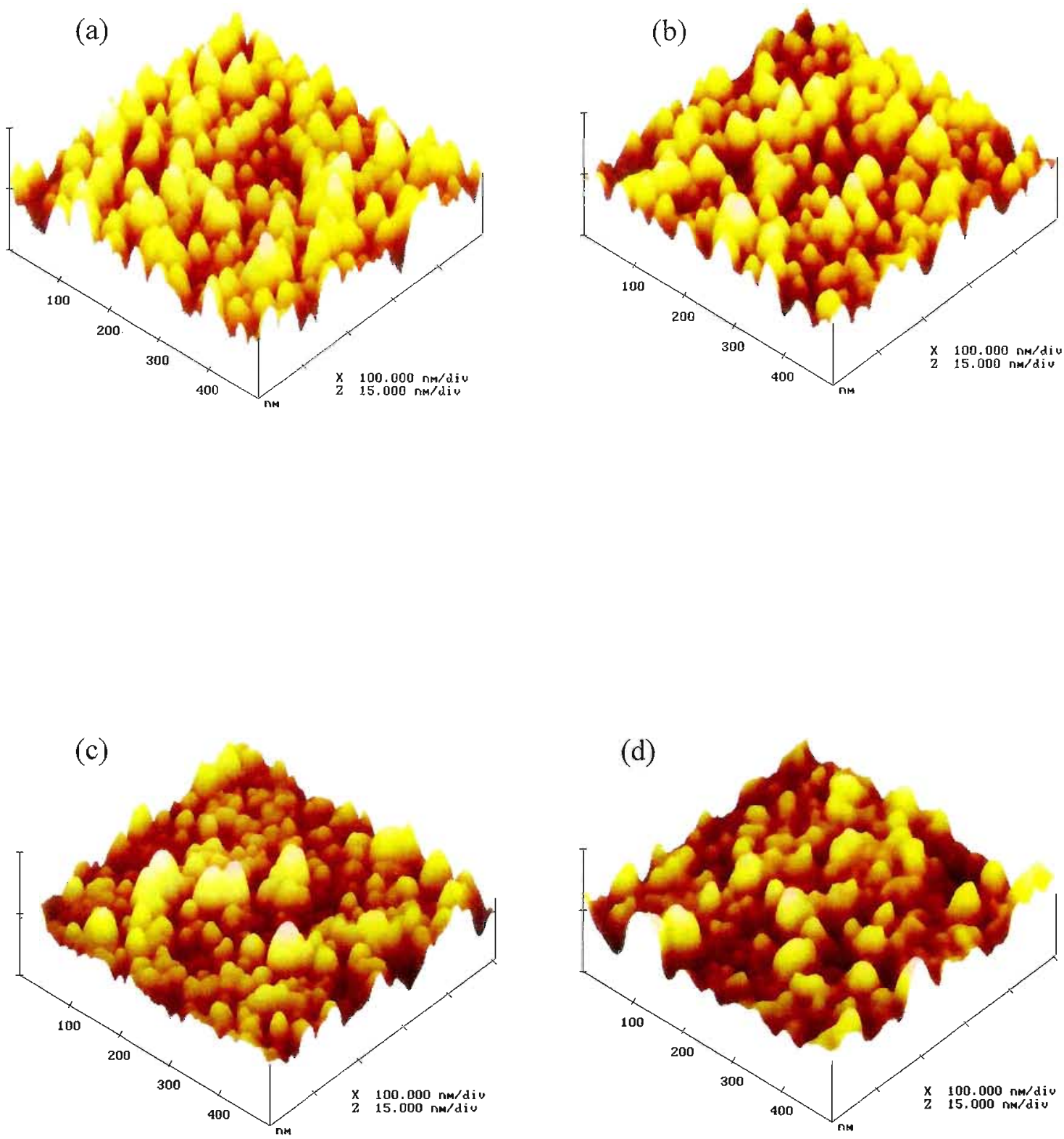

Figura 5.5. (a) Superfície do eletrodo novo;

(b) Após polarização anódica durante 24 minutos;

(c) Após polarização catódica (-0,90 V/Pt por $15 \mathrm{~min})$;

(d) Após 100 varreduras triangulares de potencial repetitivas. 
Efeito das perturbações eletroquímicas na superfície do eletrodo de $\mathrm{SnO}_{2}(\mathrm{Sb})$-OTS

(a)
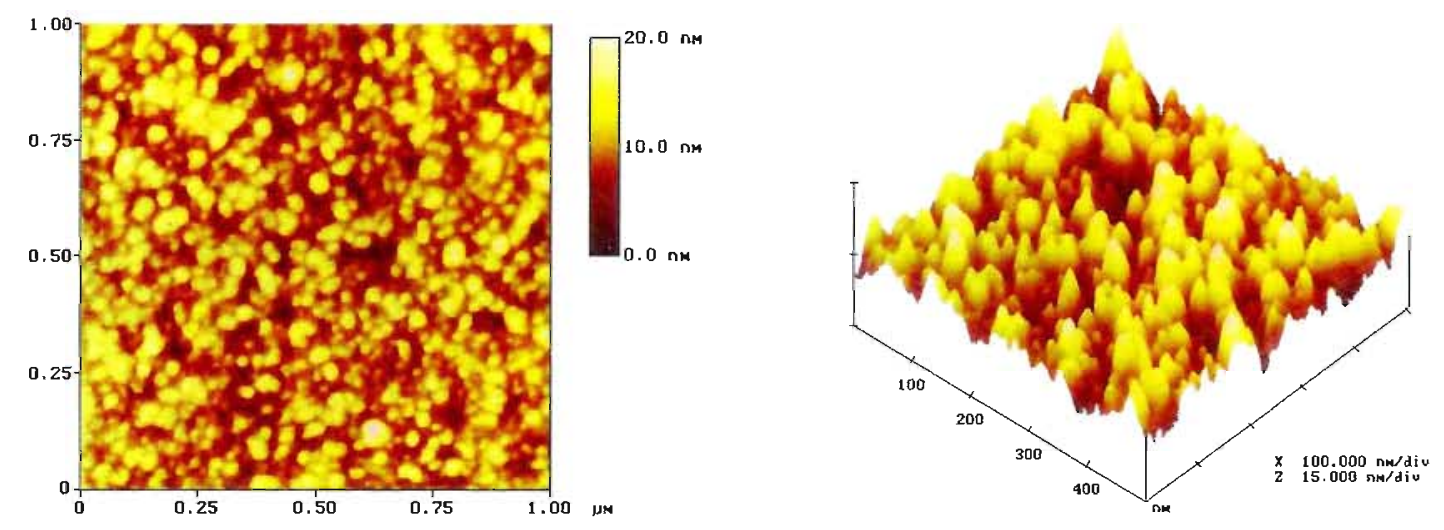

(b)
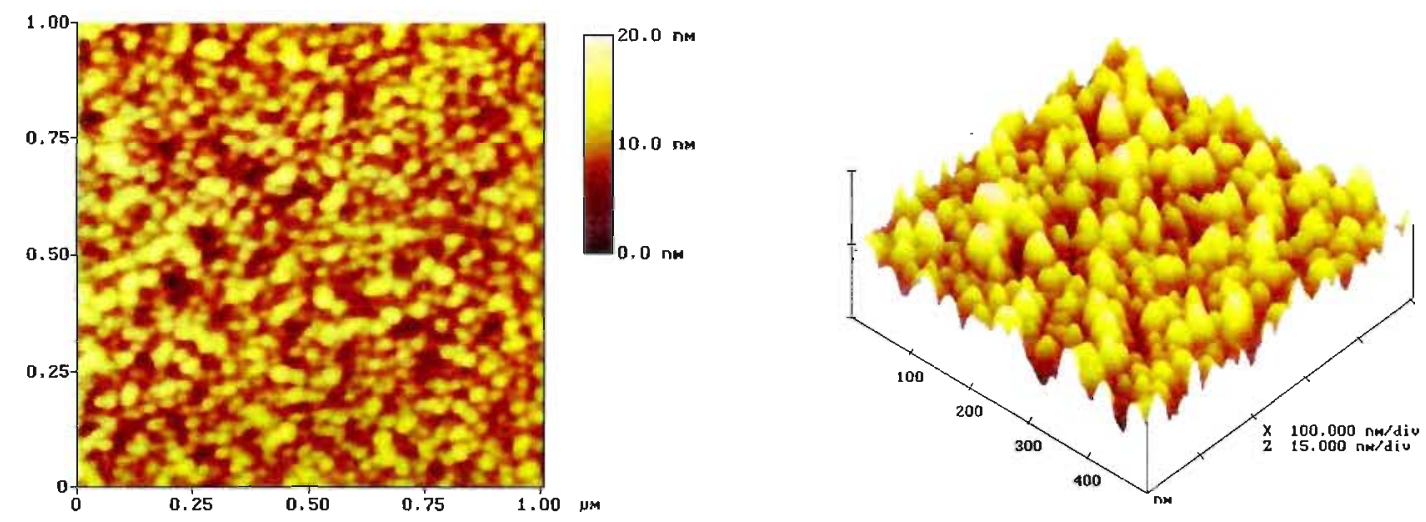

(c)
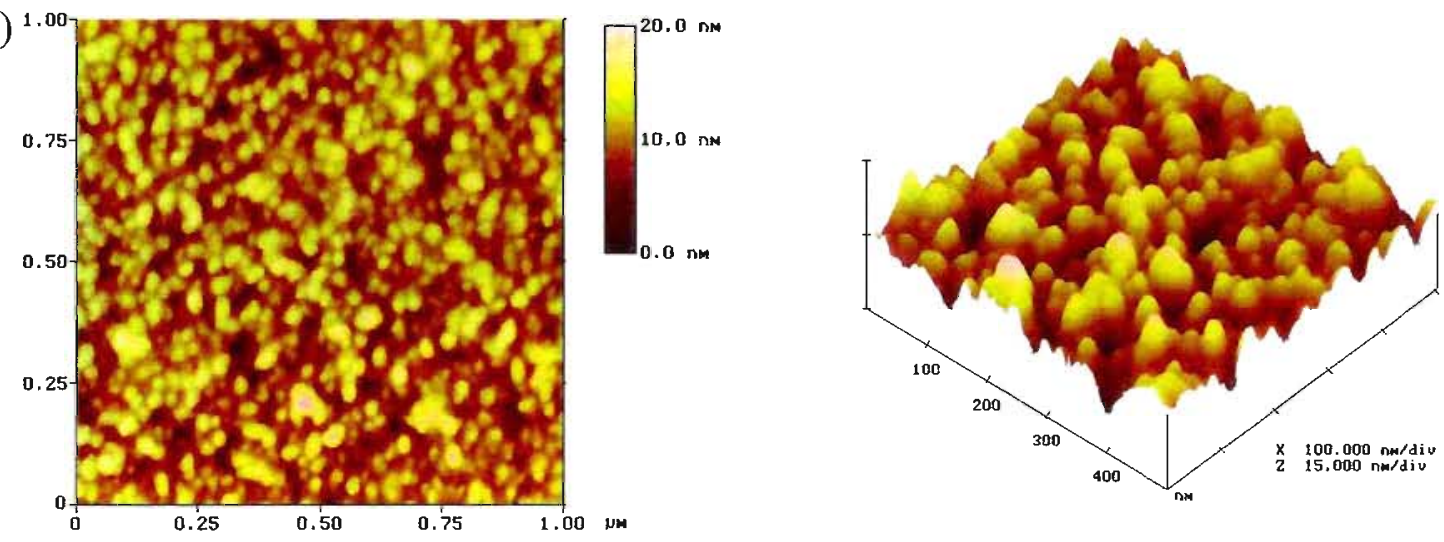

Figura 5.6. (a) Superfície do eletrodo novo;

(b) Após 100 varreduras triangulares de potencial repetitivas;

(c) Após polarização catódica (15 min a $-1,50 \mathrm{~V} / \mathrm{Pt})$. 
AFM - Topografia da superfície do eletrodo de $\mathrm{SnO}_{2}(\mathrm{Cl})$ antes e após a aplicação das perturbações eletroquímicas

(a)

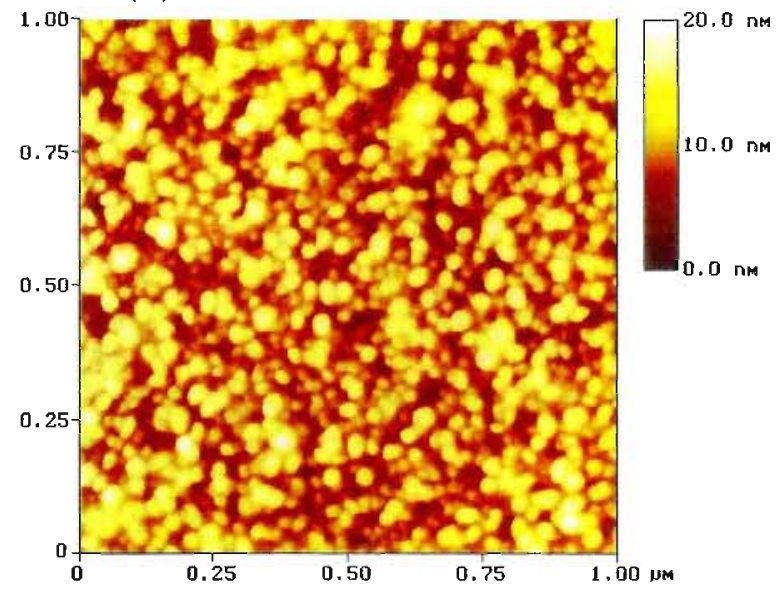

(c)

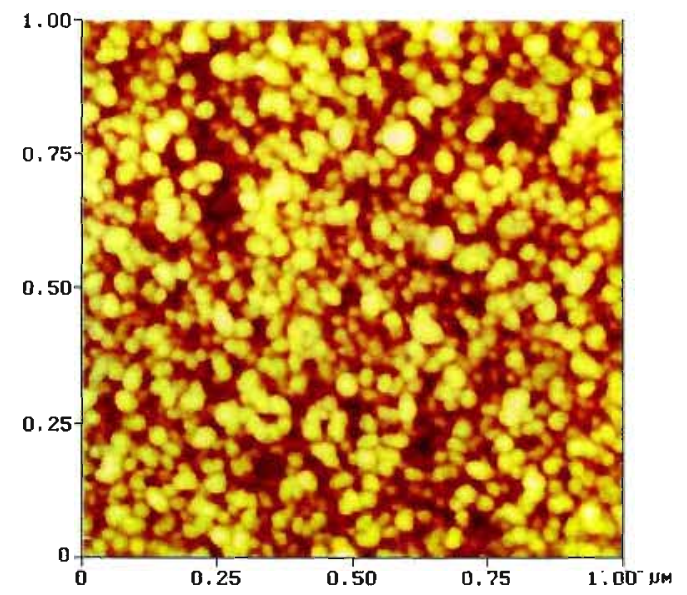

(b)

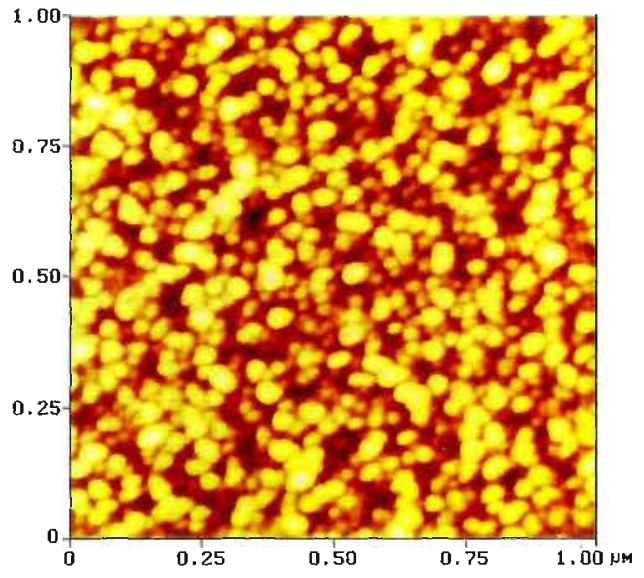

(d)

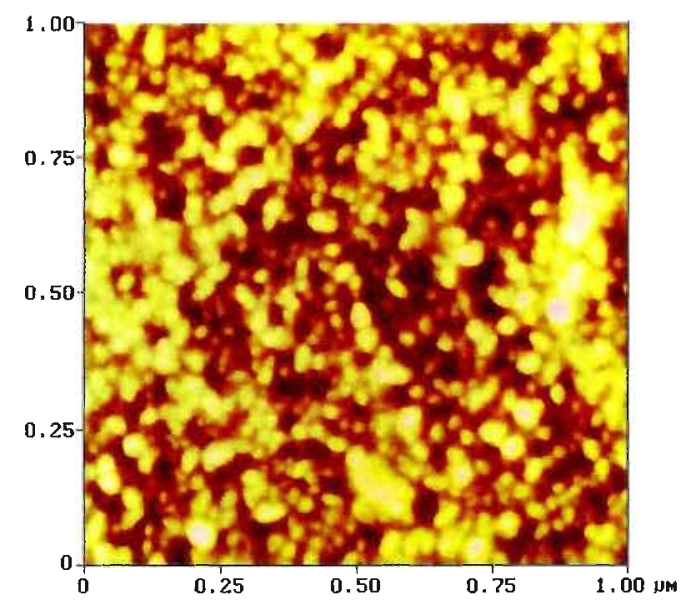

Figura 5.7. (a) Superfície do eletrodo novo;

(b) Após polarização anódica durante 24 minutos;

(c) Após polarização catódica (-0,90 V/Pt por $15 \mathrm{~min})$;

(d) Após 100 varreduras triangulares de potencial repetitivas. 
Efeito das perturbações eletroquímicas na superfície do eletrodo de $\mathrm{SnO}_{2}(\mathrm{Cl})$
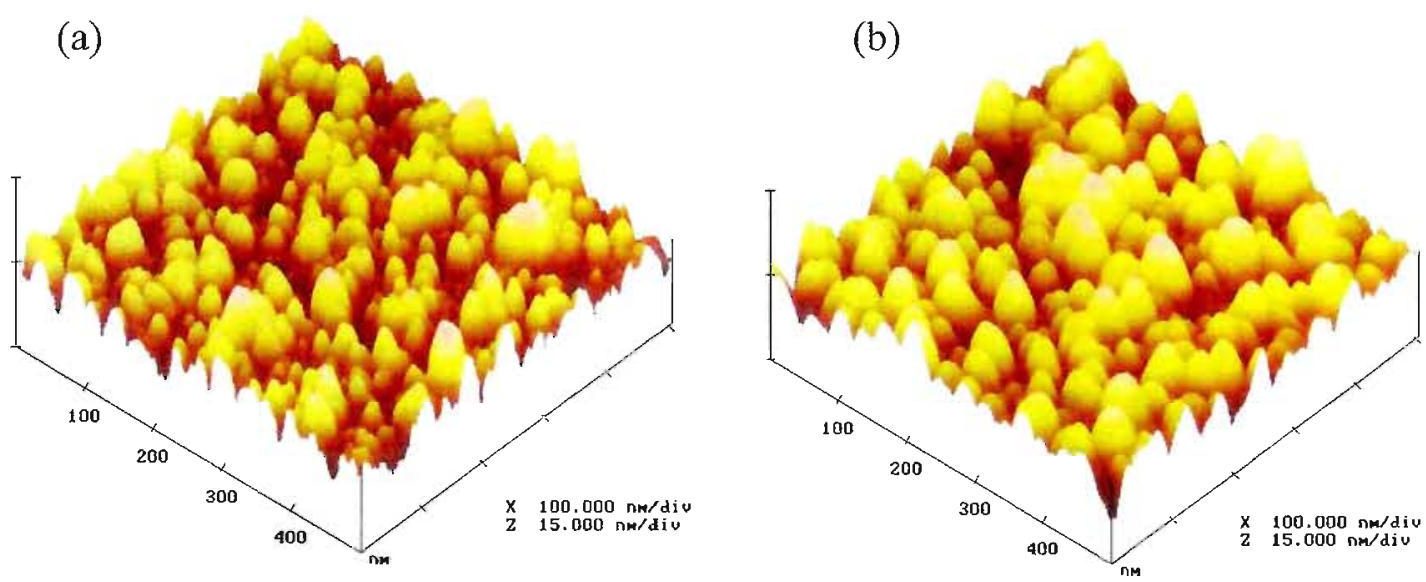

(c)

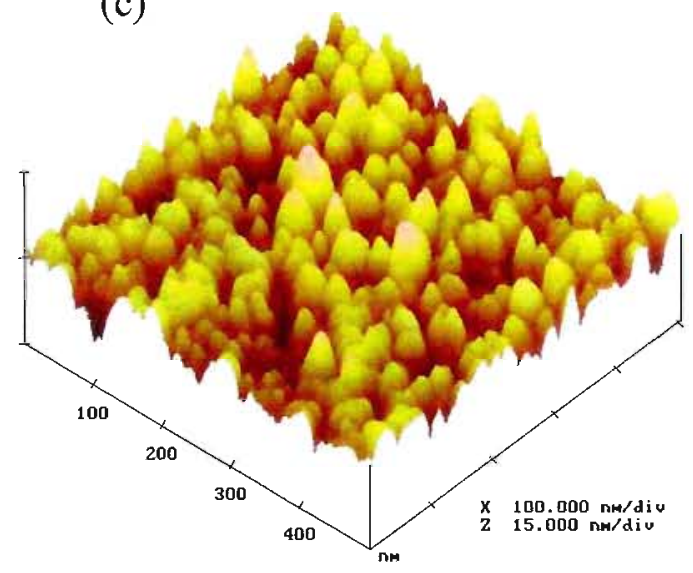

(d)

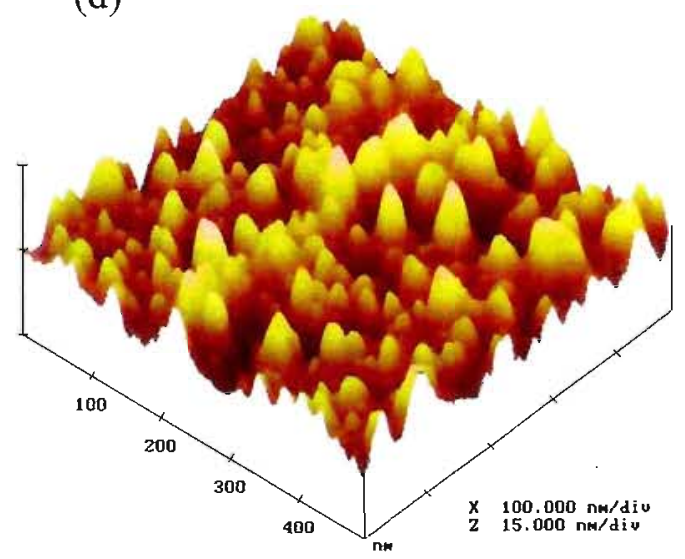

Figura 5.8. (a) Superfície do eletrodo novo;

(b) Após polarização anódica durante 24 minutos;

(c) Após polarização catódica (-0,90 V/Pt por $15 \mathrm{~min})$;

(d) Após 100 varreduras triangulares de potencial repetitivas. 
Efeito das perturbações eletroquímicas na superfície do eletrodo de $\mathrm{SnO}_{2}(\mathrm{Cl})$-OTS

(a)
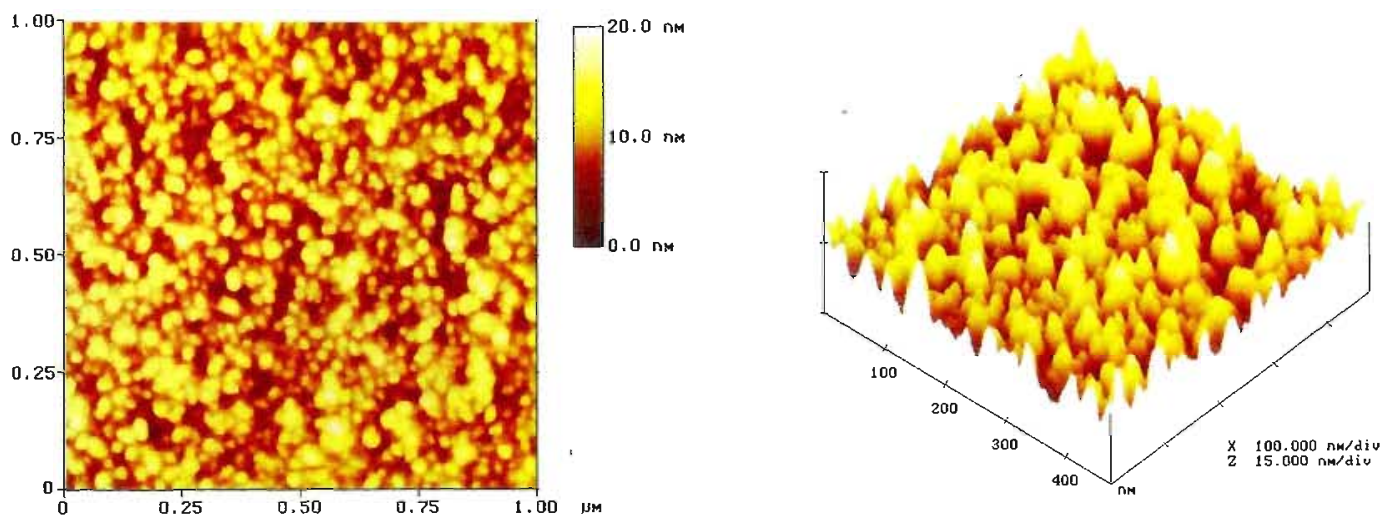

(b)
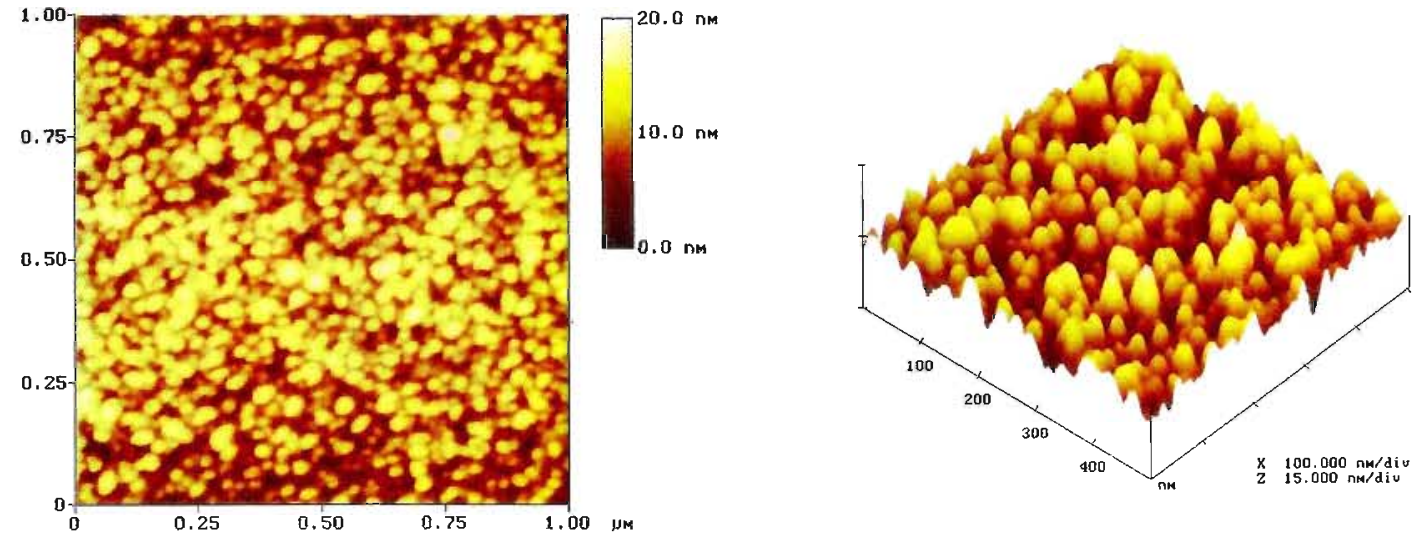

(c)
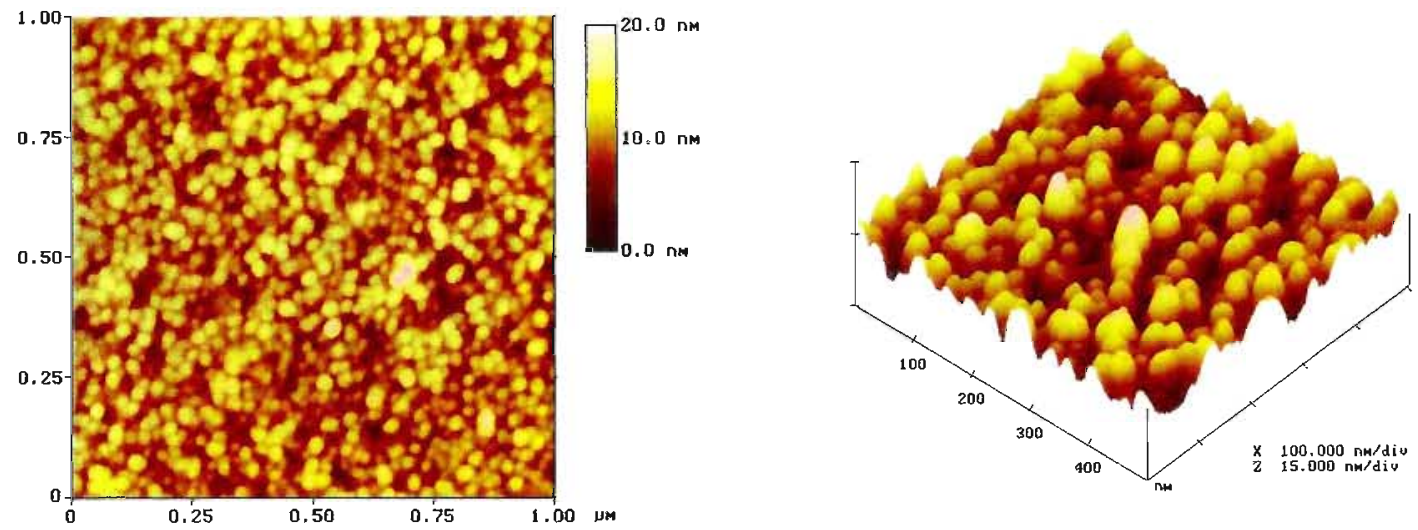

Figura 5.9. (a) Superfície do eletrodo novo;

(b) Após 100 varreduras triangulares de potencial repetitivas;

(c) Após polarização catódica $(15 \mathrm{~min}$ a $-1,5 \mathrm{~V} / \mathrm{Pt})$. 
AFM - Superfície do eletrodo de $\mathrm{SnO}_{2}(\mathrm{Cl})$ submetido à polarização catódica

(a)

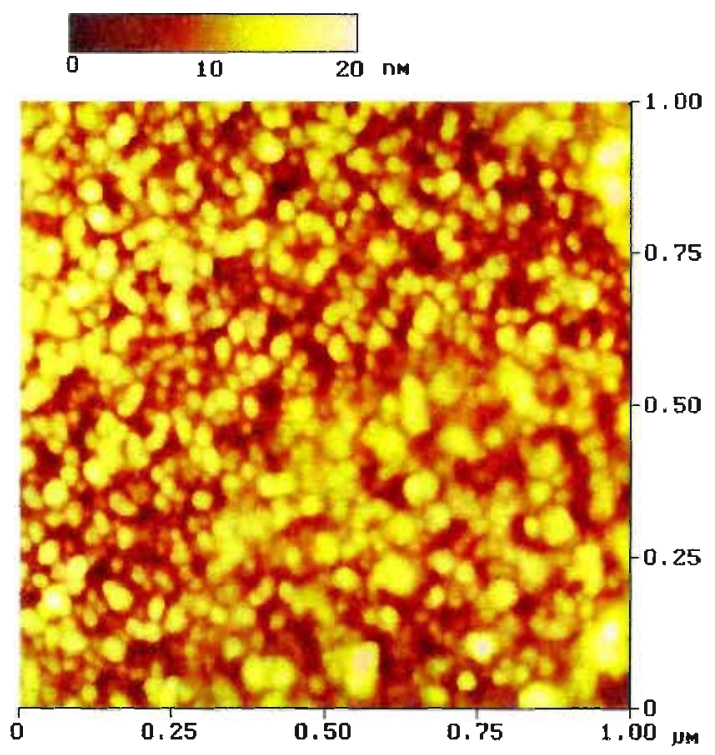

(b)

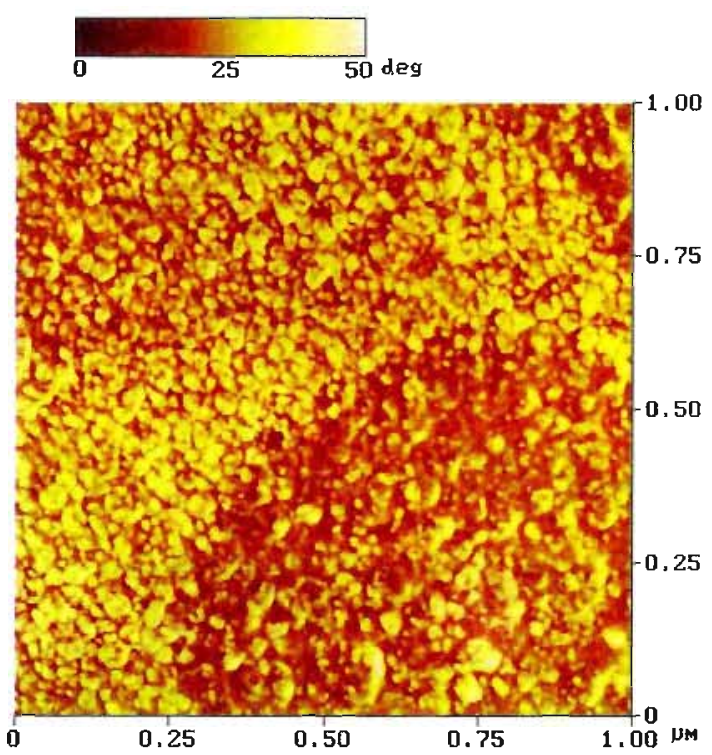

(c)

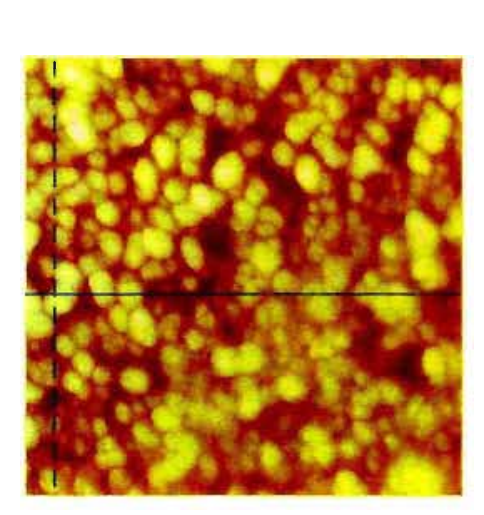

(d)

$$
\stackrel{-}{-}^{n m}
$$
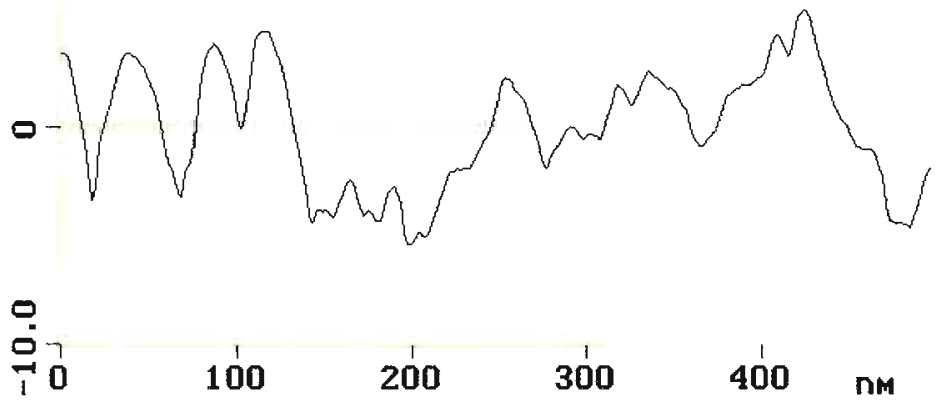

Figura 5.10. Imagens de AFM de uma região danificada da superfície do eletrodo de $\mathrm{SnO}_{2}(\mathrm{Cl})$ submetido à polarização catódica. Imagens $1 \times 1 \mu^{2}$ da topografia (a) e do contraste da fase correspondente (b); e imagem de $500 \times 500 \mathrm{~nm}^{2}$ (c) com o perfil da seção transversal indicada (d). 
Efeito da polarização catódica na superfície dos eletrodos transparentes de $\mathrm{SnO}_{2}$

(a) $\mathrm{SnO}_{2}(\mathrm{Cl})$

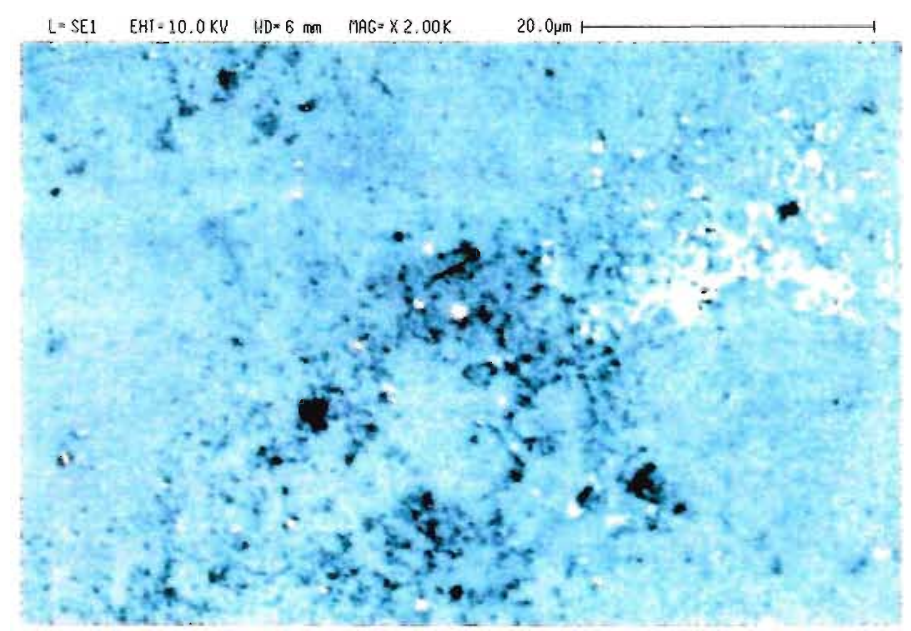

$\mathrm{L}=$ SE1 EHI $10.0 \mathrm{KV} \quad$ WD $-6 \mathrm{~mm} \quad \mathrm{MHF}=\mathrm{X} 2.00 \mathrm{~K}$

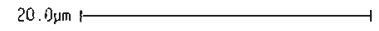

(a) $\mathrm{SnO}_{2}(\mathrm{Sb})$

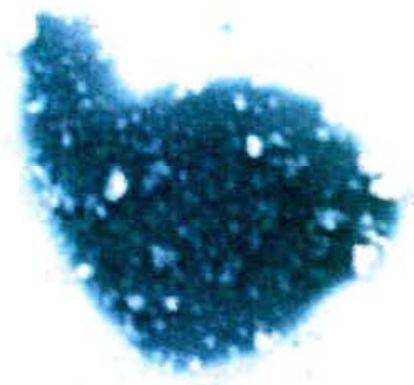

(a) $\mathrm{SnO}_{2}(\mathrm{~F})$
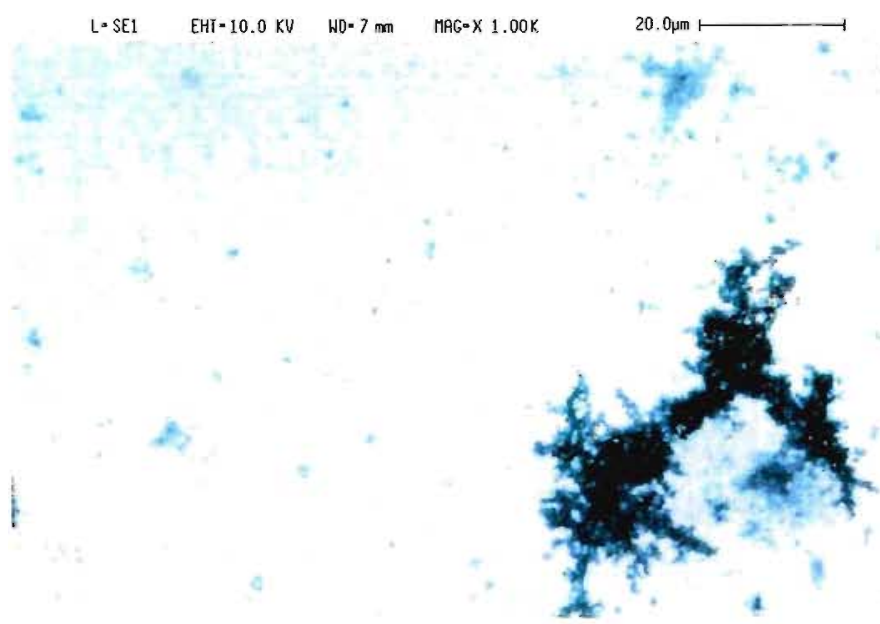

Figura 5.11. SEM - Detalhes das falhas do recobrimento da superfície dos eletrodos transparentes de $\mathrm{SnO}_{2}$ observadas após a polarização catódica. 
$\mathrm{SEM}$ - Superfície dos eletrodos transparentes de $\mathrm{SnO}_{2}$

(a) $\mathrm{SnO}_{2}(\mathrm{Cl})$

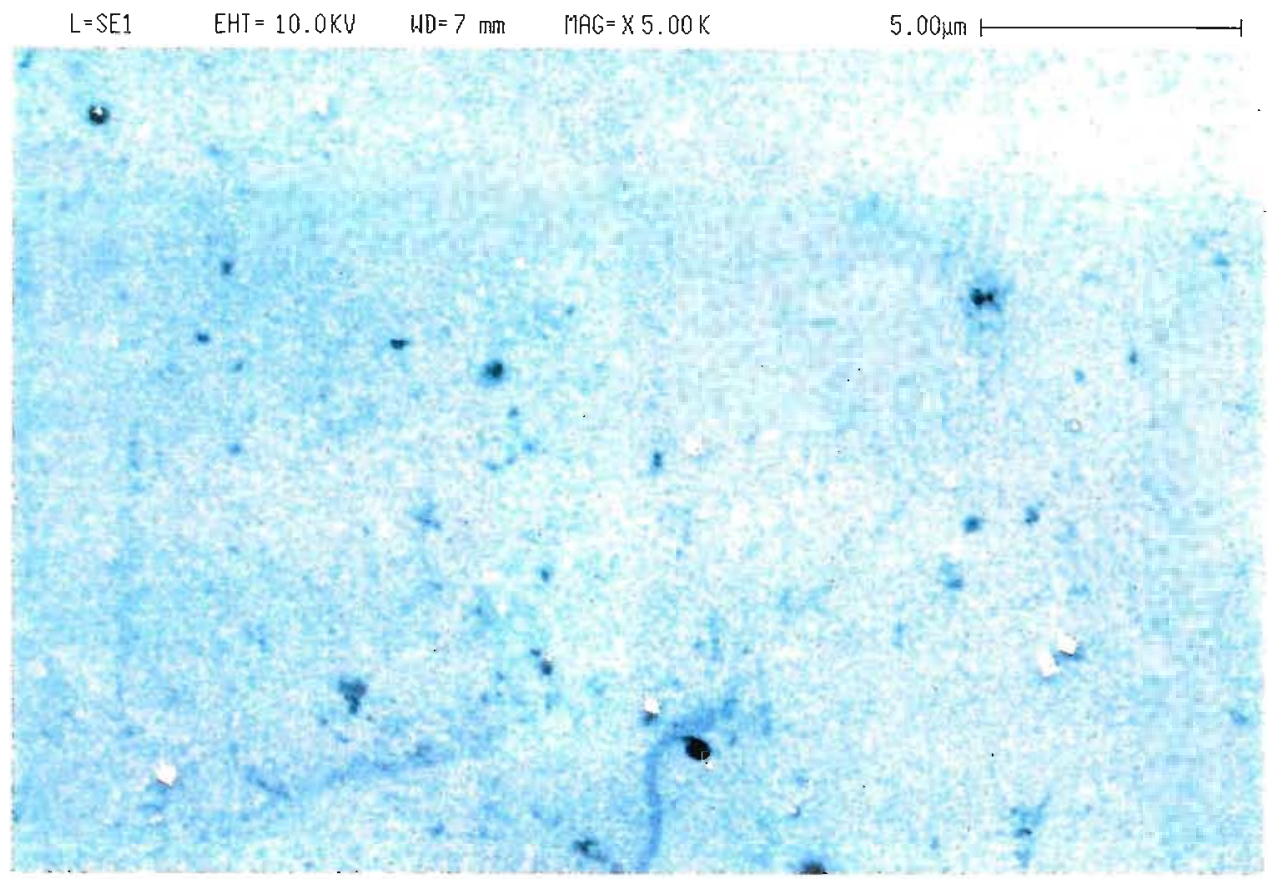

(b) $\mathrm{SnO}_{2}(\mathrm{Sb})$

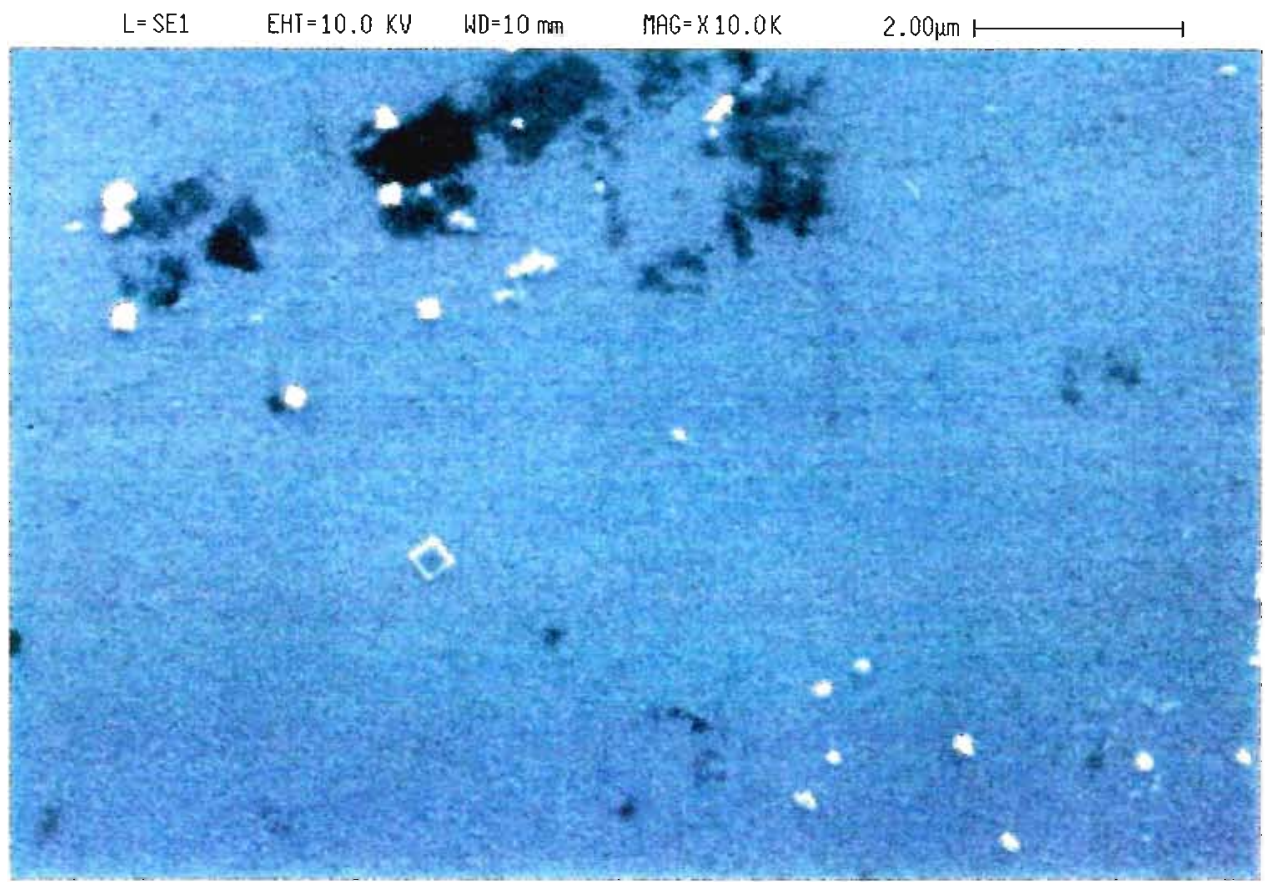

Figura 5.12. Superfície dos eletrodos de $\mathrm{SnO}_{2}(\mathrm{Cl})$ (a) e $\mathrm{SnO}_{2}(\mathrm{Sb})$ (b) após 20 varreduras repetidas de potencial, evidenciando a presença de pequenas partículas quadradas nas proximidades das falhas no recobrimento do filme. 


\subsubsection{Alterações morfológico-estruturais induzidas por perturbações eletroquímicas na superficie do eletrodo de $\mathrm{SnO}_{2}(\mathrm{Sb})$ investigadas in-situ por STM}

As imagens de uma mesma área da superficie do eletrodo transparente de $\mathrm{SnO}_{2}(\mathrm{Sb})$ obtidas in-situ por STM antes e após a aplicação das perturbações eletroquímicas estão representadas na Fig. 5.13.

A imagem da superficie do eletrodo novo está representada na Fig. 5.13a, que mostra ainda o perfil da seção transversal indicada na imagem. As imagens obtidas após a aplicação das duas primeiras perturbações eletroquímicas descritas, i.e., a imagem obtida após a polarização anódica de $1,2 \mathrm{~V}$ (vs. Pt) durante 1 minuto e a obtida após a aplicação de $1,5 \mathrm{~V}$ por 1 minuto, não apresentaram diferenças perceptiveis quando comparadas à imagem 5.13a. A Fig. 5.12b representa a imagem de STM obtida após a imposição de uma polarização de $1,5 \mathrm{~V}$ durante 5 minutos. A comparação das imagens $5.13 \mathrm{a}$ e $5.13 \mathrm{~b}$ não revela qualquer alteração morfológica na superficie do eletrodo. A rugosidade rms nestas imagens também é similar: 1,0 e 0,9 nm para as Fig. 5.13a e 5.13b, respectivamente. Estes resultados indicam que, apesar das alterações observadas para a resposta eletroquímica do eletrodo de $\mathrm{SnO}_{2}$ devido à aplicação de uma polarização anódica na região da RDO (discutidas na seção 4.3.1.2), não ocorreu qualquer alteração morfológica na superficie do eletrodo identificável por estas análises in-situ por STM.

A Fig. $5.13 \mathrm{c}$ corresponde à imagem obtida após a polarização do eletrodo no potencial catódico de $-0,95 \mathrm{~V}$ (vs. $\mathrm{Pt}$ ). A imagem e o perfil revelam um menor empacotamento das partículas em relação ao observado na Fig. 5.13a. Provavelmente, este efeito foi provocado por um ataque nos contornos das mesmas, como observado nas imagens obtidas por AFM (Fig. 5.8c). Após a aplicação desta perturbação eletroquímica, a rugosidade rms da superfície aumentou para $1,2 \mathrm{~nm}$. Este efeito deve ser resultante dos estágios iniciais da destruição do filme de $\mathrm{SnO}_{2}$ causado pela polarização catódica na região da $\mathrm{RDH}$.

A imagem adquirida após a aplicação de $1,4 \mathrm{~V}$ durante 2 minutos está representada na Fig. 5.13d. A superficie se tornou ainda mais rugosa $(1,9 \mathrm{~nm})$ e o tamanho das partículas aumentou consideravelmente. Talvez, este efeito surpreendente tenha sido causado pela re-oxidação das espécies que haviam sido reduzidas na etapa anterior.

Para finalizar estes experimentos, aplicou-se ao eletrodo uma outra polarização catódica de $-0,95 \mathrm{~V}$ durante 5 minutos. A imagem obtida após este tratamento 
eletroquímico está representada na Fig. 5.13e. Para esta imagem, a rugosidade foi estimada em 1,0 nm. A observação da imagem $5.13 \mathrm{e}$ revela que o tamanho dos grãos diminuiu consideravelmente, resultando em uma superfície com características similares às apresentadas na Fig. 5.13c.

A partir destes experimentos, parece razoável supor que, nas condições investigadas, os estágios iniciais da destruição do filme de $\mathrm{SnO}_{2}$ em consequência da polarização catódica deve-se preferencialmente à formação e dissolução de $\mathrm{SnO}$ e não de $\mathrm{Sn}^{\circ}$. A formação do $\mathrm{Sn}$ metálico pode ser descartada considerando a observação experimental de que não houve qualquer problema para a aquisição da imagem $5.13 \mathrm{c}$. Se houvessem se formado partículas ou um filme de $\mathrm{Sn}^{\circ}$ sobre a superficie, seriam esperadas interferências na aquisição das imagens de STM, o que não foi verificado.

No estudo da redução de eletrodos transparentes de $\mathrm{SnO}_{2}(\mathrm{~F})$ por $\mathrm{H}_{2}$, J. Wallinga e col. [11] também observaram que a corrosão iniciava-se nos contornos dos grãos, provocava a diminuição da transparência e da condutividade do filme e alterava a composição química da superficie, que passava a apresentar sinais de $\mathrm{Sn}^{\circ}$. Os autores verificaram que, se o filme fosse re-oxidado por aquecimento a $400{ }^{\circ} \mathrm{C}$, todas as propriedades apresentadas inicialmente eram totalmente restauradas. Porém, se o processo de redução fosse prolongado, de tal modo que a superficie apresentasse partículas brancas, identificadas como $\mathrm{Sn}^{\circ}$, as propriedades iniciais do filme não eram recuperadas após o tratamento para a re-oxidação do filme. Os autores também não apresentaram um mecanismo que explicasse estes resultados.

Os resultados observados por Wallinga foram, de certa forma, similares aos observados no presente trabalho, embora as perturbações que causaram a corrosão, assim como as propriedades investigadas tenham sido distintas. Estes experimentos revelaram que, até determinados estágios da corrosão induzida pela redução do filme de $\mathrm{SnO}_{2}$, é possível recuperar as propriedades iniciais destes materiais através de processos que induzam a re-oxidação das espécies reduzidas. Este fenômeno é um tanto surpreendente, mas, no momento, não há nenhum mecanismo para explicar este processo. 


\section{In-situ STM}

Efeito da polarização anódica e catódica na superfície do eletrodo de $\mathrm{SnO}_{2}(\mathrm{Sb})$

(a)
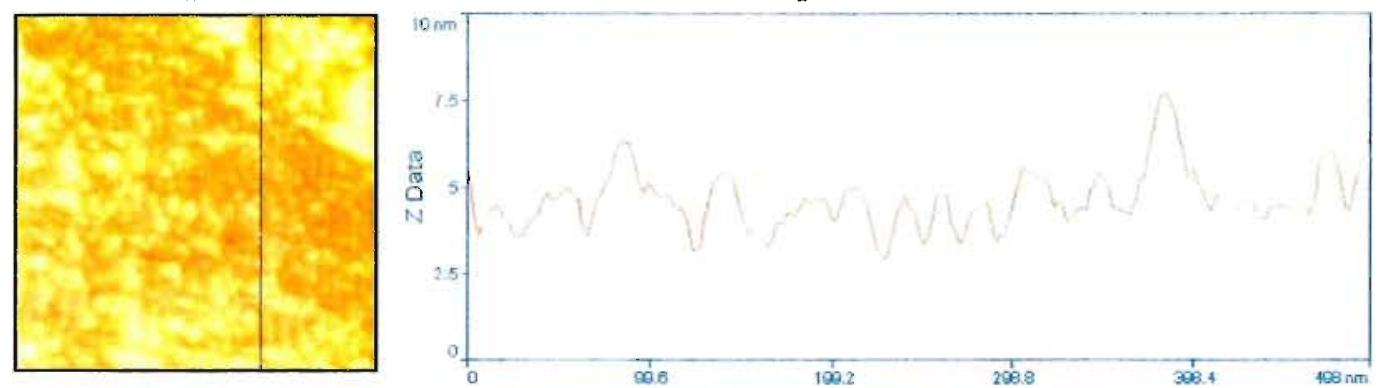

(b)
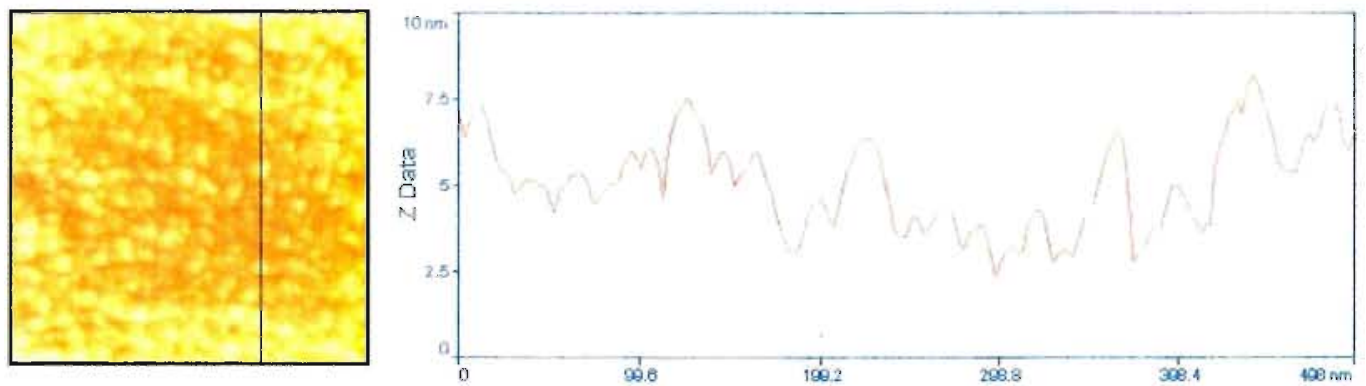

(c)
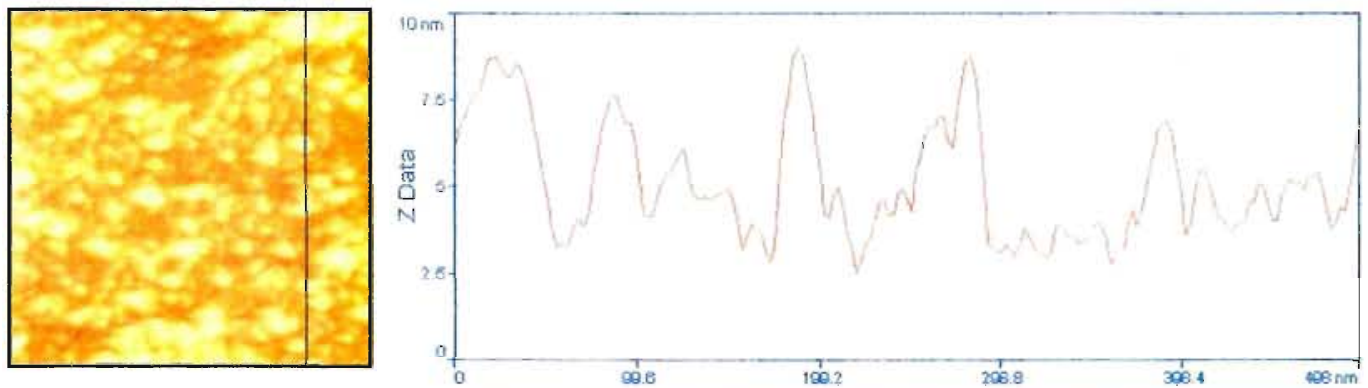

(d)
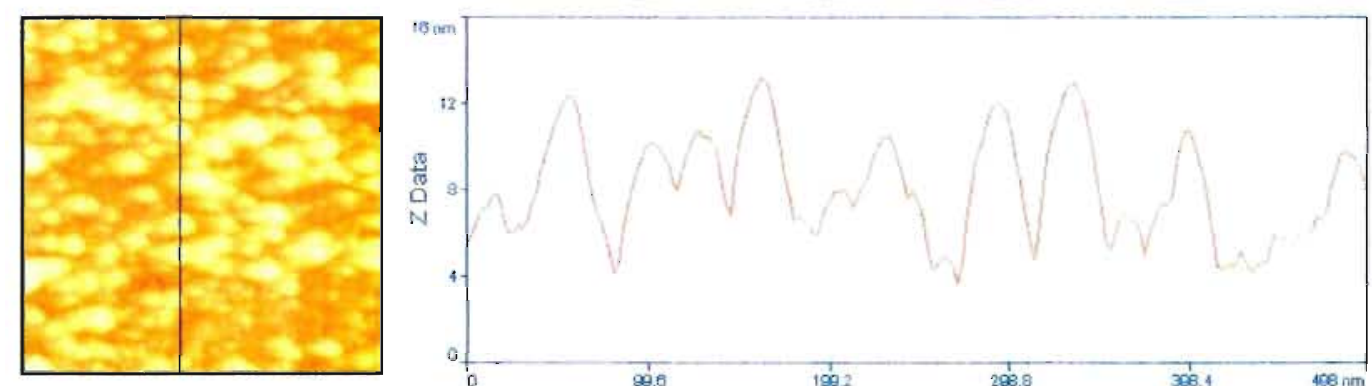

(e)
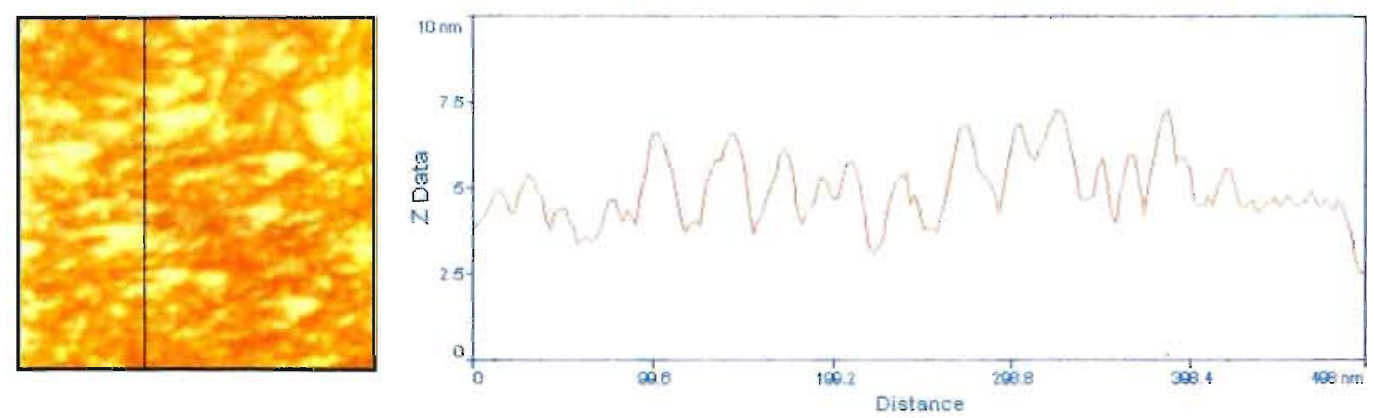

Figura 5.13. Imagens da mesma área da superfície do eletrodo de $\mathrm{SnO}_{2}(\mathrm{Sb})$ em $\mathrm{NaClO}_{4} 0,1 \mathrm{M}$ obtidas in-situ por STM: antes da aplicação das perturbações eletroquímicas (a) e, em sequência, após 6 min de polarização anódica a 1,4 V/Pt (b); após 5 min de polarização catódica a $-0,95 \mathrm{~V}$ (c); após 2 min de polarização a 1,4 V (d); e após 5 min sob $-0,95 \mathrm{~V}$ (e). 


\section{4 - CONCLUSÕES}

De modo geral, as alterações morfológicas induzidas por perturbações eletroquímicas foram similares para os três tipos de eletrodos transparentes de $\mathrm{SnO}_{2}$ investigados.

A imposição de potenciais anódicos da região da RDO provocou um aumento no diâmetro das partículas constituintes do filmes investigados, mas ainda não foram encontradas explicações para este resultado inesperado e surpreendente.

A aplicação de potenciais catódicos da região da $\mathrm{RDH}$ provocou a corrosão da superfície do eletrodo devido à redução do $\mathrm{SnO}_{2}$ a $\mathrm{SnO}$ ou a $\mathrm{Sn}^{\circ}$. Os processos de corrosão ocorreram nos contornos dos grãos e de maneira diferenciada sobre as partículas, que, de modo geral, diminuíram no diâmetro e altura. Este processo pôde ser revertido em seus estágios iniciais, já que a aplicação de potenciais anódicos da região da RDO promoveu a re-oxidação das espécies que haviam sido formadas durante a redução (provavelmente $\mathrm{SnO}$ ), causando o aumento nas dimensões das partículas.

Varreduras triangulares entre os potenciais das regiões da RDH e RDO promoverram a reconstrução do filme porque os processos de redução do $\mathrm{SnO}_{2}$ e de re-oxidação daquelas espécies reduzidas ocorreram de maneira diferenciada sobre as partículas constituintes do filme.

Os processos de corrosão foram menos pronunciados nas regiões onde o filme se apresentava mais uniforme e compacto que nas regiões nas quais o filme apresentava falhas no recobrimento.

A presença do organosilano na superfície do eletrodo de $\mathrm{SnO}_{2}$ exerceu um efeito protetor, considerando que as alterações causadas por estas perturbações foram muito menos pronunciadas sobre os eletrodos modificados com OTS.

As técnicas de AFM e STM são adequadas para investigar os estágios iniciais dos processos de corrosão que ocorrem na superficie dos eletrodos transparentes de $\mathrm{SnO}_{2}$, porque os efeitos morfológicos podem ser observados apenas em escala submicrométrica. No entanto, as análises devem ser complementadas por outras técnicas (p.ex., SEM), porque algumas regiões do filme podem ser mais susceptíveis à corrosão. 
CAPITULO 6

CONCLUSÕES GERAIS 
Este trabalho apresentou um estudo das propriedades morfológico-estruturais e eletroquímicas de eletrodos de filme de $\mathrm{SnO}_{2}$ suportado sobre sílica ou titânio, investigadas através de técnicas eletroquímicas e de análise de superficie distintas.

Os filmes de $\mathrm{Ti} / \mathrm{SnO}_{2}(\mathrm{Sb})$ foram obtidos por decomposição térmica de uma solução alcóolica de $\mathrm{SnCl}_{2}$ e $\mathrm{SbCl}_{3}$; os filmes depositados em sílica foram preparados a partir de soluções de $\mathrm{SnCl}_{4}$ em metanol através da técnica de Spray Pyrolyis. Prepararam-se ainda eletrodos modificados pela adsorção de um filme de octadeciltriclorosilano.

A caracterização física dos eletrodos transparentes foi realizada através da microscopia por interferometria de luz, SEM, TEM, AFM, XPS, XRD, medidas da espessura, da condutividade e transparência na região do vísivel; os eletrodos de $\mathrm{Ti} / \mathrm{SnO}_{2}(\mathrm{Sb})$ foram caracterizados apenas por SEM e microscopia interferométrica. As propriedades eletroquímicas de ambos os tipos de eletrodos foram investigadas porVoltametria Cíclica e Espectroscopia de Impedância Eletroquímica. Investigou-se ainda o efeito da aplicação de perturbações eletroquímicas na morfologia da superfície dos eletrodos

Os eletrodos de $\mathrm{Ti} / \mathrm{SnO}_{2}(\mathrm{Sb})$ apresentaram a superficie porosa, com rugosidade de $500 \mathrm{~nm}$. Os eletrodos transparentes de filme de $\mathrm{SnO}_{2}$, porém, apresentaram a superficie uniforme, com rugosidade média quadrática de apenas 1 a $2 \mathrm{~nm}$. Estes filmes eram condutores, policristalinos e constituídos por partículas com dimensões nanométricas (diâmetro e altura médios de 30 e $6 \mathrm{~nm}$, respectivamente). Mesmo entre os eletrodos transparentes, dependendo do dopante $(\mathrm{Cl}, \mathrm{F}$ ou $\mathrm{Sb})$, verificaram-se diferenças quanto às orientações cristalográficas predominantes, espessura, resistividade e tamanho das partículas. Os eletrodos modificados, que foram caracterizados apenas qualitativamente, apresentaram superfícies mais hidrofóbicas.

A morfologia dos filmes de $\mathrm{SnO}_{2}$ transparentes, principalmente no que se refere à uniformidade, baixa rugosidade, e à pequena dimensão e à alta coalescência das partículas, se destaca como um resultado original quando comparado aos resultados obtidos em estudos correlatos apresentados na Literatura. 
$>$ Os eletrodos de $\mathrm{Ti} / \mathrm{SnO}_{2}(\mathrm{Sb})$ apresentaram um comportamento eletroquímico bastante distinto do observado para os eletrodos transparentes. Para a reações redox do $\mathrm{K}_{4} \mathrm{Fe}(\mathrm{CN})_{6}$, p.ex., a transferência de elétrons foi muito mais rápida sobre o $\mathrm{Ti} / \mathrm{SnO}_{2}(\mathrm{Sb})$, possivelmente porque este eletrodo apresentava maior número de portadores de carga $\mathrm{e}$ menor resistência ôhmica que os eletrodos transparentes.

$>\mathrm{A}$ análise dos perfis potenciodinâmicos e dos espectros de $\mathrm{EIS}$ em $\mathrm{NaClO}_{4}$ (aq.) revelaram que o comportamento eletroquímico dos eletrodos de $\mathrm{Ti} / \mathrm{SnO}_{2}(\mathrm{Sb})$ foi fortemente influenciado pelos equilíbrios de adsorção e dissociação dos grupos $\mathrm{Sn}-\mathrm{OH}$ da superficie.

$>$ A presença do OTS nos eletrodos modificados, principalmente os de $\mathrm{Ti} / \mathrm{SnO}_{2}(\mathrm{Sb})-\mathrm{OTS}$, deve ter alterado os equilíbrios de dissociação destes grupos e provocado um maior acúmulo de carga na interfase.

$>$ A interfase $\mathrm{Ti} / \mathrm{SnO}_{2}(\mathrm{Sb}) \mid \mathrm{NaClO}_{4}$ (aq.) pôde ser bem representada por um circuito elétrico equivalente que incluía elementos que expressassem tais processos de adsorção. Os eletrodos modificados foram representados pelo mesmo circuito, que indicou que a presença do organosilano alterou apenas os processos de adsorção na superfície.

$>$ As curvas de polarização anódica indicaram que o OTS não alterou, porém, o mecanismo para a reação de geração de $\mathrm{O}_{2}$. Os coeficientes de Tafel obtidos indicaram ainda que a etapa lenta da RDO não deveria estar associada a processos de adsorção na superficie sendo, portanto, coerentes com o circuito sugerido considerando as medidas de EIS.

$>$ O eletrodo modificado com OTS não é indicado para atuar como ânodo na eletrooxidação de compostos orgânicos porque a presença deste filme hidrofóbico promove a adsorção e polimerização destas espécies, o que pode bloquear a sua superficie.

A aplicação de potenciais anódicos da região da RDO provocou um sutil aumento no diâmetro das partículas constituintes do filme de $\mathrm{SnO}_{2}$. A imposição de potenciais catódicos da região da $\mathrm{RDH}$ provocou a corrosão da superfície do eletrodo devido à redução do $\mathrm{SnO}_{2}$ a $\mathrm{SnO}$ ou a $\mathrm{Sn}^{\circ}$. A corrosão ocorreu nos contornos dos grãos e de maneira diferenciada sobre as partículas, que, de modo geral, diminuíram no diâmetro e altura. As cem repetitivas varreduras triangulares entre os potenciais das regiões da $\mathrm{RDH}$ 
e RDO promoveu a reconstrução do filme porque os processos de redução e re-oxidação do $\mathrm{SnO}_{2}$ ocorreram de maneira diferenciada sobre as partículas constituintes do filme.

Os processos de corrosão foram menos pronunciados nas regiões onde o filme se apresentava mais uniforme e compacto que nas regiões nas quais o filme apresentava falhas no recobrimento.

$>$ A presença do organosilano na superfície do eletrodo de $\mathrm{SnO}_{2}$ exerceu um efeito protetor, considerando que as alterações causadas por estas perturbações foram muito menos pronunciadas sobre os eletrodos modificados com OTS. Porém, a aplicabilidade do eletrodo $\mathrm{Ti} / \mathrm{SnO}_{2}(\mathrm{Sb})$-OTS seria muito limitada, considerando que o OTS poderia promover a polimerização de espécies orgânicas na superficie do eletrodo. 
CAPÍTULO 7

\section{SUGESTÕES PARA TRABALHO POSTERIOR}


A continuidade deste trabalho pode ser encaminhada visando o maior entendimento de diversos aspectos que foram investigados para os eletrodos de filme de $\mathrm{SnO}_{2}$.

Para os eletrodos transparentes, como as determinações da densidade de portadores de carga estimadas por Impedância Eletroquímica e Voltametria Cíclica de Baixa Amplitude não apresentaram valores reprodutíveis, tal parâmetro poderia ser determinado através de outros métodos, p.ex. por medidas de fotocorrente.

O estudo dos processos de corrosão que atingem estes eletrodos pode ser continuado investigando a evolução das alterações morfológicas que foram observadas por AFM e insitu STM apenas em seus estágios iniciais; os efeitos da aplicação de condições mais agressivas também devem ser investigados. Se tais estudos forem complementados por análises de difração de raios- $\mathrm{X}$, possibilitarão averiguar as alterações nas intensidades dos picos correspondentes às diferentes orientações dos cristalitos e determinar quais são preferencialmente atacados durante os processos de corrosão. Também seria muito interessante investigar o aumento nas dimensões das partículas constituintes dos filmes de $\mathrm{SnO}_{2}$ induzido pela polarização anódica, já que foram relatados resultados distintos na Literatura. A investigação dos processos de redução e re-oxidação destes filmes também seria de grande interesse, pois ainda não foram sugeridos mecanismos para tais processos.

Para a continuidade do estudo dos eletrodos modificados podem ser investigados outros compostos, que possam não apenas proteger a superficie do $\mathrm{SnO}_{2}$ dos processos de corrosão como também apresentar maior aplicabilidade. 
REFERÊNCIAS BIBLIOGRÁFICAS 
1. A. Nanthakumar e N.R. Armstrong, em "Semiconductor Electrodes", H.O. Finklea (Ed.), Cap.4. Studies in Physical and Theoretical Chemistry 55, Elsevier, Amsterdan (1988).

2. J.S. Liu, S.J. Laverty, J. McLaughlin, J. Molloy, J. Electrochem. Soc., 141, L38-L40 (1994).

3. H. Feng, S.J. Laverty, P. Maguire, J. Molloy and B.J. Meenan, J. Electrchem. Soc, 143, 20482052 (1996).

4. P.R. Athey, F.K. Urban III and P.H. Holloway, J. Vac. Sci. Technol. B, 14, 3436-3444 (1996).

5. U. Opara Krasovec, B. Orel, S. Hocevar and I. Musevic, J. Electrochem. Soc., 144, 3398-3409 (1997).

6. B. Orel, U. Lavrencic-Stangar, K.Kalcher, J. Electrochem. Soc., 141, L127-L130 (1994).

7. P.Olivi, E.C.Pereira, E. Longo, J.A. Varella, L.O. Bulhões, J. Electrochem. Soc., 140, L81L82 (1993).

8. K.C. Grabar, P.C. Smith, M.D. Musick, J.A. Davis, D.G. Walter, M.A. Jackson, A.P. Guthrie, M.J. Nathan, J. Am. Chem. Soc., 118, 1148-1153 (1996).

9. L-H. Guo, S. Mukamel, G. McLendon, J. Am. Chem. Soc., 117, 546-547 (1995).

10. M. Collinson, E.F. Bowden, Anal. Chem., 64, 1470-1476 (1992].

11. J. Wallinga, W.M. Arnoldbik, R.E. I. Schropp, W.F. Van der Weg, J. Phys. Chem., 102, 6219-6224 (1998).

12. C.I. Nasr, S. Hotchandani, W.Y. Kim, R.H. Schmehl, P.V. Kamat, J. Phys. Chem. B. 101, 7480-7487 (1997).

13. W.E. Ford, J.M. Wessels, M.A.J. Rodgers, J. Phys. Chem. B. 101, 7435-7442 (1997).

14. H. Cachet, J. Bruneaux, G. Folcher, C. Lévy-Clément, C. Vard, M. Neumann-Spallart, Solar Energy Mater. Sol. Cells, 46, 101-114 (1987).

15. J. Bruneaux, H. Cachet, M. Froment, J. Amblard, M. Mostafavi, J. Electroanal. Chem. 269, 375-378 (1989).

16. G. Biesmans, M. Van der Auweraer, C. Cathry, F.C. De Schryver, Y. Yonezawa and T. Sato, Chem. Phys., 160, 97-121 (1992).

17. L. Lipp and D. Pletcher, Electrochim. Acta, 42, 1091-1100 e 1101-11 (1997).

18. B. Correa-Lazano, Ch. Comninellis, A. De Battisti, J. Appl. Electrochem., 27, 970-974 (1997).

19. T.A.F. Lassali, L.O.S. Bulhões, L.M.C. Abeid, J.F.C. Boodts, J. Electrochem. Soc., 144, 3348-3354 (1997).

20. C.P. De Pauli, S. Trasatti, J. Electroanal. Chem., 396, 161-168 (1995).

21. R. Kötz, S. Stucki and B. Carcer, J. Appl. Electrochem., 21, 14-20 (1991).

22. S.Stucki, R.Kötz, B.Carcer, W. Suter, J. Appl. Electrochem., 21, 99-104 (1991).

23. Ch. Comninellis, C.Pulgarin, J. Appl. Electrochem., 23, 108-112 (1993).

24. C.S. Fugivara, P.T.A. Sumodjo, A.A. Cardoso and A.V. Benedetti, Analyst, 121, 541-545 (1996). 
25. V. Dusastre, D.E. Williams, J. Phys. Chem., 102, 6732-6737 (1998).

26. G.E. Poirier, R.E. Cavicchi, S.Semancik, J. Vac. Sci. Technol.A, 11, 1392-1395 (1993).

27. W. Gopel and K.D. Schierbaum, Sens. Actuators B, 26, 1 (1995).

28. R. Lal, R. Grover, R.D. Vispute, R. Viswanathan, V.P. Godbole, S.B. Ogale, Thin Solid Films, 206, 88-93 (1991).

29. H.A. Laitinen, C.A. Vincent, T.M. Bednarski - J. Electrochem. Soc., 115, 1024-1028 (1968).

30. F. Mollers, R. Memming, Ber. Bunsenges. Physik. Chem., 76, 469-475 (1972).

31. P. Kirkov, Electrochim. Acta, 17, 519-533 (1972).

32. P. Kirkov, Electrochim. Acta, 17, 533-547 (1972).

33. M. Székely, B. Eid, E. Caillot, M. Herlem, M. Herlem, A. Etcheberry, C. Mathieu and B. Fahys, J. Electroanal. Chem., 391, 69-75 (1995).

34. H. Cachet, M. Froment and F. Zenia, J. Electrochem. Soc., 143, 442-447 (1996).

35. A. Gewirth, B.K. Niece, Chem. Rev., 97, 1129-1162 (1997).

36. J. Li, E. Wang, Electroanalysis, 8, 107-112 (1996).

37. H. Onishi, Y. Iwasawa, Surf. Sci, 357-358, 773-776 (1996).

38. T.J. Meyer, G.J. Meyer, B.W. Pfenning, J.R. Schoonover, C.J. Timpson, J.F. Wall, C. Kobusch, X. Chen, B.M. Peek, C.G. Wall, W. Ou, B.W. Erickson and C.A. Bignozzi, Inorg. Chem., 33, 3952-3964 (1994).

39. L. Kaplan, V.N. Zhitomirsky, S. Goldsmith, R.L. Boxman and I. Rusman, Surf. Coat. Technol., 76-77, 181-77 (1995).

40. T. Asikainen, M. Ritala, M.Leskelä, T. Prohaska, G. Friedbacher and M. Grasserbauer, Appl. Surf. Sci., 99, 91-98 (1996).

41. T.K.S. Wong and W.K. Man, Thin Solid Films, 287, 45-50 (1996).

42. S. Kasiviswanathan, V. Srinivas, A.K. Kar, B.K. Mathur and K.L. Chopra, Solid State Commun., 101, 831-834 (1997).

43. L. Kaplan, I. Rusman, R.L. Boxman, S. Goldsmith, M. Nathan and E. Ben-Jacob, Thin Solid Films, 290-291, 355-361 (1996).

44. D.G. Rickerby, M.C. Horrillo, J.P. Santos, P. Serrini, Nanostruct. Mater., 9, 43-52 (1997).

45. I.A. Rauf, Surf. Sci., 325, L 413-L419 (1995).

46. E. Kubota, Y. Shigesato, M. Igarashi, T. Haranou and K. Suzuki, Jpn. J. Appl. Phys., 33, 4997-5004 (1994).

47. G.E. Poirier and R.E. Cavicchi, S. Semancik, J. Vac. Sci. Technol. A, 12, 2149-2152 (1994).

48. F.H. Jones, R. Dixon, J.S. Foord, R.G. Egdell, J.B. Pethica, Surface Science, 376, 367-373 (1997).

49. Cláudia Longo, "Estudos de Adsorção em Interfases $\mathrm{SnO}_{2} / \mathrm{H}_{2} \mathrm{O}$ ", Dissertação de Mestrado, Instituto de Quimica, Universidade de São Paulo, 1994.

50. C. Longo, P. T. A. Sumodjo, An. XI Congresso Iberoamericano de Eletroquímica/LX Simpósio Brasileiro de Eletroquímica e Eletroanalítica, p. 112-114. Aguas de Lindóia, SP, 4-9 de abril, 1994. 
51. Cecílio Sadao Fugivara, "Comportamento Eletroquímico de Eletrodos a Base de Dióxido de Estanho e sua Aplicação na Oxidação do Cianeto", Tese de Doutorado, Instituto de Química, Universidade de São Paulo, 1997.

52. C.S. Fugivara, A.A. Cardoso, R.A. Segato, A.V. Benedetti, P.T.A. Sumodjo, An. XI Congresso Iberoamericano de Eletroquímica/LX Simpósio Brasileiro de Eletroquímica e Eletroanalítica, p. 406-408. Aguas de Lindóia, SP, 4-9 de abril, 1994.

53. H.O. Finklea em "Semiconductors Electrodes", H.O. Finklea (Ed.), Cap.1. Studies in Physical and Theoretical Chemistry 55, Elsevier, Amsterdan (1988).

54. W. Schmickler, Interfacial Electrochemistry, Cap. 7. Oxford University Press, 1996.

55. H. Gerisher, Electrochim. Acta, 35,1677-1699 (1990).

56. J. N. Shive, A Fisica do estado sólido, Série "Textos Básicos em Eletrônica", Cap. 3. Ed. Edgar Bleicher Ltda, W. Schmiat, (tradutor), Ed. da Universidade de São Paulo, 1972.

57. Z.M. Jarzerbski, J.P. Marton, J. Electrochem. Soc., 123, 199C-205C (1976).

58. Z.M. Jarzerbski, J.P. Marton, J. Electrochem. Soc., 123, 299 C-310C.

59. Z.M. Jarzerbski, J.P. Marton, J. Electrochem. Soc., 123, 333C-346C.

60. C. Klein, C.S. Hurlbut, Jr., Mamual of Mineralogy, J. Wiley \& Sons, Inc., 21 edition, 1997.

61. R. Cavicchi, M. Tarlov, S. Semancik, J. Vac. Sci. Technol.A, 8, 2347-2352 (1990).

62. P. Jones, J.A. Hockey, Trans. Faraday Soc., 67, 2679-2685 (1971).

63. L.D. Loch, J. Electrochem. Soc., 110, 1081-1083 (1963).

64. L. Smart, E. Moore, Solid State Electrochemistry - An Introduction, Cap. 2 e 3, Chapman \& Hall, Londres.

65. C.A. Vincent, J. Electrochem. Soc., 119, 515-521 (1972)

66. B. Stjema, E. Olsson, C.G. Granqvist, J. Appl. Phys., 76, 3797-3817 (1994).

67. J. Brumeaux, H. Cachet, M. Froment, A. Messad. Electrochim. Acta. 39, 1251-1257 (1994).

68. A. Messad, J. Bruneaux, H. Cachet, M. Froment, J. Mat. Sci., 29, 5090-5103 (1994).

69. S.A. Knickerbocker, A.K. Kulkarni, J. Vac. Sci. Technol.A, 13, 1048-1052 (1995).

70. H.L. Ma, D.H. Zhang, S.Z. Win, S.Y. Li, Y.P. Chen, Solar Cells Mater. Solar Cells, 40, 371 380 (1996).

71. G. Gordillo, L.C. Moreno, W. de la Cruz, P. Teheran, Thin Solid Films, 252, 61-66 (1994).

72. A. Tiburcio-Silver, A. Maldonado, A. Escobosa, E. Saucedo, J.M. Montoya, J.A. Moreno, Appl. Surf. Sci., 70/71, 746-750 (1993).

73. D. Bélanger, J.P. Dodelet, B.A. Lombos and J.I. Dickson, J. Electrochem. Soc, 132,13981405 (1985).

74. K.C. Mishra, K.H. Jonhson, P.C. Schmidt, Phys. Rev. B, 51, 13972-13976 (1995).

75. C. Terrier, J.P. Chatelon, R. Berjoan and J.A. Roger, Thin Solid Films, 263, 37-41 (1995).

76. B. Correa-Lazano, Ch. Comninellis and A. De Battisti, J. Electrochem. Soc., 143, 203-209 (1996).

77. R. Kötz, em "Photoelectron Spectroscopy of Practical Electrode Materials", H. Gerischer and C.W. Tobias (Ed.), V.1, p 97. Advances in Electrochemical Science and Engineering, VCH, Weinheim (1990). 
78. L. Köver, G. Moretti, Zs. Kovács, R. Sanjinés, I. Cserny, G. Margaritondo, J. Pálinkás, H. Adachi, J. Vac. Sci. Technol. A. 13, 1382-1388 (1995).

79. H. Haitjema, J.J.Ph. Elich, C.J. Hoogendoom, Solar Energy Materials, 18, 283-297 (1989).

80. A. Smith, J.-M. Laurent, D.S. Smith, J.-P. Bonnet, R.R. Clemente, Thin Solid Films, 266, 20 30 (1995).

81. N.R. Armstrong, A.W.C. Lin, M. Fujihira and T.Kuwana, Anal. Chem., 48, 741-750 (1976).

82. J. Dutta, J. Perrin, T. Emeraud, J.M. Laurent, A. Smith, J. Mater. Sci., 30, 53-62 (1995).

83. Q. Chen, Y. Qian, Z. Chen, G. Zhou, Y. Zhang, Thin Solid Films, 264, $25-27$ (1995).

84. T. Ishida, O. Tabata, J. Park, S.H. Shin, H. Magara, S. Tamura, S. Mochizuki, T. Mihara, Thin Solid Films, 281, 228-231 (1996).

85. M.H.M. reddy, S.R. Jawalekar, A.N. Chandorkar, Thin Solid Films, 169, 117-126 (1989).

86. B. Correa-Lazano, Ch. Comninellis and A. De Battisti, J. Appl. Electrochem., 26, 83-89 (1996).

87. H. Tada, J. Electrochem. Soc., 142, L11-L13 (1995).

88. J. Bruneaux, H. Cachet M. Froment, M. Levart, J.Vedel, J. Microsc. Spectrosc. Electron., 14, 1-10 (1989).

89. J. Bruneaux, H. Cachet, M. Froment and A. Messad, Thin Solid Films, 197, 129-142 (1991).

90. J. Tanaka and S.L. Suib, J. Chem. Edu., 61, 1104-1106 (1984).

91. Z.M. Jarzebski, Phys. Stat. Sol., 71, 13-39 (1982).

92. C. Agashe, B.R. Marathe, M.G. Takwale, V.G. Bhide, Thin Solid Films, 164, 263-264 (1988).

93. G.C. Morris, A.E. McElnea, App. Surface Sci., 92, 167-170 (1996).

94. Z. Orel, B. Orel, M.K. Gunde, Solar Energy Mater. Sol. Cells, 26, 105-114 (1992).

95. V. Vasu, A. Subrahmanyam, Thin Solid Films, 189, 217-225 (1990).

96. C. Agashe, B.R. Marathe, J. Phys. D: Appl. Phys., 26, 2049-2054 (1993).

97. A.I. Ivashchenko, Ia.I. Kerner, G.A. Kiosse, I.Yu. Maronchuk, Thin Solid Films, 303, 292294 (1997)

98. W.I. Cho, H. Jang, S.R. Lee, Scripta Metallurgica et Materialia, 32, 815-820 (1995).

99. K.G. Severin and J.S. Ledford, Langmuir, 11, 2156-2162 (1995).

100. M.A. Aegerter, A. Reich, D. Ganz, G. Gasparro, J. Pütz, T. Krajewski, J. Non-Crystalline Solids, 218, 123-128 (1997).

101. S-S. Park, H. Zheng, J.D. Mackenzie, Materials Letters, 22, 175-180 (1995).

102. J.C. Giuntini, W. Granier, J.V. Zanchetta, A. Taha, J. Mater. Sci. Letters, 9, 1383-1388 (1990).

103. C.Iwakura, M. Inai, T.Uemura, H. Tamura, Electrochim. Acta 26, 579-584 (1981).

104. C. Iwakura, K. Sakamoto, J. Electrochem. Soc., 132, 2420-2423 (1985).

105. J.F.C.Boodts, S. Trasaatti, J. Electrochem. Soc., 137, 3784-3789 (1990).

106. A.I. Onuchukwu e S. Trasatti, J. Applied Electrochem., 21, 858-862 (1991).

107. T.A. Chertykovtseva, D.M. Shub, V.I. Veselovskii, Életrokhimiya, 14 (1978) 1260-1263.

108. T.A. Chertykovtseva, D.M. Shub, V.I. Veselovskii, Életrokhimiya, 14 (1978) 275-278. 
109. T.A. Chertykovtseva, Z.D. Skuridina, D.M. Shub, V.I. Veselovskii, Életrokhimiya, 14, 14121415 (1978).

110. R.U. Bondar, E.A. Kalinovskii, I.V. Kunpan, V.S. Sorokendya, Életrokhimiya, 19, 1104-1107 (1983).

111. M. Arai, S. Hamada, Y. Nishiyama, J. Coll. Interf. Sci., 178, 315-317 (1996).

112. B. Correa-Lozano, Ch. Comninellis and A. De Battisti, J. Appl. Electrochem., 26, 683-688 (1996).

113. T. Kuwana, R. K. Darlington e D.W. Leedy, Anal. Chemistry, 36, 2023-2025 (1964).

114. J.W. Strojek e T. Kuwana, J. Electroanal. Chem., 16, 471-483 (1968).

115. D.Elliot, D.L. Zellmer, H.A. Laitinen, J. Electrochem. Soc., 117, 1343-1348 (1970).

116. R. Memming, F.Mollers - Ber. Bunsenges. Physik. Chem. 76, 475-481 (1972).

117. N. Winograd, T. Kuwana, "Spectroelectrochemistry at Optically Transparent Electrodes" em "Electroanalytical Chemistry", A. J. Bard (Ed.), Vol. 7, Marcel Dekker, NY, 1974.

118. H. Kim, H.A. Laitinen, J. Electrochem. Soc. 122, 53-58 (1975)

119. I. Bedja, S. Hotchandani, P.V. Kamat, J. Phys. Chem., 98, 4133-4140 (1994).

120. G. Biesman, M. Van der Auweraer, C. Cathry, D. Meerschaut, F.C. De Schyver, W. Storck, F. Willing, J. Phys. Chem., 95, 3771-3779 (1991).

121. O. Johansen, J.W. Loder, A.W.-H. Mau, J. Rabani, W.H.F. Sasse, Langmuir, 8, 2577-2581 (1992).

122. G. Meyer, J. Chem. Educ., 74, 652-656 (1997).

123. B. O’Regan, M. Gratzel, Nature, 353, 737 (1991).

124. R. Shiratsuchi, K. Hongo, G. Nogami, S. Ishimaru, J. Electrochem. Soc., 139, 2544-2549 (1992).

125. Ch. Comminellis, "Electrochemical Treatment of Wastewater Containing Organic Pollutants", em "Chemical Oxidation-Technologies for the Nineties", W.W. Eckenfelder, A.R. Bowers, J.A. Roth (Ed.), Vol 3. Proceedings 3rd International Symposium - febr 17-19 (1993). Technomic Publishing Company, 1994, USA.

126. "Instrumental Methods in Electrochemistry", Cap.6. R. Greeef, R. Peat, L.M. Peter, D. Pletcher, J. Robinson. Ellis Horwood, John Wiley\&Sons, England, 1985.

127. W. Badawy, K. Doblhofer, I. Eiselt, H. Gerisher, S. Krause and J. Melsheimer, Electrochim. Acta, 29, 1617-1623 (1984).

128. D.N. Furlong, D.E. Yates, em "Electrodes of Conductive Metallic Oxides", S. Trasatti (Ed.), part B, Cap. 8. Elsevier Publishing Company, Amsterdam, 1981.

129. C. Boxal, G.H. Kelsall, J. Electroanal. Chem., 328, 75-97 (1992).

130. H.O. Finklea em "Semiconductors Electrodes", H.O. Finklea (Ed.), Cap.1. Studies in Physical and Theoretical Chemistry 55, Elsevier, Amsterdan (1988).

131. M. Watanabe, S. Venkatesan, H.A. Laitinen, J. Electrochem. Soc., 130, $59-64$ (1983).

132. The Encyclopedia of Chemical Electrode Potentials, M.S. Antellman, F.J. Harris, Jr. (Ed.), Plenum Press, New York, 1982.

133. M. Drogowska, L. Brossard and H. Ménard, J. Appl. Electrochem., 19, 231-238 (1989).

134. C. I. House, G.H. Kelsall, Electrochim. Acta, 29, 1459-1464 (1984). 
135. H.Yoneyama, H. Laitnen, J. Electroanal. Chem., 75, 647-659 (1977).

136. W.J. Albery and A.R. Hillman, em "Modified Electrodes", Cap. 10, 377-379.

137. A. Merz in "Chemically Modified Electrodes", Topics in Current Chemistry, Vol.152, p. 51 (1990).

138. J. Sagiv, J. Am.Chem.Soc., 102, $92-96$ (1980).

139. J. Rühe, V.J. Novotny, K.K. Kanazawa, T. Clarke, G.B. Street, Langmuir, 9, 2383-2388 (1993).

140. M. Garcia-Parajó, C. Longo, J. Servat, P. Gorostiza, F.Sanz, Langmuir, 13, 2333-2339 (1997).

141. J.F. Moulder, W.F. Stickle, P.E. Sobol and K.D. Bomben, in Handbook of X-ray Photoelectron Spectroscopy, J. Chastain (Ed.). Perkin Elmer Publication, Eden Prairie, MN (1992).

142. P.E.J. Flewitt, R.K. Wild, "Physical Methods for Materials Characterisation", Graduate Student Series in Materials Science and Engineering, B. Cantor (Ed.), Cap. 6. Institute of Physics Publishing, London, 1994.

143. D,C. Joy em "Materials Science and Technology, A Comprehensive Treatment", R.W. Cahn, P. Haasen, E.J. Kramer (Ed.), Cap. 3, Vol. 2: Characterization of Materials, Eric Lifshin (Ed). NY, 1994.

144. N.J. DiNardo in "Materials Science and Technology, A Comprehensive Treatment", R.W. Cahn, P. Haasen, E.J. Kramer (Ed.), Cap. 11, Vol. 2. Characterization of Materials, Eric Lifshin (Ed.). NY, 1994.

145. Electroquímica. Principios, Métodos e Aplicações, A.M. Oliveira Brett e C.M.A. Brett, Cap.12. Oxford University Press-Livraria Almedina, Coimbra, 1996.

146. Id.54, Cap.3.

147. Id. 126, Cap. 8.

148. "Equivalent Circuit", B.A. Boukamp, University of twente, Netherlands, 1989.

149. H.O. Finklea, J. Electrochem. Soc., 129, 2003-2008 (1982).

150. P.J. Boddy, J. Electroanal. Chem., 10, 199-244 (1965).

151. J.F. McCann, S.P.S. Badwal, J. Electrochem. Soc., 129, 551-559 (1982).

152. J.F. McCann, S.P.S. Badwal, J. Pezy, J. Electroanal. Chem., 118, 115-130 (1981).

153. P. Allongue, H. Cachet, J. Electroanal. Chem., 119, 371-377 (1981).

154. C.A. Moina, F.E. Varela, L.F. Hernández, G.O. Ybarra, J.R. Vilche, J. Electroanal. Chem., 427, 189-197 (1997).

155. J.E.A.M. Meerakker, J. Electrochem. Soc., 132, 638-642 (1985).

156. G.J. Brug, A.L.G. Van Den Eeden, M. Sluyters-Rehbach, J.H. Sluyters, J. Electroanal. Chem., 176, 275-295 (1984).

157. M. Labeau, U. Schmatz, G. Delabouglise, J. Roman, M. Vallet-Regi, A. Gaskov, Sens. Actuators B, 26-27, 49-52 (1995).

158. N. Yoshiike, M. Ayusawa, S. Kondo, J. Electrochem. Soc., 131, 2600-2604 (1984).

159. J.J. García-Jareño, J.J. Navarro, A.F. Roig, H. Scholl, F. Vicente, Electrochim. Acta, 40, 1113-1119 (1995).

160. S. Gritsch, P. Nollert, F. Jähnig, E. Sackmann, Langmuir, 14, 3118-3125 (1998). 
161. C. Gabrielli, M. Keddam, H. Takenouti, V.Q. Kinh, F. Bourelier, Electrochim. Acta, 24, 61-65 (1979).

162. D.D. Macdonald, J. Electrochem. Soc., 125, 1443-1449 (1978).

163. D.D. Macdonald, J. Electrochem. Soc., 125, 1977-1981 (1978).

164. D.D. Macdonald, B.C. Syrett, S.S. Wing, Corrosion, 34, 289-301 (1978).

165. L.G. Austin, E.G. Gagnon, J. Electrochem. Soc., 120, 251-254 (1973).

166. E.G. Gagnon, J. Electrochem. Soc., 120, 1052-1056 (1973).

167. E.G. Gagnon, J. Electrochem. Soc., 121, 512-515 (1974).

168. E.G. Gagnon, J. Electrochem. Soc., 121, 1444-1447 (1974).

169. E.G. Gagnon, J. Electrochem. Soc., 122, 521-525 (1975).

170. H. Shih, H.W. Pickering, J. Electrochem. Soc., 134, 1943-1949 (1987).

171. H. Shih, H.W. Pickering, J. Electrochem. Soc., 134, 1949-1957 (1987).

172. F. Sanz, J. Torrent, E. Videra, C. Longo, Anales de Química, no prelo.

173. J. Torrent, C. Longo., E. Videra, F. Sanz, $8^{a s}$ Jornadas de Analisis Instrumental - JAI, Barcelona, España, 22-25 de outubro, 1996.

174. R. L. Synder, in "Materials Science and Technology, A Comprehensive Treatment", R.W. Cahn, P. Haasen, E.J. Kramer (Ed.), Cap. 4, Vol. 2. Characterization of Materials, Eric Lifshin (Ed). NY, 1994.

175. "The New Siemens X-Ray Reflectometer - A Tool with Outstanding Capabilities" (Manual do Reflectômetro de Difração de Raios-X Siemens).

176. "Conductividad Electrica y Efecto hall en un Semiconductor" (Apostila de Laboratório do curso de Física da Universidade de Barcelona).

177. JCPDS - ICDD Copyrright (c) 1995 PDF -2sets database. Tin Oxide, Cassiterite, 41-1445.

178. A.F. Nassar, W.S. Willis, J.F. Rusling, Anal. Chem., 67, 2386- (1995),

179. J.L. Willit, E.F. Bowden, J. Phys. Chem., 94, 8241-8246 (1990).

180. M.J. Avena, O.R. Cámara, C.P. De Pauli, Colloids and Surfaces, 69, 217-228 (1993).

181. A. Kraft, H. Hennig, A. Herbst, K.-H. Heckner, J. Electroanal. Chem., 365, 191-196 (1994).

182. Id. 126, Cap. 11.

183. Ib.126, Cap.3.

184. S. Trasatti em "The Electrochemistry of Novel Materials", J. Lipkowski, J. Ross (Ed.), Cap. 5. 1994.

185. D. Posadas, "Introduccion a la Electroquimica", Cap. 2. Serie de Química, Monografia n 22, Secretaría General de la Organización de los Estados Americanos, Programa Regional de Desarrollo Científico y Tecnológico. Argentina, 1980.

186. R.S. Lillard, G.S. Kanner, D.P. Butt, J. Electrochem. Soc, 134, 1949-1957 (1987). 